Caracterização de carbamato de etila (CE) em cachaça não adoçada visando a produção de material de referência certificado (MRC) e sua aplicação no monitoramento de bebidas destiladas

Orientador:

Prof. Dr. Igor Renato Bertoni Olivares

Mestranda:

Pamela Aparecida Grizotto 
Pamela Aparecida Grizotto

\section{Caracterização de carbamato de etila (CE) em cachaça não adoçada visando a produção de material de referência certificado (MRC) e sua aplicação no monitoramento de bebidas destiladas}

Dissertação apresentada ao Instituto de Química de São Carlos, Universidade de São Paulo, como parte dos requisitos para obtenção do título de Mestre em Ciências.

Área de concentração:

Química Analítica e Inorgânica

Exemplar revisado. O exemplar original encontra-se em acervo reservado na Biblioteca do IQSC-USP.

Orientador:

Prof. Dr. Igor Renato Bertoni Olivares 
Grizotto, Pamela Aparecida

Caracterização de carbamato de etila (CE) em cachaça não adoçada visando a produção de material de referência certificado (MRC) e sua aplicação no monitoramento de bebidas destiladas / Pamela Aparecida Grizotto. - São Carlos, 2021.

$149 \mathrm{f}$.

Dissertação (Mestrado em Química Analítica e Inorgânica) - Instituto de Química de São Carlos / Universidade de São Paulo, 2021.

Orientador: Prof. Dr. Igor Renato Bertoni Olivares

1. Carbamato de etila. 2. Material de referência. 3. Incerteza. 4.

Homogeneidade. 5. Estabilidade. I. Título. 
Errata:

O termo "caracterização" é utilizado nas normas técnicas ISO Guia 35 e ISO Guia 80. Neste trabalho, considerou-se a definição da ISO Guia 80, mas este termo na área da metrologia também é entendido pelo conceito apresentado na ISO Guia 35 e que difere do conceito da Guia 80. Por esse motivo, para não haver interpretações dúbias, foi sugerido alterar o título do trabalho. Ao invés de detalhar que foi "caracterizado" e produzido um "MRC", os quais são definições dentro das ferramentas estatísticas para Gestão da Qualidade, foi então adotado um título mais abrangente:

"Aplicação de ferramentas estatísticas para Gestão da Qualidade dos Laboratórios visando o monitoramento de carbamato de etila (CE) em cachaça não adoçada".

Entretanto, a Universidade de São Paulo não permite a alteração oficial do título (D.O.E.: 01/11/2011, Resolução CoPGr № 6018, de 13 de outubro de 2011, retificada em 24/11/2011), por isso é informada a alteração em forma de errata. 
Dedico a...

Aparecida, minha mãe.

Ela me ensinou como encontrar forças nas derrotas e a garra para continuar.

Mauro, meu pai. Ele primeiro me ensinou a humildade e depois me ensinou a perdoar.

Fábio, meu irmão.

Meu melhor amigo, você me ensinou a sorrir. 


\section{AGRADECIMENTOS}

À Deus pela saúde que não me faltou, pela sabedoria de vida adquirida, pelas oportunidades que me foram apresentadas e pela paz que desfruto.

Ao Prof. Dr. Igor Renato Bertoni Olivares, pelas orientações necessárias e que criou a oportunidade do desenvolvimento e conclusão desse mestrado.

À Prof. Dr. Maria Olímpia de Oliveira Rezende e à Dr. Maria Diva Landgraf que cederam tempo e condições para a realização dos experimentos.

À Capes, CNPq e FAPESP pelo apoio financeiro.

Ao Ministério da Agricultura, Pecuária e Abastecimento (MAPA) pelo apoio formal do projeto, à Companhia Müller de Bebidas que forneceu material para a produção do lote de material de referência e aos laboratórios acreditados na Rede Brasileira de Laboratórios de Ensaio (RBLE) do Inmetro que contribuíram com os estudos do ensaio de proficiência.

Aos funcionários do Laboratório de Físico-Química de Bebidas e Vinagres do LFDASP que tornaram possível a realização desse trabalho.

Por fim, entre amigos de longa data, amigos de laboratório, funcionários e familiares, agradeço a todos os que estiveram próximos durante as diversas dificuldades que se apresentaram, seja resolvendo problemas, dando ideias ou simplesmente me ouvindo. Tenho a sorte de terem sido tantos e em momentos tão diferentes, mas igualmente significativos, que nem ouso citar apenas alguns nomes aqui. Simplesmente, obrigada. 
"Podemos julgar nosso progresso pela coragem de nossas perguntas e pela profundidade de nossas respostas, por nossa vontade de abraçar o que é verdadeiro ao invés daquilo que nos faz sentir bem" Carl Sagan. 


\section{RESUMO}

Os materiais de referência (MR) são fundamentais para o controle dos processos de calibração e na avaliação da qualidade dos resultados analíticos. O desenvolvimento de um MR envolve um substancial investimento em pesquisas direcionadas a resolver problemas como adequação da matriz original ao método de análise, estudos de homogeneidade, estudos de estabilidade do material sob condições adequadas de embalagem, armazenamento e transporte. Há alguns anos que a comunidade científica vem alertando sobre os perigos de um composto orgânico naturalmente presente em bebidas destiladas, o carbamato de etila. É de conhecimento público que o Ministério da Agricultura, Pecuária e Abastecimento (MAPA) tem interesse em monitorar carbamato de etila nas bebidas destiladas produzidas e comercializadas no Brasil, tendo já publicado a Instrução Normativa № 28 de 08 de agosto de 2014, estabelecendo um limite máximo de $210 \mu \mathrm{g} \mathrm{L}^{-1}$. Entretanto, por questões analíticas e governamentais, esse controle precisou ser temporariamente interrompido e não estava sendo realizado no país. Portanto, em parceria com o MAPA através do Laboratório de Análises Físico-Químicas de Bebidas e Vinagres (LABV/LFDA-SP), Seção Laboratorial Avançada (SLAV/BEB Jundiaí) do Laboratório Federal de Defesa Agropecuária (LFDA-SP), foi validado um método no GC-MS do SLAV/BEB Jundiaí e desenvolvido um MR para carbamato de etila em matriz de cachaça não adoçada com valor de referência em $(236,500 \pm 105,006) \mu \mathrm{g} / \mathrm{L}$ $(k=2$, normal), com adequada homogeneidade e estabilidade. Foi realizado um ensaio de proficiência com esse material sendo distribuído entre laboratórios cadastrados na Rede Brasileira de Laboratórios de Ensaio (RBLE). Com 18 amostras de fiscalização cedidas pelo SLAV/BEB Jundiaí, foi realizado um diagnóstico da concentração de carbamato de etila em cachaças não adoçadas, sendo que apenas 5 delas estavam em conformidade com a legislação. O lote de MR desenvolvido foi cedido ao SLAV/BEB Jundiaí para uso nas análises de rotina, colaborando assim com o monitoramento deste composto.

Palavras chave: carbamato de etila, uretana, material de referência, MR, Ministério da Agricultura, Pecuária e Abastecimento, MAPA, homogeneidade, estabilidade, incerteza, validação. 


\begin{abstract}
Reference materials (RMs) are essential to quality control of the validation process and quality evaluation of analytical data. The development of an RM entails quite a research investment in order to solve problems as original matrices adequation to the analytical method, homogeneity assays, and stability studies of the CRMs regarding proper storage, packing, and transportation conditions. The scientific community has been concerned about human health risks by consuming ethyl carbamate, an organic compound naturally found in distilled beverages. The Ministry of Agriculture, Livestock and Supply (MAPA) is interested in ethyl carbamate monitoring in distilled beverages produced and commercialized in Brazil, following a maximum residue limit (LMR) of $210 \mu \mathrm{g} L-1$ established by the Normative Instruction N. 28, of August 8th, 2014. However, this monitoring was temporarily interrupted for some analytical and governmental issues, being no longer performed in our country. In this work, a partnership was established with the Laboratory of Physical-Chemical Analysis of Beverages and Vinegars (LABV/LFDA-SP) of the Advanced Laboratorial Section (SLAV/BEB Jundiaí) from the Federal Laboratory of Animal and Plant Health and Inspection (LFDA-SP) to validate a GC-MS method in the SLAV/BEB equipment. A RM for ethyl carbamate was developed in an unsweetened sugar spirit matrix, presenting a reference value of $(236,500 \pm 105,006) \mu \mathrm{g} / \mathrm{L}(\mathrm{k}=2$, normal) with adequate homogeneity and stability. It was also performed proficiency testing by distributing the developed RM amongst the Brazilian Network of Testing Laboratories (RBLE). In eighteen inspection samples were kindly given by SLAV/BEB, a diagnosis essay was carried out to determine ethyl carbamate concentration in unsweetened sugar spirits; only five of them were conforming samples. The developed RM lot was donated to SLAV/BEB for routine analysis usage, collaborating to this compound monitoring.
\end{abstract}

Keywords: ethyl carbamate, urethane, reference material, RM, Ministry of Agriculture, Livestock and Supply, MAPA, homogeneity, stability, uncertainty, validation. 


\section{LISTA DE FIGURAS}

Figura 1 - Ciclo da Garantia da Qualidade Analítica (Analytical Quality Assurance Cycle - AQAC) .20

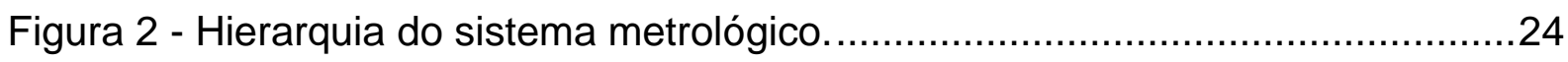

Figura 3 - Diferenciação entre precisão e exatidão. .25

Figura 4 - Etapas do desenvolvimento de um material de referência certificado (MRC).

Figura 5 - Exemplo da importância da curva de calibração na validação para a determinação de vários parâmetros de desempenho. 43

Figura 6 - Demonstração gráfica para a definição de resíduo

Figura 7 - Forma geral do comportamento dos limites de confiança para casos homocedásticos e heterocedásticos.

Figura 8 - Correlação da distribuição normal com os desvios padrão (s), incertezas padrão $(\mathrm{u})$, fatores de cobertura $(\mathrm{k})$ e probabilidades de cobertura $(\%)$ do valor médio das replicatas (ym). .51

Figura 9 - Inter-relações entre valor verdadeiro, valor medido, erro e incerteza. ......53

Figura 10 - Incerteza e limites de conformidade para a aprovação de resultados. ...53 Figura 11 - Inter-relações entre os diferentes tipos de erros, as características de desempenho usadas para calcular as estimativas e os modos de expressá-las quantitativamente. .55

Figura 12 - Diagrama da criação da ISO/IEC 17025 e suas revisões. 58 Figura 13 - Etapas de ensaio de proficiência aplicado na abordagem de programa simultâneo.

Figura 14 - Distribuição percentual dos principais países importadores de destilados de cana produzidos no Brasil (rum, cachaça e aguardentes) em valor (USD). 65 Figura 15 - Principais estados exportadores de destilados de cana produzidos no Brasil (rum, cachaça e aguardentes) em quilograma líquido. .65

Figura 16 - Fluxograma da produção de cachaças e aguardentes de cana. 66 Figura 17 - Estrutura química, fórmula molecular e espectro de massas do carbamato de etila. .68

Figura 18 - Fluxograma da classificação geral dos métodos cromatográficos. .71

Figura 19 - Exemplo de cromatograma e os termos cromatográficos. .74 
Figura 20 - Fluxograma da classificação dos tipos de colunas capilares aplicadas em CG.

Figura 21 - Representação esquemática do interior das colunas empacotadas e capilares.

Figura 22 - Exemplo de cromatograma para CE no método IQSC/USP - RQA Lab.

Figura 23 - Exemplo de cromatograma para CE no método LFDA/SP - SLAV/BEB. .96

Figura 24 - Planejamento do estuda da homogeneidade. .99

Figura 25 - Planejamento do estudo da estabilidade de longa duração pelo método isócrono de amostragem. 100

Figura 26 - Estrutura molecular, fórmula molecular e espectro de massas do etanol. 102

Figura 27 - Estrutura molecular, fórmula molecular e espectro de massas da água. 102

Figura 28 - Gráfico da linearidade para a primeira curva de calibração (IQSC/USP).

Figura 29 - Gráfico da linearidade para a segunda curva de calibração (IQSC/USP). 105

Figura 30 - Representação gráfica do comportamento dos resíduos na segunda curva de calibração comprovando a heterocedasticidade (IQSC/USP) 106

Figura 31 - Fontes de incerteza consideradas na caracterização. 112

Figura 32 - Gráfico do estudo de estabilidade do armazenamento. 119

Figura 33 - Gráfico comparativo das contribuições das incertezas padrão percentuais e combinadas de cada fonte de incerteza considerada. 124 


\section{LISTA DE TABELAS}

Tabela 1 - Tabela ANOVA - Análise de Variância

Tabela 2 - Variações da cromatografia gasosa (CG) em relação aos mecanismos de separação e às fases estacionárias envolvidas.

Tabela 3 - Fases estacionárias comumente empregadas em CGL e suas principais aplicações.

Tabela 4 - Impurezas comuns dos principais gases de arraste. .82

Tabela 5 - Programação da temperatura do método IQSC/USP - RQA Lab. 94

Tabela 6 - Fragmentos de identificação e quantificação do CE e tempo de retenção no método IQSC/USP - RQA Lab.

Tabela 7 - Programação da temperatura do método LFDA/SP - SLAV/BEB Jundiaí.

Tabela 8- Fragmentos de identificação e quantificação do $C E$ e tempo de retenção no método LAFDA/SP - SLAV/BEB Jundiaí.

Tabela 9 - Valores experimentais para a primeira curva de calibração (IQSC/USP).

Tabela 10 - Parâmetros de desempenho para a primeira curva de calibração (IQSC/USP).

Tabela 11 - Valores experimentais para a segunda curva de calibração (IQSC/USP). 105

Tabela 12 - Parâmetros de desempenho para a segunda curva de calibração (IQSC/USP). 106

Tabela 13 - Precisão intermediária do método validado no IQSC/USP. 107

Tabela 14 - Incertezas padrão e expandidas do método IQSC/USP. 108

Tabela 15 - Parâmetros de desempenho para a primeira curva de calibração (LFDASP) 109

Tabela 16 - Parâmetros de desempenho para a segunda curva de calibração (LFDA/SP). 110

Tabela 17 - Precisão intermediária do método validado no LFDA/SP. 110

Tabela 18 - Incertezas padrão e expandidas do método LFDA/SP. 111

Tabela 19 - Background do teor de CE na matriz. 112

Tabela 20 - Caracterização do valor de propriedade após a fortificação. 112

Tabela 21 - Componentes de incerteza da uchar para o valor de $210 \mu \mathrm{g} / \mathrm{L}$ 114 
Tabela 22 - Concentração de CE correspondente aos sinais analíticos de cada área integrada. 116

Tabela 23 - ANOVA de fator único do estudo da homogeneidade. 116

Tabela 24 - Componentes de incerteza da unom.

Tabela 25 - ANOVA de fator único para o estudo da estabilidade de transporte. ...121 Tabela 26 - Teste-t de duas variáveis com variâncias equivalentes para os valores de área de pico cromatográfico do estudo de estabilidade de transporte. 121

Tabela 27 - Valores de referência para incertezas expandidas de congêneres orgânicos em uísque - material de referência produzido pelo FAPAS. 125 Tabela 28 - Parâmetros de desempenho dos laboratórios participantes do ensaio de proficiência. 127

Tabela 29 - Concentrações de CE encontradas em amostras de cachaça não adoçada o programa de fiscalização do MAPA. 129 


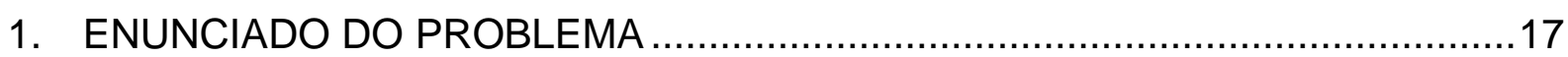

2. INTRODUÇÃO

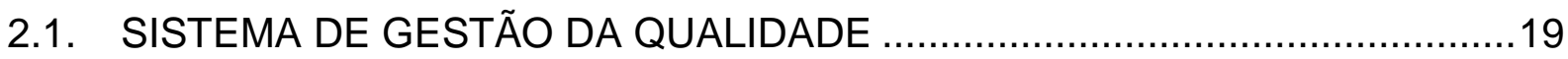

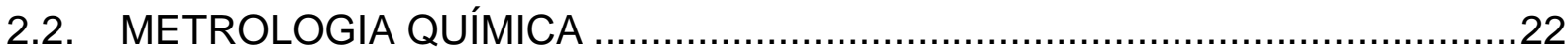

2.3. MATERIAL DE REFERÊNCIA (MR) E MATERIAL DE REFERÊNCIA

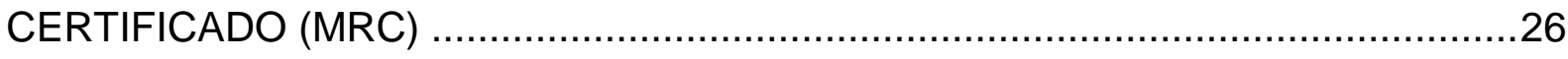

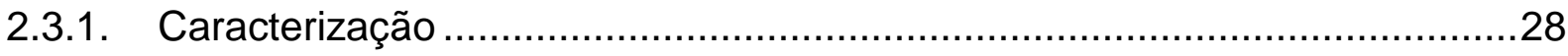

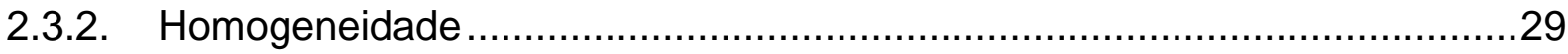

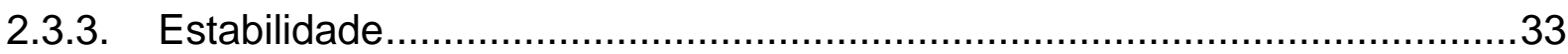

2.3.3.1. Avaliação da componente de incerteza relativa à estabilidade na ausência

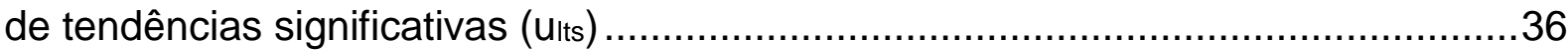

2.3.3.2. Estimativa do tempo de vida útil (tempo de prateleira) proveniente do estudo

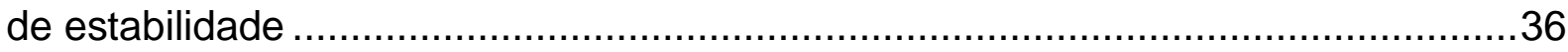

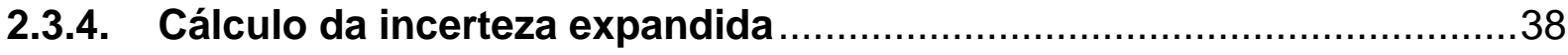

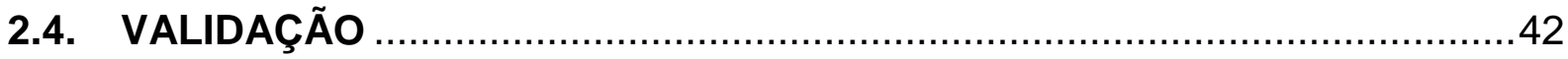

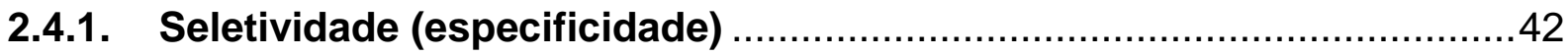

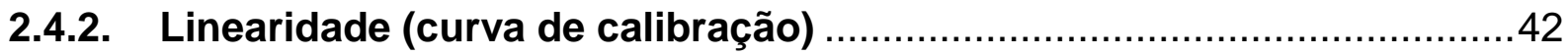

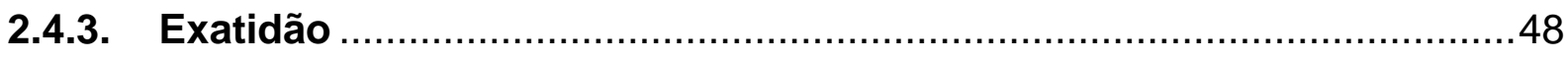

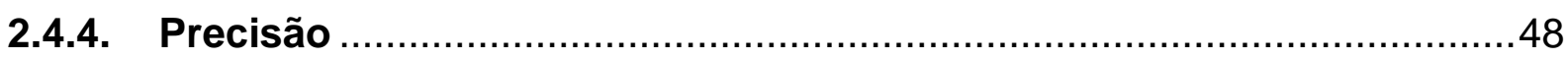

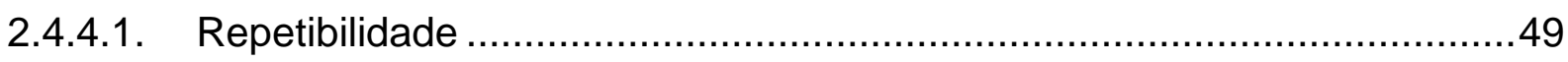

2.4.4.2. Precisão intermediária (precisão intralaboratorial) ..................................49

2.4.4.3. Reprodutibilidade (precisão interlaboratorial)..........................................49

2.4.5. Faixa de trabalho e faixa linear de trabalho .......................................49

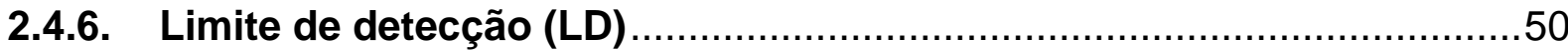

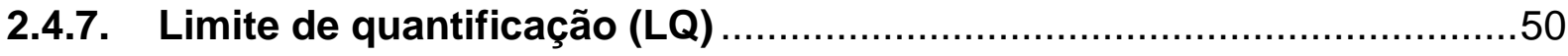

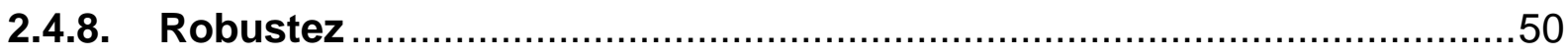


2.5. ESTIMATIVA DA INCERTEZA DE MEDIÇÃO EM QUÍMICA ANALÍTICA (GUM

- Guide to expression of Uncertainty in measurement - 2008)

2.6. ENSAIO DE PROFICIÊNCIA (EP)

2.6.1. Requisitos gerais para ensaios de proficiência (ABNT NBR ISO/IEC 17043) 59

2.6.2. Análise estatística dos resultados do EP 62

2.7. CACHAÇAS E AGUARDENTES DE CANA .64

2.8. CARBAMATO DE ETILA (CE) .68

2.9. CROMATOGRAFIA EM FASE GASOSA (CG) 69

2.9.1. Método cromatográfico gás-líquido - colunas e fases estacionárias ...77

2.9.2. Qualidade do método e dos resultados experimentais 82

2.9.2.1. Gás de arraste .82

2.9.2.2. Coluna cromatográfica .83

2.9.2.3. Controle da temperatura .84

OBJETIVOS. .88

1.1. GERAL .88

1.2. ESPECÍ́FICOS .88

2. MATERIAIS E MÉTODOS .90

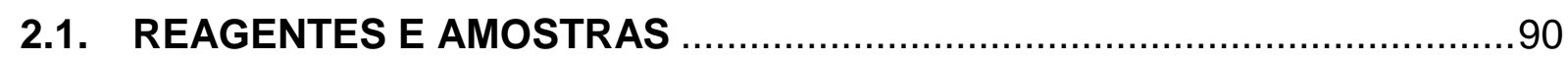

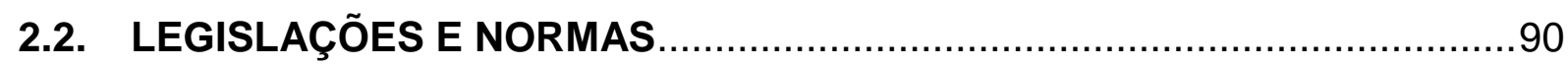

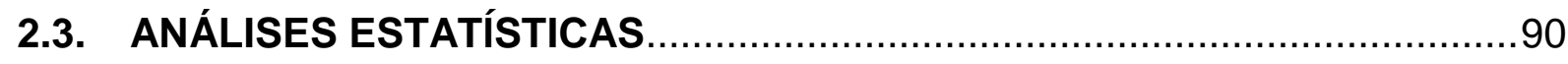

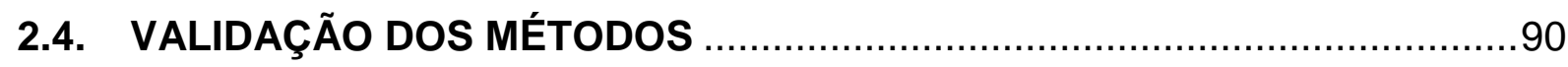

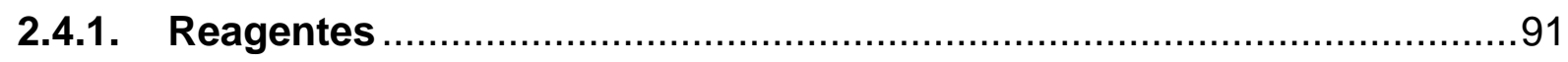

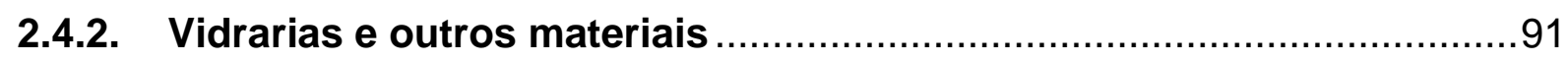

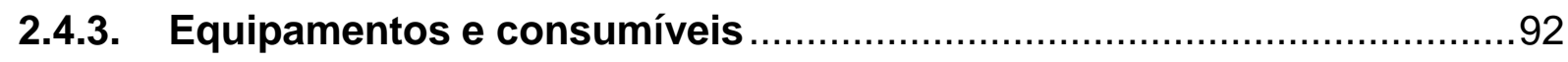

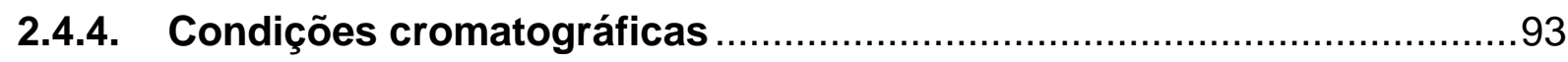

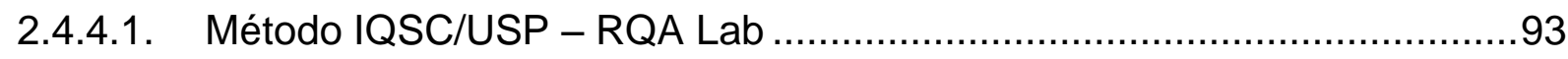

2.4.4.2. Método LFDA/SP - SLAV/BEB Jundiaí ..................................................95 
2.5. PRODUÇÃO DO MATERIAL DE REFERÊNCIA $\ldots \ldots \ldots \ldots \ldots \ldots \ldots \ldots \ldots \ldots \ldots \ldots$

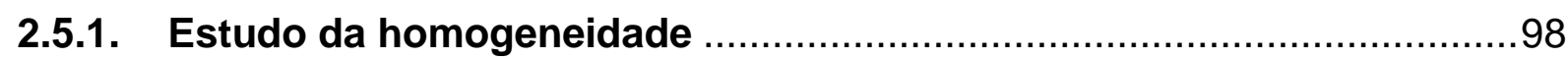

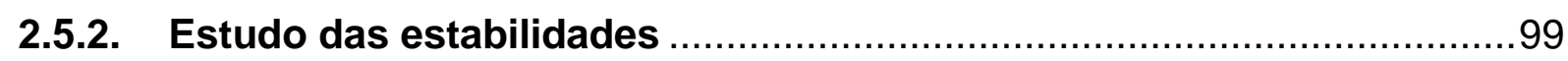

2.5.2.1. Estabilidade do armazenamento.................................................. 99

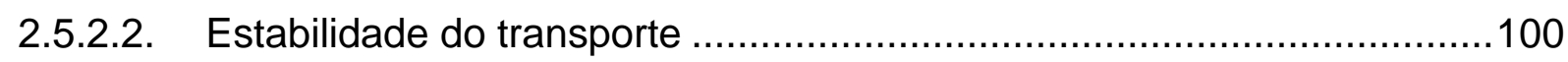

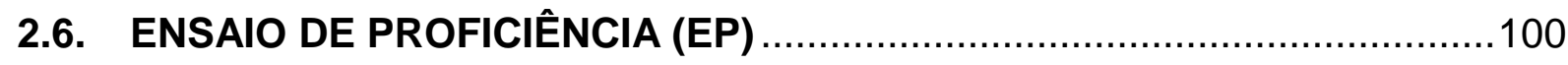

2.7. DIAGNÓSTICO DE CE EM CACHAÇAS DE FISCALIZAÇÃO ..................101

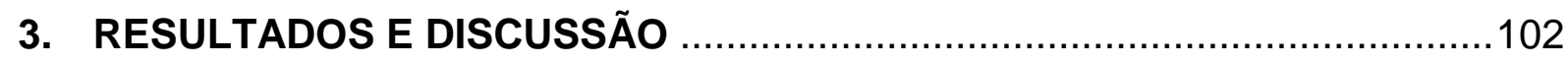

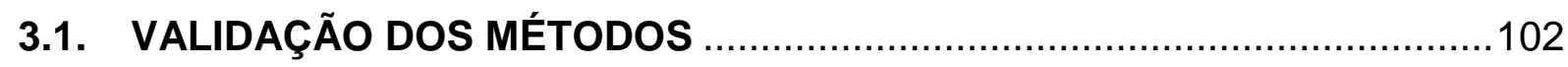

3.1.1. Validação do método usado para a caracterização da amostra candidata a material de referência (MR) .103

3.1.2. Validação do método desenvolvido para o Laboratório Federal de Defesa Agropecuária (LFDA-SP), Seção Laboratorial Avançada de análises físicoquímicas de bebidas e vinagres (SLAV/BEB Jundiaí) ..................................109

3.2. PRODUÇÃO DO MATERIAL DE REFERÊNCIA ................................112

3.2.1. CARACTERIZAÇÃO DO MATERIAL DE REFERÊNCIA (MÉTODO

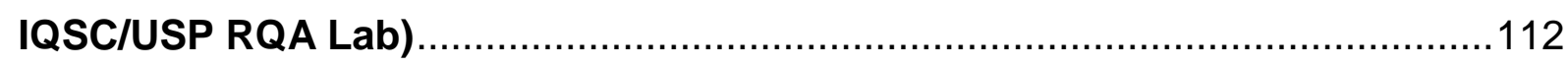

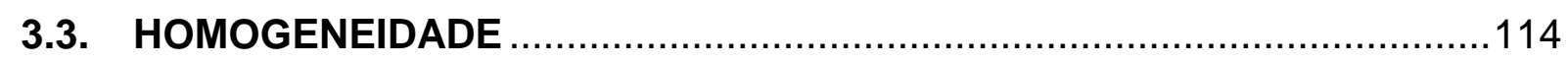

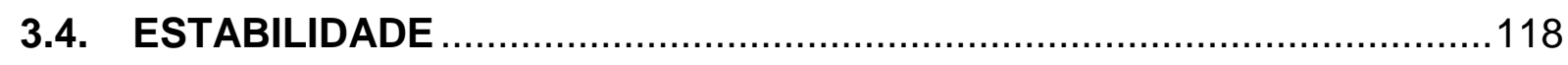

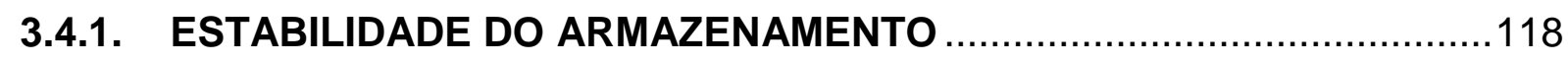

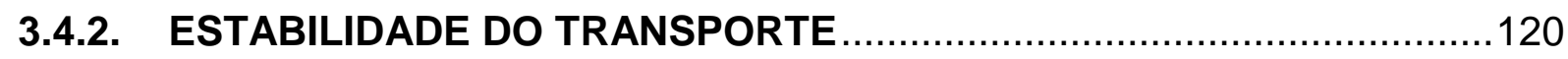

3.5. ESTIMATIVA DA INCERTEZA DO MATERIAL DE REFERÊNCIA .............122

3.6. CERTIFICAÇÃO DO MATERIAL DE REFERÊNCIA ..............................125

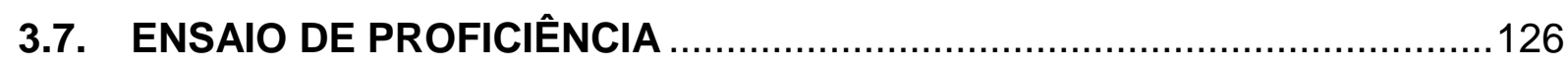

3.8. DIAGNÓSTICO DE TEOR DE CE EM CACHAÇA NACIONAIS - AMOSTRAS

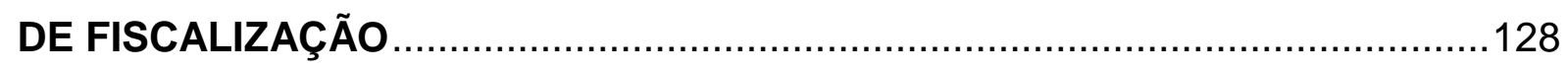

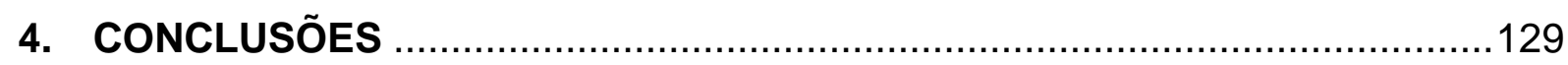

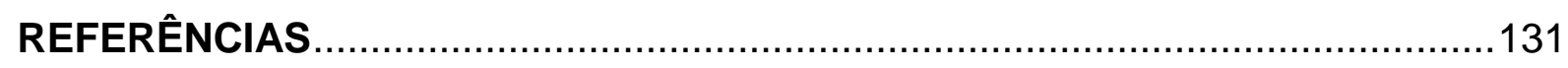




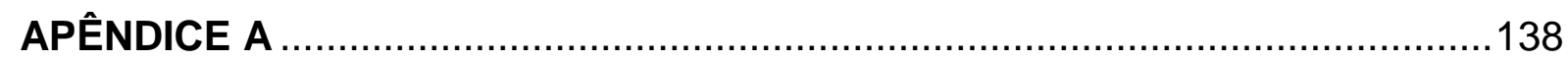

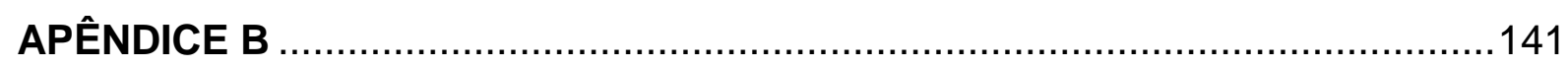

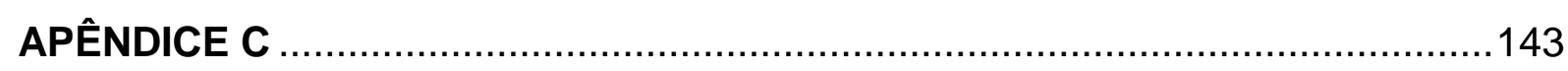

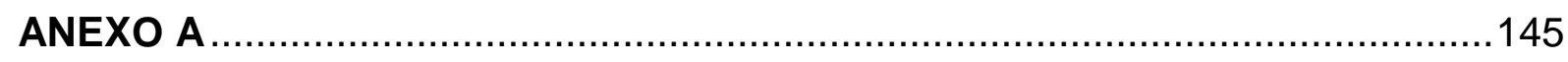

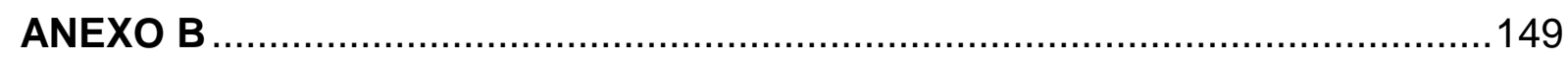




\section{ENUNCIADO DO PROBLEMA}

O Ministério da Agricultura, Pecuária e Abastecimento (MAPA) objetiva desenvolver uma competitividade responsável no setor do agronegócio defendendo interesses da população como segurança alimentar e o aumento da produção agropecuária para atender a demanda interna de consumo (BRASIL, 2015; OLIVARES, 2019). Consequentemente, gera empregos e renda, inclusão social e redução da desigualdade social. Também almeja gerar excedentes com qualidade para a exportação além de colocar o país em boas condições de competição internacional nesse setor. São com essas intenções que o MAPA exerce grande pressão em laboratórios que realizam análises relacionadas com a qualidade de alimentos para a implementação de um Sistema de Gestão da Qualidade (SGQ), principalmente aos laboratórios integrantes da Rede Nacional de Laboratórios Agropecuários do Sistema Unificado de Atenção à Sanidade Agropecuária (LFDA Laboratórios Federais de Defesa Agropecuária). Para isso, é exigido que seja aplicada a Norma ABNT NBR ISO/IEC 17025, específica para a gestão da qualidade em laboratórios para garantir a confiabilidade dos resultados dos serviços prestados e a manutenção de um padrão de funcionamento dentro da organização (SORATO; VARVAKIS; HORII, 2007; OLIVARES, 2019).

O Ciclo da Garantia da Qualidade Analítica (AQAC) é uma ferramenta de suporte à ISO/IEC 17025. Essa ferramenta é sustentada por três requisitos técnicos principais: validação do método, estimativa de incerteza e o controle de qualidade (CQ); todos interligados pelo uso de equipamentos devidamente calibrados e pelo uso de materiais de referência (MR), assegurando a rastreabilidade e a confiabilidade dos resultados gerados (ABNT, 2012; BRASIL, 2015; ABNT, 2017; OLIVARES, 2019).

Atualmente existe uma demanda de serviço para o controle de carbamato de etila em bebidas destiladas, um composto orgânico que se forma durante o processo de produção dessas bebidas e reconhecido como uma substância potencialmente carcinogênica (WHO, 2010). Por meio do MAPA, o governo brasileiro publicou a Instrução Normativa № 28, de 08 de agosto de 2014, e estabeleceu um limite máximo para carbamato de etila em cachaça, $210 \mu \mathrm{g} \mathrm{L}^{-1}$ (BRASIL, 2014). Entretanto, a unidade do LFDA-SP de Jundiaí necessitava de um método validado e de um material de referência (MR) para controle de qualidade intralaboratorial para promover esse monitoramento em âmbito nacional. Portanto, em parceria com o MAPA pelo 
Laboratório de Análises Físico-Químicas de Bebidas e Vinagres - Seção Laboratorial Avançada (SLAV - Jundiaí/SP), nesse trabalho se desenvolveu e validou um método de análise para carbamato de etila por cromatografia gasosa acoplada a espectrometria de massas (CG-EM) em cachaça não adoçada, caracterizou-se o carbamato de etila em cachaça não adoçada visando a produção de um MR, de acordo com a ISO Guia 80:2014 para ser aplicado em análises de rotina do monitoramento desse composto orgânico e, posteriormente, foi distribuído para laboratórios de ensaio acreditados na ISO/IEC 17025 cadastrados na Rede Brasileira de Laboratórios de Ensaio (RBLE) do Inmetro para um ensaio de proficiência. 


\section{INTRODUÇÃO}

\subsection{SISTEMA DE GESTÃO DA QUALIDADE}

Com a globalização e a crescente expansão das fronteiras comerciais dos países, também se estabeleceu uma maior concorrência em produzir produtos e serviços de melhor qualidade. A garantia da qualidade passou a ser vista pelos meios administrativos, de produção e comerciais como um pré-requisito para se fazer visível e se firmar entre as tendências de mercado. Para isso, é preciso tornar o cliente fiel ao serviço prestado e isso somente é possível se suas necessidades forem atendidas e com um padrão de qualidade que garanta que sempre irá receber o mesmo produto ou serviço.

Com essa preocupação que ferramentas para Sistemas de Gestão da Qualidade (SGQ) começaram a se desenvolver e, conforme Joseph Juran definiu em seu livro Quality Control Handbook, qualidade está relacionada com a "adequação ao uso" do produto ou serviço à necessidade do cliente. Essa adequação pode ser feita investindo em melhorar as qualidades já presentes, ou reduzindo suas falhas para poupar o retrabalho e insatisfações dos clientes. Dessa forma, uma grande variedade de ferramentas, de normas, autarquias ou instituições privadas foram sendo criadas ao longo do tempo com o objetivo de gerenciar a padronização de processos e garantir a qualidade dos produtos, a confiabilidade e a rastreabilidade dos resultados (OLIVARES, 2019).

Uma norma amplamente empregada em laboratórios por ser bastante genérica e conseguir abranger diferentes tipos de laboratórios é a ISO/IEC 17025. Possui uma série de exigências pertinentes desde o funcionamento do laboratório (requisitos de gestão) até aos métodos de ensaio e calibração de equipamentos (requisitos técnicos). Entretanto, conforme Olivares e Lopes (2012) observaram, essa norma apresenta inúmeras exigências, mas não demonstra como devem ser aplicadas e, portanto, viram a necessidade de propor uma forma prática de interpretá-la com os principais requisitos técnicos essenciais para a gestão da qualidade em um laboratório de ensaio que irão garantir a confiabilidade e rastreabilidade dos resultados analíticos. 
Figura 1 - Ciclo da Garantia da Qualidade Analítica (Analytical Quality Assurance Cycle - AQAC)

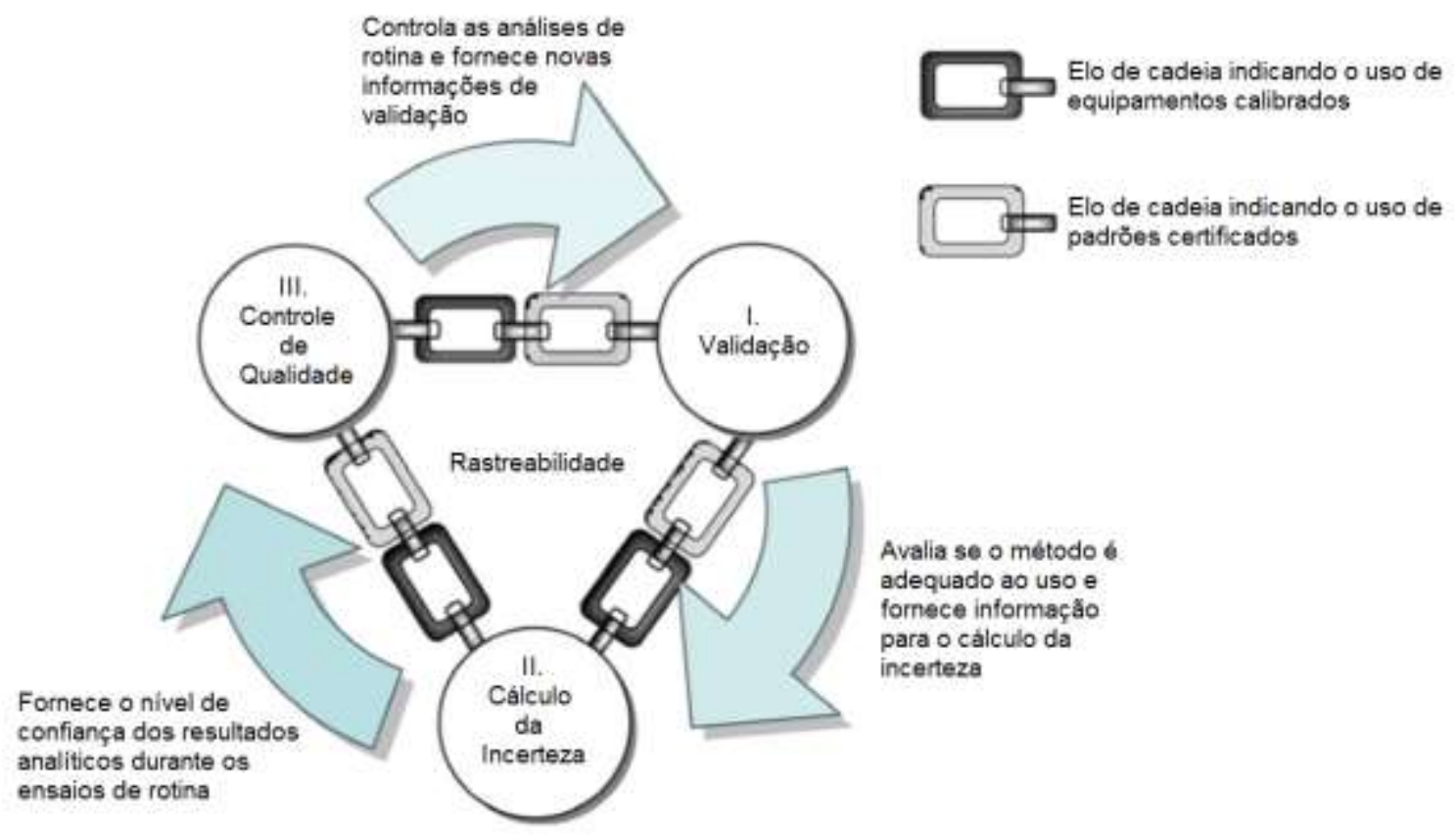

Fonte: adaptado de OLIVARES, I. R. B.; LOPES, F. A. Essential steps to providing reliable results using the analytical quality assuarance cycle. Trends in Analytical Chemistry, v. 35, p. $109-121,2012$. DOI: $10.1016 / j . t r a c .2012 .01 .004$

Com a introdução dos conceitos de gestão da qualidade, alguns diagramas foram sendo desenvolvidos para melhorar a interpretação e aplicação de um SGQ, como o diagrama de Ishikawa para estimativa de incerteza, ou os ciclos PDCA e PDSA de W. Edward Deming. Dessa mesma forma, foi desenvolvido o Ciclo AQAC, um diagrama para melhorar a interpretação da aplicação das exigências da norma ISO/IEC 17025 em laboratórios, representado pela Figura 1 (OLIVARES; LOPES, 2012). Esse diagrama deixa evidente os principais requisitos técnicos necessários para garantir a qualidade dos resultados analíticos de um laboratório:

I. Validação dos métodos: é necessário que todos os métodos de ensaio passem por um processo de validação analítica antes de serem empregados para que seja verificada e garantida a sua adequação para a finalidade da análise;

II. Estimativa de incerteza: é imprescindível ter uma estimativa do nível de confiança dos resultados gerados pelo método empregado. É nessa etapa que se confere a confiabilidade dos resultados;

III. Controle de qualidade (CQ): visa manter o monitoramento dos resultados dentro dos lotes de ensaios (cálculos de exatidão) e entre os eles ao longo do 
tempo (precisão intermediária) podendo ser verificada a dispersão dos resultados. Tanto a exatidão quanto a precisão intermediária, como será abordado no tópico 2.4 deste trabalho, são parâmetros de validação e, portanto, pode-se dizer que um $C Q$ fornece dados para que o Ciclo AQAC possa girar e se manter sempre atualizado.

Visto a importância da implementação de Sistemas de Gestão da Qualidade (SGQ) em laboratórios, com o intuito de se garantir a confiabilidade e rastreabilidade dos resultados analíticos, autoridades governamentais começaram a estabelecer alguns critérios e obrigatoriedade na adoção destes sistemas. Diferentes áreas como meio ambiente, investigação forense, controle de saúde pública (alimentar ou sanitária), políticas farmacêuticas, são estratégicas e muitas vezes estruturadas em resultados analíticos. Desta maneira, merecem atenção especial com relação à confiabilidade e rastreabilidade se fazendo necessário um SGQ fortemente desenvolvido e ordenado para atender às demandas governamentais (OLIVARES, 2019). No Brasil, existem órgãos responsáveis pelo incentivo e avaliação da manutenção da qualidade dos serviços de laboratórios de ensaios ou calibração em diferentes áreas:

- Ministério da Agricultura, Pecuária e Abastecimento (MAPA);

- Instituto Brasileiro do Meio Ambiente e dos Recursos Naturais (IBAMA);

- Agência Nacional de Vigilância Sanitária (ANVISA);

- Agência Nacional das Águas (ANA);

- Instituto Nacional de Metrologia, Qualidade e Tecnologia (INMETRO).

Especificamente no MAPA, há a preocupação de estimular a produção agropecuária com produtos de qualidade, tanto para atender o mercado interno com segurança alimentar, como também para gerar excedentes de qualidade para expandir o agronegócio no mercado internacional com competitividade. Com esses fins, incentiva a implementação de SGQ em laboratórios que estão relacionados com análises da qualidade de alimentos. Pelo destaque e evolução de Sistemas de Gestão da Qualidade e o estabelecimento de normas específicas para laboratórios como a ISO/IEC 17025 e as Boas Práticas de Laboratório (BPL), o MAPA publicou a Instrução Normativa 01 em 16 de janeiro de 2007, atualizada em 2011. Esse documento estabelece critérios específicos de credenciamento e reconhecimento dos laboratórios 
que realizam as análises das demandas do MAPA, participando assim da Rede Nacional de Laboratórios Agropecuários do Sistema Unificado de Atenção à Sanidade Agropecuária (LFDA - Laboratórios Federais de Defesa Agropecuária). Laboratórios privados que também tenham interesse em fornecer serviços para as demandas não supridas pelos LFDAs, também devem seguir os critérios estabelecidos pela Instrução Normativa 57, de 11 de dezembro de 2013 (BRASIL, 2007; BRASIL, 2013; BRASIL, 2015; ABNT, 2017; OLIVARES, 2019).

Portanto, é notório que para o Ministério da Agricultura, Pecuária e Abastecimento, manter um Sistema de Gestão da Qualidade em seus laboratórios credenciados é de suma importância para garantir a confiabilidade dos resultados analíticos. Sendo responsável por áreas estratégicas do país como a segurança alimentar e intimamente ligado à geração de empregos, PIB e comércio exterior, é coerente que tenha interesse em controlar de forma sistemática a qualidade, confiabilidade e rastreabilidade dos dados gerados em análises de âmbito nacional.

\subsection{METROLOGIA QUÍMICA}

O termo "metrologia" é definido pelo Vocabulário Internacional de Metrologia (VIM) como a ciência das medições e suas aplicações (INMETRO, 2012). O objetivo dessa área de pesquisa e aplicação é a de agregar qualidade para as medições. A metrologia científica e industrial se certifica de que as transferências dos valores padrões serão transferidos, aos instrumentos de medida ou métodos de análises com confiabilidade em domínio internacional, seja nos setores de indústria, comércio ou pesquisa. A partir do momento em que valores podem ser comparados com segurança estatística, pode-se delinear estratégias para o desenvolvimento de melhorias em cima de determinado produto ou serviço. À vista disso, pode-se considerar as ciências metrológicas como parte da infraestrutura estratégica do país, por conseguinte, desenvolver competitividade e avanços científicos e tecnológicos (ALVES; DE MORAES, 2003; DA ROCHA, 2016; OLIVARES, 2019).

Sendo metrologia a ciência responsável pela confiabilidade e padronização das medições, a metrologia química deve dar credibilidade às instrumentações e aos resultados analíticos dos ensaios químicos. Olivares (2019) relata que em 2012 foi criada a Rede de Metrologia Química do INMETRO (Remeq-I) e expõe que na portaria da criação dessa rede é frisado que "Materiais de Referência são as principais ferramentas para a área de metrologia química e que existe no Brasil uma demanda 
metrológica reprimida". No entanto, somente em 04 de janeiro de 2017, é aprovada pelo Ministério da Economia (Ministério da Indústria, Comércio Exterior e Serviços MDIC) pela Portaria № 2 em que o INMETRO cria a Divisão de Metrologia Química e Térmica (Dimqt) (BRASIL, 2017; INMETRO, 2018a). Dentre várias abordagens, esse segmento ficou incumbido principalmente de:

- Implantar métodos primários e técnicas de alto valor metrológico para quantificação e qualificação de espécies químicas, medições de temperatura e umidade;

- Desenvolvimento de procedimentos de referência para análises químicas;

- Desenvolvimento, produção e certificação de materiais de referência para medição de substâncias químicas puras ou em matrizes;

- Prestação de serviços de calibração e ensaios;

- Coordenação de intercomparações nacionais e internacionais;

- Organização de ensaios de proficiência.

É evidente que o país se encontra com uma defasagem em metrologia química. Basicamente, o Brasil apresenta cerca de 100 anos de atraso nessa área em relação aos Estados Unidos. A produção de materiais de referência (MR) para o setor industrial nos EUA começaram no início do século XX pelo National Institute Standards and Technology (NIST), fundado em 1901, um dos laboratórios de ciências físicas mais antigos desse país; criado para aumentar a competitividade industrial com os maiores rivais econômicos da época como Reino Unido e Alemanha (ALVES; DE MORAES, 2003; NIST, 2017).

Quando se trata de análises químicas, é mais complexo de relacionar os valores experimentais diretamente com o Sistema Internacional de Unidades (SI). É mais fácil assimilar a ideia de rastrear medições de temperaturas, distâncias ou massas às unidades do SI (kelvin, metro e quilo, respectivamente), pois são medições diretas. Nesse contexto, a metrologia física é mais simples de compreender. Entretanto, a química analítica exige medições indiretas de propriedades físicas dos materiais para, por exemplo, encontrar um valor de concentração de determinado analito em uma solução, sendo medidas propriedades como a emissão ou absorção de luz, potencial elétrico ou interações polares entre fases. Isto posto, constata-se que a metrologia química está fundamentada em medições relativas e não absolutas. Por 
esse motivo que a introdução de materiais de referência é tão importante nessa esfera metrológica. São os MR que incorporam rastreabilidade metrológica aos valores experimentais (ALVES; DE MORAES, 2003; DA ROCHA, 2016; OLIVARES, 2019).

A rastreabilidade metrológica é a "propriedade de um resultado de medição pela qual tal resultado pode ser relacionado a uma referência através de uma cadeia ininterrupta e documentada de calibrações, cada uma contribuindo para a incerteza de medição" (INMETRO, 2018b). Por consequência, se estabelece um sistema ordenado de calibrações denominado hierarquia do sistema metrológico, melhor detalhado pela Figura 2.

Figura 2 - Hierarquia do sistema metrológico.

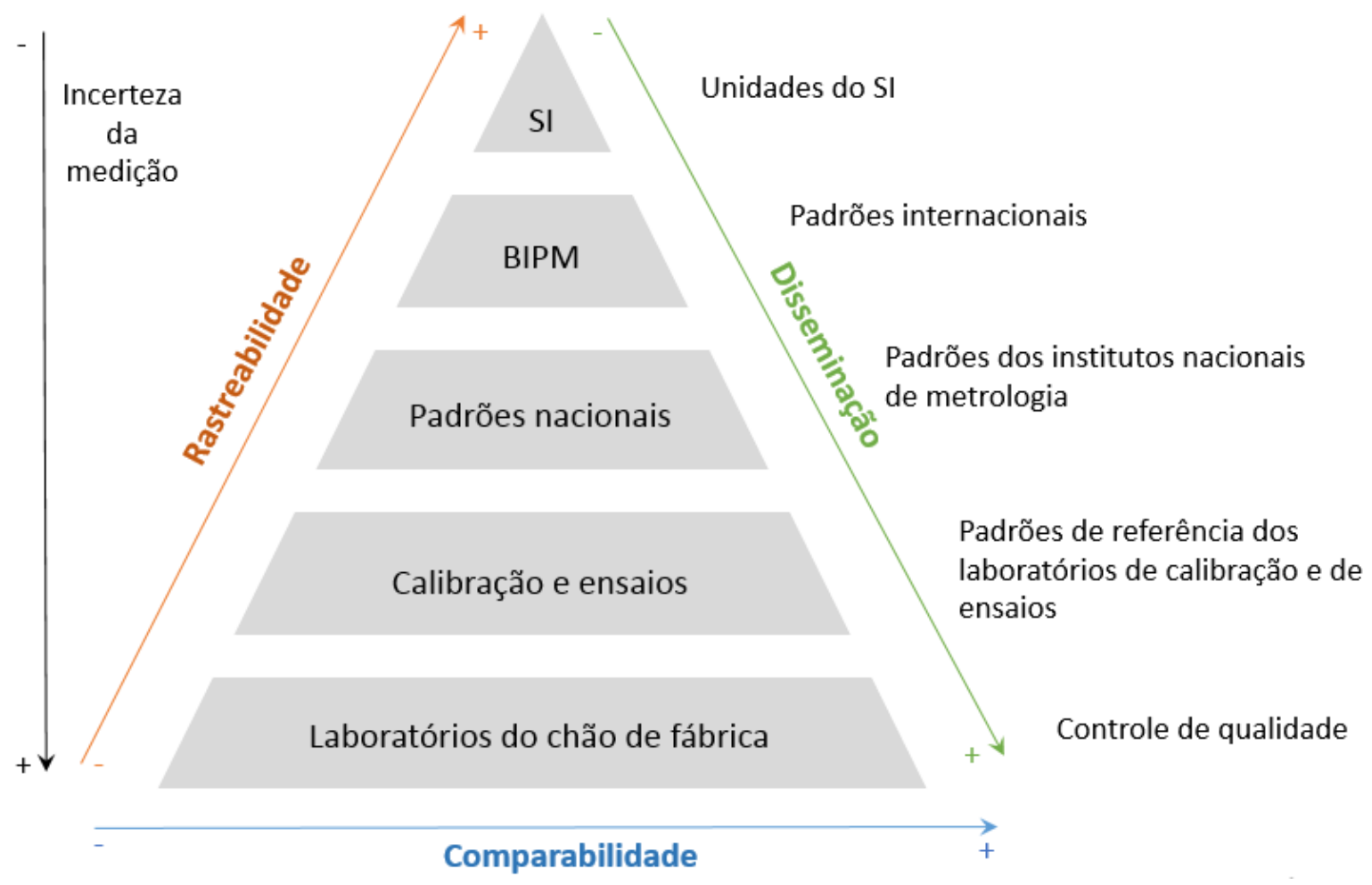

Fonte: ilustração própria adaptada de INSTITUTO NACIONAL DE METROLOGIA, NORMALIZAÇÃO E QUALIDADE INDUSTRIAL (INMETRO). Metrologia Científica: Estrutura Hierárquica de Rastreabilidade. 2018b. Disponível em < http://www.inmetro.gov.br/metcientifica/estrutura.asp > Acesso em: setembro de 2019.

A Figura 2 demonstra com mais clareza o papel dos MR dentro de uma cadeia hierárquica de rastreabilidade. Esses materiais são desenvolvidos para estabelecerem uma correlação com os padrões internacionais do Escritório Internacional de Pesos e Medidas (Bureau International des Poids et Mesures BIPM), uma organização intergovernamental em que os Estados membros são interessados em questões científicas e às normas de medição (BIPM, 2019). O BIPM 
tem como função assegurar uma padronização mundial das medições sendo responsável por (IPEM-SP, 2019):

- Estabelecer as unidades e os padrões internacionais das principais grandezas físicas e de conservar os protótipos internacionais;

- Efetuar a comparação dos padrões nacionais e internacionais;

- Assegurar a coordenação das técnicas de medições correspondentes;

- Efetuar e coordenar as determinações relativas às constantes físicas que intervêm naquelas unidades.

Quando se aborda sobre sistema metrológico, calibrações e tratamento de dados, é indispensável discutir sobre os conceitos de precisão e exatidão. Conforme representado pela Figura 3, um método de medição é preciso quando retorna valores que reproduzem, mas não necessariamente próximos do valor real; uma medição exata consegue produzir valores próximos do valor "real", porém não garante uma dispersão de dados baixa (HARRIS, 2012).

Figura 3 - Diferenciação entre precisão e exatidão.

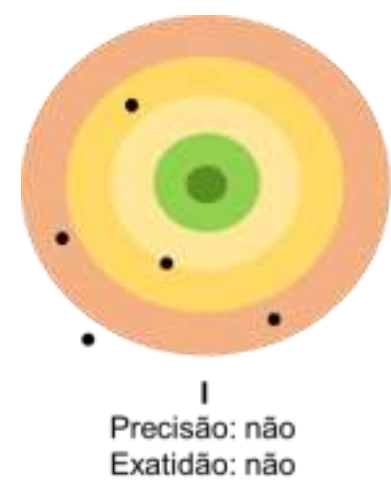

Precisão: nāo

Legenda:

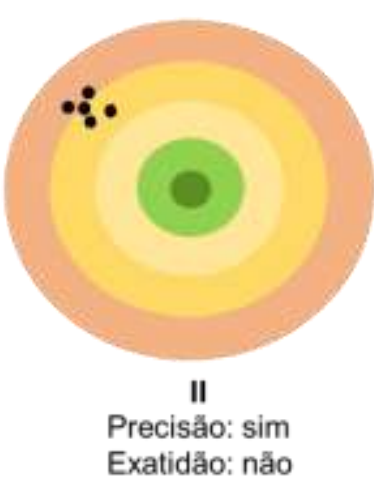

Faixa de valores verdadeiros

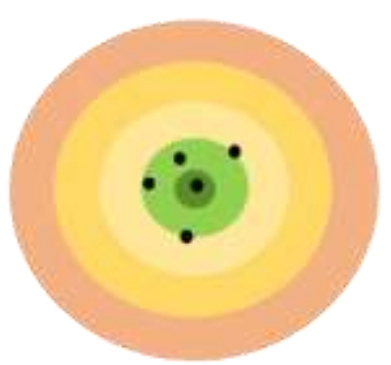

III

Precisăo: não Exatidäo: sim

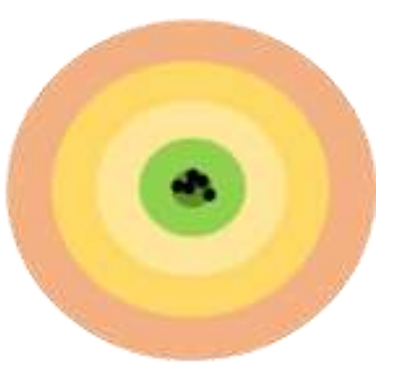

IV

Precisăo: sim

Exatidão: sim

Valores fora da faixa aceitável

Fonte: ilustração própria adaptada de Skoog et al. (2006).

É importante ressaltar que um valor real ainda está associado ao erro inerente a qualquer medida, contudo, esse é um resultado obtido sob as condições mais confiáveis possíveis. Pela Figura 3 pode-se observar que um instrumento pode ser preciso por sempre reproduzir valores próximos entre si, porém, não significa que esses valores são corretos (situação II); um instrumento pode apresentar exatidão, muito embora, mesmo retornando valores corretos - próximos do valor real - está 
com grande dispersão nas medidas (situação III) e, nesse caso, um grande número de medidas é necessário para o resultado médio ser estatisticamente confiável. Diante disso, é fácil compreender a importância de manter um sistema de calibrações e o uso de padrões certificados nas metodologias analíticas: garante-se a rastreabilidade metrológica e a confiabilidade dos resultados.

Os MRCs são para os laboratórios analíticos referências em que podem ancorar seus resultados com rastreabilidade até padrões internacionalmente aceitos. Os valores de incertezas ainda fornecem suporte para que os laboratórios realizem comparabilidade e tenham aceitação global das atividades que desempenham (BIPM, 2019).

O desenvolvimento industrial e tecnológico dos Estados Unidos pode ser correlacionado com o investimento em sistemas metrológicos ainda no início do século XX. Apostar em uma forte infraestrutura de padronizações e medições teve impacto direto nos sistemas de produção, qualidade e desenvolvimento nos EUA, e que em função disso, puderam conquistar o mercado internacional exportando produtos de alto valor agregado (ALVES; DE MORAES, 2003; BIPM, 2019).

Com o mercado globalizado, as transações comerciais são ainda mais intensas; no caso do Brasil, as principais exportações são de soja (US \$33,2 Bi.), óleos brutos (US \$25,2 Bi.) e minérios de ferro (US \$20,5 Bi.). Nesse quadro, o país foi considerado a 25ำ economia de exportação de 2018 (OEC, 2019). Diante disso, é inteligente que o governo brasileiro invista em melhorar a infraestrutura metrológica, tanto para melhorar e garantir a qualidade dos bens que já são exportados, como também para alavancar o desenvolvimento tecnológico no país. Isso fará o Brasil ser capaz de exportar e competir no mercado internacional com produtos de maior valor agregado.

\subsection{MATERIAL DE REFERÊNCIA (MR) E MATERIAL DE REFERÊNCIA CERTIFICADO (MRC)}

Conforme ABNT ISO Guia 30:2016, um material de referência (MR) é um termo genérico para um "material suficientemente homogêneo e estável com respeito a uma ou mais propriedades especificadas, que foi estabelecido como sendo adequado para o seu uso pretendido em um processo de medição". Já os materiais de referência certificados (MRC) são definidos pela mesma norma como "material de referência (MR) caracterizado por mais de um procedimento metrologicamente válido para uma 
ou mais propriedades especificadas, acompanhado de um certificado que fornece 0 valor de propriedade especificada, sua incerteza associada e uma declaração de rastreabilidade metrológica". Portanto, pode-se dizer que um MR se difere de um MRC pelo fato de que o segundo é acompanhado de uma documentação com os valores de suas propriedades específicas e adequadas ao uso e, com as devidas incertezas. Consequentemente, há todo um estudo de caracterização, estabilidade e homogeneidade agregado ao material, garantindo a confiabilidade e a rastreabilidade dos valores analíticos (TAYLOR, 1985).

Os MRs e MRCs são de grande relevância dentro da metrologia científica e industrial atuando no controle dos processos de calibração e na avaliação da qualidade dos resultados analíticos (TAYLOR, 1985; DA ROCHA, 2016). Conforme ilustrado pela Figura 1 (vide tópico 2.1), o Ciclo AQAC está estruturado em três requisitos técnicos: validação, cálculo das incertezas e o controle de qualidade. É interessante observar que as etapas do ciclo estão interligadas por meio do uso de equipamentos calibrados e de materiais de referência certificados, expondo com clareza a extensão da importância que a metrologia química e a aplicação de MR e MRC têm na manutenção da estrutura de um SGQ em laboratórios, essencialmente dentro das exigências da norma ISO/IEC 17025, que é de onde o ciclo deriva.

Averiguou-se que com o decorrer dos anos houve um crescente aumento pelo interesse em utilizar e desenvolver novos materiais de referência para as mais distintas áreas (OLIVARES et al., 2018). Esse resultado é coerente com os efeitos que o mercado globalizado incorpora aos setores industriais, empresariais e tecnológicos com a declarada busca pela melhoria e garantia da qualidade dos produtos produzidos e serviços prestados.

Destaca-se que ainda existem poucos MRCs se comparado com a vasta diversidade de análises químicas efetuadas diariamente nas mais diversas áreas analíticas. Normalmente, os MRCs são produzidos quando há uma demanda alta de análises rotineiras, sendo uma grande maioria comercializados pela National Institute of Standards and Technology (NIST). Outro fator relevante a se considerar é o alto custo agregado a esse tipo de material, pois as etapas de certificação são demoradas e dispendiosas. O desenvolvimento de MRs e MRCs envolve um substancial investimento em pesquisas direcionadas a resolver problemas como adequação da matriz original ao método de análise (por exemplo, preparos de amostra como derivatização ou digestão), técnicas de homogeneização, estudos de estabilidade do 
material sob condições adequadas de embalagem, armazenamento e transporte. Além do mais, o desenvolvimento de um lote para uma baixa demanda de produção pode tornar o custo unitário ainda mais elevado (TAYLOR, 1985; ALVES; DE MORAES, 2003).

Figura 4 - Etapas do desenvolvimento de um material de referência certificado (MRC).

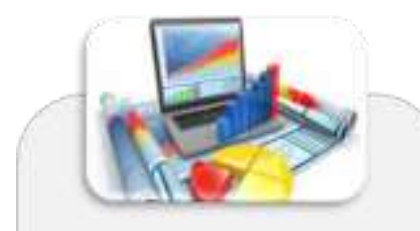

1. Caracterização

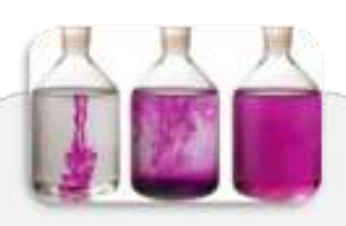

2. Homogeneidade

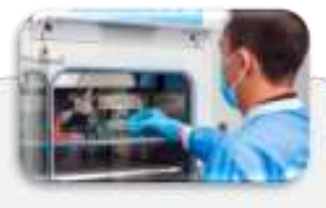

3.

4. Cálculo da incerteza expandida do MRC produzido

Fonte: ilustração própria adaptada de OLIVARES, I. R. B. Gestão de qualidade em laboratórios. 4 ed. Campinas: Editora Átomo, 2019. 176 p.

Conforme elucidado pela Figura 4, a produção de um MRC consiste nas etapas de caracterização do material, estudos de homogeneidade e de estabilidade desse material caracterizado e, por fim, o cálculo da incerteza expandida. Considerando a necessidade de se desenvolver e produzir novos MRCs, assim como Olivares et al. (2018) investigaram na literatura e apuraram um crescente aumento do interesse acadêmico nessa área.

\subsubsection{Caracterização}

A caracterização de um material pode ser executada por um único método ou por múltiplos métodos, em diferentes laboratórios ou não. O importante, é que toda caracterização deve ser acompanhada de sua incerteza (Uchar). É nessa etapa que os métodos analíticos devem ser estudados se são adequados para a finalidade da análise, ou seja, precisam passar por uma validação caso não sejam normalizados, ou por uma avaliação de desempenho se forem métodos já normalizados.

O objetivo dessa etapa é mensurar o valor da propriedade estudada (concentração, $\mathrm{pH}$, acidez, condutividade, etc.). Independente da forma adotada para a caracterização do MR, um laboratório sempre possuirá um conjunto de dados dessa caracterização, réplicas dos ensaios de uma mesma amostra e é a 
partir desses dados que o cálculo da incerteza da caracterização é efetuado (OLIVARES, 2019).

Pela ISO Guia 35, a caracterização de um MRC deve ser realizada por mais de uma técnica analítica. No entanto, a ISO Guia 80 considera o valor de referência de um material de controle de qualidade interno (ou material de referência, MR) caracterizado pelo valor determinado pela média geral do estudo de homogeneidade, assim como o valor do desvio da média desses valores por ser utilizado como estimativa da incerteza do valor de propriedade.

\subsubsection{Homogeneidade}

Pela variação da homogeneidade é possível detectar a presença de impurezas, interferências ou irregularidades no material de referência que podem ocorrer durante o seu processo de preparação. São avaliadas as variações dentro e entre os frascos de um lote de materiais de referência para garantir que uma amostra é representativa em todo o lote. Para a avaliação da homogeneidade, é recomendada a escolha aleatória de frascos dentro do lote, uma quantidade mínima entre 10 e 30 amostras sendo avaliadas em triplicata ou quintuplicata. Procura-se utilizar um número mínimo de 10 unidades para o estudo de homogeneidade pois estimativas aceitáveis de variabilidade entre os frascos para os cálculos de incerteza são obtidas a partir de nove graus de liberdade.

Para lotes grandes, com número de produção ( $\left.N_{\text {prod}}\right)$ superior a 100 unidades, o número mínimo de frascos para o estudo de homogeneidade pode ser calculado conforme a Equação 1. O número mínimo deve ser sempre superior a 10 devido aos graus de liberdade necessários e o número máximo adotado pode ser até o triplo do valor mínimo. Para lotes pequenos, de 100 unidades ou menos, o estudo de homogeneidade pode ser realizado com 3 unidades ou em 10\% da totalidade do lote; escolhe-se a opção com mais amostras. A condição de repetibilidade recomendada é a com maior número possível, isso assegura cálculos estatísticos mais seguros.

$$
\mathrm{N}_{\min }=\sqrt[3]{\mathrm{N}_{\text {prod }}}
$$

Equação 1

A amostragem para o estudo de homogeneidade pode ser do tipo: (i) aleatória simples: retirando 1 amostra do lote; (ii) aleatória estratificada: divide-se o lote em frações e retira-se aleatoriamente números iguais de frascos de cada fração e são 
escolhidos com o uso de ferramentas de geração de números aleatórios (softwares ou tabelas) - essa forma assegura que o estudo será feito com amostras distribuídas uniformemente dentro do lote; (iii) sistemática: os frascos são retirados a cada intervalo pré-estabelecido.

O método de análise escolhido deve ter boa precisão de repetibilidade; no caso de as repetições serem divididas entre várias corridas, o método deve possuir uma boa precisão intermediária. É recomendável que o desvio padrão da repetibilidade do método $(\mathrm{sr})$ seja inferior a 1/3 da incerteza padrão desejada para o valor a ser certificado (Utrg). Caso não seja possível cumprir esses requisitos pela natureza do MRC não permitir diversas repetições, ao menos a relação $s_{r} / \sqrt{n_{a l}}$ não deve ser superior a incerteza padrão alvo, utrg. Sendo $\mathrm{n}_{\mathrm{l}} \mathrm{o}$ número de replicatas de cada frasco, a Equação 2 mostra a relação entre sr e utrg.

$$
\frac{\mathrm{s}_{\mathrm{r}}}{\sqrt{\mathrm{n}_{\mathrm{al}}}} \leq \frac{\mathrm{u}_{\mathrm{trg}}}{3}
$$

Equação 2

Para um planejamento de estudo de homogeneidade do tipo aleatorizado simples, todas as amostras são analisadas em batelada com as replicatas em ordem aleatória. Nesse caso, a homogeneidade é avaliada pelos desvios padrão dentro e entre os frascos. Esses valores são calculados por ANOVA de fator único (Tabela 1) enquanto que os outliers são identificados pelo teste de Grubbs como na Equação 3 (BRASIL, 2015). O objetivo é avaliar as variâncias devido à heterogeneidade inerente à produção do material; se os desvios padrão entre as unidades são suficientemente baixos, fica comprovado que não há diferenças estatisticamente significativas entre as unidades comparadas. 
Tabela 1 - Tabela ANOVA - Análise de Variância

\begin{tabular}{|c|c|c|c|c|}
\hline $\begin{array}{l}\text { Fonte da } \\
\text { Variação }\end{array}$ & $\begin{array}{l}\text { Graus de } \\
\text { liberdade }\end{array}$ & $\begin{array}{c}\text { Soma dos } \\
\text { quadrados (SQ) }\end{array}$ & $\begin{array}{l}\text { Quadrado } \\
\text { médio (MQ) }\end{array}$ & $\begin{array}{c}\text { Teste } F \\
\left(F_{\text {calculado }}\right)\end{array}$ \\
\hline $\begin{array}{l}\text { Entre os } \\
\text { frascos } \\
\text { (efeito do Fator) }\end{array}$ & $p-1$ & $\begin{array}{c}S Q F= \\
\mathrm{n}_{\mathrm{i}} \sum_{\mathrm{i}}^{\mathrm{j}}\left(\overline{\mathrm{x}_{\mathrm{i}}}-\overline{\overline{\mathrm{x}_{\mathrm{j}}}}\right)\end{array}$ & $\begin{array}{c}\text { Mbetween }(M Q F)= \\
\frac{S Q F}{(p-1)}\end{array}$ & $\mathrm{M}_{\text {between }}$ \\
\hline $\begin{array}{l}\text { Dentro dos } \\
\text { frascos } \\
\text { (Erro) }\end{array}$ & $n-p$ & $\begin{array}{c}S Q E= \\
\sum_{j}^{p} \sum_{i}^{n}\left(x_{i j}-\overline{x_{j}}\right)^{2}\end{array}$ & $\begin{array}{c}\text { Mwithin }(M Q E)= \\
\frac{S Q E}{n-p}\end{array}$ & $\mathrm{M}_{\text {within }}$ \\
\hline Total & $n-1$ & $\mathrm{SQT}=\mathrm{SQF}+\mathrm{SQE}$ & & \\
\hline
\end{tabular}

Fonte: adaptado de ISO Guia 35:2020 e de Skoog et al. (2006).

Onde,

$p$ : é o número de frascos

$\mathrm{n}$ : é o número de replicatas em cada frasco

$\overline{\mathrm{x}_{\mathrm{i}}}$ : média dos valores das replicatas em determinado frasco, $\mathrm{i}$

$\overline{\mathrm{x}_{\mathrm{j}}}$ : média do j-ésimo valor, ou j-ésimo frasco

$\overline{\mathrm{X}_{\mathrm{J}}}:$ média global; média das médias de todos os frascos

$\mathrm{x}_{\mathrm{ij}}=\overline{\overline{\mathrm{x}}}_{\mathrm{j}}+\left(\overline{\mathrm{x}_{\mathrm{j}}}-\overline{\mathrm{x}_{\mathrm{j}}}\right)+\left(\mathrm{x}_{\mathrm{ij}}-\overline{\mathrm{x}_{\mathrm{j}}}\right)$ ou seja, o valor observado ( $\left.\mathrm{x}_{\mathrm{ij}}\right)$ é a soma das parcelas média global com o desvio devido ao tratamento e com o resíduo entre o valor experimental observado e a média do seu grupo (frasco).

$$
\mathrm{G}=\frac{\left|\mathrm{x}_{\exp }-\overline{\mathrm{x}}\right|}{\mathrm{s}}
$$

Equação 3

Onde,

s : é o desvio padrão dos valores das replicatas dentro do grupo

$x_{\text {exp }}$ : valor experimental de uma replicata para um mesmo grupo

$\overline{\mathrm{X}}$ : média das replicatas do grupo

O teste de Grubbs rejeita um valor outlier comparando o valor $\mathrm{G}$ calculado com valores críticos tabelados, assim como o teste $F$, explicado a seguir. 
A análise de variância de fator único, também conhecida como ANOVA de única direção, é geralmente calculada com auxílio de softwares que fornecem as informações descritas pela Tabela 1. Esse método estatístico faz a comparação entre as várias médias das populações (frascos) para uma única variável independente em estudo e responde se há diferença significativa entre essas médias pelo teste F. A ANOVA de fator único não é utilizada para experimentos afetados simultaneamente por mais de um fator de variação; neste caso, utiliza-se ANOVA de dois fatores. O teste $F$ se baseia na comparação do $F$ calculado com os valores críticos de $F$, que são tabelados. Se a razão $F_{\text {calculado }} / F_{\text {tabelado }}$ for muito superior a 1 , a hipótese nula $\left(\mathrm{H}_{0}\right)$ de que não há variação estatisticamente significativa nos valores médios da fonte de variação estudada entre os frascos e dentro dos frascos é rejeitada. Isto posto, assume-se que há diferença significativa nas variâncias entre os frascos e dentro dos frascos, ou seja, não há homogeneidade no lote (SKOOG et al., 2006; ABNT, 2020).

Pela ISO Guia 35:2020, o critério de aceitabilidade para homogeneidade suficiente pode ser calculado a partir de uma dessas três formas:

- O desvio padrão entre os frascos (Sbb) com a incerteza associada $\left(s^{2} b\right.$ b) deve ser pequeno em relação à incerteza da caracterização (Uchar); sendo o parâmetro no o número de replicatas por unidade;

$s_{\mathrm{bb}}^{2}=\frac{\left(M_{\mathrm{between}}-\mathrm{M}_{\text {within }}\right)}{\mathrm{n}_{0}} ; \mathrm{s}_{\mathrm{bb}}^{2}=\mathrm{u}_{\mathrm{bb}}^{2} ; \mathrm{s}_{\mathrm{bb}}=\sqrt{\mathrm{s}_{\mathrm{bb}}^{2}}<\frac{\mathrm{u}_{\mathrm{char}}}{3} \quad$ Equação 4

- O desvio padrão dentro dos frascos (Swb) com a incerteza associada $\left(s^{2}\right.$ wb) deve ser pequeno em relação à incerteza da caracterização (Uchar); sendo o parâmetro no o número de replicatas por unidade;

$$
\mathrm{s}_{\mathrm{wb}}^{2}=\mathrm{M}_{\mathrm{within}} ; \mathrm{s}_{\mathrm{wb}}^{2}=\mathrm{u}_{\mathrm{wb}}^{2} ; \mathrm{s}_{\mathrm{wb}}=\sqrt{\mathrm{s}_{\mathrm{wb}}^{2}}<\frac{\mathrm{u}_{\mathrm{char}}}{3} \quad \text { Equação } 5
$$

- A confirmação também pode ser realizada pelo teste $F$ que pode comprovar que a variância entre os frascos $\left(\mathrm{s}^{2} \mathrm{bb}\right)$ não é estatisticamente significante com 95\% de confiança ao não ser rejeitada a $\mathrm{H}_{0}$. 
2.3.2.1. Avaliação da componente de incerteza relativa à homogeneidade (Uhom)

A incerteza associada à homogeneidade é a somatória das incertezas padrão $u^{2}$ bb (componente da contribuição da heterogeneidade entre os frascos) e $u^{2} w b$ (componente da contribuição da heterogeneidade dentro dos frascos), calculada conforme a Equação 6.

$$
u_{\text {hom }}=\sqrt{\left(u_{\mathrm{bb}}^{2}+u_{\mathrm{wb}}^{2}\right)}
$$

Equação 6

A componente da incerteza dentro dos frascos $\left(u^{2} w b\right)$ é relevante nos casos em que o material de referência possui quantidade suficiente para mais de um uso, caso contrário, a unom pode ser estimada considerando apenas a componente da incerteza entre os frascos; se for comprovada heterogeneidade significativa nesse caso, então considera-se a $u^{2}$ wb na estimativa.

É esperado que unom não seja menor que o desvio padrão entre os frascos (Sbb). Se esse desvio padrão for nulo ou desprezível em relação às outras incertezas, o termo unom pode ser omitido do cálculo da incerteza, a menos que a componente $u^{2} w b$ seja importante, como nos casos em que o material de referência foi planejado para uso múltiplo.

\subsubsection{Estabilidade}

A estabilidade do material atribui confiabilidade ao valor certificado. Os estudos de estabilidade são aplicados tanto para estimar a incerteza das medições associadas à instabilidade do material após a sua preparação, quanto para especificar as condições recomendadas de armazenamento e transporte. Devido essas condições, é natural que a estabilidade seja estudada a curto e a longo prazo:

i. Estabilidade de curta duração: associada a qualquer efeito devido às condições de transporte, sendo a incerteza-padrão da estabilidade a curto prazo denominada como $\mathrm{u}_{\text {sts; }}$;

ii. Estabilidade de longa duração: associada ao comportamento dos materiais de referência nas condições de armazenamento, sendo a incerteza-padrão da estabilidade a longo prazo denominada como ults. 
Ainda há dois modos de aplicar o teste de estabilidade de longa duração, segundo a ABNT ISO Guia 35:2020:

i. Clássico: todos os frascos são acondicionados sob as mesmas condições e são avaliados periodicamente com o transcorrer do tempo. Gera maior dispersão dos dados e por isso é pouco utilizado;

ii. Isócrono: os frascos colocados nas condições de armazenamento periodicamente, do maior para o menor, e são analisados todos ao mesmo tempo no final do período de testes. É o método mais empregado por reduzir a dispersão dos pontos no tempo e gerando uma incerteza relativa menor pois são analisados sob melhores condições de repetibilidade.

Para comprovar a estabilidade, o material em estudo é submetido às condições de transporte ou de armazenamento por um período de tempo. Como o objetivo do estudo é estimar a taxa de variação dos valores das propriedades estudadas ao longo do tempo, a estabilidade é verificada por meio de análises de tendências. Nos casos em que a área do pico cromatográfico do analito é proporcional ao valor de propriedade investigado (por exemplo, concentração do analito), em que há apenas uma condição de exposição aplicada e apenas uma propriedade em que se quer estudar uma possível instabilidade, o modelo de regressão linear simples é o recomendado pela norma.

Para avaliar taxas simples de alteração e sua significância estatística, utiliza-se o modelo descrito pela Equação 7.

$$
y=\beta_{0}+\beta_{1} x+\varepsilon
$$

Onde,

x: tempo de exposição do material à condição de estresse escolhida;

$y$ : valor de propriedade investigado (concentração do analito);

$\beta_{0}$ : intersecção da reta (coeficiente linear);

$\beta_{1}$ : inclinação da reta (coeficiente angular);

$\varepsilon$ : componente de erro aleatório que para distribuições normais é geralmente assumido como nulo. 
O coeficiente angular é o parâmetro analisado para averiguar qualquer tendência de variação do valor de propriedade com o tempo. Pela ISO Guia 35, é esperado que um material estável apresente coeficiente angular muito pequeno, até mesmo nulo. É também realizado um teste de significância estatística para esse parâmetro de regressão.

$$
\begin{aligned}
& \beta_{1}=\frac{\sum_{\mathrm{i}=1}^{\mathrm{n}}\left(\mathrm{x}_{\mathrm{i}}-\overline{\mathrm{x}}\right)\left(\mathrm{y}_{\mathrm{i}}-\overline{\mathrm{y}}\right)}{\sum_{\mathrm{i}=1}^{\mathrm{n}}\left(\mathrm{x}_{\mathrm{i}}-\overline{\mathrm{x}}\right)^{2}} \\
& \mathrm{~s}_{(\beta 1)}=\frac{\mathrm{s}}{\sqrt{\sum_{\mathrm{i}=1}^{\mathrm{n}}\left(\mathrm{x}_{\mathrm{i}}-\overline{\mathrm{x}}\right)^{2}}}
\end{aligned}
$$

Equação 8

A Equação 8 é a forma como se calcula a inclinação da reta pare esse modelo de regressão, e a Equação 9 é a forma de se estimar o desvio padrão desse coeficiente angular. Esse desvio padrão $S_{(\beta 1)}$ é a incerteza associada à inclinação da regressão, em outras palavras, é a incerteza padrão associada à tendência de variação do valor de propriedade. Para o cálculo de $\mathbf{S}_{(\beta 1)}$ é necessário possuir o valor do desvio padrão dos resíduos, calculado conforme exemplificado pela Equação 10.

$$
S=\sqrt{\frac{\sum_{i=1}^{n}\left(y_{i}-\beta_{0}-\beta_{1} x_{i}\right)^{2}}{n-2}}
$$

Para confirmar a significância estatística da estabilidade, a norma recomenda que se aplique a Equação 11 como ensaio comparativo com o teste t de Student.

$$
\mathrm{t}_{\beta 1}=\frac{\left|\beta_{1}\right|}{\mathrm{s}_{\beta 1}}
$$

Equação 11

O coeficiente angular do modelo de regressão é comparado ao valor crítico bilateral t de Student para $n-2$ graus de liberdade no nível de confiança de 95\%. Portanto, se a condição $|\beta 1|<\mathrm{t}_{0,95} \mathrm{n}-2 \cdot \mathrm{s}_{\beta 1}$ for verdadeira, pode-se concluir que o candidato a material de referência é estável; não possui tendências significativas à degradação no período de tempo estudado. 
2.3.3.1. Avaliação da componente de incerteza relativa à estabilidade na ausência de tendências significativas (Ults)

A norma ISO Guia 35:2020 orienta que em casos de ausência de tendências para variação do valor certificado, ou seja, quando a estabilidade de longo prazo é confirmada, a incerteza associada à instabilidade pelo tempo de prateleira ( $u_{\text {lts }}$ ) em relação à incerteza do valor certificado geralmente é desprezível (menor que $\mathrm{u}_{\mathrm{char}} / 3$ ) e pode ser considerada nula e omitida do cálculo da incerteza do valor certificado.

Nos casos em quem não houver uma justificativa técnica embasada em experiência comprovando a estabilidade do material, o produtor pode optar por estimar a incerteza associada a uma possível instabilidade usando intervalos de monitoramento mais longos. Essa estimativa estará correlacionada com uma previsão de alteração no valor certificado no período de tempo entre o primeiro ponto de monitoramento até o tempo de validade estimado. Alguns produtores de MR não estabelecem um tempo específico de validade no certificado expedido. Nesse caso, a estimam um tempo de prateleira para o material e agregam ao cálculo da incerteza, conforme a Equação 12:

$$
\mathrm{u}_{\mathrm{lts}}=\mathrm{s}_{(\beta 1)} \cdot \mathrm{t}_{\mathrm{cert}}
$$

Equação 12

Onde S(ß1) é calculado conforme a Equação 9 e tcert é tempo de vida planejado para o material, podendo ser a partir do início do monitoramento da estabilidade do material, do segundo ponto de monitoramento, ou a partir da expedição do certificado do MR.

2.3.3.2. Estimativa do tempo de vida útil (tempo de prateleira) proveniente do estudo de estabilidade

Pela ABNT ISO Guia 35:2012, nos casos em que a estabilidade foi comprovada, ou seja, ausência de tendências significativas, a determinação do tempo de prateleira era realizada da forma como Linsinger et al. (2001) propôs; assumindo que a degradação do material é uma função linear (Equação13)

$$
\mathrm{Y}\left(\mathrm{b}_{0}, \mathrm{~b}^{\prime}, \mathrm{X}\right)=\mathrm{Y}_{0}\left(1+\mathrm{b}^{\prime} \mathrm{X}\right) \quad \text { Equação } 13
$$


O fundamento é que a validade pode ser relacionada com a incerteza padrão relativa à estabilidade de longo prazo (Ults, Equação 12). Nesse caso, o valor de propriedade $(\mathrm{Y})$ diminui linearmente em relação ao valor inicial $\left(\mathrm{Y}_{0}\right)$ a uma taxa de degradação constante (b') em função do tempo $(X)$. A incerteza associada a esse valor de propriedade $\mathrm{Y}, \mathrm{u}(\mathrm{Y})$, pode ser estimada propagando as incertezas relacionadas às variáveis (Equação 14): valor de propriedade inicial, $u\left(Y_{0}\right)$; tempo, $\mathrm{u}(\mathrm{X})$; constante da taxa de degradação, u (b').

$$
\mathrm{u}^{2}(\mathrm{Y})=\left(\frac{\partial \mathrm{Y}}{\partial \mathrm{Y}_{0}}\right)^{2} \cdot u^{2}\left(Y_{0}\right)+\left(\frac{\partial Y}{\partial X}\right)^{2} \cdot u^{2}(X)+\left(\frac{\partial Y}{\partial b^{\prime}}\right)^{2} \cdot u^{2}\left(b^{\prime}\right)
$$

Equação 14

Onde,

u (Y): incerteza do valor certificado com a taxa de degradação b' após tempo um tempo $X$;

u $\left(Y_{0}\right)$ : incerteza do valor de propriedade no tempo zero da certificação.

$\mathrm{Na}$ Equação 14, conforme Linsinger et al. (2001), $u^{2}\left(\mathrm{Y}_{0}\right)$ e relaciona com a incerteza do valor certificado do material $\left(u^{2} c h a r+u^{2} b b\right)$ e derivada parcial de $Y$ em relação a Yo é igual a 1, que é a degradação do valor de propriedade logo após a certificação, portanto, esse termo não é influenciado pela estabilidade de longo prazo do MRC. A derivada parcial de $Y$ em relação a $X$ do segundo termo é o mesmo que Yo.b e corresponde degradação real do valor inicialmente certificado e que não está sendo considerado com o passar do tempo. Entretanto, com a comprovação ausência de instabilidade a longo prazo (ausência de tendências), não há inclinação significante da reta do modelo do estudo de estabilidade e o valor da constante da taxa de variação (b) é nula, assim como todo o segundo termo da Equação 14. Já o termo $\left(\frac{\partial \mathrm{Y}}{\partial \mathrm{b}^{\prime}}\right)^{2} \cdot \mathrm{u}^{2}\left(\mathrm{~b}^{\prime}\right)$ é o que se relaciona a incerteza padrão da estabilidade de longo prazo com o tempo de prateleira e que pode ser convertida como a expressão linear X.u(b), para os casos de ausência de tendências onde os viés de medição e erros padrão da inclinação são insignificantes. Dessa forma, a degradação do valor certificado $\left(\mathrm{Y}_{0}\right)$ é linearmente proporcional à variação de tempo $(X)$ e da incerteza da degradação, conforme a expressão Yo.X.ub. Entretanto, para combinar a contribuição de incertezas, deve- 
se utilizar incertezas padrão nos cálculos. Portanto, essa expressão é dividida por Yo (valor da caracterização) para obter-se a incerteza padrão da degradação relacionada à estabilidade de longo prazo. Como o termo $u(b)$ é a incerteza relacionada à tendências do modelo (taxa de degradação) ele também é o desvio padrão do coeficiente angular do modelo do estudo da estabilidade de longo prazo, $\mathbf{S}_{(\beta 1)}$ (Equação 9). Isto posto, a Equação 15 pode ser utilizada para estimar a incerteza devido a uma possível instabilidade do valor de propriedade certificado passado determinado tempo de prateleira.

$$
\mathrm{u}_{\mathrm{lts}}(\mathrm{X})=\mathrm{X} \cdot \mathrm{s}_{(\beta)}
$$

Equação 15

Com a atualização da guia, ISO Guia 35:2020, a estimativa da validade do material só é necessária quando for comprovada uma variação significativa nos valores de propriedade do material. Pelo tópico 8.7.3 dessa guia, alguns produtores de MR podem optar por não fornecer uma data de validade específica para cada tempo monitorado, optando por aplicar uma data de validade de um tempo de vida planejado para o material. Quando houver comprovação de degradação do material, em níveis aceitáveis, é necessário realizar os cálculos de predição do tempo de vida de armazenamento para estimar com um intervalo de 95\% de confiança os valores de propriedade futuros de acordo com o anexo B4 dessa norma; considerando a taxa de degradação, seleciona-se o tempo de dentro dos limites de confiança do valor certificado.

Após a caracterização e os estudos de homogeneidade e estabilidade, todos esses resultados são combinados para determinar o valor atribuído e a sua incerteza. É o valor atribuído (XMRC, Equação 16) e a sua incerteza expandida (UMRC Equação 18) que são emitidos no certificado.

\subsubsection{Cálculo da incerteza expandida}

O cálculo da incerteza mensura a estimativa do nível de confiança dos resultados produzidos pelo método validado durante a caracterização do material. Esse tipo de cálculo pode ser realizado com o auxílio do diagrama de Ishikawa (OLIVARES, 2019) assim como um grupo do INMETRO utilizou para estimar a incerteza da medição de carbamato de etila em amostras de cachaça por cromatografia gasosa (DE LA CRUZ et al., 2010). 
O valor da propriedade certificado o material de referência ( $x$ MRc) pode ser afetado pelos processos da caracterização, pela variabilidade entre os frascos determinada pelo estudo de homogeneidade e também por alterações provocadas pelas condições de armazenamento e de transporte, determinadas nos estudos de estabilidade de curto e longo prazo. Convém que o valor certificado (assim como estimativa da incerteza associada) leve em consideração todas essas fontes de variação. Um modelo simples para esse fim que a ISO Guia 35:2020 recomenda está descrito pela Equação 16:

$$
\mathrm{x}_{\mathrm{MRC}}=\mathrm{y}_{\text {char }}+\delta_{\text {hom }}+\delta_{\text {lts }} \quad \text { Equação } 16
$$

Onde X MRC: o valor de propriedade; ychar: o valor de propriedade obtido a partir da caracterização; రhom: um termo de erro devido à heterogeneidade que inclui a variação entre frascos junto com qualquer contribuição da heterogeneidade dentro dos frascos; סIts: um termo de erro representando os efeitos de estabilidade sob condições de armazenamento.

Geralmente, os estudos de homogeneidade e estabilidade orientados pela norma já são planejados para que os valores dos termos $\delta_{\text {hom }}$ e $\delta_{\text {lts }}$ sejam considerados como nulos, o que não implica que suas incertezas também sejam nulas.

A incerteza padrão associada ao valor certificado nada mais é do que a combinação das incertezas obtidas nos estudos de caracterização, homogeneidade e estabilidade. É definida na ISO Guia 35:2020 pela Equação 17:

$$
\mathrm{u}_{\mathrm{MRC}}=\sqrt{\left(\mathrm{u}_{\mathrm{char}}\right)^{2}+\left(\mathrm{u}_{\mathrm{bb}}\right)^{2}+\left(\mathrm{u}_{\mathrm{lts}}\right)^{2}}
$$

Equação 17

Sendo, u MRC: incerteza associada ao valor de propriedade do MRC; $u$ char: incerteza associada à caracterização; u bb: incerteza associada ao estudo de homogeneidade, variabilidade entre os frascos; $u$ Its: incerteza associada ao estudo de estabilidade a longo prazo.

Normalmente são apresentados os valores da incerteza expandida associada ao valor de interesse. É essa incerteza que fornece o intervalo x MRC $\pm U$ MRC ao valor certificado. A incerteza expandida do material (U MRc) é a incerteza padrão multiplicada por um fator de abrangência, conforme a Equação 18:

$$
\mathrm{U}_{\mathrm{MRC}}=\mathrm{k} \cdot \mathrm{u}_{\mathrm{MRC}}
$$


Onde k é o fator de abrangência, também denominado fator ou coeficiente de expansão. Conforme será explicado posteriormente no tópico 2.5 deste trabalho, existem algumas formas para encontrar o valor de $\mathrm{k}$ e que dependem do tipo de distribuição considerada, Gaussiana ou t de Student.

Em alguns casos, pode ser necessário considerar termos adicionais ao cálculo da incerteza expandida do MRC (Equação 17). Por exemplo, quando as condições do transporte podem provocar instabilidade ao material comprovado pelo estudo da estabilidade de curto prazo, uma incerteza adicional da estabilidade do transporte (Usts), frequentemente denominada de "estabilidade de curto prazo", pode ser adicionada ao modelo. Entretanto, é recomendado pela ISO Guia 35:2020 que o estudo da estabilidade das condições de transporte seja realizado com antecedência para planejar as condições ideais de transporte; para essa finalidade não é necessário explorar condições rigorosas para o estudo de estabilidade de curto prazo. Dessa forma, garante-se condições controladas que não irão alterar significativamente os valores de propriedade do material evitando o aumento da incerteza do valor certificado ao não ser necessário inserir termos adicionais ao cálculo de u MRC.

Aqui vale ressaltar que "incerteza de uma medição" e "erro" são conceitos diferentemente distinguidos pelo Vocabulário Internacional de Metrologia (VIM). Podese considerar que não existe um valor verdadeiro e único, mas que devido à dificuldade de se definir uma grandeza, existem um conjunto de valores verdadeiros. Portanto, o resultado de uma medição é expresso como um valor acompanhado de uma incerteza de medição. Já para a abordagem de erro, este é entendido como o desvio do valor verdadeiro provocado por erros sistemáticos ou aleatórios, erros estes que são detectáveis e possuem tratamentos específicos.

De forma geral, mesmo que o usuário de um MRC não possa executar as mesmas condições analíticas que certificou o material (técnicas ou metodologias), é preciso que tenha o discernimento para averiguar se o MRC e suas amostras possuem matrizes semelhantes. Garantir características físicas ou químicas similares entre o padrão e a amostra é fundamental para que operações unitárias, como diluições ou dissoluções, possam ser realizadas nas mesmas condições (ALVES; DE MORAIS, 2003). 
Em suma, compreende-se que existe um amplo campo em pesquisa e desenvolvimento para novos MRCs. Conforme foi observado na literatura (DE ANDRADE-SOBRINHO et al., 2002; BARCELOS et al., 2007; DE ANDRADESOBRINHO et al., 2009; CARUSO; NAGATO; ALABURDA, 2010; LACHENMEIER et al., 2010; GALINARO; FRANCO, 2011; DOS ANJOS et al., 2011; ZACARONI et al., 2011; LELIS et al., 2014; DE OLIEIRA FILHO; BORTOLETTO; ALCARDE, 2016), há alguns anos que a comunidade científica vem alertando sobre os perigos de um composto orgânico naturalmente presente em bebidas destiladas, o carbamato de etila (CE). É de conhecimento público que o Ministério da Agricultura, Pecuária e Abastecimento (MAPA) tem interesse em monitorar CE nas bebidas destiladas produzidas e comercializadas no Brasil, tendo já publicado a Instrução Normativa № 28 de 08 de agosto de 2014 que estabelece um limite máximo de $210 \mu \mathrm{g} \mathrm{L}^{-1}$. Entretanto, mesmo tendo estabelecido aos produtores um limite desse contaminante em cachaças, ainda não existe um controle sobre isso no país. Dessa forma, vê-se a necessidade de ser validado um método e de produzir um MRC específico para CE em matriz alcoólica (especificamente cachaça não adoçada, conforme as especificações da Instrução Normativa №13) para que o MAPA possa ter um controle oficial adequado sobre o carbamato de etila dentro do país. 


\subsection{VALIDAÇÃO}

O objetivo dessa etapa é dar validade a um método por uma série de testes e os parâmetros testados serão analisados por ferramentas estatísticas. A validação é a ferramenta que irá demonstrar o nível de confiança de um determinado método experimental. É um importante recurso que um SGQ tem para implantar, manter o controle e garantir a qualidade laboratorial (HARRIS, 2012; BRASIL, 2015; OLIVARES, 2019).

Um método não validado expressa apenas resultados numéricos, sem validade analítica. Em razão disso, validar o método de análise na etapa da caracterização de um material de referência é imprescindível, só assim é possível decidir se o método analítico escolhido atende as necessidades da finalidade do material de referência.

Normalmente os parâmetros de validação frequentemente estudados são (HARRIS, 2012; BRASIL, 2015; OLIVARES, 2019):

\subsubsection{Seletividade (especificidade)}

É a capacidade que o método analítico tem para determinar um analito sem equívocos em uma matriz com substâncias passíveis de interferir na determinação do composto de interesse. Deve-se analisar 6 amostras brancas (amostras isentas do composto de interesse) e preferencialmente 6 amostras de fontes diferentes para identificar as possíveis interferências; em cromatografia são avaliados os picos que possuem mesmo tempo de retenção em que se prevê a eluição do analito. O sinal do interferente deve ser inferior a $30 \%$ do sinal do analito em sua menor concentração (menor nível calibrado).

\subsubsection{Linearidade (curva de calibração)}

Esse parâmetro mede o quanto uma curva de calibração segue uma linha reta, isto é, se a resposta experimental é proporcional à concentração do analito. Para a construção de uma curva de calibração, a concentração do analito deve ser variada em um intervalo apropriado. Geralmente cria-se a curva de calibração com 5 níveis com triplicatas em cada nível com esses níveis variando linearmente. Pode-se avaliar a linearidade por diferentes parâmetros, como por exemplo: coeficiente de correlação "r" com valores acima de 0,99; porcentagem de variação dos resíduos (de triplicata por nível) em relação ao valor teórico, o qual é obtido pela curva de calibração - espera-se resíduos inferiores a 20\%. 
Além da quantificação, a maioria dos parâmetros de desempenho (ou parâmetros de validação) são obtidos da curva de calibração conforme exemplificado pela Figura 5. Outro aspecto importante para a verificação da linearidade é a necessidade de uma verificação prévia de valores outliers (também conhecidos como pontos fora da curva ou valores aberrantes) para cada nível; essa varredura pode ser realizada por teste de Grubbs. Após eliminar todos os outliers do cálculo da regressão, é necessário verificar a homocedasticidade para a escolha do melhor método de regressão; a avaliação da homogeneidade da variância dos resíduos (homocedasticidade) pode ser realizada por teste de Cochran (INMETRO, 2016).

Figura 5 - Exemplo da importância da curva de calibração na validação para a determinação de vários parâmetros de desempenho.

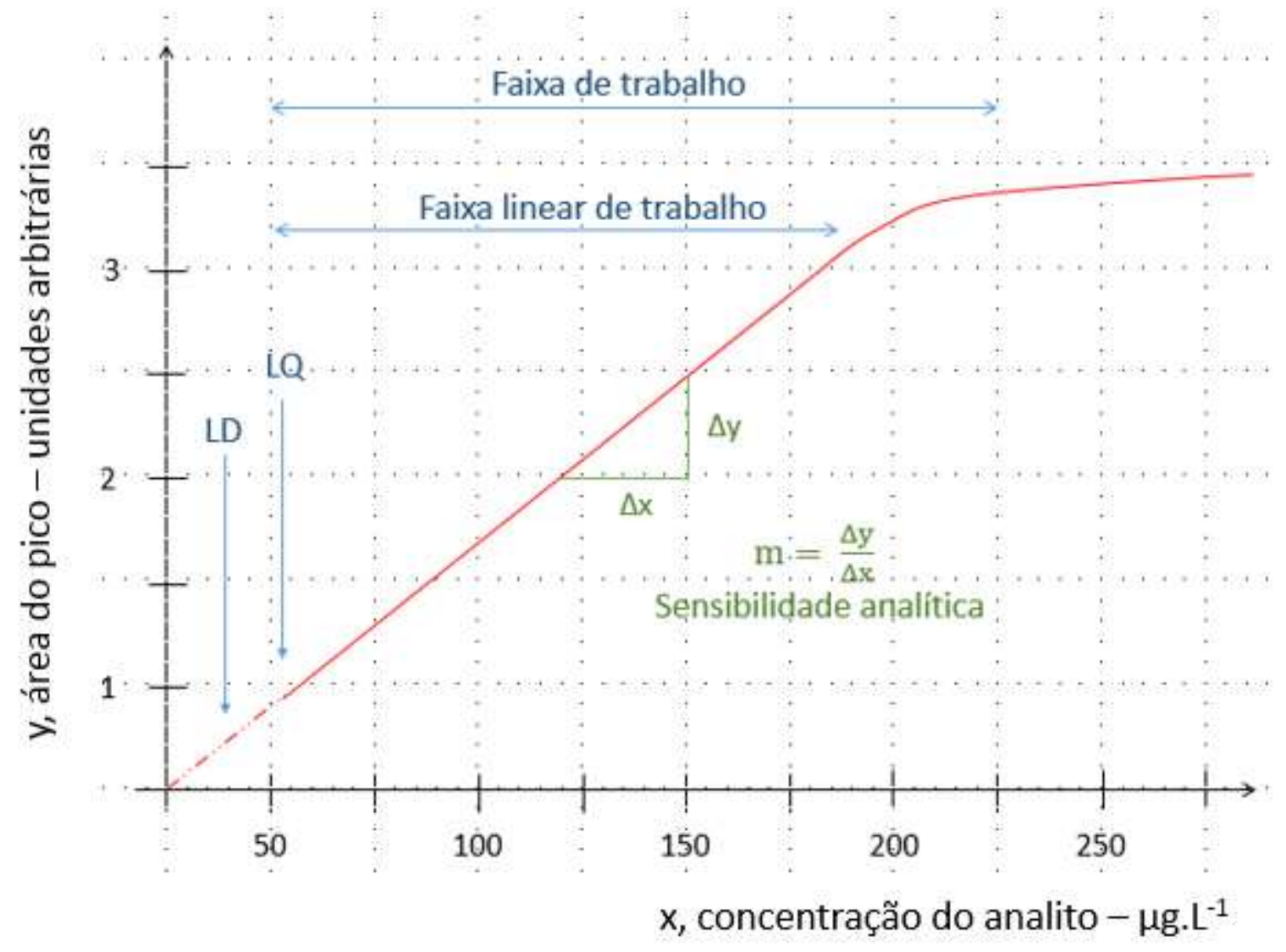

Fonte: ilustração própria adaptada de INMETRO (2016).

Sendo linearidade a habilidade que o método possui para produzir resultados (sinais analíticos) diretamente proporcionais às concentrações investigadas dos analitos, é muito importante que o método utilizado para o cálculo da equação da reta (análise de correlação linear) seja o mais adequado. Existem duas formas de 
encontrar a reta que melhor represente essa correlação (modelos de regressão): pelo método dos mínimos quadrados ordinários não ponderados (MMQO) ou pelo método dos mínimos quadrados ordinários ponderados (MMQP). A escolha do método de cálculo depende do comportamento dos resíduos dos valores das análises; todos os dados possuem incertezas associadas e quando as incertezas dos sinais analíticos (eixo das ordenadas, y) variarem significativamente em relação às incertezas dos valores de concentração (eixo das abscissas, x), é necessário atribuir diferentes pesos aos fatores dos cálculos do modelo de regressão utilizando uma análise ponderada pelo MMQP (SKOOG et al., 2006).

Figura 6 - Demonstração gráfica para a definição de resíduo.

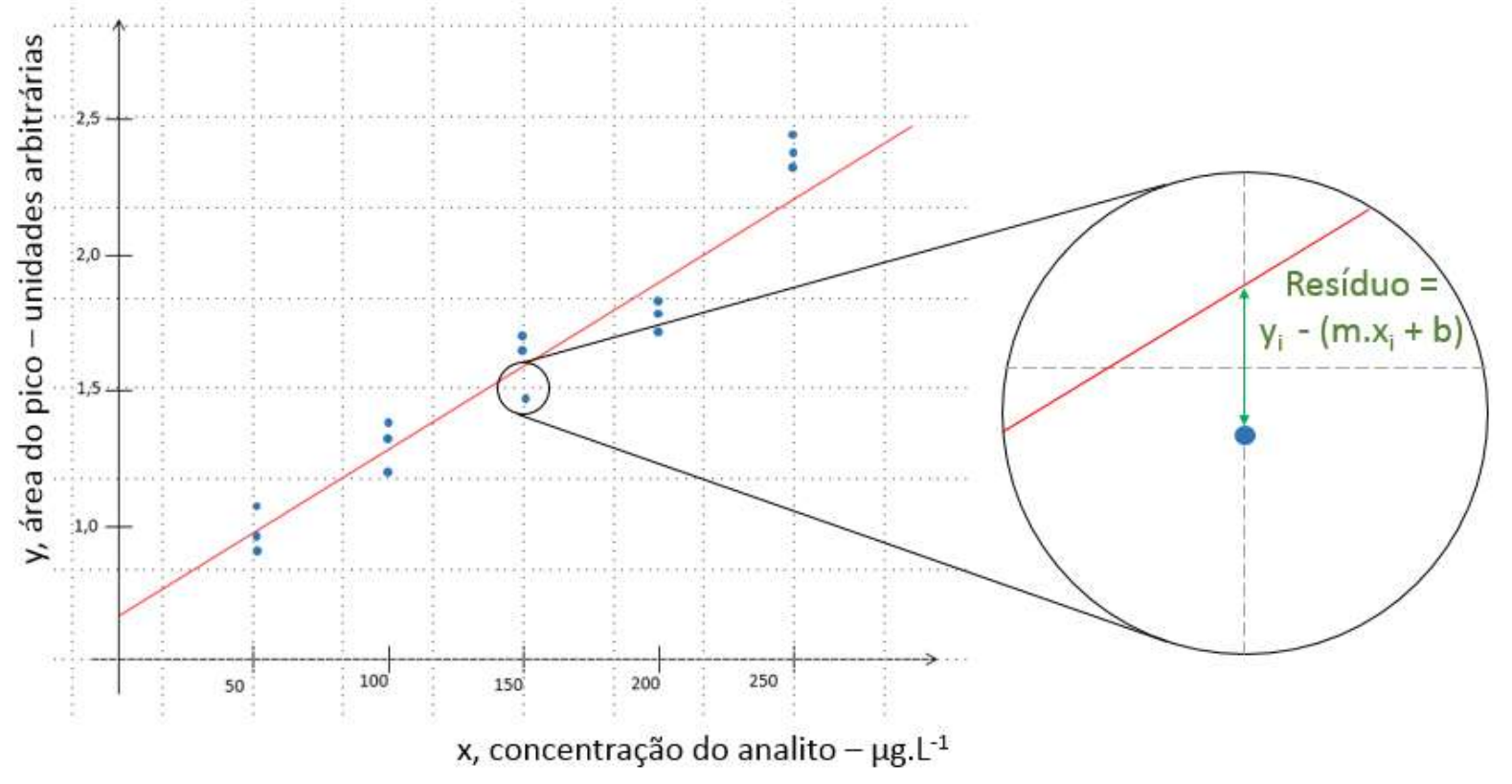

Fonte: ilustração própria adaptada de Skoog et al. (2016).

A equação da reta da curva de calibração, representada pela linha vermelha da Figura 6, é calculada pelos métodos dos mínimos quadrados que tem como função

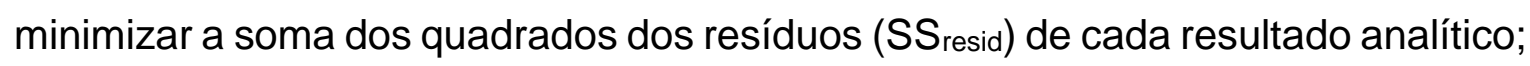
essa técnica de cálculo de minimização das somas dos quadrados visa obter a melhor regressão linear que correlaciona o sinal analítico com o valor experimental. Conforme ilustrado nessa figura, os resíduos são os desvios dos valores experimentais em relação ao seu ponto equivalente à concentração calibrada projetado na equação da reta obtida pelos mínimos quadrados (SKOOG et al., 2006). A partir do estudo da linearidade se obtém uma série de parâmetros 
analíticos importantes tanto para a quantificação do analito, como para a validação do método. As fórmulas desses parâmetros, para um modelo de regressão do tipo $y=m \cdot x+b$, são descritas logo a seguir:

- Soma dos quadrados dos resíduos, SS resid:

$$
\mathrm{SS}_{\text {resid }}=\sum_{\mathrm{i}=1}^{\mathrm{n}}\left[\mathrm{y}_{\mathrm{i}}-\left(\mathrm{b}+\mathrm{m} \cdot \mathrm{x}_{\mathrm{i}}\right)\right]^{2}
$$

Equação 19

n: número de níveis calibrados;

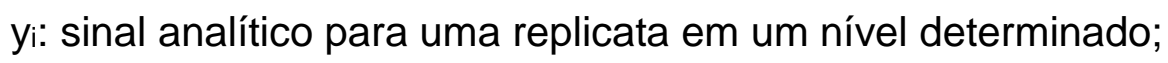

Xi: valor de concentração para determinado nível;

$\mathrm{m}$ : coeficiente angular, inclinação da reta;

b: coeficiente linear, intercepto.

- Coeficiente angular da reta, $\mathrm{m}$

$$
\mathrm{m}=\frac{\mathrm{s}_{\mathrm{xy}}}{\mathrm{S}_{\mathrm{xx}}}
$$

Equação 20

Sendo que $S_{x y}$ é o numerador da covariância entre os valores x e y,

$$
\mathrm{S}_{\mathrm{xy}}=\sum\left(\mathrm{x}_{\mathrm{i}}-\overline{\mathrm{x}}\right) \cdot\left(\mathrm{y}_{\mathrm{i}}-\overline{\mathrm{y}}\right)
$$

Equação 21

e que $S_{x x}$ é a parcela da variância em $x$,

$$
\mathrm{S}_{\mathrm{xx}}=\sum\left(\mathrm{x}_{\mathrm{i}}-\overline{\mathrm{x}}\right)^{2}
$$

Equação 22

onde $\bar{x}$ e $\bar{y}$ são os valores médios de $\mathrm{x}$ e $\mathrm{y}$.

- Coeficiente linear, $b$

$$
\mathrm{b}=\overline{\mathrm{y}}-\mathrm{m} \overline{\mathrm{x}}
$$

Equação 23

- Desvio padrão da inclinação, Sm

$$
s_{m}=\sqrt{\frac{s_{i}^{2}}{S_{x x}}}
$$

Equação 24

- Desvio padrão do intercepto, sb

$$
s_{b}=s_{r} \sqrt{\frac{\sum x_{i}^{2}}{n \sum x_{i}^{2}-\left(\sum x_{i}\right)^{2}}}
$$


- Desvio padrão dos resultados obtidos pela curva de calibração, sc

$$
\mathrm{s}_{\mathrm{c}}=\frac{\mathrm{s}_{\mathrm{r}}}{\mathrm{m}} \sqrt{\frac{1}{\mathrm{p}}+\frac{1}{\mathrm{n}}+\frac{\left(\overline{\mathrm{y}_{\mathrm{c}}}-\overline{\mathrm{y}}\right)^{2}}{\mathrm{~m}^{2} \mathrm{~S}_{\mathrm{xx}}}}
$$

onde $\mathrm{p}$ é o número total de réplicas em todos os $\mathrm{n}$ níveis usados na calibração.

- Desvio padrão para a regressão, sr

$$
S_{r}=\sqrt{\frac{S_{y y}-m^{2} S_{x x}}{n-2}}=\sqrt{\frac{S S_{r e s i d}}{n-2}}
$$

Equação 27

sendo que $S_{y y}$ é a parcela da variância em y,

$$
\mathrm{S}_{\mathrm{yy}}=\sum\left(\mathrm{y}_{\mathrm{i}}-\overline{\mathrm{y}}\right)^{2}
$$

Equação 28

O desvio padrão da regressão é também chamado como erro padrão da estimativa. É o desvio padrão dos sinais analíticos em relação à reta prevista pelo método dos mínimos quadrados. Nesse caso, número de graus de liberdade é $\mathrm{n}-2$ pois perde-se um grau no cálculo do coeficiente angular (m) e outro para a determinação do intercepto (b).

As equações acima são apenas para MMQO, quando os valores de y possuem desvios padrão muito similares em toda a linha de regressão. É dito que esses dados são homocedásticos; isso significa os resíduos são homogêneos e que todos os pontos de calibração têm peso igual para a os limites de confiança e incertezas dos valores. Entretanto, é comum que em muitas análises os dados sejam heterocedásticos onde os resíduos e os desvios padrão dos valores de y tendem aumentar com a concentração do analito; é necessário estabelecer linhas de regressão ponderadas por meio de MMQP para garantir valores analíticos mais precisos (MILLER \& MILLER, 2010). 
Figura 7 - Forma geral do comportamento dos limites de confiança para casos homocedásticos e heterocedásticos.

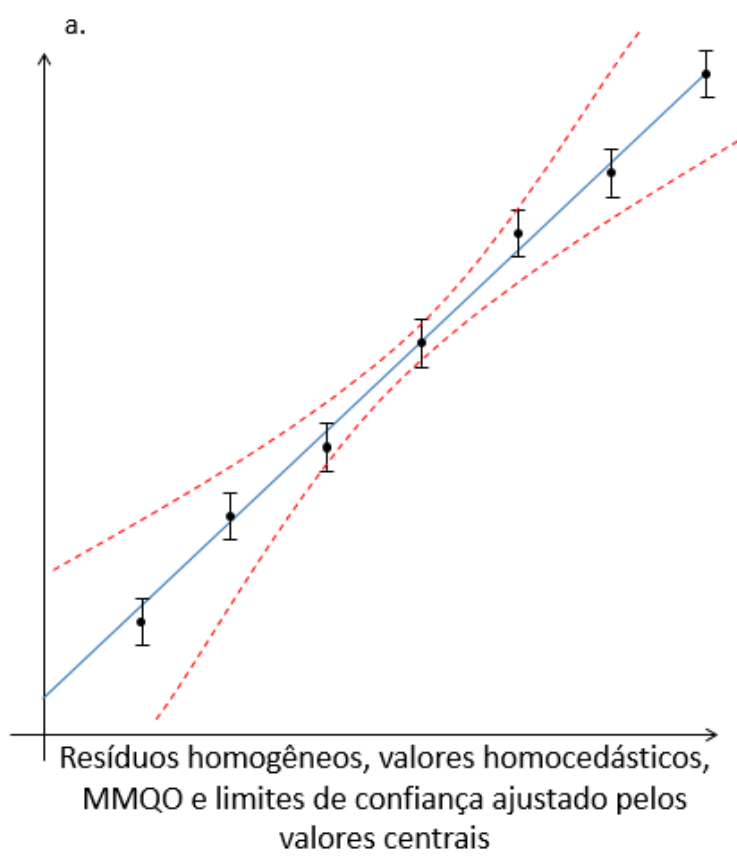

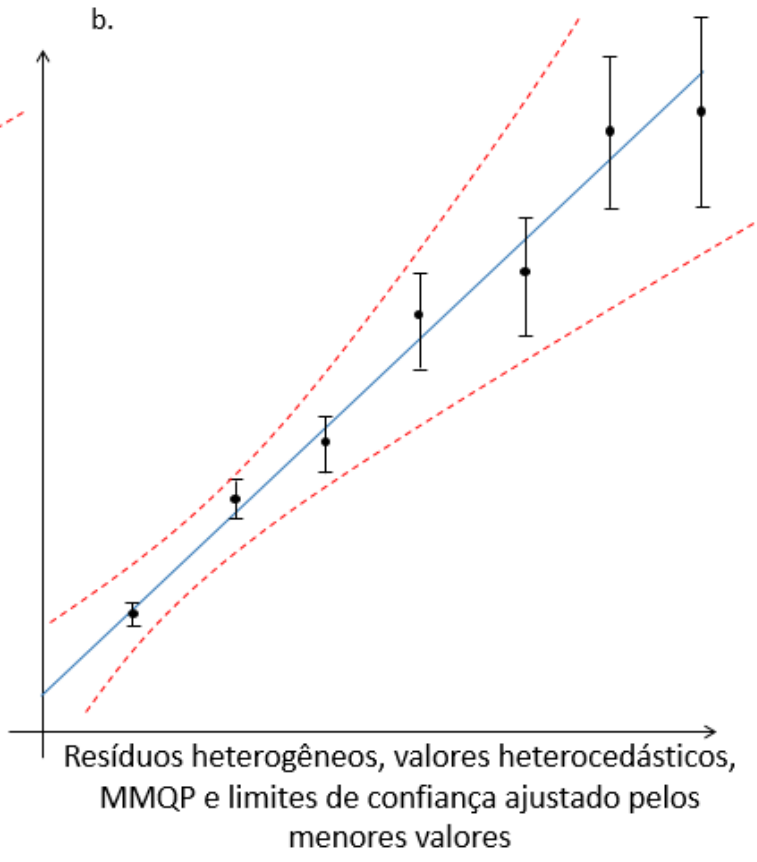

Fonte: ilustração própria adaptada de Miller \& Miller (2010).

Conforme pode ser observado pela Figura 7 , não é somente o valor da quantificação que pode ficar comprometido ao utilizar uma equação de reta predita por um método de mínimos quadrados equivocado; os limites de confiança, e consequentemente as incertezas dos resultados, também são afetados. Portanto, é imprescindível realizar uma análise prévia dos resíduos para a obtenção de resultados mais precisos (MILLER \& MILLER, 2010; INMETRO, 2016).

Visto a complexidade e a quantidade de cálculos envolvidos para a determinação de uma curva de calibração e sabendo o quão importante é ter um bom ajuste dos pontos experimentais no modelo de regressão para uma quantificação mais precisa possível, é sempre importante observar se o método utilizado para a predição da equação da melhor reta é o mais adequado. Felizmente existem alguns softwares próprios para validação de métodos e que realizam todos esses cálculos para o químico analista, como exemplo, o Conflab Validação ${ }^{\circledR}$ e o Conflab Incertezas ${ }^{\circledR}$ utilizados na parte experimental deste trabalho. 


\subsubsection{Exatidão}

Define a proximidade de um valor verdadeiro, ou seja, expressa a concordância entre o valor encontrado e o valor "real". Existem várias formas de se investigar esse parâmetro:

i. Pode-se utilizar MRC para o cálculo. É a diferença percentual entre o valor conhecido de uma amostra (amostra fortificada ou MRC) e as médias dos valores experimentais (Equação 29). Geralmente são aceitos valores entre $80 \%$ e $120 \%$ (CV = $\pm 20 \%)$;

$$
\text { Exatidão }=\frac{\text { valor observado }}{\text { valor esperado }} \times 100
$$

ii. Comparar as respostas analíticas provenientes de diferentes métodos analíticos, devendo concordar entre si dentro da precisão esperada dentro do método;

iii. Na mesma matriz da amostra desconhecida, intencionalmente se produz um branco contaminado com uma quantidade conhecida do analito. Deve ser preparado em três níveis de concentrações diferentes (geralmente dentro de uma faixa entre $50 \%$ e $150 \%$ de seu valor esperado) e as análises em triplicata. Em análises de impurezas, as dopagens do branco devem cobrir uma faixa entre 0,1 e 2,0\% em massa.

iv. Caso reproduzir um branco com a mesma matriz da amostra desconhecida não seja possível, é habitual realizar adições de uma quantidade conhecida de padrão do analito à amostra desconhecida. $O$ aumento provocado no sinal do analito permite que seja descoberta a sua concentração inicial. Esse método é vantajoso quando a matriz da amostra é desconhecida ou complexa e compromete o sinal do analito (efeito matriz).

\subsubsection{Precisão}

É a capacidade de um método produzir valores experimentais semelhantes e geralmente expressa por meio de um desvio-padrão. Como está associada à dispersão dos valores experimentais de uma série de medidas, também está relacionada com as incertezas aleatórias da medição, ou seja, há uma relação direta com a qualidade dos instrumentos de medição. 
Existem diferentes tipos como precisão do instrumento, precisão intrínseca, repetibilidade, reprodutibilidade e a precisão intermediária. As mais estudadas em uma validação são:

\subsubsection{Repetibilidade}

É o grau de concordância entre os resultados produzidos sob as mesmas condições de analista, instrumentação e laboratório, no menor intervalo de tempo possível. Seriam as condições de replicatas de análises e as fontes de variação que estão em função da instrumentação de medição. É calculada pelo coeficiente de variação $(\mathrm{CV})$ de pelo menos uma quintuplicata do experimento (Equação 30). Pode-se utilizar MRC, amostra fortificada ou amostra de rotina. Geralmente são aceitos valores inferiores a $20 \%$.

$$
\mathrm{CV}=\frac{\text { desvio padrão }}{\text { média dos experimentos }} \times 100
$$

\subsubsection{Precisão intermediária (precisão intralaboratorial)}

Também conhecida como reprodutibilidade dentro do laboratório, é o grau de concordância entre os resultados obtidos para um mesmo método realizado no mesmo laboratório, mas considerando-se a variação de uma ou mais condições como analista, instrumentação, coluna cromatográfica ou dias diferentes. Os critérios de cálculos e aceitação costumam ser os mesmos da repetibilidade.

\subsubsection{Reprodutibilidade (precisão interlaboratorial)}

Alíquotas da mesma amostra são analisadas por diferentes analistas, em diferentes laboratórios e em diferentes métodos. Quanto menor o teor do analito na amostra, pior é o resultado da precisão interlaboratorial.

\subsubsection{Faixa de trabalho e faixa linear de trabalho}

Define o intervalo em que os parâmetros linearidade, exatidão e reprodutibilidade são aceitáveis, ou seja, compreende a faixa de concentrações entre a menor e a maior concentração do analito na amostra em que a linearidade foi atingida com precisão e exatidão aceitáveis. A faixa linear de trabalho é o intervalo de concentrações do analito em que os sinais analíticos foram proporcionais à concentração. 


\subsubsection{Limite de detecção (LD)}

É a menor quantidade (concentração) de um analito que pode ser identificado, porém não quantificado. Calculado pela relação sinal ruído $2: 1$, ou seja, em métodos que possuem ruído na linha de base, o LD pode ser calculado como sendo a concentração do analito que fornece um sinal 2 vezes maior que o sinal do ruído da linha de base.

\subsubsection{Limite de quantificação (LQ)}

É a menor quantidade (concentração) de um analito em uma amostra que pode ser quantificado com adequada precisão e exatidão. Pode ser calculado pela razão sinal ruído 10:1, ou seja, o LQ é a concentração do analito que fornece um sinal 10 vezes maior que o ruído da linha de base, ou que o desvio-padrão do branco. Existe também o limite de registro, que é a concentração abaixo das que a legislação considere o analito como "não detectado", mesmo que tenha sido observado. Destaca-se que após determinar o limite de quantificação, este deve ser testado experimentalmente, ou seja, o laboratório deve demonstrar que consegue analisar uma amostra na concentração do limite de quantificação com adequada exatidão e precisão.

\subsubsection{Robustez}

É a capacidade que o método tem de não ser afetado ao se introduzir pequenas alterações nos parâmetros do método de validação. Para o cálculo, utiliza-se o teste de Youden. Seleciona-se 7 parâmetros do método para serem avaliados, caso isso não seja possível, deve-se repetir alguns até que se estabeleça 7 variações. Para cada um desses sete parâmetros, seleciona-se um valor acima ou abaixo do valor de referência estabelecido pelo método (dentro da faixa de interesse) para ser avaliado. Deve-se utilizar amostras fortificadas na concentração mais baixa da faixa de nível da amostra escolhida para o teste de reprodutibilidade. O método é considerado robusto quando as variações não afetarem significativamente os resultados das análises. 


\subsection{ESTIMATIVA DA INCERTEZA DE MEDIÇÃO EM QUÍMICA ANALÍTICA (GUM - Guide to expression of Uncertainty in measurement - 2008)}

Pelo Vocabulário Internacional de Metrologia (VIM), a incerteza de medição é definida como "parâmetro não negativo que caracteriza a dispersão dos valores atribuídos a um mensurando, com base nas informações utilizadas". A incerteza padrão (u) expressa o conceito como um desvio padrão. A incerteza expandida (U) define a faixa que abrange uma grande fração dos valores dentro dos quais a quantidade sendo medida estará, sendo obtida pela multiplicação da incerteza padrão (u) por um fator de cobertura "k" escolhido de acordo com o grau de confiança desejado, ou seja, $U$ = u.k. Como "u" é análogo a um desvio padrão, se $k=2$ (geralmente considerado como o valor padrão caso nenhuma outra informação for fornecida), então $U$ fornece um intervalo de incerteza com 95,5\% de confiança (Figura 9 e Figura 10). A distribuição normal e os desvios padrão são as bases de cálculo para as incertezas padrão.

Figura 8 - Correlação da distribuição normal com os desvios padrão (s), incertezas padrão (u), fatores de cobertura $(\mathrm{k})$ e probabilidades de cobertura $(\%)$ do valor médio das replicatas (ym).

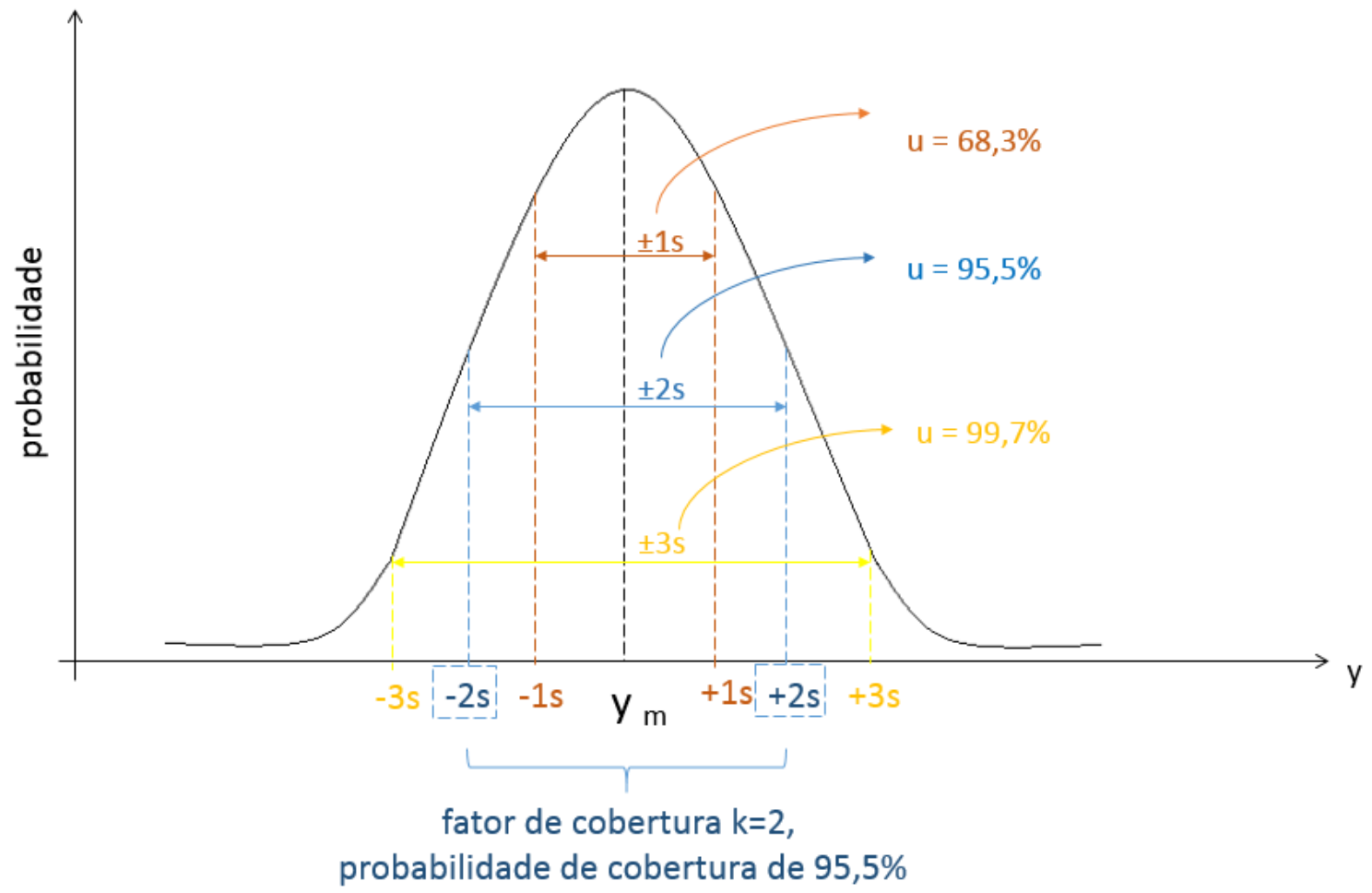

Fonte: ilustração própria adaptada de SKOOG et al. (2006), GUM (BIPM, 2008) e EURACHEM (2012). 
O cálculo da incerteza leva em consideração as fontes de variação a que o resultado está sujeito e, por isso, está relacionada com as funções de distribuição de dados. Existem várias funções de distribuição na natureza, mas para a ciência de medições a mais comum de ser encontrada é a distribuição normal (ou distribuição Gaussiana) ilustrada pela Figura 8. Essa distribuição considera que existem inúmeras fontes de incerteza influenciando o resultado da medição, se aproximando de um número infinito. Isso acontece porque os erros aleatórios são originados de variações incontroláveis e inevitável em qualquer análise (SKOOG et al., 2006).

A incerteza padrão (u) é a incerteza expressa no nível do desvio padrão (s), ou seja, é uma incerteza de aproximadamente 68,3\% de probabilidade de que o valor real esteja dentro de uma faixa de cobertura. Para experimentos analíticos, essa é uma probabilidade muito baixa para ser utilizada. Por isso é comum utilizar a incerteza expandida $(U)$ que por meio do fator de cobertura ( $k=2$, por exemplo) a probabilidade do valor real estar dentro da faixa de cobertura é estendida até 95,5\% (Figura 8).

$$
f(y)=\frac{1}{s \sqrt{2 \pi}} e^{\frac{-(y-y m)^{2}}{2 s^{2}}}
$$

Equação 31

A Equação 31 é a equação da função da distribuição normal. Conforme pode ser observado pela Figura 8, o desvio padrão caracteriza a dispersão dos dados e, portanto, influencia na largura da curva da distribuição normal. Portanto, pode-se entender as incertezas padrão como frações de áreas da função de distribuição. Independentemente do valor do mensurando (y), a função sempre será maior que zero devido à exponencial presente na equação. Isso implica que a função da distribuição normal nunca toca o eixo das abscissas e é impossível obter uma incerteza com 100\% de probabilidade de cobertura. Em outras distribuições, mesmo utilizando um mesmo fator de cobertura k, é normal que a probabilidade de cobertura seja diferente da obtida pela distribuição normal.

Como é considerado que a distribuição Gaussiana se refere a um número infinito de resultados e isso é experimentalmente impraticável, sempre se considera que os valores médios e desvios padrão são estimativas dos valores reais. A Figura 9 ilustra a importância do cálculo da incerteza da medição. Não é possível conhecer o valor real do mensurando na amostra (ou valor verdadeiro) e dessa forma o valor do erro também não pode ser determinado; o erro não é parâmetro de avaliação da qualidade de um resultado de medição. A concordância do valor verdadeiro com o 
valor medido se obtém dos cálculos de precisão, pois a precisão é a incerteza da medição, ou seja, é um intervalo em torno do valor medido onde o valor real pode ser encontrado com alguma probabilidade. Na Figura 9 fica claro que a incerteza da medição é sempre a meia largura da faixa de incerteza.

Figura 9 - Inter-relações entre valor verdadeiro, valor medido, erro e incerteza.

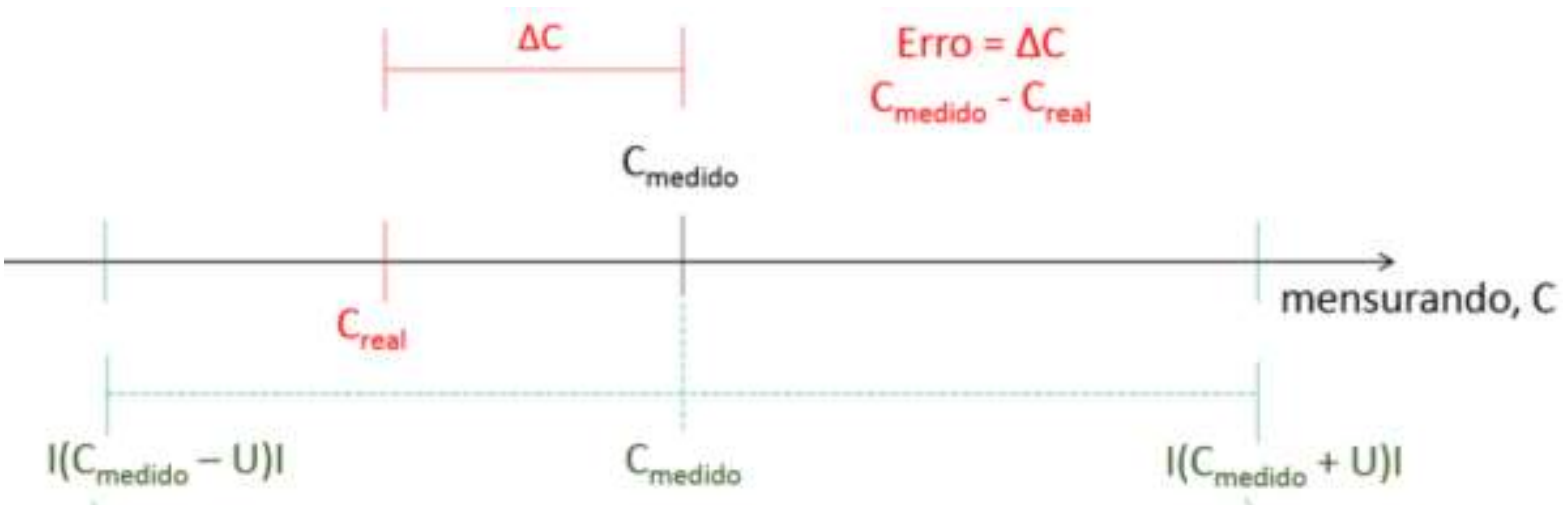

Faixa de incerteza

Fonte: autoria própria.

A incerteza difere do erro e não pode ser considerada como uma estimativa do erro pelo fato de que ela não possui um sinal e não indica possíveis erros sistemáticos existentes, por isso também não pode ser utilizada como valor de correção do resultado. Deve ser considerada como estimativa de qual é a maior diferença absoluta possível entre o valor medido e o valor real (Figura 10).

Figura 10 - Incerteza e limites de conformidade para a aprovação de resultados.

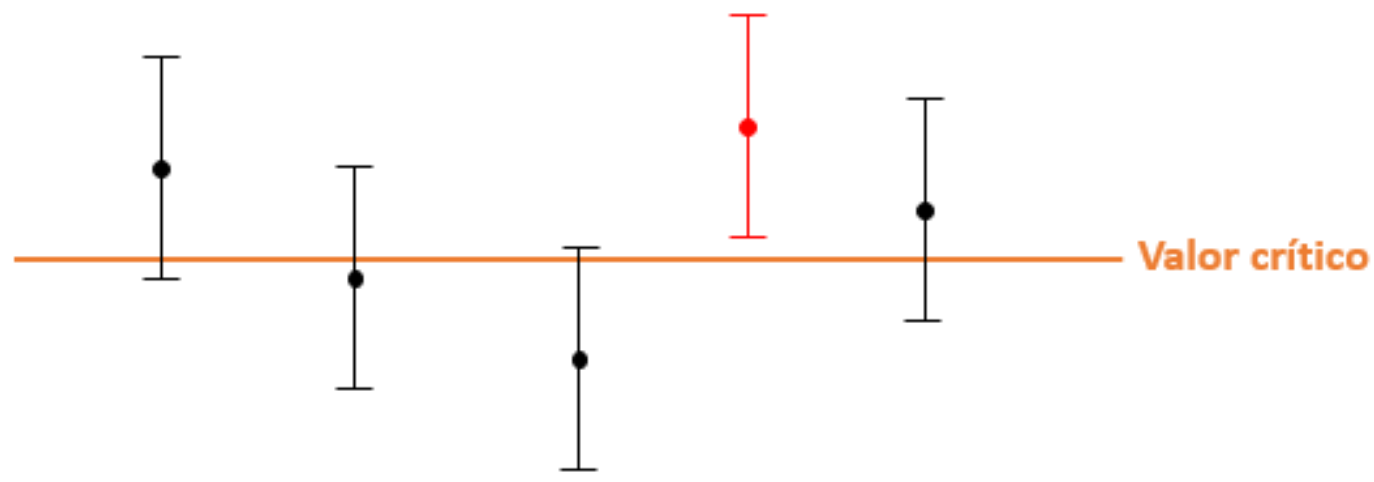

Fonte: ilustração própria adaptada de EURACHEM (2012).

A Figura 10 ilustra a importância do conhecimento do valor de incerteza do resultado para, por exemplo, a reprovação de um resultado. Em casos de análises de 
contaminantes ou de compostos nocivos à saúde (como as análises de carbamato de etila) o valor da incerteza pode ser decisivo para a avaliação do resultado.

Quanto mais erros aleatórios estiverem influenciando na aquisição de dados, mais o experimento se aproxima de uma distribuição normal. Geralmente, a partir de 3 fontes de incertezas significativas já é possível considerar distribuição normal e aplicar um fator de cobertura $k=2$. Isso infere que para distribuições diferentes da normal o fator de cobertura pode mudar e, portanto, também o valor de cobertura da incerteza expandida. Outra distribuição comum de ser aplicada é a t de Student com uma forma própria de calcular o valor de k.

Quando o número de graus de liberdade (df) se aproxima de infinito em magnitude, a forma da curva de distribuição t se aproxima da curva de distribuição normal. Em contrapartida, quanto menor for o número de graus de liberdade, mais alargadas são as caudas da curva de distribuição t de Student e sua forma é menos semelhante à distribuição normal. Na prática, de 30 a 50 graus de liberdade já são suficientes para tratar a distribuição t como uma distribuição normal. O valor de df é calculado como o número de repetições subtraído de um.

À vista disso, existem duas formas distintas para encontrar a estimativa da incerteza expandida: (i) pelo método do coeficiente de expansão com k=2 e probabilidade de cobertura de 95\%; (ii) considerando a distribuição t e utilizando o valor $\mathrm{t}$ de Student correspondente ao nível de confiança desejado como fator de cobertura da incerteza expandida aplicando o método de Welch-Satterthwaite.

O método de Welch-Satterthwaite é uma abordagem mais sofisticada que pressupõe que a função de distribuição da quantidade de saída é uma distribuição de Student com um parâmetro adicional: o número de graus de liberdade efetivos (dfeff) calculado pela equação de Welch-Satterthwaite (Equação 32). Essa equação depende dos índices de incerteza das quantidades de entrada (Index $\mathrm{x}_{\mathrm{i}}$ ) calculados a partir das componentes de incerteza. Essas componentes são obtidas pelo método de Kragten com derivadas parciais e planilhas de cálculos, detalhado em Eurachem (2012).

$$
d f_{e f f}=\frac{1}{\sum_{i=1}^{n} \frac{\operatorname{Index} x_{i}^{2}(y)}{d f_{i}}}
$$


A partir do valor de $\mathrm{df}_{\text {eff }}$ encontrado, adota-se o valor tabelado t de Student para esse valor de graus de liberdade efetivos no nível de confiança desejado ( $95 \%$ ou $\alpha=$ $0,05)$ como coeficiente de expansão k da incerteza expandida.

No artigo de Mendito, Patriarca e Magnusson (2007), os autores fazem uma distinção bem clara de conceitos bases e muito importantes para a compreensão dos resultados e que se relacionam com as incertezas das medições, correlacionados conforme ilustra a Figura 11.

Figura 11 - Inter-relações entre os diferentes tipos de erros, as características de desempenho usadas para calcular as estimativas e os modos de expressá-las quantitativamente.

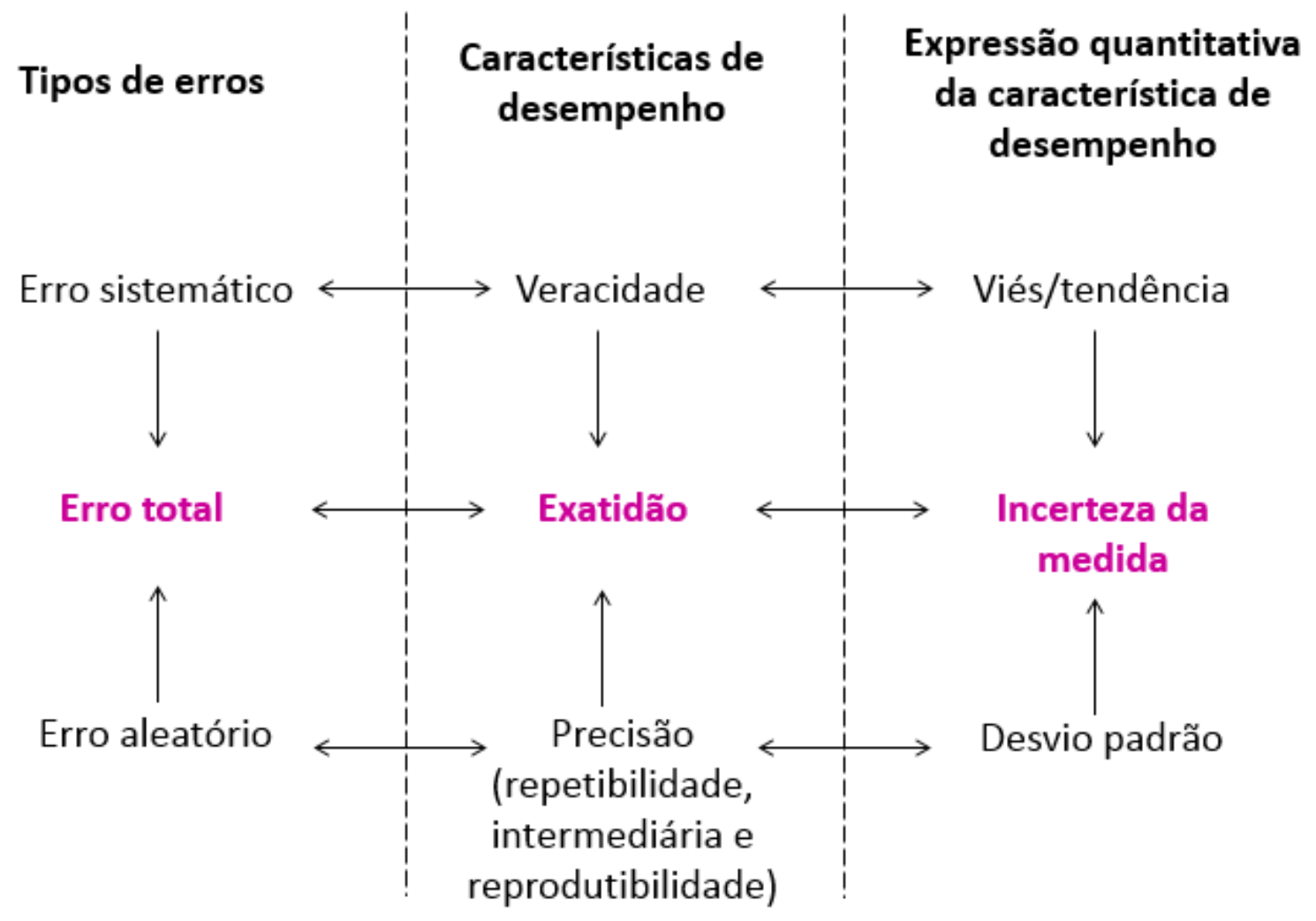

Fonte: ilustração própria adaptada de Mendito, Patriarca e Magnusson (2007).

Da figura acima, podemos extrair as seguintes informações:

- Eixo erro total / exatidão / incerteza da medida: a diferença entre o valor medido e o valor real é chamado de erro total;

- Eixo erro sistemático / erro total / erro aleatório: o erro total pode ser dividido em erro sistemático (para medições repetidas possui mesmo sinal e magnitude) e erro aleatório (para medições repetidas possui sinais e magnitudes distintas para cada medição); 
- Eixo veracidade / exatidão / precisão: como não é possível conhecer os valores exatos dos erros pois os valores reais sempre são desconhecidos, é comum trabalhar com estimativas de erros ou com as características de desempenho;

- Eixo erro sistemático / veracidade: a veracidade é uma estimativa do erro sistemático. Para determinar a veracidade não é preciso conhecer o valor verdadeiro, mas é necessário conhecer um valor de referência que possui uma incerteza associada que costuma ser pequena;

- Eixo erro aleatório / precisão: os diferentes tipos de precisão são estimativas de erros aleatórios. Repetibilidade está relacionada com erros aleatórios da repetição e a precisão intermediária e reprodutibilidade são estimativas de erros aleatórios entre as análises ao longo do tempo;

- Eixo veracidade / exatidão / precisão: a exatidão abrange tanto a veracidade quanto as precisões e é considerada como descritora do erro total. Como as precisões são estimativas dos erros aleatórios, para se conhecer as precisões verdadeiras seria necessário um número infinito de medidas repetidas;

- Eixo veracidade / viés: o viés é a diferença entre o valor medido de uma mesma amostra com várias repetições e o valor de referência. É a expressão quantitativa da veracidade;

- Eixo precisão / desvio padrão: o desvio padrão é obtido de várias medidas repetidas da mesma amostra e é a expressão quantitativa da precisão;

- Eixo viés / incerteza de medição / desvio padrão: a combinação do viés (fontes de erros sistemáticos) com o desvio padrão (fontes de erros aleatórios) são a incerteza da medição que é a expressão quantitativa da exatidão, ou seja, o quanto um valor medido pode estar próximo ou longe do valor real. Se um resultado possui boa veracidade e boa precisão então ele pode ser considerado como tendo boa exatidão.

O cálculo de incerteza deve levar em consideração todas as variáveis descritas pela Figura 11. Para análises com várias repetições se considera a distribuição normal. Entretanto, para outras fontes de incertezas pode ser necessário utilizar 
outras distribuições, como as retangulares ou as triangulares, assim como a forma de calcular a incerteza padrão e a incerteza expandida também muda. Isso por tornar a tarefa muito trabalhosa e até negligenciada por muitos laboratórios. Todavia, existem ferramentas para esse fim, como software Conflab Incertezas ${ }^{\circledR}$ utilizado na parte experimental desse trabalho.

\subsection{ENSAIO DE PROFICIÊNCIA (EP)}

Por pressão de laboratórios europeus, em setembro de 1978 foi publicada a ISO/IEC Guia 24:1978, como ferramenta de avaliação de conformidade. Nessa mesma época começaram a surgir os primeiros trabalhos publicados para EP e MRC (OLIVARES et al., 2018). Em dezembro de 1983, da Guia 24 originou-se a Guia 38 e a Guia 40 (ISO, 1978). Em 1985 foi criada a Guia 45 e em 1986 a Guia 49 (ISO, 1983; ISO, 1985). A Guia 38 foi usada em 1993 para a produção da Guia 58, que estabelecia os requisitos gerais para a aplicação de um sistema de acreditação de laboratórios de ensaio e de calibração (ISO, 1986; ISO, 1993), mas também foi usada juntamente com as Guias 45 e 49 para a criação da ISO/IEC Guia 25 em 1990 - Requisitos gerais para a competência dos laboratórios de calibração e teste (ISO, 1990). Essa guia tinha como objetivo definir os requisitos gerais que um laboratório deveria possuir para ser reconhecido como proficiente em calibrações ou ensaios específicos.

Examinando todas as publicações de ensaios de proficiência referentes à área de química na base de dados Web of Science, percebe-se que após 1990 houve um incremento expressivo no número de publicações, tanto que apenas nos cinco anos entre 1991 e 1995 publicou-se praticamente a mesma quantidade de estudos na área que os 15 anos anteriores. A implementação da Guia 25 teve um forte impacto na implementação de sistemas de gestão com foco na qualidade analítica.

A Figura 12 ilustra como se deu a origem da ISO 17025 em dezembro de 1999 (ISO/IEC, 1999), mesmo período em que, desde o surgimento da Guia 24, começou a ser pulicado um volume de estudos com EP muito superior aos anos anteriores. A Guia 25 foi cancelada e transformada em norma, a ISO/IEC 17025 - Requisitos gerais para a competência de laboratórios de ensaio e calibração. Essa norma abrange todas as atividades de qualquer laboratório, regulamentando ensaios, calibrações, amostragens e validação de resultados (ISO/IEC, 2017). 
Figura 12 - Diagrama da criação da ISO/IEC 17025 e suas revisões.

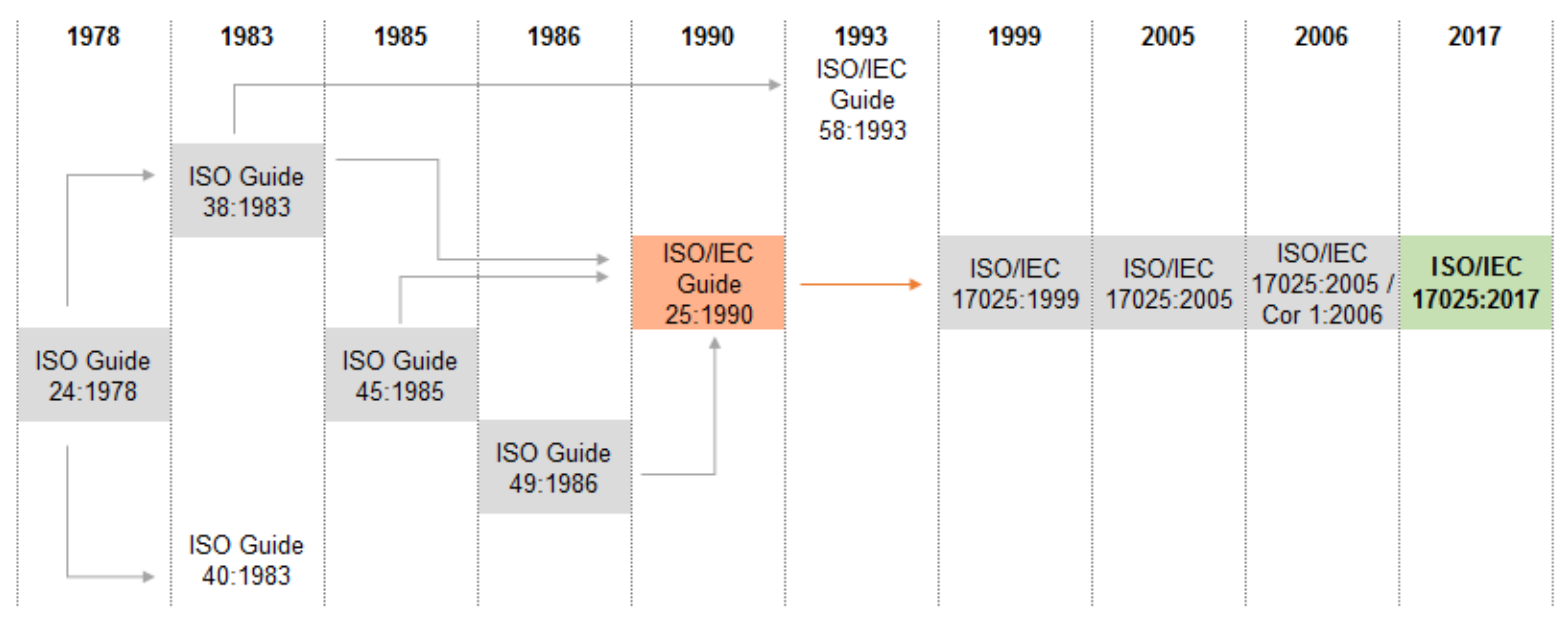

Fonte: autoria própria.

A implementação de uma norma internacional específica para conduzir sistemas de gestão de qualidade em laboratórios de ensaio e calibração forçou os laboratórios a se preocuparem em garantir a sua competência técnica nos padrões internacionais, por isso, notou-se que a partir dos anos 2000 aumentou o volume de publicações de estudos com ferramentas da qualidade, como produção de materiais de referência certificados (OLIVARES et al., 2018) e ensaios de proficiência, devido às exigências da norma. Além disso, por ser uma norma de padronização internacionalmente bem-conceituada, além de garantir a validade dos resultados dos laboratórios em território nacional, a ISO 17025 também facilita bastante o trabalho colaborativo de pesquisa e desenvolvimento entre diferentes países. Isso incentiva uma adesão cada vez maior dos laboratórios aos requisitos gerais da norma, consequência da tendência mundial na exigência de sistemas gestão da qualidade que faz com que o número de laboratórios de ensaios acreditados nessa norma estar em crescimento constante.

Os ensaios de proficiência são uma ferramenta de qualidade tão procurada e largamente aplicada em âmbito internacional que surgiu a necessidade da criação do European PT Information System (EPTIS), um projeto da União Europeia que consiste em reunir em uma base de dados internacional com o registro de esquemas de EP regularmente aplicados pelos participantes do projeto. Sem fins lucrativos, a base de dados funciona sob a coordenação geral do Federal Institute for Materials Research and Testing (BAM), na Alemanha (EPTIS, 2020). A base EPTIS iniciou nos anos 2000, mesmo ano em que a norma ISO/IEC 17025 entrou em vigor cancelando a Guia 25. Até o momento há 59 categorias de cadastros de esquemas de PT; somente os 
setores "human test material" e "food and drink" já são $28,3 \%$ de todo o inventário, cerca de 1258 cadastros. O Brasil e a Alemanha são os países que mais contribuem para o inventário, com $37 \%$ dos cadastros.

Pelas tendências observadas pelas publicações de artigos científicos na base Web of Science e também pelos cadastros na base EPTIS, "alimentos" é a área que mais gera interesse e aplicações de ensaios de proficiência por todo o mundo, provavelmente pelas rígidas fiscalizações que existe sob esse setor que se estendem de matéria-prima até embalagens de produtos.

\subsubsection{Requisitos gerais para ensaios de proficiência (ABNT NBR ISO/IEC 17043)}

Há uma cobrança para que os laboratórios mantenham uma gestão do controle de qualidade de seus métodos, análises e tratamento de dados, tanto por pressão dos clientes quanto de órgãos reguladores e de acreditação de laboratórios. Para manter essa credibilidade existem certas ferramentas que podem ser implantadas, uma delas é a participação em ensaios de proficiência (EP).

Ensaios de proficiência são estudos de resultados analíticos provenientes de vários laboratórios por meio de comparações interlaboratoriais; são aplicados internacionalmente e nas mais diversas áreas. Para um laboratório manter a acreditação, pela norma ISO 17025 é obrigatória uma participação periódica em ensaios interlaboratoriais pois nesses estudos o desempenho do laboratório participante é confrontado contra critérios pré-estabelecidos. Essas comparações abrangem uma série de propósitos benéficos com apontamentos pertinentes para a melhoria da qualidade analítica. As principais são:

i. Avaliação e monitoramento contínuo do desempenho do laboratório em análises específicas expondo a sua efetividade em entregar resultados confiáveis;

ii. Identificação de possíveis problemas analíticos dentro do laboratório (ensaios ou medições inadequadas) proporcionando ações corretivas (calibração de vidrarias e equipamentos analíticos, treinamento da equipe);

iii. Atribuição de maior confiança dos clientes nos serviços fornecidos pelo laboratório;

iv. Validação da incerteza declarada; 
v. Caracterização de materiais de referência e avaliação de adequação ao uso.

Os itens de ensaio de proficiência (amostras, materiais de referência, padrões, conjunto de dados, equipamentos, etc.) podem ser empregados nos programas de comparação interlaboratorial em diversas abordagens:

- Quantitativo: o objetivo é quantificar um ou mais mensurandos de um item de EP;

- Qualitativo: com a finalidade de identificar ou descrever uma ou mais propriedades de um item de EP;

- Sequencial: os itens do programa são distribuídos para um participante e depois de devolvidos, esses mesmos itens são encaminhados para outro participante, sequencialmente assim até o último participante;

- Simultâneo: uma ou mais itens do programa são distribuídos simultaneamente aos participantes com um tempo definido para as análises;

- Único: é realizada uma única rodada do programa para os itens distribuídos;

- Contínuo: os itens de EP são fornecidas regularmente em várias rodadas;

- Amostragem: onde é solicitado que se realize amostragem do item do programa para uma análise subsequente;

- Interpretação e transformação de dados: são fornecidos conjuntos de dados para que o participante processe as informações e entregue as interpretações dos resultados.

Preliminarmente ao envio dos itens do ensaio de proficiência para os participantes, o provedor deve realizar testes de estabilidade de curto e longo prazo, testes de homogeneidade do lote e atribuir os valores designados e as incertezas associadas ao(s) mensurando(s) desse item. Isso é importante para garantir a integridade do material até o fim do EP e assegurar que todos os participantes receberão materiais comparáveis entre si, salvaguardando-os de mal desempenho errôneo no programa.

É importante salientar que apesar de algumas distinções entre as abordagens acima descritas, a determinação do valor designado, da homogeneidade e das estabilidades, bem como o cálculo das estatísticas e avaliação de desempenho são etapas fundamentais e comuns a praticamente todos os EP. O programa 
aplicado neste trabalho é do tipo simultâneo e segue os passos conforme ilustrados pela Figura 13.

Figura 13 - Etapas de ensaio de proficiência aplicado na abordagem de programa simultâneo.

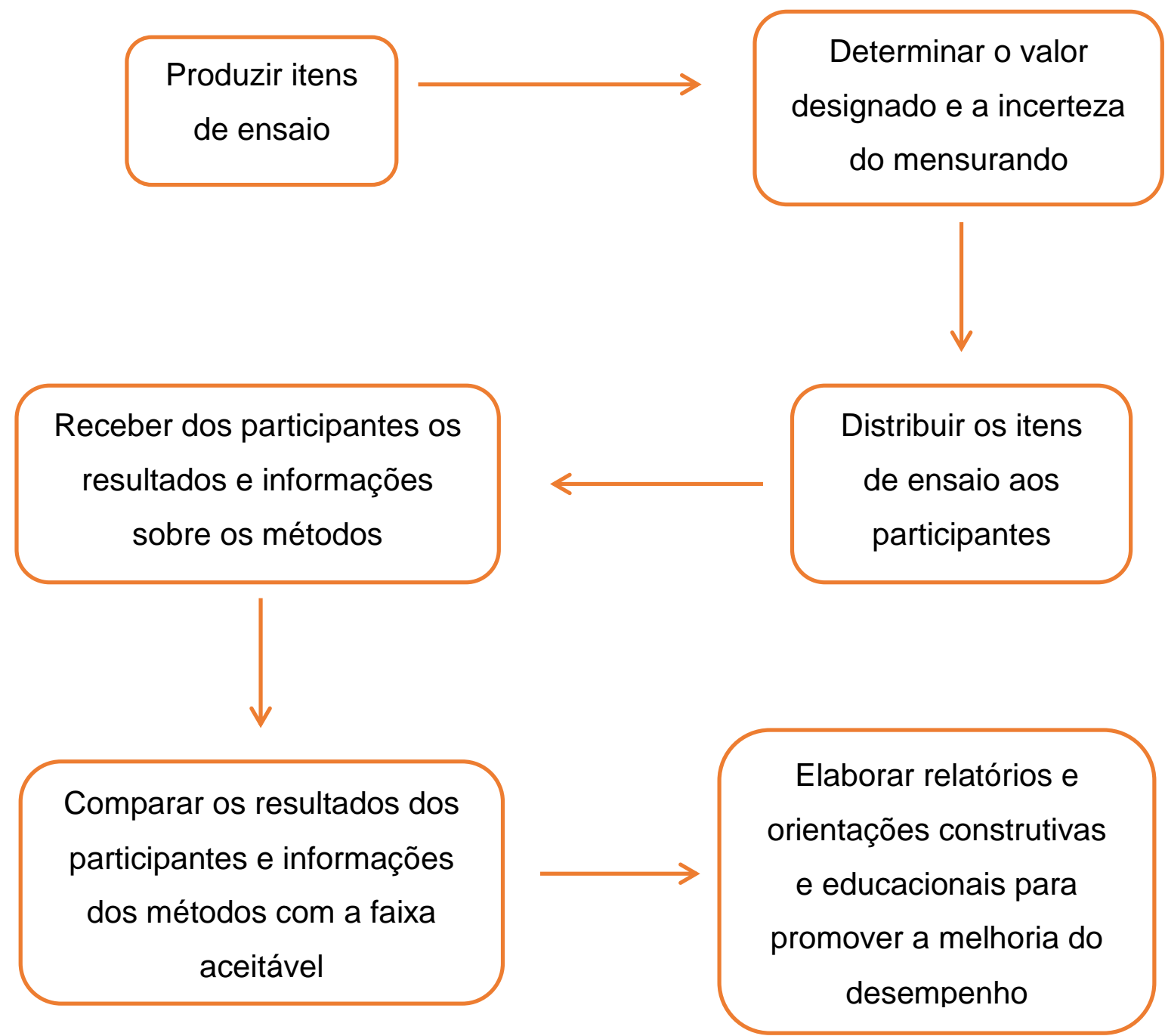

Fonte: adaptado de ASSOCIAÇÃO BRASILEIRA DE NORMAS TÉCNICAS (ABNT), 2011.

É previsto pela ISO/IEC 17043 que EP novos apresentem baixa concordância entre os participantes por inúmeros motivos: novos problemas a resolver, novos formulários, itens de ensaio artificiais ou diferentes dos comumente utilizados, procedimentos de medição variados e baixa concordância entre os métodos de ensaio empregados. Até que o EP esteja bem ajustado, os provedores podem precisar usar métodos estatísticos mais refinados até que o EP esteja bem estabelecido e a concordância entre os participantes sejam melhores; indicadores robustos como desempenho relativo (percentuais) são frequentemente usados nesses casos. 


\subsubsection{Análise estatística dos resultados do EP}

O provedor deve considerar os seguintes aspectos ao realizar a análise estatística dos resultados do EP:

- Exatidão (veracidade e precisão) e a incerteza esperada para o mensurando;

- Número mínimo de participantes;

- Relevância dos algarismos significativos;

- Número de itens do EP e número de replicatas;

- Métodos para estabelecer o desvio padrão;

- Método para tratamento de outliers.

As estatísticas de desempenho dos resultados de um EP precisam ser calculadas para que os desvios em relação ao valor designado sejam conhecidos. Isso permite a comparabilidade entre os resultados dos laboratórios participantes. Os cálculos mais utilizados seguem abaixo:

i. Diferença (D)

$$
\mathrm{D}=\frac{(\mathrm{x}-\mathrm{X})}{\mathrm{X}}
$$

$x$ : resultado do participante;

$X$ : valor designado.

ii. Diferença percentual (D\%)

$$
\mathrm{D} \%=\frac{(\mathrm{x}-\mathrm{X})}{\mathrm{X}} \cdot 100
$$

$x$ : resultado do participante;

$X$ : valor designado.

É um valor independente de magnitude e usualmente bem compreendida pelos participantes.

iii. Escores z

$$
\mathrm{z}=\frac{(\mathrm{x}-\mathrm{X})}{\sigma}
$$

$\sigma$ : desvio padrão do ensaio de proficiência.

Pela norma ISO 13528, o valor de $\sigma$ pode ser calculado como um desvio padrão tradicional dos resultados dos participantes após exclusão de outliers. 
iv. $\quad$ Escore zeta (ל)

$$
\zeta=\frac{(x-X)}{\sqrt{u_{\text {c.lab }}^{2}+u_{c . v d}^{2}}}
$$

$u_{c . l a b}^{2}$ : incerteza padrão combinada do resultado do laboratório participante;

$u_{c . v d}^{2}$ : incerteza padrão combinada do valor designado.

v. Números $E_{n}$

$$
\mathrm{E}_{\mathrm{n}}=\frac{(\mathrm{x}-\mathrm{X})}{\sqrt{\mathrm{U}_{\mathrm{lab}}^{2}+\mathrm{U}_{\mathrm{ref}}^{2}}}
$$

$U_{l a b}^{2}$ : incerteza expandida do resultado do laboratório participante;

$U_{r e f}^{2}$ : incerteza expandida do valor designado.

Calculado da mesma forma que o escore zeta (ל), alterando-se apenas as incertezas padrão combinadas pelas incertezas expandidas.

A diferença entre o resultado do participante e o valor designado, $(x-X)$, é sempre mais simples dos participantes compreenderem e é denominada de "estimativa de tendência do laboratório" pela ISO 13528.

Quando a avaliação de desempenho é realizada por escores z ou $\zeta$ é comum se estabelecerem os seguintes critérios de aceitação:

$|z| \leq 2$ ou $|\zeta| \leq 2$ : desempenho satisfatório;

$2 \leq|z| \leq 3$ ou $2 \leq|\zeta| \leq 3$ : desempenho questionável, sinal de alerta;

$|z| \geq 3$ ou $|\zeta| \geq 3$ : desempenho insatisfatório, necessária tomada de ação.

O mesmo se aplica para números $E_{n}$ com os seguintes critérios:

$\left|E_{n}\right| \leq 1:$ desempenho satisfatório;

$\left|E_{n}\right|>1$ : desempenho insatisfatório, necessária tomada de ação. 


\subsection{CACHAÇAS E AGUARDENTES DE CANA}

Ambas são bebidas obtidas pelo destilado simples ou pela destilação do mosto da cana-de-açúcar, podendo ser adicionadas de até $6 \mathrm{~g} \mathrm{~L}^{-1}$ de sacarose, mas são diferenciadas pelo MAPA através da Instrução Normativa № 13, de 29 de junho de 2005 em relação ao teor alcoólico. A $20^{\circ} \mathrm{C}$, aguardente de cana é caracterizada por uma graduação alcoólica entre 38 e 54\% (v/v); cachaça é caracterizada por possuir uma graduação alcoólica de entre 38 e 48\% (v/v). O termo "cachaça" somente pode ser empregado para as aguardentes de cana exclusivamente produzidas no Brasil (BRASIL, 2005; VENTURINI FILHO, 2016).

Há duas formas de se destilar o mosto de cana-de-açúcar para a produção de cachaça, em coluna e em alambique. Estima-se que da produção de cachaça, 70\% do volume comercializado provém de destilação em coluna e 30\% em alambique. Pequenas destilarias costumam utilizar alambiques de cobre, enquanto que grandes produtores já adotam o sistema de coluna, geralmente construídas em aço inox (VENTURINI FILHO, 2016).

A cachaça é a bebida destilada mais consumida no Brasil e aguardente de cana é a quarta bebida destilada mais produzida no mundo. O volume exportado pelo país corresponde cerca de $1 \%$ de um total de aproximadamente 2 bilhões de litros produzidos por ano (VENTURINI FILHO, 2016). Pela Figura 14, observa-se que EUA Paraguai, Portugal e Itália foram os principais importadores de destilados de cana que o Brasil exportou em 2019, mais da metade do volume comercializado. Entre os estados brasileiros que se destacaram no ano de 2019, em volume exportado, estão São Paulo, Paraná, Pernambuco, Rio de Janeiro e Minas Gerais, conforme dados do Ministério da Indústria, Comércio Exterior e Serviços (BRASIL, 2019b) e ilustrado pela Figura 15. Tanto a cachaça quanto o etanol para combustível possuem o processo de produção muito semelhantes. A diferenciação ocorre principalmente após a etapa de destilação em que não se aproveita as frações cabeça (início, rico em metanol) e cauda (final, com maior índice de água e de impurezas com maior ponto de ebulição que o etanol). É a fração intermediária, que representa cerca de $80 \%$ do volume destilado e denominada "coração", a que se destina para consumo como bebida destilada por possuir menor quantidade de congêneres orgânicos como ácidos, álcoois superiores e furfural (VENTURINI FILHO, 2016; EMBRAPA, 2008). As etapas da produção da cachaça estão esquematizadas pela Figura 16. 
Figura 14 - Distribuição percentual dos principais países importadores de destilados de cana produzidos no Brasil (rum, cachaça e aguardentes) em valor (USD).

\section{Principais países importadores de destilados de cana}

(de janeiro a dezembro de 2019)

Total: US\$ 14.603.011,00

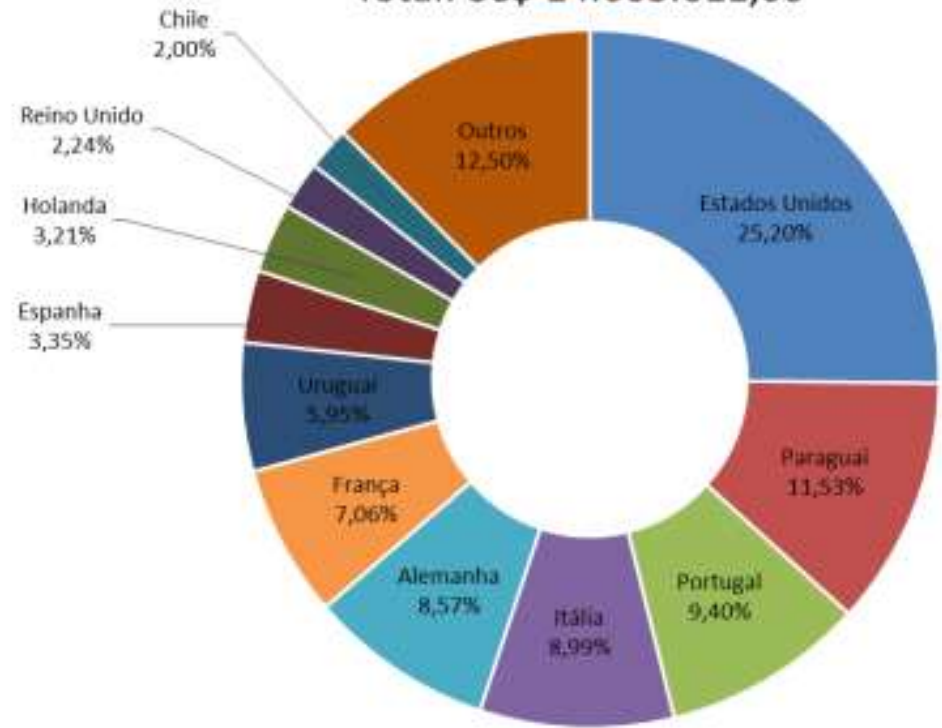

Fonte: ilustração de autoria própria; dados de MDIC - ALICEWEB - NCM 2208.40.00. Disponível em: <http://comexstat.mdic.gov.br/pt/geral/2820 >. Acesso em: 27 de março de 2020.

Figura 15 - Principais estados exportadores de destilados de cana produzidos no Brasil (rum, cachaça e aguardentes) em quilograma líquido.

Principais estados exportadores de destilados de cana

(de janeiro a dezembro de 2019)

Total: 7.686.923,00 quilograma líquido

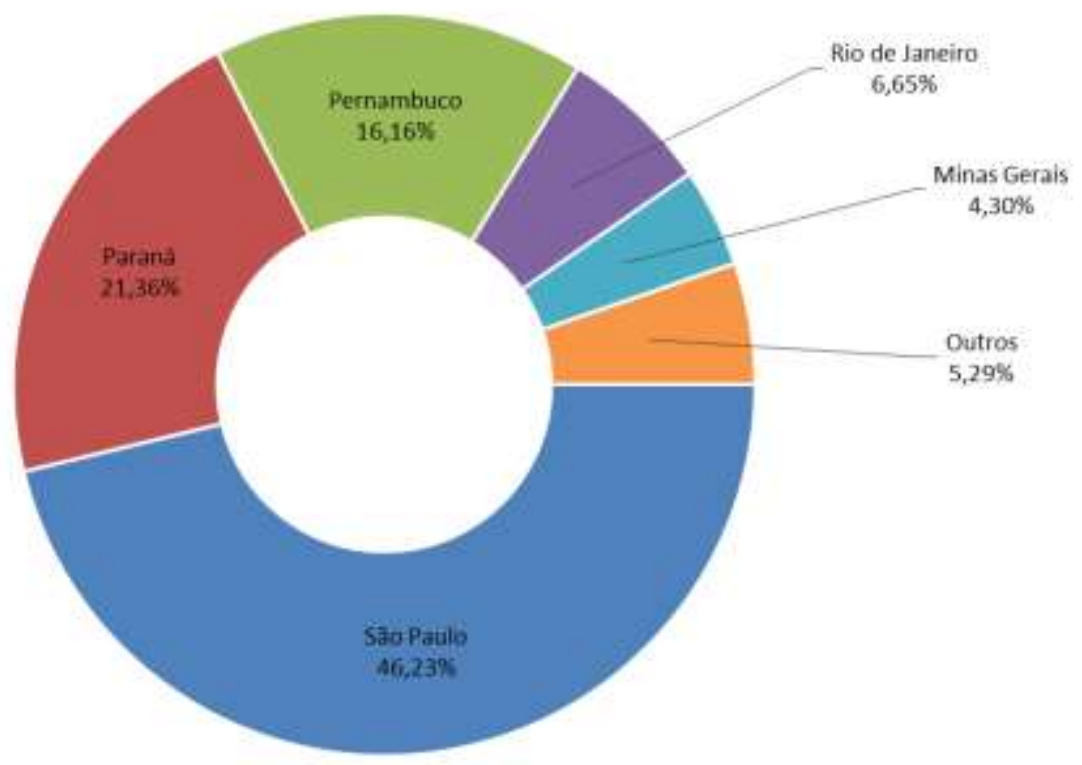

Fonte: ilustração de autoria própria; dados de MDIC - ALICEWEB - NCM 2208.40.00. Disponível em: <http://comexstat.mdic.gov.br/pt/geral/2821>. Acesso em: 27 de março de 2020. 
Figura 16 - Fluxograma da produção de cachaças e aguardentes de cana.

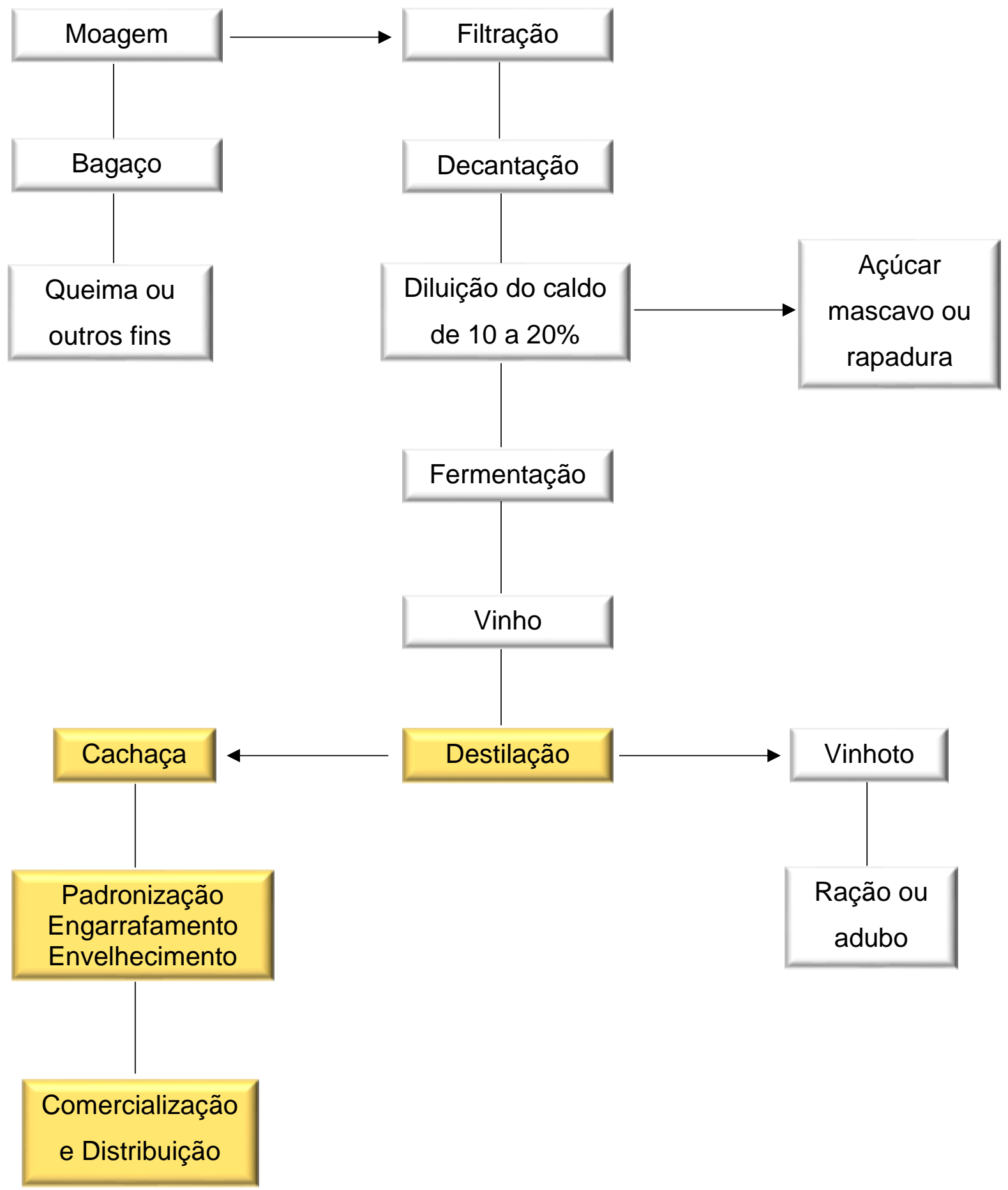

Fonte: adaptado de Agência Embrapa de Informação Tecnológica (EMBRAPA, 2008). 
Cachaças produzidas em alambiques de cobre possuem propriedades organolépticas distintas das de coluna. Destilação em coluna costuma agregar defeitos sensoriais pela liberação de dimetil sulfeto à bebida, enquanto que o cobre dos alambiques reduziria os teores de compostos sulfurosos e de aldeídos indesejáveis (ANDRADE-SOBRINHO et al., 2002). Entretanto, há pesquisadores que estudam a possibilidade de que carbamato de etila (CE) possa ser formado com mais facilidade pela presença de íons $\mathrm{Cu}$ (II) em processos oxidativos (ARESTA et al., 2001; CANTANHEDE et al., 2005), muito embora, Andrade-Sobrinho et al. (2002) tenha encontrado que cachaças de alambique continham menores teores de CE $(\leq 150 \mu \mathrm{g}$ $\left.\mathrm{L}^{-1}\right)$ que as destiladas em coluna. Já Zacaroni et al. (2011) não encontraram correlação entre o material do alambique e a presença de carbamato de etila nas amostras analisadas.

$\mathrm{Na}$ composição química das cachaças e aguardentes, há uma série de compostos "não álcool" (ácido acético; aldeídos; ésteres; álcool n-propílico, isobutílico e isoamílico; furfural e hidroximetilfurfural). A soma dessas substâncias, chamadas de congêneres, não deve ser inferior a $200 \mathrm{mg}$ e nem superior a $650 \mathrm{mg}$ a cada $100 \mathrm{~mL}$ de álcool anidro (coeficiente de congêneres). Da mesma forma, essas bebidas possuem compostos contaminantes inorgânicos - cobre, chumbo, arsênio - e orgânicos - álcool metílico, 2-propenal, 1-butanol, 2-butanol e carbamato de etila (VENTURINI FILHO, 2016).

Voltando a atenção para o carbamato de etila (CE), também chamado de uretana, é um éster do ácido carbâmico e naturalmente presente em diversos alimentos como pão, iogurtes, queijos, molho de soja e em bebidas alcoólicas (vinhos, uísque, aguardente, cachaça, vodca, rum, tiquira, cidras) (GALINARO; FRANCO, 2011; VENTURINI FILHO, 2016). A presença do carbamato de etila em alimentos é bastante estudada pois esse é um composto classificado como um agente potencialmente carcinogênico para seres humanos, ou seja, há poucos resultados experimentais em humanos mas há evidências suficientes de carcinogenicidade em animais (WHO, 2010; LACHENMEIER et al., 2010).

Desde 1985 que o Canadá estabelece teores máximos para CE em bebidas alcoólicas, sendo que para os destilados foi adotado um limite de $150 \mathrm{\mu g} \mathrm{L}^{-1}$ e desde 1990 que os uísques americanos têm carbamato de etila controlado para um máximo de $125 \mathrm{\mu g} \mathrm{L}^{-1}$ (ANDRADE-SOBRINHO et al., 2002). Sabe-se que além de Canadá e EUA, a França, República Tcheca, Alemanha e Suíça também controlam CE em 
bebidas alcoólicas (GALINARO; FRANCO, 2011). Preocupado com a segurança alimentar, o MAPA publica a Instrução Normativa № 13, de 29 de junho de 2005 Regulamento Técnico para Fixação dos Padrões de Identidade e Qualidade para Aguardente de Cana e para Cachaça - e entre diversos aspectos discutidos, é fixado um limite máximo de $150 \mu \mathrm{g} \mathrm{L}^{-1}$ de CE, assim como a legislação canadense. Em 2014 esse limite foi alterado para quantidade não superior a $210 \mu \mathrm{g} \mathrm{L}^{-1}$ pela Instrução Normativa N²8, de 08 de agosto de 2014 (BRASIL, 2005; BRASIL, 2014).

Além de estabelecer esse limite é incentivado que os produtores de cachaças certifiquem seus produtos para assim agregar valor e segurança alimentar; ainda estimula concorrência e melhoria da qualidade desses destilados, fortalecendo 0 mercado interno e externo (SORATTO; VARVAKIS e HORII, 2007), visto que, pela Figura 14, ao menos $41,06 \%$ do valor exportado são de países atentos a esse padrão de qualidade. Portanto, é visível a necessidade de se estabelecer um método e um material de referência interno para o controle de CE nas cachaças brasileiras.

\subsection{CARBAMATO DE ETILA (CE)}

Figura 17 - Estrutura química, fórmula molecular e espectro de massas do carbamato de etila.

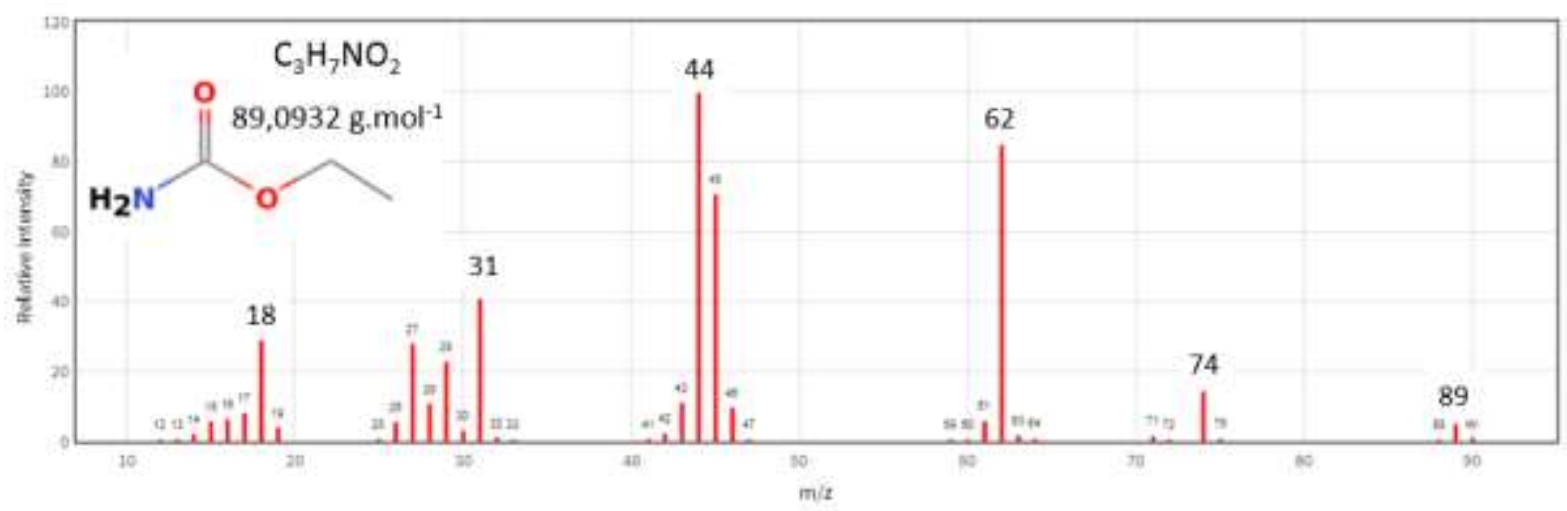

Fonte: adaptado de NIST - Urethane. Disponível em:

https://webbook.nist.gov/cgi/cbook.cgi?ID=C51796\&Mask=200\#Mass-Spec

O CE não é detectável por DIC (detecção por ionização de chama, ou no inglês, FID - flame ionisation detector) devido a sua estrutura molecular (Figura 17). Átomos eletronegativos como oxigênio, nitrogênio, fósforo, enxofre e os halogênios diminuem a sensibilidade da detecção; outro fator preponderante para a não utilização de DIC é que a magnitude do sinal é proporcional ao número de átomo de carbono ligados à hidrogênios (LANÇAS 1993; VISENTAINER, 2012). É mais recorrente utilizar detector de massas para as análises de CE, assim como o método OIV-MA-BS-25 da International Organisation of Vine and Wine (OIV) e o método IAL 229/IV do Instituto Adolfo Lutz (ITAL). 


\subsection{CROMATOGRAFIA EM FASE GASOSA (CG)}

A química analítica se dedica tanto na determinação e quantificação de compostos como também na separação deles. Métodos de separação são importantes procedimentos analíticos, uma vez que a quantificação de um analito é mais acurada ao livrá-lo de potenciais interferentes presentes na matriz de estudo. Até a metade do século $X X$ os métodos clássicos como precipitação, destilação ou extração eram empregados para a separação dos analitos. Em meados da década de 50 a cromatografia começou a se desenvolver rapidamente e, na década de 60 , já estava sendo acoplada a sistemas computacionais para o monitoramento de parâmetros experimentais e tratamentos dos dados obtidos. Atualmente, cromatografia e eletroforese são amplamente empregadas como técnicas de separação permitindo o estudo de matrizes mais complexas e análises de multicomponentes (LANÇAS, 1993; SKOOG; HOLLER; NIEMAN, 2002).

De forma sucinta, a cromatografia consiste em duas fases usadas para particionar os constituintes da matriz: a fase estacionária (FE) é fixa e de grande área; a fase móvel (FM) pode ser um gás ou um líquido inerte que percola pela estacionária carregando os analitos. As diferentes interações entre os analitos e a fase estacionária durante a eluição (remoção por frações) viabilizada pela fase móvel determinará a separação dos compostos. Quanto maior a interação entre o soluto e a FE, mais tempo será necessário para que esse composto seja removido pela FM. Por exemplo, caso uma fase móvel seja menos polar que a fase estacionária, os analitos menos polares eluem primeiro, e os mais polares por último por interagirem mais fortemente com a FE. Portanto, cromatografia é classificada como um método físico-químico, uma das técnicas sensíveis para a separação de misturas que logra das diferentes capacidades das substâncias em aderir às superfícies (CIOLA, 1985; ATKINS; JONES, 2012).

Do grego, chroma significa cor e graphein significa escrever, surgiu o nome "cromatografia", com as pesquisas de Mikhail Tswett, um botânico russo. Ele usou um tubo de vidro recheado com carbonato de cálcio (giz moído) para separar pigmentos de folhas e flores como clorofila e xantofila. Isso se dava ao passar extratos das plantas pela coluna que, ao interagir com o material empacotado, formavam-se diferentes bandas coloridas, evidenciando a separação dos compostos coloridos (SKOOG; HOLLER; NIEMAN, 2002; ATKINS; JONES, 2012). M. Tswett foi o primeiro 
a compreender e interpretar cromatografia como zonas de compostos que se separavam dentro de uma coluna, ideia essencial para que em 1941, os químicos britânicos Archer John Porter Martin e Richard Laurence Millington Synge desenvolvessem a base teórica da cromatografia em fase gasosa. Em 1952 esses pesquisadores publicaram o primeiro trabalho na área recebendo o prêmio Nobel de química pela invenção da cromatografia de partição (LANÇAS, 1993; THE NOBEL PRIZE, 2019). A partir de então, essas técnicas se desenvolveram rapidamente sendo extensivamente empregadas, permitindo novas formas de se estudar e de compreender a matéria.

Diferentes métodos de separações cromatográficas surgiram e a classificação deles deriva de critérios como (SKOOG; HOLLER; NIEMAN, 2002):

i. Meio físico em que a FE e a FM entram em contato. Na cromatografia em coluna a FE está dentro de um tubo por onde a FM é forçada a passar sob pressão. Cromatografia planar é a que a FE está ancorada sob uma superfície plana ou nos poros de um papel e a FM move-se através da FE por capilaridade ou gravidade;

ii. Tipos de fases utilizadas, móvel e estacionária, bem como nos tipos de equilíbrio envolvidos nas separações dos analitos entre as fases. Nessa classificação teremos a cromatografia líquida, cromatografia gasosa e a cromatografia com fluido supercrítico. Um adendo importante é que somente a cromatografia líquida pode ser realizada no modo planar ou em coluna, as cromatografias gasosas e com fluidos supercríticos necessariamente ocorrem em coluna, devido à natureza da fase móvel.

Para uma melhor compreensão, essa explicação está organizada em forma de um fluxograma, pela Figura 18.

Conforme ilustrado na Figura 18, há duas diferentes formas de realizar a cromatografia em fase gasosa, sendo essas discriminadas de acordo com o mecanismo de separação envolvido: adsorção ou partição; fundamentalmente, essa distinção ocorre de acordo com a fase estacionária escolhida. Para a cromatografia a gás, quando a FE for sólida, trata-se de uma cromatografia gás-sólido (CGS); quando a FE empregada for um líquido, trata-se de uma cromatografia gás-líquido ( $\mathrm{CGL}$ ) (CIOLA, 1985; SKOOG; HOLLER; NIEMAN, 2002). 
É interessante observar que, independente da fase móvel, tanto para a cromatografia líquida (CL) quanto para a cromatografia gasosa (CG), sempre que se fizer uso de uma fase estacionária sólida o mecanismo de separação ocorrerá por adsorção e, sempre que a fase estacionária for líquida, o fenômeno de separação envolvido será de partição. Em contrapartida, o tipo de fase móvel não influencia no mecanismo de separação, mas a composição da FM líquida tem grande influência na eficiência da separação dos analitos enquanto que a composição de uma FM gasosa pouco interfere (CIOLA, 1985).

Figura 18 - Fluxograma da classificação geral dos métodos cromatográficos.

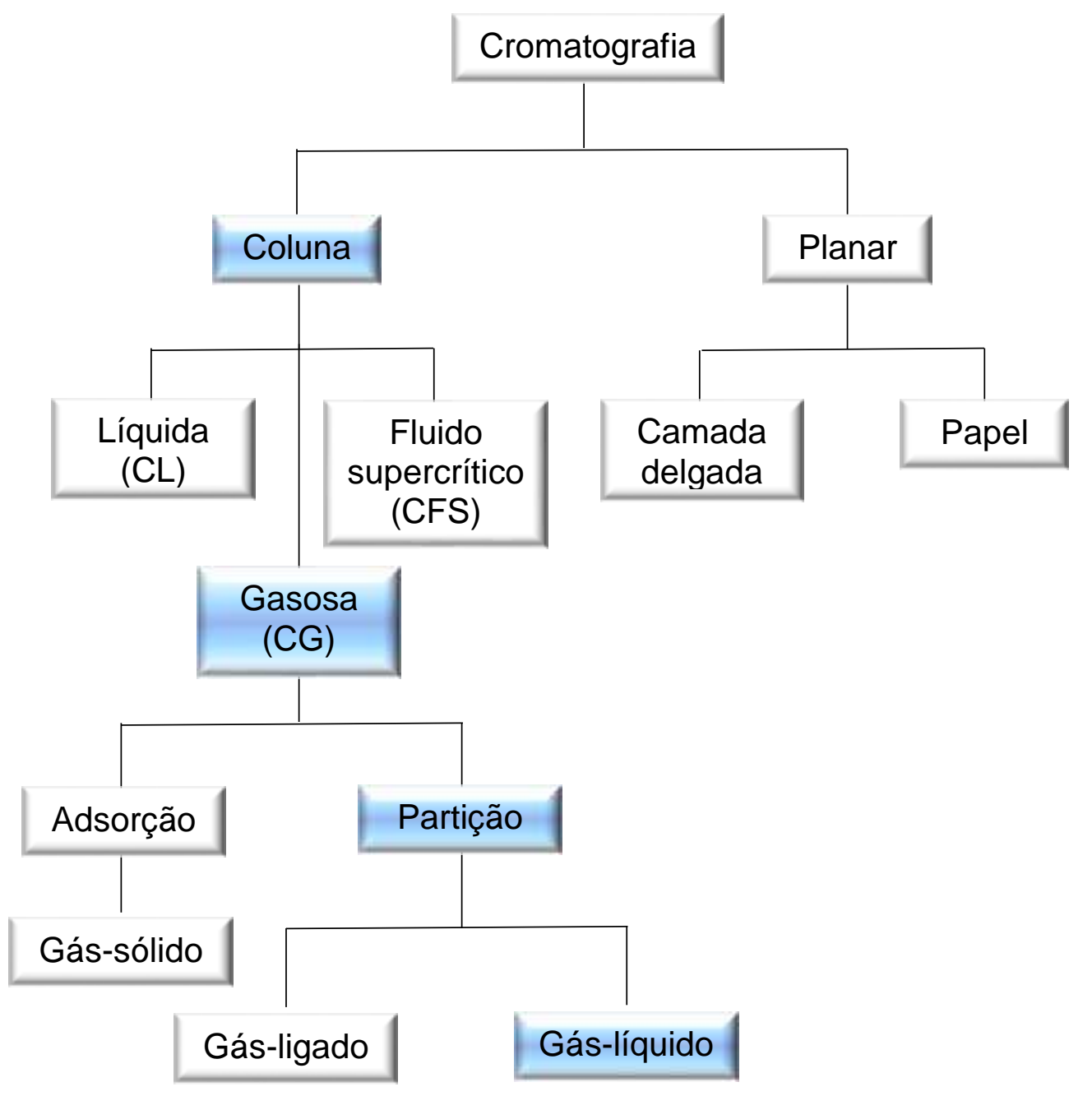

Fonte: adaptado de Lanças (1993, p. 3) e SKOOG, HOLLER e NIEMAN (2002, p. 599).

Aqui vale diferenciar adsorção de partição. Ambos são fenômenos de interação entre soluto e fase estacionária, o que os diferencia é o tipo de sorção envolvida (McNAIR; MILLER, 1997). Adsorção é o processo que ocorre em superfícies, sólidas ou líquidas, onde forças atrativas são responsáveis pela fixação de um soluto em um 
material adsorvente. Inclusive, alguns compostos com alta adsortividade e em baixas concentrações podem se adsorver irreversivelmente em qualquer lugar do sistema de um cromatógrafo onde exista sítios ativos como: componentes do injetor, coluna cromatográfica, interface entre o cromatógrafo e o detector de massas e até mesmo na fonte de um espectrômetro de massas (KARASEK; CLEMENT, 1988). Devido à similaridade da grafia com a palavra adsorção, partição é um termo alternativo para descrever o processo de absorção. Enquanto a adsorção ocorre nas superfícies dos materiais, a partição (absorção) é a sorção que ocorre em todo o volume da fase estacionária. O que na prática ocorre é que ambos os processos estarão presentes quando houver interação de uma mistura de solutos com uma fase estacionária, entretanto, um tipo de sorção sempre prevalece em relação a outra para uma determinada coluna cromatográfica (McNAIR; MILLER, 1997).

Como exemplo de material adsorvente cotidiano temos o carvão ativado, material poroso com elevada área superficial, de 500 a $3000 \mathrm{~m}^{2} \mathrm{~g}^{-1}$. Para comparação, outros materiais não passam dos $800 \mathrm{~m}^{2} \mathrm{~g}^{-1}$ (CIOLA, 1985). O carvão ativado é muito utilizado em sistemas de filtração de água, com capacidade para reter matéria orgânica, cloro residual e substâncias que possam agregar cor ou sabor. Conforme apresentado na Tabela 2, o carvão ativado é um material utilizado em fases estacionárias de adsorção, para cromatografia gasosa do tipo gás-sólido.

Na cromatografia gás-líquido (CGL), conforme exemplificado na Tabela 2 as fases estacionárias são materiais líquidos depositados em uma superfície inerte (suporte). Esses suportes podem ser sólidos porosos, paredes ou em tubos (colunas cromatográficas). Esses líquidos devem possuir baixíssima pressão de vapor na faixa de temperatura de trabalho e alta estabilidade química às variações de calor empregadas (CIOLA, 1985).

Como a CGL é fundamentada na partição dos componentes da amostra entre a FE (líquido) e a FM (gás de arraste), é altamente indesejável o fenômeno de adsorção que pode ocorrer com o suporte do líquido da FE. Idealmente a função do suporte deveria ser apenas uma âncora para a deposição da fase estacionária e não ter interação com a amostra. Entretanto, sabe-se que isso não ocorre na prática. Portanto, há uma preocupação também com a produção do material do suporte; deve possuir uma estrutura de poros bem definida, em geral, com dimensões aproximadas a $1 \mu \mathrm{m}$. Se forem muito grandes, a FE apenas preencherá as lacunas e não formará paredes, logo, o suporte poderia agir como material adsorvente assim como a sílica, 
o carvão ativado, a alumina, dentre outros exemplificados na Tabela 2. Essa interação pode provocar picos assimétricos e com longas caudas (LANÇAS, 1993).

Tabela 2 - Variações da cromatografia gasosa (CG) em relação aos mecanismos de separação e às fases estacionárias envolvidas.

\begin{tabular}{|c|c|c|c|}
\hline $\begin{array}{c}\text { Método } \\
\text { Cromatográfico }\end{array}$ & $\begin{array}{c}\text { Mecanismo } \\
\text { de Separação }\end{array}$ & $\begin{array}{c}\text { Fase } \\
\text { estacionária }\end{array}$ & Tipo de fase estacionária \\
\hline \multirow{4}{*}{$\begin{array}{l}\text { Gás-líquido } \\
\text { (CGL) }\end{array}$} & \multirow{4}{*}{$\begin{array}{l}\text { Partição entre } \\
\text { gás e líquido }\end{array}$} & \multirow{4}{*}{$\begin{array}{l}\text { Líquido } \\
\text { adsorvido em } \\
\text { um sólido }\end{array}$} & $\begin{array}{l}\text { Hidrocarbonetos. Ex.: } \\
\text { escalano }\end{array}$ \\
\hline & & & $\begin{array}{l}\text { Ftalatos. Ex.: Dibutila; di-2- } \\
\text { etilexila; didecila; etc. }\end{array}$ \\
\hline & & & $\begin{array}{l}\text { Poliésteres. Ex.: poli } \\
\text { (succinato de etilenoglicol); } \\
\text { poli (succinato de } \\
\text { dietilenoglicol); etc. }\end{array}$ \\
\hline & & & $\begin{array}{l}\text { Polisiloxanas (siliconas). } \\
\text { Ex.: polimetilsiloxanas; } \\
\text { polimetilfenilsiloxanas; } \\
\text { polimetilpropilciano } \\
\text { fenilsilicona; } \\
\text { polietilenoglicol. }\end{array}$ \\
\hline \multirow{5}{*}{ Gás-ligado } & \multirow{5}{*}{$\begin{array}{l}\text { Partição entre } \\
\text { líquidos e } \\
\text { superfície } \\
\text { ligada }\end{array}$} & \multirow{5}{*}{$\begin{array}{l}\text { Espécies } \\
\text { orgânicas } \\
\text { ligadas a uma } \\
\text { superfície } \\
\text { sólida de } \\
\text { grande área } \\
\text { superficial }\end{array}$} & Octadecil sílica \\
\hline & & & Octil sílica \\
\hline & & & Propilciano sílica \\
\hline & & & Alquilidroxi sílica \\
\hline & & & Alquilamino sílica \\
\hline \multirow[b]{5}{*}{$\begin{array}{l}\text { Gás-sólido } \\
\text { (CGS) }\end{array}$} & \multirow[b]{5}{*}{ Adsorção } & \multirow[b]{5}{*}{ Sólido } & Carvão ativado \\
\hline & & & Sílica-gel \\
\hline & & & Alumina (óxido de alumínio) \\
\hline & & & $\begin{array}{l}\text { Peneiras moleculares } \\
\text { (alumino silicatos) }\end{array}$ \\
\hline & & & $\begin{array}{l}\text { Polímeros porosos. Ex.: } \\
\text { poli (estireno-co- } \\
\text { divinilbenzeno); poli } \\
\text { (estireno-co-divinilbenzeno- } \\
\text { co-cianovinilbenzeno); poli } \\
\text { (estireno-co-divinilbenzeno- } \\
\text { co-etilvinilbenzeno) }\end{array}$ \\
\hline
\end{tabular}

Fonte: adaptado de Ciola (1985, p. 3-4) e de Skoog, Holler e Nieman (2002, p. 599). 
Aqui é necessário definir algumas nomenclaturas importantes próprias das análises cromatográficas, conforme ilustra a Figura 19 e que serão utilizadas em futuras discussões deste trabalho (CORDEIRO, 2011; SCOTT, 1998):

Figura 19 - Exemplo de cromatograma e os termos cromatográficos.

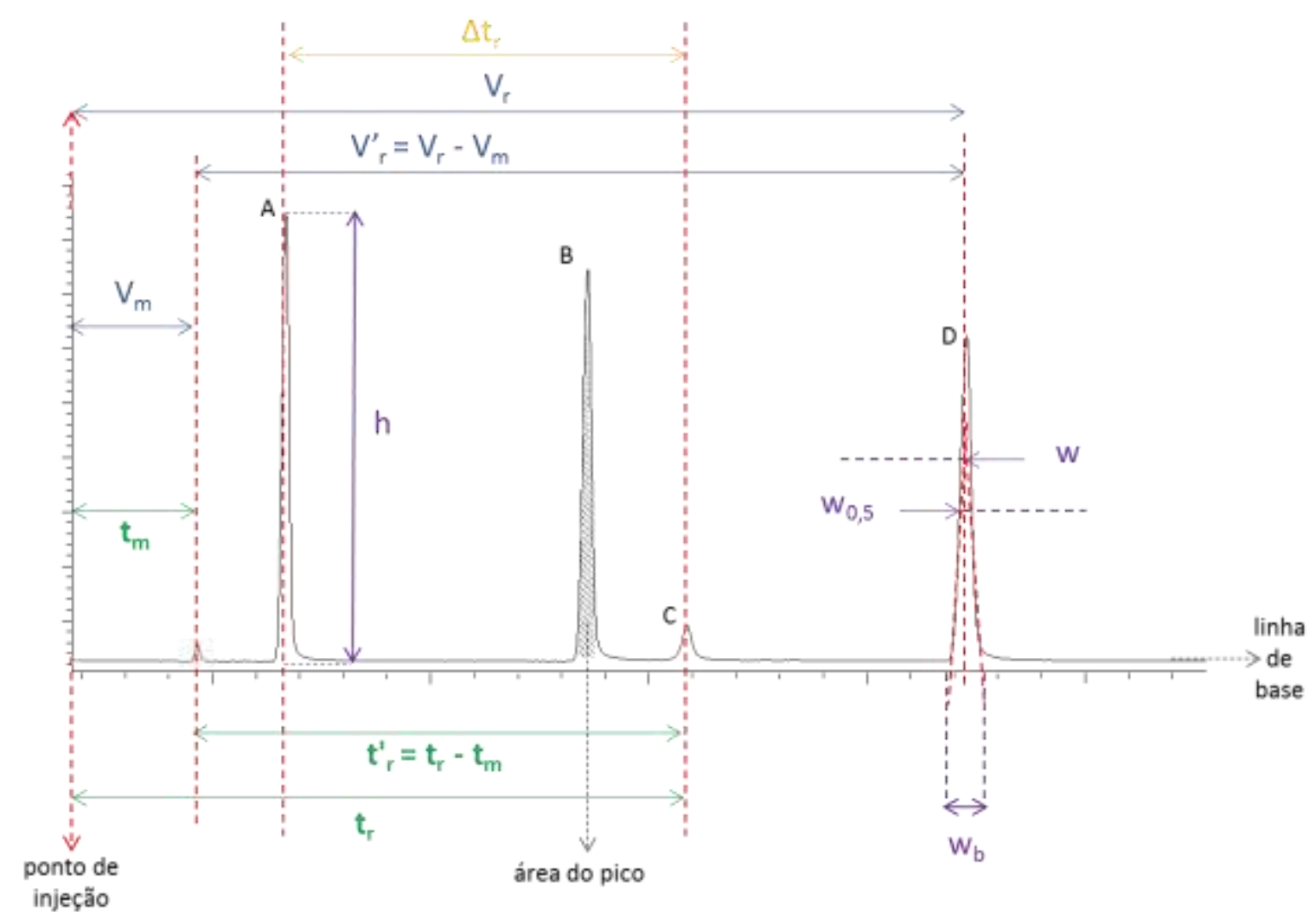

Fonte: ilustração própria adaptada de Scott (1998, p. 16-18) e Cordeiro (2011, p. 19-22).

- Linha de base: qualquer parte do cromatograma correspondente apenas à eluição da FM, sem picos de analitos;

- Ponto de injeção: tempo correspondente à inserção da amostra na coluna;

- Área do pico: área abaixo da linha do pico, esses valores são utilizados para quantificação dos analitos;

- $t_{m}$ (tempo morto ou tempo não-retido): é o tempo que um composto que não interage com a fase estacionária seja detectado a partir do ponto de injeção

- $\operatorname{tr}$ (tempo de retenção): tempo decorrido entre o ponto de injeção da amostra e o tempo do máximo pico cromatográfico;

- t'r (tempo de retenção ajustado): a correção do tempo de retenção descontado do tempo morto fornece as condições físico-químicas de retenção de um 
determinado composto, ou seja, é o tempo médio que as moléculas do analito passam sorvidas na FE;

- $V_{m}$ (volume morto): é o volume de gás da FM que passou pela coluna durante o tempo morto;

- $\operatorname{Vr}$ (volume de retenção): é o volume de fase móvel necessária para eluir determinado composto desde a injeção da amostra na coluna até a sua detecção; corresponde ao volume de FM gasto dentro de um certo tempo de retenção. Também um parâmetro que pode ser utilizado para a determinação de um pico cromatográfico.

- V'r (volume de retenção ajustado): é o volume de FM gasta para eluir um composto pela coluna descontada do volume morto;

- h (altura do pico): distância entre a linha de base e o ponto máximo do pico;

- Wb (largura da base do pico): é a distância entre as interseções das tangentes laterais do pico e a linha de base. A largura do pico na base é equivalente a quatro desvios padrão $(4 \sigma)$ da curva Gaussiana;

- W0,5 (largura do pico na meia altura): a largura do pico medida na metade da altura. Esse valor é utilizado quando não é possível determinar wb por causa de variações na linha de base;

- w (largura do pico): é a distância entre cada lado do pico a 0,6065 da sua altura. O valor da largura do pico medida nesta altura é equivalente a dois desvios padrão $(2 \sigma)$ da curva Gaussiana;

- $\Delta$ tr: diferença entre dois tempos de retenção ou distâncias de eluição entre dois compostos.

É possível converter o $\mathrm{tr}_{\mathrm{r}}$ em $\mathrm{V}_{\mathrm{r}}$ pela Equação 38, desde que o fluxo do gás de arraste $\left(F_{c}\right)$ seja constante durante a análise (LANÇAS, 1993).

$$
\mathrm{V}_{\mathrm{r}}=\operatorname{tr} \times \mathrm{F}_{\mathrm{c}}
$$

Equação 38

A seletividade ou fator de separação ( $\alpha$ ) é a capacidade que uma coluna cromatográfica tem de diferenciar dois compostos $(A$ e $B)$ e está relacionado, pela Equação 39, com o tempo que esses dois compostos passam interagindo com a FE. Quanto maior o valor de $\alpha$, mais seletiva é a fase líquida o que implica em uma melhor separação cromatográfica (LANÇAS, 1993; CORDEIRO, 2011). 


$$
\alpha=\frac{\operatorname{t}^{\prime} r(B)}{\operatorname{t}^{\prime} r(A)}
$$

Equação 39

A eficiência de uma coluna é determinada pelo número de pratos teóricos $(\mathrm{N})$, conforme a Equação 40 e Equação 41. Quanto maior o N, maior a eficiência e a separação (LANÇAS, 1993; CORDEIRO, 2011).

$$
\begin{gathered}
\mathrm{N}=16\left(\frac{t r}{w b}\right)^{2} \\
\mathrm{~N}=5,5456\left(\frac{t r}{w 0,5}\right)^{2}
\end{gathered}
$$

Equação 41

A Equação 41 é utilizada quando não é possível determinar o parâmetro wb. Isso pode ocorrer quando há muita variação na linha de base ou quando os picos estão mal resolvidos. Nesse caso, adota-se a largura da meia altura do pico, $\mathbf{w}_{0,5}$ (LANÇAS, 1993; CORDEIRO, 2011).

Conforme mencionado, a resolução $(R)$ dos picos é um aspecto importante para a análise da largura da base dos picos, ou seja, para a separação dos analitos. Basicamente, a resolução é a medida de quão separados dois picos estão entre si e é calculada conforme a Equação 42; é a razão entre a diferença das distâncias de eluição entre os picos (tempos de retenção) e a média das larguras de suas bases. Quanto maior a resolução, maior é a capacidade da FE de uma coluna de separar esses compostos, logo, maior a eficiência (LANÇAS, 1993; CORDEIRO, 2011).

$$
\mathrm{R}=\frac{\Delta t r}{1 / 2(w b 1+w b 2)}=\frac{2 \Delta t r}{w b 1+w b 2}
$$




\subsubsection{Método cromatográfico gás-líquido - colunas e fases estacionárias}

O método gás-líquido é a variação da cromatografia gasosa mais utilizada e possui importantes funções em química analítica. Primeiramente como estratégia de separação de compostos, sendo altamente eficiente para compostos orgânicos ou complexos organometálicos, sistemas bioquímicos e para espécies voláteis. Além de permitir o isolamento de analitos pela sua função de fracionamento dos compostos das amostras, pode ser acoplada a diversas técnicas de identificação e permitir análises quantitativas por métodos analíticos que variam entre determinação de altura e áreas de picos cromatográficos, curvas de calibração, uso de padrões internos e normalizações das áreas dos picos cromatográficos determinados (McNAIR; MILLER, 1997; SKOOG; HOLLER; NIEMAN, 2002).

Fundamentalmente, a separação dos analitos em cromatografia gasosa se dá por meio de colunas recheadas com algum material eficiente, ou seja, que possibilite uma diferença significativa entre os tempos de retenção dos analitos. Quanto maior for essa diferença, maior é o coeficiente de partição dos compostos e mais eficiente é a coluna. A eficiência de uma coluna é determinada em termos de "números de pratos teóricos" e são diversas as variáveis que podem interferir e variar a eficácia da separação: tempos de retenção, comprimento da coluna, temperatura de trabalho, natureza da fase estacionária e dos analitos, fluxo do gás de arraste, quantidade de amostra, espessura do filme da fase estacionária, etc. De forma resumida, é como se uma coluna cromatográfica fosse comparada a uma coluna de destilação e cada interação que o analito estabelece entre FM e FE é chamada de prato teórico; quanto maior o número de pratos teóricos, mais interações os analitos estabelecem entre o líquido da FE e gás de arraste da FM, logo, maior é a eficiência de separação da coluna. Alguns autores descrevem essas interações como equilíbrios, porém outros defendem que nunca se estabelecem reais condições de equilíbrio dentro de uma coluna cromatográfica já que a FM está em constante movimento, mas ainda assim, são essas interações que explicam a movimentação dos analitos dentro da coluna, os diferentes tempos de retenção e a forma gaussiana dos picos cromatográficos (CIOLA, 1985; LANÇAS, 1993; SKOOG; HOLLER; NIEMAN, 2002).

Via de regra, os materiais empregados como FE para CGL, além de facilmente reprodutíveis e de baixo custo, devem possuir algumas características como: ser inerte para não haver interação química com a composição da amostra; apresentar 
capacidade seletiva tal como um solvente atuaria separando pigmentos, a fase estacionária líquida deve ser capaz separar os componentes de uma matriz por diferentes tempos de retenção; estabilidade térmica em uma ampla faixa de temperatura (geralmente variam entre $200^{\circ} \mathrm{C}$ e $350^{\circ} \mathrm{C}$ ) e não volatilizar nessas condições operacionais (LANÇAS, 1993; SCOTT, 1998; SKOOG; HOLLER; NIEMAN, 2002). A Tabela 3 resume alguns dos materiais comumente comercializados.

Tabela 3 - Fases estacionárias comumente empregadas em CGL e suas principais aplicações.

\begin{tabular}{|c|c|c|}
\hline $\begin{array}{c}\text { Material da fase } \\
\text { estacionária }\end{array}$ & $\begin{array}{c}\text { Temperatura } \\
\text { crítica de } \\
\text { estabilidade } \\
\text { térmica }\left({ }^{\circ} \mathrm{C}\right)\end{array}$ & Principais aplicações \\
\hline Polidimetil-siloxano & 350 & $\begin{array}{l}\dot{E} \text { uma fase apolar de aplicação } \\
\text { geral: drogas, hidrocarbonetos, } \\
\text { aminas, ésteres metílicos de ácidos } \\
\text { graxos celulares, fragrâncias, } \\
\text { aromáticos polinucleados, fenóis, } \\
\text { pesticidas, esteroides, PCB's, } \\
\text { compostos sulfurados e flavors. }\end{array}$ \\
\hline $\begin{array}{l}\text { Poli(fenilmetildimetil)- } \\
\text { siloxano (10\% em fenil) }\end{array}$ & 350 & $\begin{array}{l}\text { Drogas, ésteres metilados de ácidos } \\
\text { graxos, compostos halogenados e } \\
\text { alcaloides. }\end{array}$ \\
\hline $\begin{array}{l}\text { Poli(fenilmetil)-siloxano } \\
\text { (50\% em fenil) }\end{array}$ & 250 & $\begin{array}{l}\text { Drogas, esteroides, pesticidas e } \\
\text { glicóis. }\end{array}$ \\
\hline $\begin{array}{l}\text { Poli(trifluoropropildimetil)- } \\
\text { siloxano }\end{array}$ & 200 & $\begin{array}{l}\text { Aromáticos clorados, nitroaromáticos } \\
\text { e benzenos alquil-substituídos. }\end{array}$ \\
\hline Polietileno-glicol & 250 & $\begin{array}{l}\text { Ácidos livres, álcoois, éteres, óleos } \\
\text { essenciais e glicóis. }\end{array}$ \\
\hline Poli(dicianoalildimetil) & 240 & $\begin{array}{l}\text { Ácidos livres, ácidos graxos } \\
\text { insaturados, resinas ácidas e álcoois. }\end{array}$ \\
\hline
\end{tabular}

Fonte: adaptado de Skoog, Holler e Nieman (2002, p. 632) e Analiticaweb (2020). 
Figura 20 - Fluxograma da classificação dos tipos de colunas capilares aplicadas em CG.

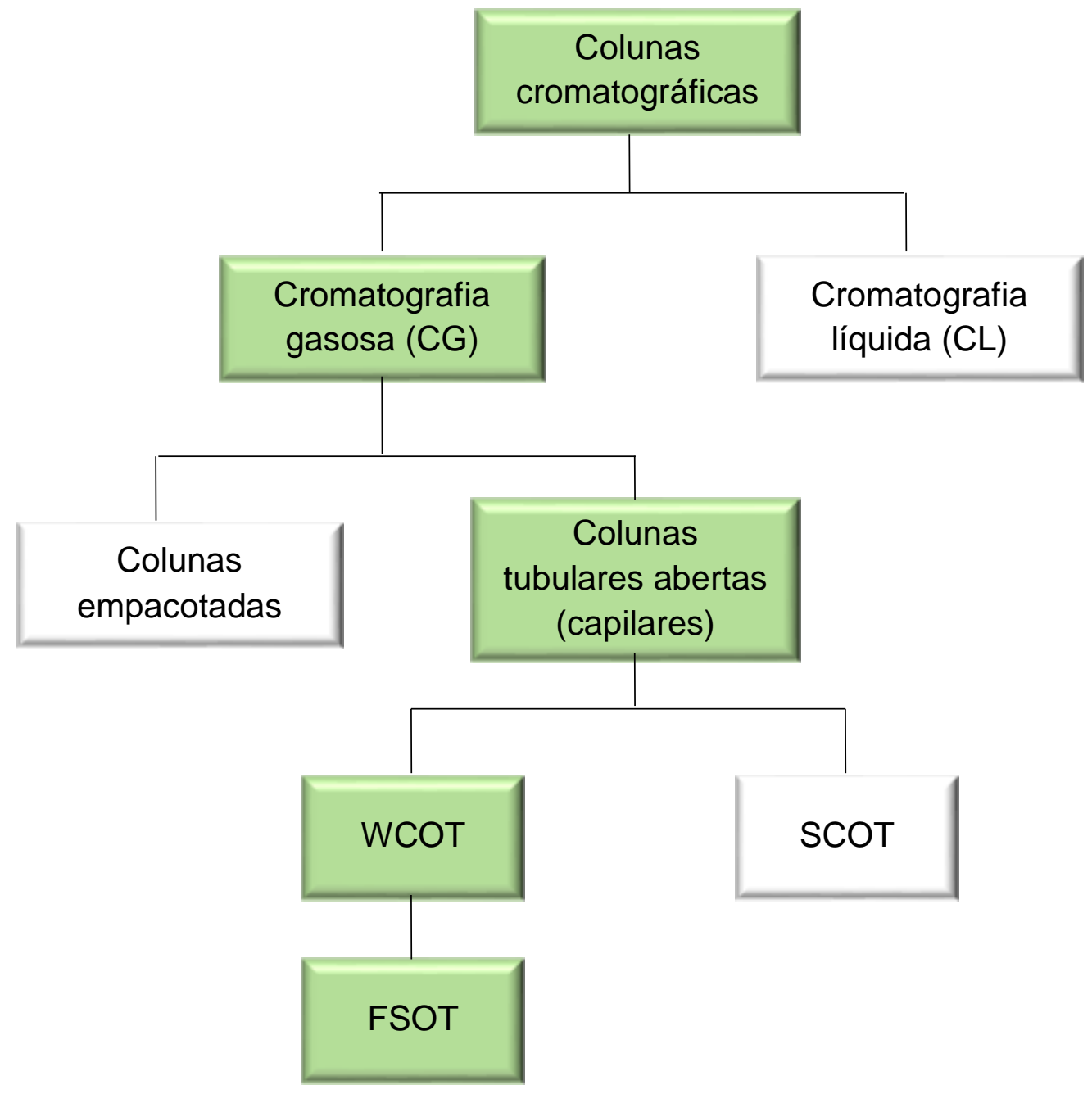

SCOT (support-coated open tubular): coluna tubular aberta com suporte revestido. WCOT (wall-coated open tubular): coluna tubular aberta com parede revestida. FSOT (fused-silica open tubular): coluna tubular aberta de sílica fundida.

Fonte: adaptado de McNair e Miller (1997, p. 4) e de Skoog, Holler e Nieman (2002, p. 629-630).

A Figura 20 ilustra os tipos de colunas já desenvolvidas para CG e pela Figura 21 é possível entender principais diferenças estruturais. As primeiras colunas comercializadas no início dos anos 50 foram as do tipo empacotadas, feitas de tubos metálicos e com não mais de $6 \mathrm{~m}$ de comprimento. Entretanto, estudos teóricos demonstravam que a engenharia das colunas empacotadas implicava em uma separação bem menos eficiente que uma estrutura não empacotada e com diâmetro interno muito menor, as colunas tubulares abertas também denominadas de colunas capilares. Devido às dificuldades tecnológicas da época em se produzir essas colunas, apenas em meados de 1980 é que foi possível realizar a aplicação das 
colunas capilares. Atualmente, praticamente não se utiliza as colunas empacotadas (McNAIR; MILLER, 1997; SKOOG; HOLLER; NIEMAN, 2002).

Figura 21 - Representação esquemática do interior das colunas empacotadas e capilares.

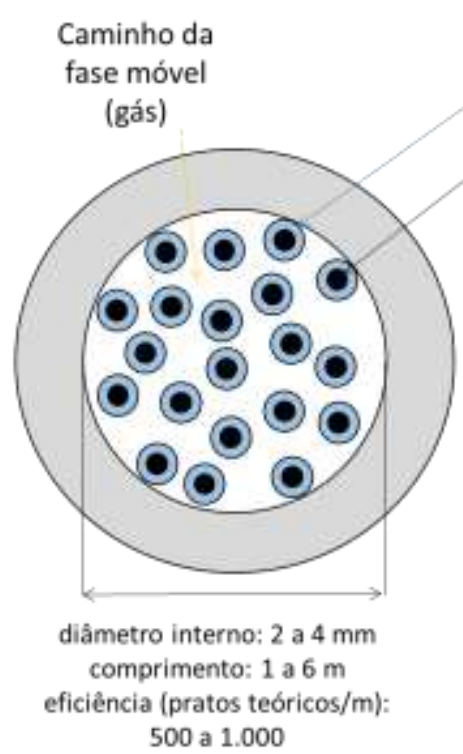

500 a 1.000

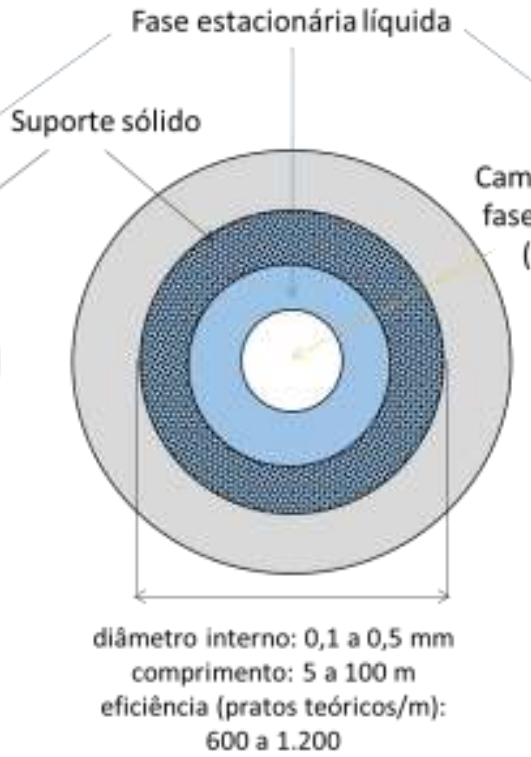

600 a 1.200

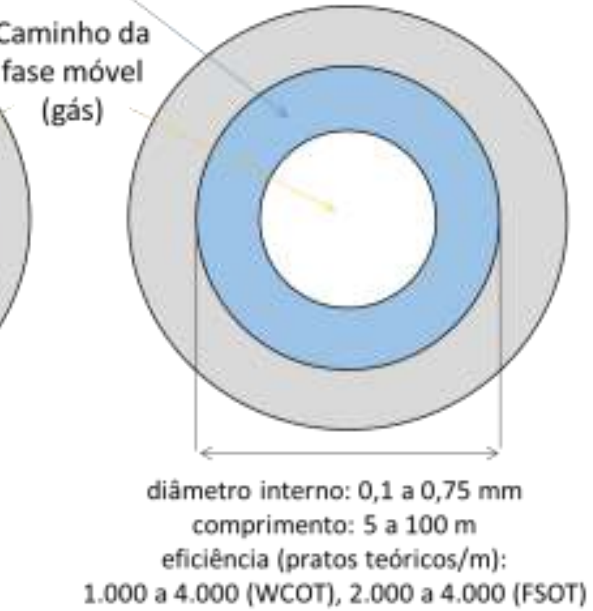

colunas capilares

b) SCOT

c) WCOT ou FSOT

Fonte: ilustração própria adaptada de Lanças (1993, p. 128-129), McNair e Miller (1997, p. 13; p. 88) e Skoog, Holler e Nieman (2002, p. 629-630).

A desvantagem das colunas empacotadas em relação às capilares se dá no fato de que os suportes sólidos do empacotamento obstruem a passagem dos compostos arrastados pela fase móvel. Nas colunas capilares, a FE é apenas uma fase líquida disposta na forma de um filme fino que recobre as paredes de um longo tubo, conforme apresentado pela Figura 21. Essa nova disposição para a FE permite que a difusão dos compostos dentro da fase líquida e no tubo aberto com o gás de arraste seja mais intensa e, por consequência, favoreça as análises com melhores resoluções em um tempo menor (LANÇAS, 1993). Nesse seguimento, as colunas capilares são uma vantagem da cromatografia gasosa sobre a líquida. Devido à possibilidade de se fabricar colunas longas para CG, a análise cromatográfica no modo gasoso usufrui de maior sensibilidade e resolução que se realizada por $\mathrm{CL}$, devido ao maior número de pratos teóricos das colunas capilares em comparação com as empacotadas (SCOTT, 1998).

Das colunas capilares, as primeiras a surgir foram as WCOT e as SCOT (Figura 20). O modelo SCOT possui uma maior quantidade de FE e, portanto, mais 
capacidade para maiores volumes de amostras que uma coluna WCOT, contudo, as WCOT são muito mais eficientes. Das colunas WCOT (originalmente produzidas com paredes metálicas, de plástico ou vidro), surgiram as FSOT, fabricadas de sílica fundida com recobrimento externo de polimida (polímero resistente a altas temperaturas) e se tornaram muito populares substituindo as WCOT, pois não mais apresentavam problemas de corrosão, além de serem mais flexíveis e resistentes (McNAIR; MILLER, 1997; SKOOG; HOLLER; NIEMAN, 2002).

Conforme listado na Tabela 3, as FE mais empregadas em colunas capilares são as metilsiloxanas por formarem filmes estáveis. As fases apolares costumam ser mais eficientes e estáveis que a polares. Siliconas com grupos polares costumam ser modificadas introduzindo-se ligações cruzadas durante a produção dos polímeros para conferir maior estabilidade à fase estacionária polar (CIOLA, 1985).

Em suma, a cromatografia foi o primeiro método que permitiu a separação de espécies químicas com grande semelhança. Cresceu muito e continua se desenvolvendo (Figura 18), principalmente devido a sua simplicidade, sendo empregada nas mais diversas aplicações como ferramenta de separação e também acoplada a outras técnicas, assistindo na identificação qualitativa e na determinação quantitativa de compostos. (SKOOG; HOLLER; NIEMAN, 2002). Via de regra, a cromatografia é bastante eficiente para análises de composto orgânicos. No que tange à cromatografia gasosa, há algumas limitações próprias da técnica: (i) é limitada à compostos de baixo peso molecular, passíveis de ser volatilizados, ou que possam ser convertidos em outros compostos voláteis (por derivatização); (ii) adequada apenas para amostras termicamente estáveis; (iii) não é adequada para grandes quantidades de amostras; (iv) requer associação com espectroscopia, geralmente espectroscopia de massas. Dentro dessas limitações, em relação à separação de compostos voláteis, CG é um método rápido, com alta capacidade de resolução e de simples aplicação (CIOLA, 1985; LANÇAS, 1993; McNAIR; MILLER, 1997). 


\subsubsection{Qualidade do método e dos resultados experimentais}

É desejável que as análises quantitativas sejam precisas e exatas. Evidentemente, antes de qualquer coisa, o cromatógrafo deve estar em boas condições de uso: precisão no controle de temperatura e vazão de gases ou a precisão dos experimentos (repetibilidade e reprodutibilidade) será prejudicada. Em CG há alguns parâmetros cromatográficos que, por meio de otimizações das condições operacionais do cromatógrafo, 0 analista pode alcançar melhores experimentos em menor tempo, com mais seletividade e maior resolução; naturalmente, a otimização contribui para a validação do método e para que o projeto experimental produza resultados confiáveis. Para isso, apresenta-se nos itens que seguem formas de alcançar um bom método cromatográfico.

\subsubsection{Gás de arraste}

Além de todo cuidado com a amostragem e com o preparo da amostra (homogeneidade e contaminação), também é fundamental que a FM seja pura. A análise deve ser o mais livre possível de impurezas que possam atrapalhar a identificação ou a determinação das áreas dos picos cromatográficos.

O gás de arraste não pode interagir nem com a FE e nem com a amostra, ser barato e também adequado ao detector acoplado (LANÇAS, 1993). Os gases mais comuns empregados em colunas FSOT são $\mathrm{H}_{2}, \mathrm{~N}_{2}$, $\mathrm{He}$ e Ar; podem carregar impurezas para a coluna e alterar a estabilidade química da $\mathrm{FE}$, interagir com os analitos e até mesmo interferir no sistema de detecção (CIOLA, 1985).

Tabela 4 - Impurezas comuns dos principais gases de arraste.

\begin{tabular}{lc}
\hline Gás & Impureza \\
\hline $\mathrm{H}_{2}$ & $\mathrm{O}_{2}, \mathrm{~N}_{2}, \mathrm{CH}_{4}, \mathrm{H}_{2} \mathrm{O}$ e $\mathrm{CO}_{2}$ \\
\hline $\mathrm{N}_{2}$ & $\mathrm{O}_{2}, \mathrm{H}_{2} \mathrm{O}$ e CO \\
\hline $\mathrm{He}$ & $\mathrm{O}_{2}, \mathrm{~N}_{2}$ e $\mathrm{H}_{2} \mathrm{O}$ \\
\hline Ar & $\mathrm{O}_{2}, \mathrm{~N}_{2}$ e $\mathrm{H}_{2} \mathrm{O}$ \\
\hline & Fonte: Ciola (1985, p. 98).
\end{tabular}


Conforme a Tabela 4, água e oxigênio são impurezas frequentes. Dependendo da concentração que se encontram, devido às altas temperaturas aplicadas à CG (conforme a Tabela 3 , de $200^{\circ} \mathrm{C}-350{ }^{\circ} \mathrm{C}$ ), podem provocar alterações na FE (CIOLA, 1985):

i. Oxigênio: um forte oxidante que causa a formação de peróxidos e hidroperóxidos; essas moléculas são muito instáveis e passíveis de se decomporem termicamente, liberam radicais livres que, além de reagir com os analitos, promovem ligações cruzadas na FE; por consequência, há uma alteração química do polímero de revestimento da coluna. Mais polar e com grupos mais reativos, a separação é prejudicada e aparecem picos com caudas. Também é comum aparecerem sinais de grupamento silanol no cromatograma, uma vez que o oxigênio pode reagir com os grupamentos metílicos das siliconas liberando formaldeído e silanol. Praticamente todas as fases estacionárias sofrem degradação por ação do oxigênio, principalmente as de poliglicóis;

ii. Água: seja proveniente da matriz da amostra ou como impureza da FM, ela pode atuar tanto no suporte de sílica fundida como na FE; no suporte pode hidratar os oxigênios da sílica formando sítios de forte adsorção; a FE pode sofrer hidrólise aumentando a sua polaridade e causando variações nos tempos de retenção dos analitos. Independente da qualidade do gás de arraste, é uma impureza comum a todos os gases comercializados e por isso é necessária atenção à pressão interna no cilindro de gás: quando a pressão está alta a água fica adsorvida na parede do cilindro e não se mistura com o gás, já quando a pressão está baixa a água se desprende da parede do cilindro e elui com o gás para dentro da coluna.

A resolução dos picos cromatográficos e a eficiência da coluna são bastantes dependentes da pureza da FM. A longo prazo as impurezas podem ter efeito negativo sobre a reprodutibilidade da análise, por isso é preciso cuidado com esse aspecto.

\subsubsection{Coluna cromatográfica}

Antes de qualquer coisa, é imprescindível conhecer a natureza da amostra (analitos e matriz). A coluna deve possuir uma FE capaz de separar os compostos 
com boa resolução. Os analitos por sua vez precisam ser detectáveis pelo sistema de detecção disponível ou não há como prosseguir com uma quantificação confiável. Além da FE, algumas outras características da coluna podem ser otimizadas (McNAIR; MILLER, 1997):

i. Diâmetro interno: pode variar de 0,1 $\mathrm{mm}$ a $0,53 \mathrm{~mm}$, entretanto são as de $0,25 \mathrm{~mm}$ e 0,32mm mais vantajosas em relação à resolução, velocidade de análise, capacidade de amostra;

ii. Comprimento: a quantidade do número de pratos é diretamente proporcional ao comprimento da coluna, ou seja, quanto mais comprida maior a quantidade de pratos teóricos e melhor a separação. Já a resolução é proporcional à raiz quadrada do comprimento da coluna. Dessa forma, mesmo que se dobre o comprimento, a resolução aumenta proporcionalmente à $\sqrt{2}$ (ou em 41\%). Em função disso, recomenda-se utilizar colunas muito longas somente quando necessário, seja por disponibilidade, ou quando a amostra for complexa como em análises de voláteis em produtos naturais (geralmente para 50 componentes ou mais) pois os tempos de retenção também são proporcionais ao comprimento da coluna, ou seja, análises muito longas. Colunas de $25 \mathrm{~m}$ e $30 \mathrm{~m}$ são as que melhor combinam boa resolução e menor tempo de análise;

iii. Espessura do filme da fase estacionária: filmes muito espessos ( $1 \mu \mathrm{m}$ ou mais) são muitos bons para análises de voláteis em amostras complexas pois a interação com a FE é maior. Entretanto, também possuem uma grande desvantagem de serem mais susceptíveis à sangramento da fase líquida e, portanto, maior ruído na linha de base, principalmente quando são atingidas temperaturas mais elevadas. Os filmes mais vantajosos para análises mais simples são os de $0,25 \mu \mathrm{m}$, sangram menos e a separação pode ser otimizada aumentando ou diminuindo o fluxo do gás de arraste na coluna.

\subsubsection{Controle da temperatura}

É uma das variáveis mais importantes em CG. Pode acontecer isomerizações e decomposições térmicas dos analitos em todo o sistema cromatográfico: na agulha do injetor, no liner, na coluna ou até mesmo no detector. Por isso é necessário ter um bom conhecimento da natureza da amostra e dos 
analitos. O sistema cromatográfico é influenciado de maneiras distintas pelas temperaturas da câmara de injeção, forno da coluna capilar e do detector, conforme segue abaixo (CIOLA, 1985; LANÇAS, 1993; McNAIR; MILLER, 1997):

i. Temperatura do injetor

O injetor deve estar aquecido o bastante para vaporizar a amostra rapidamente, mas sem degradar os analitos (desidrogenação, desidratação, isomerização, craqueamento, etc.). A alteração da composição da amostra pode provocar aparecimento de caudas ou de novos picos cromatográficos.

ii. Temperatura da coluna

Pode ser controlada de duas formas:

- Isoterma: uma única temperatura ao longo do tempo da análise, geralmente aplicada em matrizes muito simples ou com poucos analitos;

- Programação de temperatura: pode ser por uma programação linear onde a taxa de variação da temperatura é constante ou por programação em degraus, onde há uma combinação de isotermas intercaladas com diferentes incrementos de temperatura (programações lineares de resfriamento ou aquecimento da coluna).

Variações na temperatura influenciam nas interações dos analitos entre as fases móvel e estacionária; alterando os coeficientes de partição e adsorção, todos os outros parâmetros utilizados para a identificação ou quantificação também são afetados (tr, t'r, $\Delta \operatorname{tr}, w b, \alpha, R$ ). Os tempos de retenção são muito dependentes da programação da temperatura e, por consequência, a resolução dos picos também é; em geral, altas temperaturas estão associadas a análises rápidas com baixa resolução; baixas temperaturas a análises lentas de alta resolução.

É desejável que a temperatura da coluna seja otimizada de tal forma que seja alta o suficiente para o menor tempo de análise e baixa o suficiente para um cromatograma com boa resolução. Os tempos de retenção (tr e t'r) e os fatores de separação ( $\alpha$, Equação 39 e Equação 45) tendem a decrescer o com o aumento da temperatura já que as constantes de distribuição (K, Equação 43) são dependentes da temperatura de acordo com a equação de Clapeyron (Equação 44). 


$$
K=\frac{\text { concentração da amostra da } F E}{\text { concentração da amsotra na } F M}
$$

Equação 43

A constante de distribuição, $K$, é uma constante termodinâmica existente em todo processo de distribuição. Mensura a solubilidade de uma amostra na fase líquida (FE). Como o aumento da temperatura tende a diminuir a solubilidade e a interação de compostos em uma fase líquida, a magnitude da constante de distribuição diminui.

$$
\log \rho^{0}=-\frac{\Delta H}{2,3 R \cdot T}+\text { constante }
$$

Equação 44

Sendo que $\Delta \mathrm{H}$ é a entalpia de vaporização na temperatura absoluta, $\mathrm{T} ; \mathrm{R}$ é a constante dos gases; $\rho 0$ é a pressão de vapor do soluto na temperatura T. A equação de Clapeyron indica que a pressão de vapor do soluto decresce logaritimicamente com a redução da temperatura. Em outros termos, temperaturas baixas expressam termodinamicamente pressões de vapor menores provocando menores quantidades de soluto na FM; os componentes da amostra ficam mais retidos na FE e os coeficientes de distribuição, K, são maiores. O tempo da análise fica mais longo e os tempos de retenção dos analitos aumentam pois esses passam mais tempo adsorvidos na FE, por consequência, os fatores de separação ( $\alpha$, Equação 45) crescem e a seletividade da separação também (McNAIR; MILLER, 1997, LANÇAS, 1993).

$$
\alpha=\frac{t^{\prime} r(B)}{t^{\prime} r(A)}=\frac{K(B)}{K(A)}
$$

Equação 45

Entretanto, nem sempre baixas temperaturas são capazes de promover separações, ou que uma mesma temperatura (isotermas) sejam eficientes para separar todos os compostos de uma amostra, por isso são utilizadas as programações de temperatura, lineares ou em degraus. Geralmente incrementos de temperatura diminuem os tempos e volumes de retenção (tr, t'r, Vr, V'r) e a seletividade ( $\alpha$ ) também decresce, mesmo que haja um pequeno aumento do número de pratos teóricos (N) (McNAIR; MILLER, 1997). Uma tendência comum provocada pela temperatura em CG é que os tempos de retenção são linearmente dependentes do número de átomos de carbono dos analitos; dentro de uma mesma classe de compostos, os tempos de retenção tendem aumentar com o ponto de ebulição (CIOLA, 1985). 
Métodos desenvolvidos com variação de temperatura ao longo do tempo, desde que sejam respeitados os limites de temperatura máxima da FE da coluna, podem ser muito vantajosos: diminui o tempo de análise para amostras complexas; melhora a separação em uma ampla faixa de temperatura; melhora os limites de detecção e precisão; melhora a resolução dos picos; excelente meio de promover limpeza da coluna no final da análise (McNAIR; MILLER, 1997).

iii. Temperatura do detector

Depende muito do tipo de detector acoplado ao cromatógrafo. Como regra geral, interface entre a conexão com a saída da coluna e o detector deve estar aquecida o suficiente para que não aconteçam condensações, da FE ou da amostra; até $10^{\circ} \mathrm{C}$ acima da temperatura final da programação. Isso evita o alargamento de picos e conserva a precisão da análise (LANÇAS, 1993).

Um outro ponto importante para uma análise criteriosa não é de domínio instrumental, mas estatístico. Além de conhecer as normas vigentes compatíveis com a análise, é necessário possuir conhecimento sobre as possíveis fontes de erros do método bem como os cálculos de incertezas e a forma correta de aplicar os cálculos estatísticos (precisão, exatidão, linearidade, etc.) e de interpretar os resultados. A comunidade científica está aplicando cada vez mais as ferramentas da qualidade em seus estudos, como pesquisa e desenvolvimento de materiais de referência certificados e ensaios de proficiência.

A preocupação com a qualidade dos resultados analíticos é notória e crescente, mas talvez ainda não o suficiente. Uma tendência preocupante foi recentemente apontada por Monya Baker: em um contexto geral, a comunidade científica reconhece que atualmente existe uma crise de reprodutibilidade de experimentos publicados, com destaque para as áreas de química, biologia, física e engenharia (BAKER, 2016). Diversos fatores foram apontados pelos pesquisadores entrevistados como causas para essa crise, mas destacam-se esses:

i. Pobreza de análises estatísticas dos dados;

ii. Experimentos originais feitos com baixa repetibilidade;

iii. Projeto experimental ruim;

iv. Dados brutos indisponíveis no laboratório original. 
A adoção dos requisitos gerais da ISO 17025, força a aplicação de ferramentas da qualidade dentro do laboratório de ensaio como calibrações, aplicação de materiais de referência, validação dos métodos e dos softwares e cálculos da estimativa de incerteza da medição, que poderiam melhorar muito a reprodutibilidade dos experimentos publicados. Entretanto, apenas comparações interlaboratoriais (como participações periódicas em EP) poderiam de fato avaliar o desempenho dos laboratórios e a concordância entre eles (ISO, 2017) ou seja, avalia uma série de parâmetros como a robustez de um método e a capacidade do laboratório de reproduzi-lo. Portanto, a adoção dessas ferramentas da qualidade pode diminuir parte dessa crise de reprodutibilidade dentro da área acadêmica, assim como faz dentro dos laboratórios de ensaio e calibração que estão sujeitos à fiscalização de órgãos governamentais regulamentadores, sejam esses laboratórios públicos ou pertencentes ao setor privado de produção de bens e serviços.

\section{OBJETIVOS}

\subsection{GERAL}

Produzir um material de referência (MR) de carbamato de etila (CE) em cachaça não adoçada para controle de qualidade interno do SLAV-BEB Jundiaí aplicando-se as principais ferramentas estatísticas para laboratórios.

\subsection{ESPECÍFICOS}

Considerando que as ferramentas estatísticas aplicadas para gestão da qualidade de laboratórios, sumarizadas pelo ciclo AQAC, esse trabalho compreende a validação de métodos analíticos, produção de um lote de material de referência (MR) para o monitoramento da qualidade intralaboratorial, os cálculos de incerteza, a realização de um ensaio de proficiência com o MR produzido e uma avaliação do controle de CE em cachaças nacionais. Dessa forma, o trabalho fica dividido nas seguintes etapas:

i. Desenvolver e validar um método em CG-EM para a análise para carbamato de etila em uma amostra de cachaça não adoçada no laboratório de química ambiental (IQSC-USP) para a produção do MR;

ii. Quantificar o carbamato de etila inicialmente presente na matriz e fortificar a matriz no limite máximo da legislação $\left(210 \mu \mathrm{g} \mathrm{L}^{-1}\right)$; 
iii. Realizar os estudos de estabilidade e homogeneidade desse material, segundo a ISO Guia 35:2020 e ISO Guia 35:2020;

iv. De acordo com os conceitos de metrologia química detalhada pela ISO Guide 80:2014, caracterizar carbamato de etila em cachaça não adoçada para a produção de um material de referência interno (MR) nos limites de concentração da legislação, $210 \mu \mathrm{g} \mathrm{L}^{-1}$ (Instrução Normativa № 28, de 08 de agosto de 2014) para o controle intralaboratorial do LFDA-SP;

v. Desenvolver e validar um método em CG-EM para a análise para carbamato de etila em uma amostra de cachaça não adoçada no SLAV-BEB Jundiaí (LFDA-SP) para a análise de rotina do laboratório;

vi. Aplicar esse MR por meio de um diagnóstico de amostras nacionais coletadas pelo programa de fiscalização de bebidas do MAPA;

vii. Distribuição do MR para a realização de um ensaio de proficiência. 


\section{MATERIAIS E MÉTODOS}

\subsection{REAGENTES E AMOSTRAS}

Para a produção do material de referência, a matriz cachaça não adoçada foi fornecida pela Companhia Müller de Bebidas. As amostras de cachaças não adoçadas utilizadas para o monitoramento de $C E$ nas cachaças nacionais foram fornecidas pelo LFDA-SP/SLAV-BEB Jundiaí pelo programa de fiscalização de bebidas do Ministério da Agricultura, Pecuária e Abastecimento (MAPA), bem como o padrão analítico de carbamato de etila para a produção do MR.

\subsection{LEGISLAÇÕES E NORMAS}

- Instrução Normativa № 28, de 08 de agosto de 2014 (BRASIL, 2014).

- Manual de garantia da qualidade analítica: Áreas de identidade e qualidade de alimentos e de insumos (BRASIL, 2015).

- ABNT ISO GUIA 35:2020 - Materiais de Referência: Guia para caracterização e avaliação da homogeneidade e estabilidade.

- ISO GUIDE 80 - Guidance for the in-house preparation of quality control materials (QCMs).

\subsection{ANÁLISES ESTATÍSTICAS}

Todas os cálculos e análises dos parâmetros de validação do método e os cálculos de incertezas da caracterização do MR foram realizadas pelos softwares ConfLab Validação® (2018) e ConfLab Incertezas @ (2018) (disponível em www.confLab.com.br). Cálculos e gráficos auxiliares foram produzidos pelo Microsoft Excel 2013®.

\subsection{VALIDAÇÃO DOS MÉTODOS}

Para a caracterização do carbamato de etila, inicialmente foram estudadas as melhores condições cromatográficas por CG-EM em cachaça não adoçada. De acordo com o Manual de Garantia da Qualidade Analítica (BRASIL, 2015), para estudos de identidade e qualidade de alimentos. Foram estudados os seguintes parâmetros obrigatórios para a validação do método: linearidade, seletividade, exatidão, repetibilidade, precisão intermediária e LQ. 
Foram desenvolvidos e validados dois métodos: um no IQSC/USP para a produção do MR e outro para o Laboratório Federal de Defesa Agropecuária (LFDASP), Seção Laboratorial Avançada de Análises Físico-Químicas de Bebidas e Vinagres (SLAV/BEB Jundiaí) para ser utilizado nas suas análises de rotina.

\subsubsection{Reagentes}

Etanol grau HPLC

Água ultrapura, Milli-Q

Carbamato de etila Sigma-Aldrich com pureza $\geq 99 \%$

\subsubsection{Vidrarias e outros materiais}

- 1 Balão volumétrico de $250 \mathrm{~mL}$

- Pipetas descartáveis

- 1 Balão volumétrico de $5 \mathrm{~mL}$

- Pera de sucção

- 1 Balão volumétrico de $200 \mathrm{~mL}$

- Micropipetas: 1000uL, de 100uL

- 2 Balões volumétricos de $50 \mathrm{~mL}$ e de 10uL

- 5 Balões volumétricos de $10 \mathrm{~mL}$

- Ponteiras para as micropipetas

- 1 Béquer de 10mL

- Espátula

- 2 Béqueres de $25 \mathrm{~mL}$

- Vials

- 1 Pipeta volumétrica de $100 \mathrm{~mL}$ (ou uma de $50 \mathrm{~mL}$ ou de $25 \mathrm{ml}$ )

Ambos os métodos utilizaram o mesmo planejamento da curva de calibração. A curva foi planejada para que o valor crítico da legislação e também o valor alvo para a certificação do MR (210 $\left.\mathrm{g} \cdot \mathrm{L}^{-1}\right)$ ficasse próximo ao centro, onde as incertezas tendem a serem menores (Figura 7), e que os extremos fossem de 50\% a 150\% desse valor. Os preparos das soluções estão descritos a seguir:

- Sol. EtOH 40\% v/v - Solução hidroalcoólica Etanol

Com uma pipeta volumétrica, transferir $100 \mathrm{~mL}$ de etanol grau HPLC para balão de 250mL e completar com água ultrapura, Milli-Q.

- SE: Solução padrão estoque $1 \mathrm{~g} / \mathrm{L}$

Pesar $100 \mathrm{mg}(0,100 \mathrm{~g})$ de CE e diluir com a Sol. EtOH 40\% v/v. Transferir para balão de $100 \mathrm{~mL}$ e completar com sol. EtOH 40\%v/v para evitar desperdício de reagentes. 
- P6: Solução padrão diluída $368 \mu \mathrm{g} / \mathrm{L}$

Em balão de $50 \mathrm{~mL}$, pipetar $18,40 \mu \mathrm{L}$ da solução estoque (SE) e completar com sol. EtOH 40\%v/v.

- P5: Solução padrão diluída $320 \mu \mathrm{g} / \mathrm{L}$

Em balão de $50 \mathrm{~mL}$, pipetar $16 \mu \mathrm{L}$ da solução estoque (SE) e completar com sol. $\mathrm{EtOH} 40 \% \mathrm{v} / \mathrm{v}$.

- P4: Solução padrão diluída $265 \mu \mathrm{g} / \mathrm{L}$

Em balão de $10 \mathrm{~mL}$, pipetar $8,28125 \mathrm{~mL}(8 \mathrm{ml}+281 \mu \mathrm{L})$ da solução P5 e completar com sol. EtOH $40 \% \mathrm{v} / \mathrm{v}$.

- P3: Solução padrão diluída $210 \mu \mathrm{g} / \mathrm{L}$

Em balão de $10 \mathrm{~mL}$, pipetar $6,5625 \mathrm{~mL}(6 \mathrm{~mL}+562 \mu \mathrm{L})$ da solução P5 e completar com sol. EtOH 40\%v/v.

- P2: Solução padrão diluída $155 \mu \mathrm{g} / \mathrm{L}$

Em balão de $10 \mathrm{~mL}$, pipetar $4,84375 \mathrm{~mL}(4 \mathrm{~mL}+843 \mu \mathrm{L})$ da solução P5 e completar com sol. EtOH $40 \% \mathrm{v} / \mathrm{v}$.

- P1: Solução padrão diluída $100 \mu \mathrm{g} / \mathrm{L}$

Em balão de $10 \mathrm{~mL}$, pipetar $3,125 \mathrm{~mL}(3 \mathrm{~mL}+125 \mu \mathrm{L})$ da solução P5 e completar com sol. EtOH 40\%v/v.

Para o preparo das soluções, no método IQSC/USP RQA Lab foi utilizada uma balança analítica Sartorius TE214S com precisão de $\pm 0,0001 \mathrm{~g}$ e carga mínima de $0,01 \mathrm{~g}$. Previamente aos preparos, todas as micropipetas utilizadas (Eppendorf Research plus) estavam calibradas e também foram verificadas por gravimetria com a balança analítica por meio de 10 replicatas cada. O mesmo procedimento foi aplicado aos balões utilizados; a calibração foi verificada por meio de gravimetria com 10 replicatas. No método LFDA/SP foi utilizada uma balança analítica AND HR-200 com precisão de $\pm 0,0001 \mathrm{~g}$ e carga mínima de $0,01 \mathrm{~g}$. Todas as micropipetas e balões utilizados possuem a calibração verificada pelo laboratório federal.

\subsubsection{Equipamentos e consumíveis}

- Liner splitless e lã de vidro.

- Balança analítica com precisão de $\pm 0,0001 \mathrm{~g}$.

- Coluna capilar de fase estacionária polar, polietilenoglicol.

- Cromatógrafo gasoso acoplado a um espectrômetro de massas. 


\subsubsection{Condições cromatográficas}

Os métodos desenvolvidos foram embasados em trabalhos já existentes na literatura (ANDRADE-SOBRINHO et al., 2002; BARCELOS et al., 2007; ANDRADESOBRINHO et al., 2009; CARUSO et al., 2010; GALINARO; FRANCO, 2011; ZACARONI et al., 2011) e também nos métodos OIV-MA-BS-25 da International Organisation of Vine and Wine (OIV) e o método IAL 229/IV do Instituto Adolfo Lutz (ITAL). Todos os métodos utilizam colunas capilares de FE polar devido à natureza química do $\mathrm{CE}$, conforme pode ser observado pela Figura 17. Os métodos são baseados em monitoramento de íon seletivo $\mathrm{m} / \mathrm{z} 62$. Esse íon é o mais empregado para a determinações de carbamato de etila (CLEGG; FRANK, 1988) e, conforme verificado com um estudo de seletividade por Andrade-Sobrinho et al. (2002), é possível quantificar e identificar o CE nesse modo sem problemas de co-eluições com outros compostos comuns em uma matriz de cachaça.

As análises cromatográficas realizadas pelo método IQSC/USP RQA Lab utilizaram o cromatógrafo do Laboratório de Química Ambiental - IQSC/USP. Pelo método LFDA/SP as análises foram realizadas no cromatógrafo do laboratório SLAV/BEB Jundiaí.

\subsubsection{Método IQSC/USP - RQA Lab}

Método realizado por curva de calibração externa (curva analítica) de 6 níveis com soluções de carbamato de etila em solução hidroalcóolica $40 \%$ v. As soluções devem ser moduladas e preparadas de acordo com o teor de carbamato de etila presente no meio. Realiza-se injeção direta em cromatógrafo a gás Shimadzu, modelo GC-2010 PLUS em coluna DB-WAX $(60 \mathrm{~m} \times 0,25 \mathrm{~mm} \times 0,25 \mu \mathrm{m})$ acoplado a um espectrômetro de massas quadrupolo. A quantificação do analito é feita em quintuplicata por meio da equação da regressão linear encontrada pela curva analítica.

(i) Injetor

- Temperatura: $250^{\circ} \mathrm{C}$

- Modo de injeção: splitless

- Tempo de amostragem: $1 \mathrm{~min}$

- Volume de injeção: $2 \mu \mathrm{L}$

- Fluxo de gás (He) na coluna: $1 \mathrm{~mL} / \mathrm{min}$

- Modo: velocidade linear 
(ii) Programação da temperatura do forno

Programação da temperatura do forno (Tabela 5): $90^{\circ} \mathrm{C}$ estável por $2 \mathrm{~min}$, de $90^{\circ} \mathrm{C}$ a $200^{\circ} \mathrm{C}$ com incremento de $10^{\circ} \mathrm{C} / \mathrm{min}$, estável por $2 \mathrm{~min}$. Tempo total da corrida de $15 \mathrm{~min}$.

Tabela 5 - Programação da temperatura do método IQSC/USP - RQA Lab.

\begin{tabular}{ccc}
\hline $\begin{array}{c}\text { Incremento de } \mathbf{T} \\
\left({ }^{\circ} \mathrm{C} / \mathrm{min}\right)\end{array}$ & $\begin{array}{c}\text { Temperatura final do } \\
\text { forno }\left({ }^{\circ} \mathrm{C}\right)\end{array}$ & Tempo de espera (min) \\
\hline 10 & 90 & 2 \\
\hline
\end{tabular}

Fonte: autoria própria.

(iii) Detector de massas

- Temperatura da interface: $230^{\circ} \mathrm{C}$

- Fonte de íons: $250^{\circ} \mathrm{C}$

- Sistema de ionização: impacto de elétrons a 70 eV

- Corte de solvente para ligar o detector: 9 min

- Modo de aquisição: SIM

- Íons monitorados: 44, 62 e 74

- Event time: 0,30s

A Figura 22 é um cromatograma obtido de uma replicata da solução P1 (100 $\mu \mathrm{g} / \mathrm{L}$ ) para exemplificar o layout da aquisição dos dados. O pico integrado, de cor rosa, é correspondente ao íon 62 e o tempo de retenção do CE nesse método é de aproximadamente 11,45 min (suscetível às variações instrumentais normais do método: tempo de retenção do CE está entre 11,4 min e 11,50min). Ver Tabela 6. 
Figura 22 - Exemplo de cromatograma para CE no método IQSC/USP - RQA Lab.

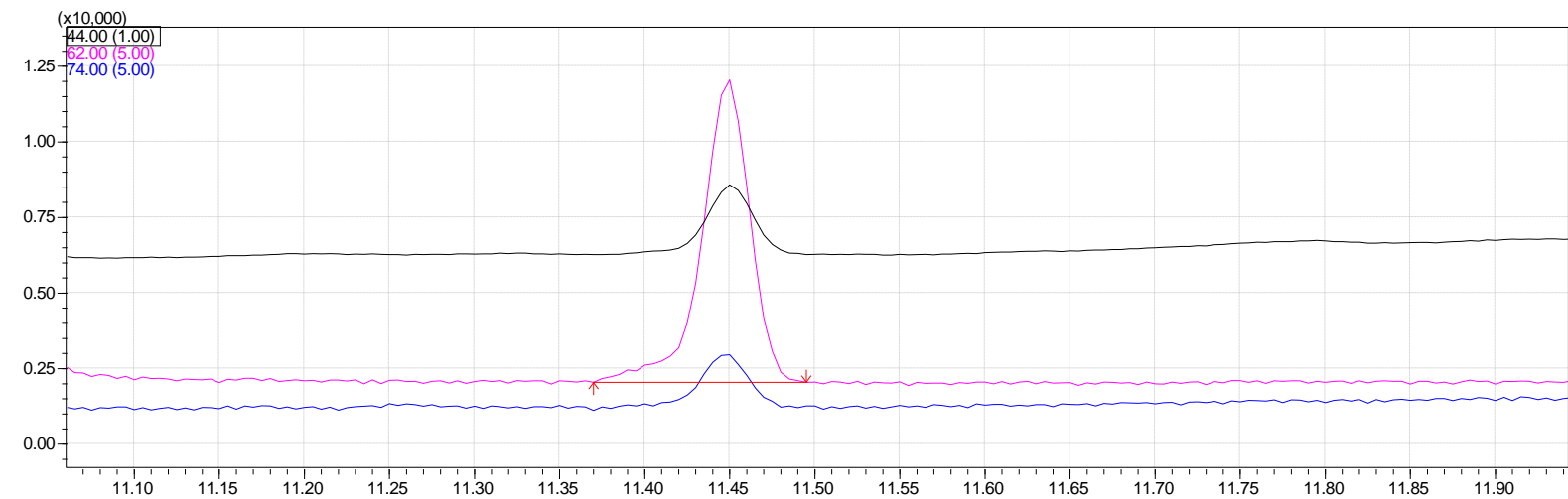

Fonte: autoria própria.

Tabela 6 - Fragmentos de identificação e quantificação do CE e tempo de retenção no método IQSC/USP - RQA Lab.

\begin{tabular}{cccc}
\hline Analito & $\begin{array}{c}\text { Fragmento de } \\
\text { Identificação }\end{array}$ & $\begin{array}{c}\text { Fragmento de } \\
\text { Quantificação }\end{array}$ & $\begin{array}{c}\text { Tempo de } \\
\text { retenção (min) }\end{array}$ \\
\hline Carbamato de etila & $44,62,74$ & 62 & 11,45 \\
\hline
\end{tabular}

Fonte: autoria própria.

\subsubsection{Método LFDA/SP - SLAV/BEB Jundiaí}

Esse método foi desenvolvido e validado com uma coluna capilar Zebron ZBWAX $30 \mathrm{~m} \times 0,25 \mathrm{~mm} \times 0,25 \mu \mathrm{m}$ (fase estacionária polar, polietilenoglicol) em um cromatógrafo gasoso Shimadzu modelo GC 2010, equipado com amostrador automático modelo AOC-5000, acoplado a um espectrômetro de massas modelo GCMS-QP2010 Plus.

(i) Injetor

- Temperatura: $250^{\circ} \mathrm{C}$

- Modo de injeção: splitless

- Tempo de amostragem: $1 \mathrm{~min}$

- Volume de injeção: $2 \mu \mathrm{L}$

- Fluxo de gás $(\mathrm{He})$ na coluna: $1 \mathrm{~mL} / \mathrm{min}$

- Modo: velocidade linear

(ii) Programação da temperatura do forno

Programação da temperatura do forno (Tabela 7): $90^{\circ} \mathrm{C}$ estável por 3 min, de $90^{\circ} \mathrm{C}$ a $160^{\circ} \mathrm{C}$ com incremento de $5^{\circ} \mathrm{C} / \mathrm{min}$, estável por $1 \mathrm{~min}$, de $160^{\circ} \mathrm{C}$ a $240^{\circ} \mathrm{C} \mathrm{com}$ incremento de $40^{\circ} \mathrm{C} / \mathrm{min}$, estável por $5 \mathrm{~min}$. Tempo total da corrida de $25 \mathrm{~min}$. 
Tabela 7 - Programação da temperatura do método LFDA/SP - SLAV/BEB Jundiaí.

\begin{tabular}{ccc}
\hline $\begin{array}{c}\text { Incremento de } \mathbf{T} \\
\left({ }^{\circ} \mathbf{C} / \mathrm{min}\right)\end{array}$ & $\begin{array}{c}\text { Temperatura final do } \\
\text { forno }\left({ }^{\circ} \mathbf{C}\right)\end{array}$ & Tempo de espera (min) \\
\hline 5 & 90 & 3 \\
\hline 40 & 160 & 5 \\
\hline
\end{tabular}

Fonte: autoria própria.

(iii) Detector de massas

- Temperatura da interface: $240^{\circ} \mathrm{C}$

- Fonte de íons: $250^{\circ} \mathrm{C}$

- Sistema de ionização: impacto de elétrons a 70 eV

- Corte de solvente para ligar o detector: $10 \mathrm{~min}$

- Modo de aquisição: SIM

- Íons monitorados: 44, 62 e 74

- Event time: 0,30s

A integração do pico para quantificação é feita com o íon 62 , que é o mais empregado para a determinação de CE (CLEGG; FRANK, 1988; DE ANDRADESOBRINHO et al., 2002). A Figura 23 é um cromatograma obtido de uma replicata da solução P2 (155 $\mathrm{mg} / \mathrm{L})$ para exemplificar o layout da aquisição dos dados. O pico integrado, de cor rosa, é correspondente ao íon 62 e o tempo de retenção do CE nesse método é de aproximadamente 12,30min (suscetível às variações instrumentais normais do método: tempo de retenção do CE está entre 12,25min e 12,50min). Ver Tabela 8.

Figura 23 - Exemplo de cromatograma para CE no método LFDA/SP - SLAV/BEB.

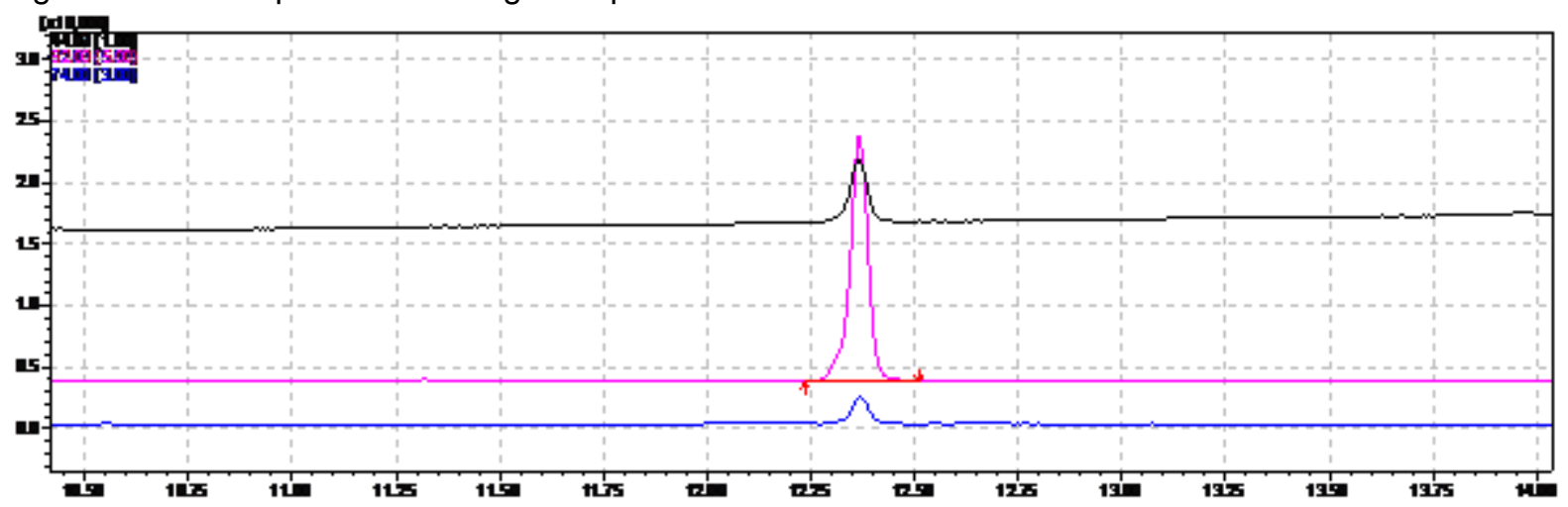

Fonte: autoria própria. 
Tabela 8- Fragmentos de identificação e quantificação do CE e tempo de retenção no método LAFDA/SP - SLAV/BEB Jundiaí.

\begin{tabular}{cccc}
\hline Analito & $\begin{array}{c}\text { Fragmento de } \\
\text { Identificação }\end{array}$ & $\begin{array}{c}\text { Fragmento de } \\
\text { Quantificação }\end{array}$ & $\begin{array}{c}\text { Tempo de } \\
\text { retenção (min) }\end{array}$ \\
\hline Carbamato de etila & $44,62,74$ & 62 & 12,30 \\
\hline
\end{tabular}

Fonte: autoria própria.

Para a realização da validação, escolha dos parâmetros a serem avaliados e seus critérios de aceitabilidade, respeitou-se as exigências do Manual de Garantia da Qualidade Analítica: Áreas de Identidade e Qualidade de Alimentos e de Insumos (BRASIL, 2015). Parâmetros obrigatórios avaliados nesse estudo, segundo exigências do MAPA:

- Linearidade: fortificação na matriz ou branco semelhante em no mínimo 5 níveis de concentração, preferencialmente equidistantes. Análises realizadas no mínimo em triplicata. Se o experimento for realizado em no mínimo quintuplicata, é aceito até 1 outlier com CV > 20\% por nível. Critérios de aceitabilidade:

$r$ (coeficiente de correlação) $\geq 0,99$;

CV (coeficiente de variação individual) $\leq 20 \%$.

- Seletividade: precisa ser assegurada por dados experimentais ou pela literatura.

- Precisão (repetibilidade) e exatidão: devem ser realizadas em no mínimo 2 níveis com 5 replicatas por nível. Critérios de aceitabilidade:

CV (coeficiente de variação) $\leq 20 \%$; calculado na quintuplicada de cada nível;

- Precisão intermediária (precisão intralaboratorial): deve ser realizado em no mínimo dois estudos de precisão (repetibilidade), calcular o CV em cada nível definidos no estudo da repetibilidade. Se o experimento for realizado pelo mesmo analista, deve-se ter um intervalo superior a $24 \mathrm{hs}$ entre as duas curvas de calibração. Critérios de aceitabilidade:

CV (coeficiente de variação) $\leq 20 \%$; calculado na quintuplicada de cada nível;

- LQ (limite de quantificação): com precisão e exatidão, o sinal deve ser 10 vezes maior que o ruído (relação sinal / ruído 10:1) ou pode ser estimado considerando-se 10 vezes o desvio padrão da concentração obtida com a 
amostra branca. Se atender aos critérios acima, o LQ pode ser adotado como o nível de menor concentração da curva de calibração.

Para o cálculo da incerteza do método, o Brasil (2015) recomenda:

- Incerteza da linearidade: calculado no ponto de menor concentração da curva onde a incerteza é maior, ou no ponto da concentração alvo do analito ou a mais próxima disso.

- Incerteza da precisão intermediária: calcular como incerteza padrão nos níveis de interesse do estudo, rotina ou legislação.

- Incerteza expandida: necessária quando calculadas as incertezas da linearidade e da precisão intermediária realizando a somatória dessas duas incertezas e utilizando o t de Student para 4 graus de liberdade (quintuplicatas) e $95 \%$ de confiança $(2,78)$ como fator de expansão.

\subsection{PRODUÇÃO DO MATERIAL DE REFERÊNCIA}

Para eliminar o efeito matriz que a unidade SLAV/BEB alertou acontecer com os MRs comercializados em matriz hidroalcoólica $40 \% \mathrm{v} / \mathrm{v}$, foi pedido para que o MR de CE fosse produzido em matriz de cachaça não adoçada. Portanto, pelo método IQSC/USP-RQA Lab validado anteriormente, primeiramente determinou-se a concentração natural de CE presente na cachaça não adoçada utilizada como matriz. Posteriormente, foi realizada uma fortificação dessa matriz por gravimetria até o limiar de $210 \mu \mathrm{g} \mathrm{L}^{-1}$ com padrão analítico para carbamato de etila. Foram envasados 100 vials de $2 \mathrm{~mL}$ desse candidato a MR.

\subsubsection{Estudo da homogeneidade}

A amostragem do estudo de homogeneidade foi realizada com 30 frascos analisados em quintuplicata, escolhidos de forma aleatória estratificada, conforme ilustrado pela Figura 24. 
Figura 24 - Planejamento do estuda da homogeneidade.

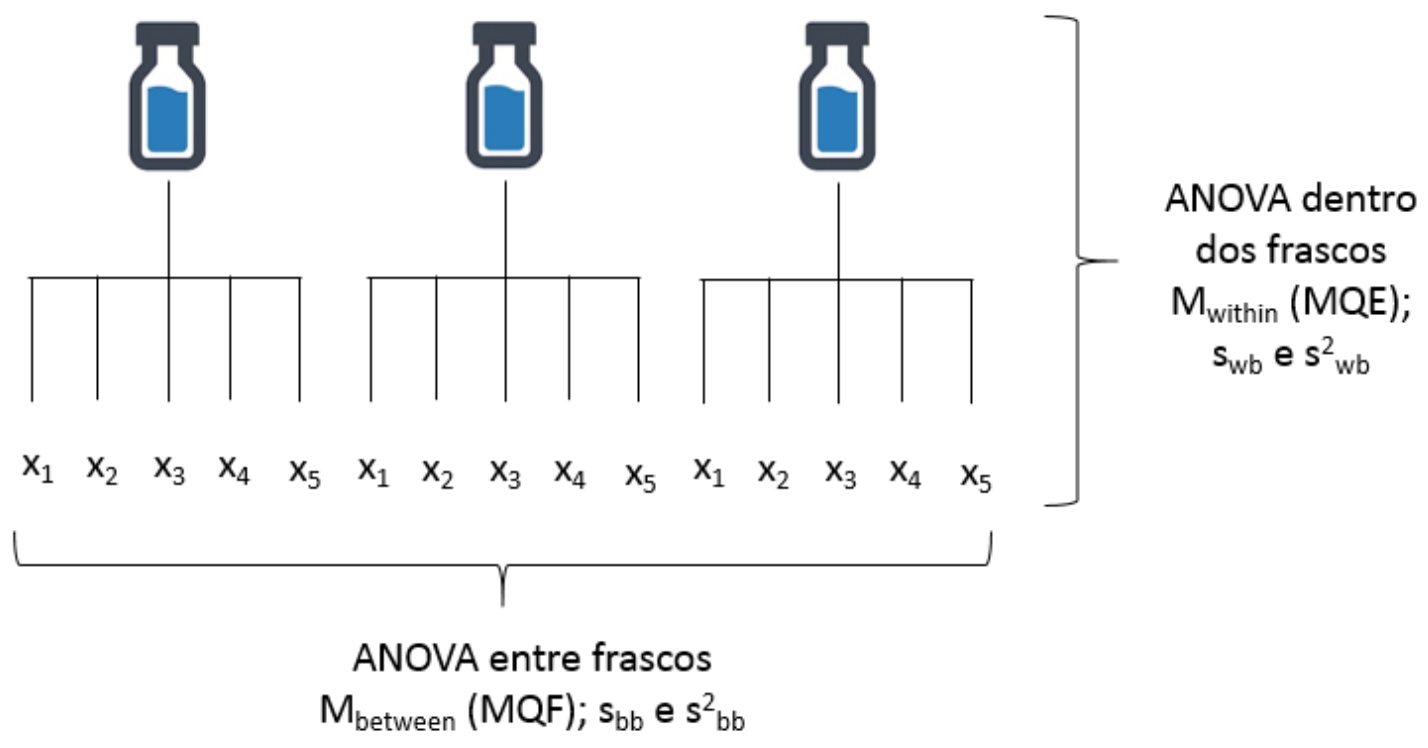

Fonte: autoria própria.

\subsubsection{Estudo das estabilidades}

Para evitar alterações no valor de propriedade do lote do material durante o período em que estava sob testes, as amostras ficaram refrigeradas em congelador convencional entre $-1^{\circ} \mathrm{C}$ e $-4^{\circ} \mathrm{C}$.

\subsubsection{Estabilidade do armazenamento}

É recomendado realizar o estudo com mais de um frasco para cada ponto no tempo. Sendo assim, adotou-se o método isócrono de amostragem por 9 meses. Conforme ilustra a Figura 25, a cada mês retirava-se 2 frascos do lote condicionado entre $-1^{\circ} \mathrm{C}$ e $-4^{\circ} \mathrm{C}$ e eram colocados em temperatura ambiente. Cada frasco foi analisado em triplicata. 
Figura 25 - Planejamento do estudo da estabilidade de longa duração pelo método isócrono de amostragem.

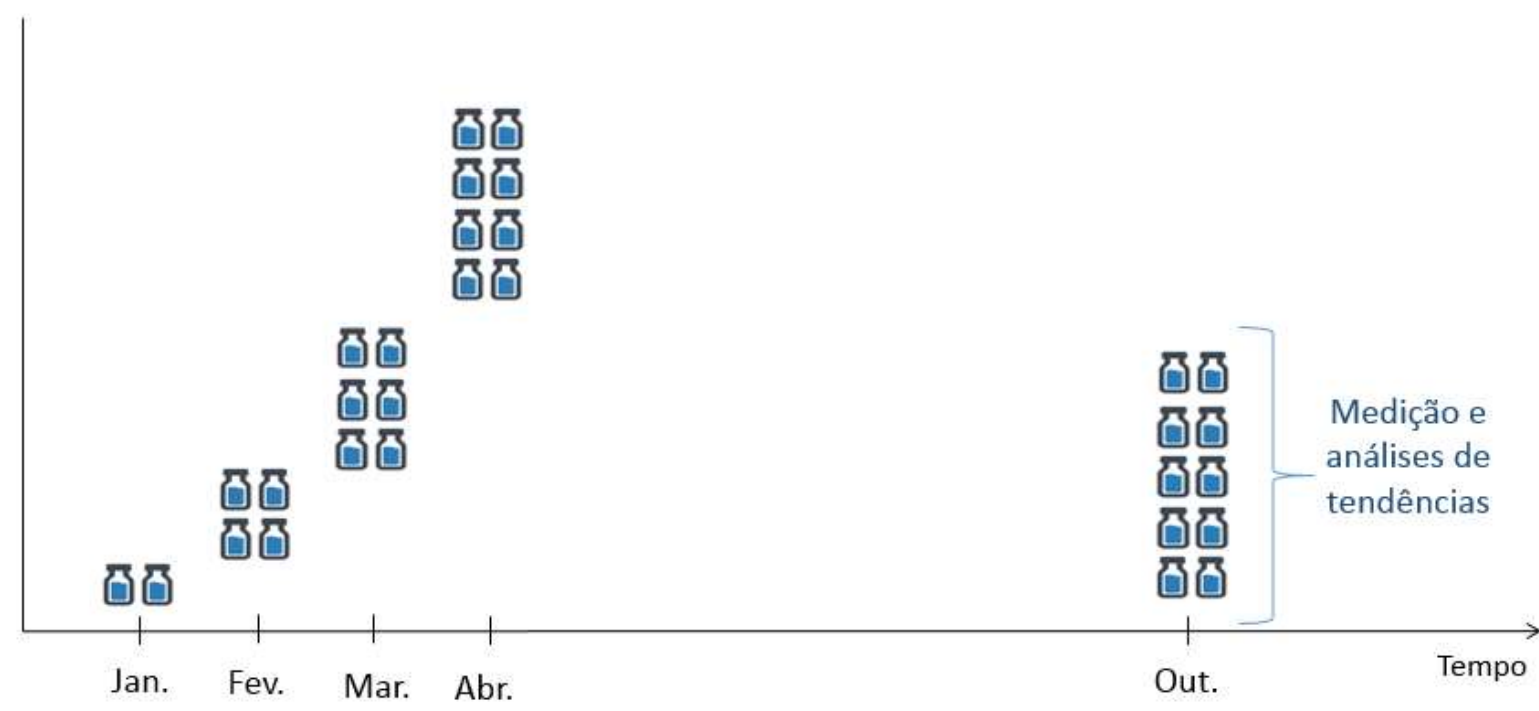

Fonte: autoria própria.

2.5.2.2. Estabilidade do transporte

A fim de reproduzir as condições do transporte dos candidatos a MR para os laboratórios participantes do ensaio de proficiência promovido, dois frascos foram condicionados a $40^{\circ} \mathrm{C}$ em estufa termostatizada por $72 \mathrm{hs}$ e analisadas em triplicata logo em seguida.

\subsection{ENSAIO DE PROFICIÊNCIA (EP)}

Para o ensaio de proficiência, foram convidados os laboratórios da Associação Brasileira de Bebidas (Abrabe) e os laboratórios acreditados na Rede Brasileira de Laboratórios de Ensaio (RBLE) do Inmetro que realizavam análise de CE. Por meio de transportadora privada, foram enviados para cada laboratório um frasco do candidato a material de referência. Além disso, para cada participante foi enviado o formulário elaborado para o envio dos resultados (Apêndice A) e o protocolo do ensaio de proficiência de congêneres orgânicos em bebidas destiladas. Esse protocolo teve como objetivo informar o participante de que sua identificação não seria divulgada, informar métodos utilizados para o tratamento dos dados de seus resultados, sobre a forma como estava sendo feito o estudo de homogeneidade, os estudos de estabilidade e também forneceu o método de análise desenvolvido no IQSC/USPRQA Lab e os métodos OIV-MA-BS-25 da International Organisation of Vine and Wine (OIV) e o método IAL 229/IV do Instituto Adolfo Lutz (ITAL) como orientação. Os 
participantes eram livres para escolher algum método ou utilizar os que já estavam habituados na rotina do laboratório.

A todos eles, foi fornecido um prazo de 1 mês para a entrega dos resultados conforme as exigências do protocolo:

- A unidade adotada para o resultado deve ser $\mu \mathrm{g} \cdot \mathrm{L}^{-1}$;

- As quantificações devem ser feitas em quintuplicata;

- Informar as concentrações dos níveis adotados na curva analítica e as áreas dos picos de cada replicata para todos os níveis de concentração;

- Caso o laboratório utilize o método de padrão interno: informar o valor da concentração desse padrão e os valores das suas áreas dos picos para cada replicata;

- Caso o laboratório envie o valor da incerteza expandida, o cálculo do desempenho do participante será realizado tanto por índice $Z$ quanto pelo índice zeta e En, senão a avaliação do desempenho será feita apenas pelo cálculo do índice Z;

- Caso o participante não possua o valor da incerteza e achar interessante possuir esse dado, o provedor irá calcular a incerteza pelo software ConfLab Incerteza ${ }^{\circledR}$ (que também contará com uma avaliação detalhada da linearidade, por ser uma das fontes que mais influência na incerteza final) para isso, solicitase o certificado de calibração da seringa de injeção e sua tolerância para ser adicionada ao cálculo da incerteza.

\subsection{DIAGNÓSTICO DE CE EM CACHAÇAS DE FISCALIZAÇÃO}

Para essa etapa, o SLAV/BEB Jundiaí forneceu 18 amostras de cachaças não adoçadas provenientes do programa de fiscalização do MAPA. As amostras foram codificadas e analisadas em triplicata pelo método validado no IQSC/USP. 


\section{RESULTADOS E DISCUSSÃO}

\subsection{VALIDAÇÃO DOS MÉTODOS}

Conforme a norma utilizada, Brasil (2015), a seletividade pode ser assegurada pela literatura, dessa forma não foi preciso fazer um estudo profundo desse parâmetro, apenas verificou-se experimentalmente em ambos os laboratórios. Entretanto, como o LFDA/SP notificou que nas análises surgiam muitas dúvidas quanto à identificação do CE apenas pelo íon 62, os métodos desenvolvidos foram realizados com os íons 44, 62 e 74 para assegurar a identificação e a quantificação continuando com o íon 62. Esses fragmentos foram escolhidos por serem os majoritários no espectro de massas do $\mathrm{CE}$ e por não existirem nos espectros de massas da água (possui o fragmento $\mathrm{m} / \mathrm{z} 18 \mathrm{em}$ comum) e do etanol (possui o fragmento m/z 31 em comum), componentes majoritários da matriz (Figura 17, Figura 26 e Figura 27). O íon molecular de m/z 89 do CE não foi possível ser observado.

Figura 26 - Estrutura molecular, fórmula molecular e espectro de massas do etanol.

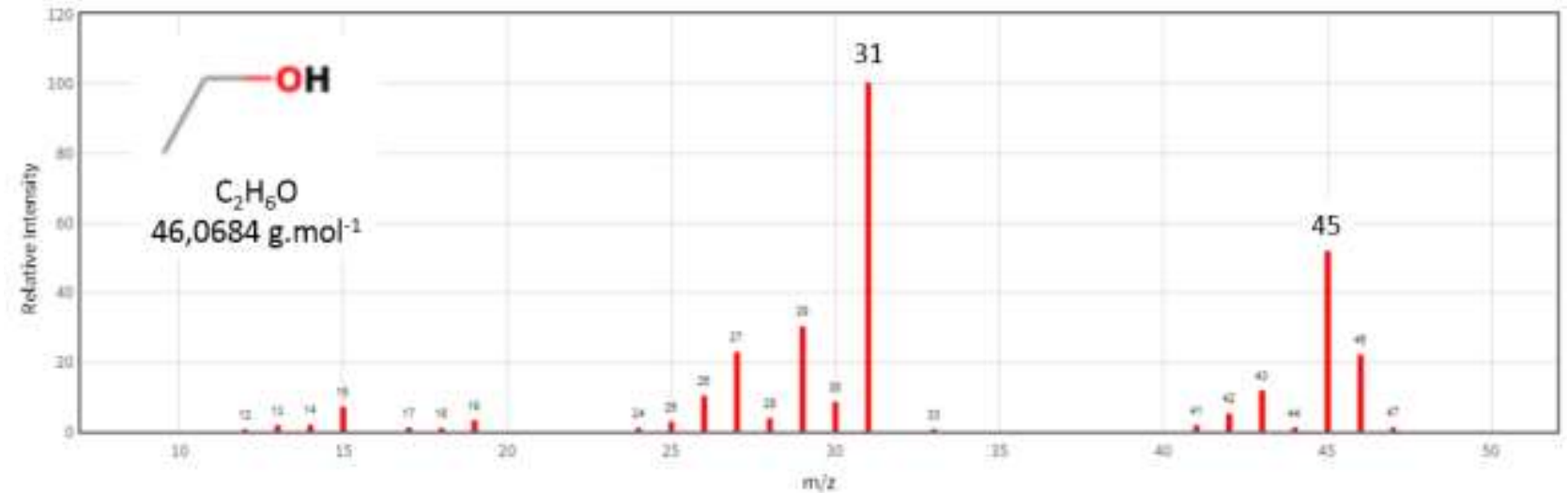

Fonte: adaptado de NIST - Ethanol. Disponível em: <https://webbook.nist.gov/cgi/cbook.cgi?ID=64-17-5>

Figura 27 - Estrutura molecular, fórmula molecular e espectro de massas da água.

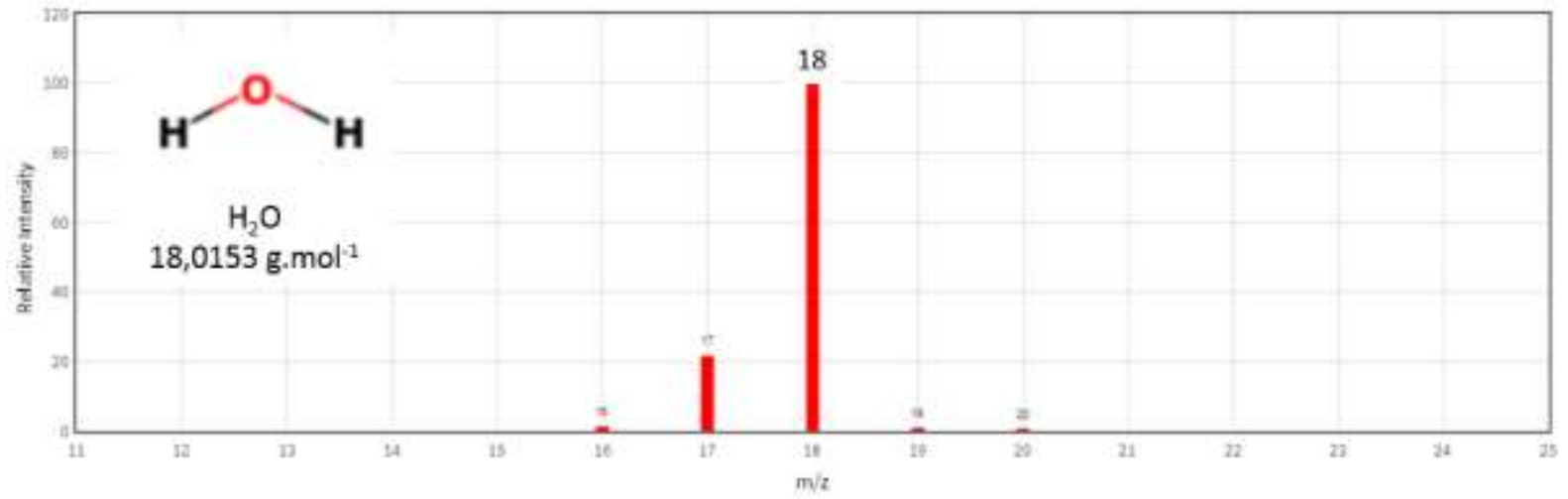

Fonte: adaptado de NIST - Water. Disponível em:

$<$ https://webbook.nist.gov/cgi/cbook.cgi?Name=water\&Units=SI> 
Os experimentos de validação são realizados com uma quantidade maior de repetições que as análises de rotina pois essas condições retornam uma faixa de valores com uma probabilidade mais assertiva do valor real.

\subsubsection{Validação do método usado para a caracterização da amostra candidata a material de referência (MR)}

Para o estudo de precisão intermediária, foram realizadas duas curvas de calibração com um intervalo de 4 dias. Como o objetivo do método é quantificar o teor de CE próximo ao limite da legislação para aprovação ou reprovação de amostras de fiscalização, a incerteza da linearidade foi calculada para a concentração alvo da legislação para CE $(210 \mu \mathrm{g} / \mathrm{L})$ regulamentada pela Instrução Normativa № 28 de 08 de agosto de 2014 (BRASIL, 2014), mesma concentração alvo da produção do candidato a MR; no método validado, corresponde ao P3 $(210 \mu \mathrm{g} / \mathrm{L})$ da curva de calibração. Todas as análises estatísticas realizadas são apresentadas a seguir:

Tabela 9 - Valores experimentais para a primeira curva de calibração (IQSC/USP).

\begin{tabular}{c|c|c|c|c|c|}
\hline $\begin{array}{c}\text { Nível de } \\
\text { concentração } \\
(\boldsymbol{\mu g} / \mathbf{L})\end{array}$ & \multicolumn{5}{|c|}{ Sinais das replicatas (área) } \\
\hline $\mathbf{1 0 0}$ & 9033,1 & 9615,1 & 9595,1 & 11545 & 11570 \\
\hline $\mathbf{2 1 0}$ & 19932 & 16471 & 17335 & 20014 & 14906 \\
\hline $\mathbf{2 6 5}$ & 23296 & 22353 & 20357 & 18465 & 18811 \\
\hline $\mathbf{3 2 0}$ & 21826 & 25505 & 23519 & 23163 & 25722 \\
\hline $\mathbf{3 6 8}$ & 30397 & 32264 & 28194 & 23845 & 27136 \\
\hline
\end{tabular}

Fonte: autoria própria. 
Figura 28 - Gráfico da linearidade para a primeira curva de calibração (IQSC/USP).

\section{Linearidade}

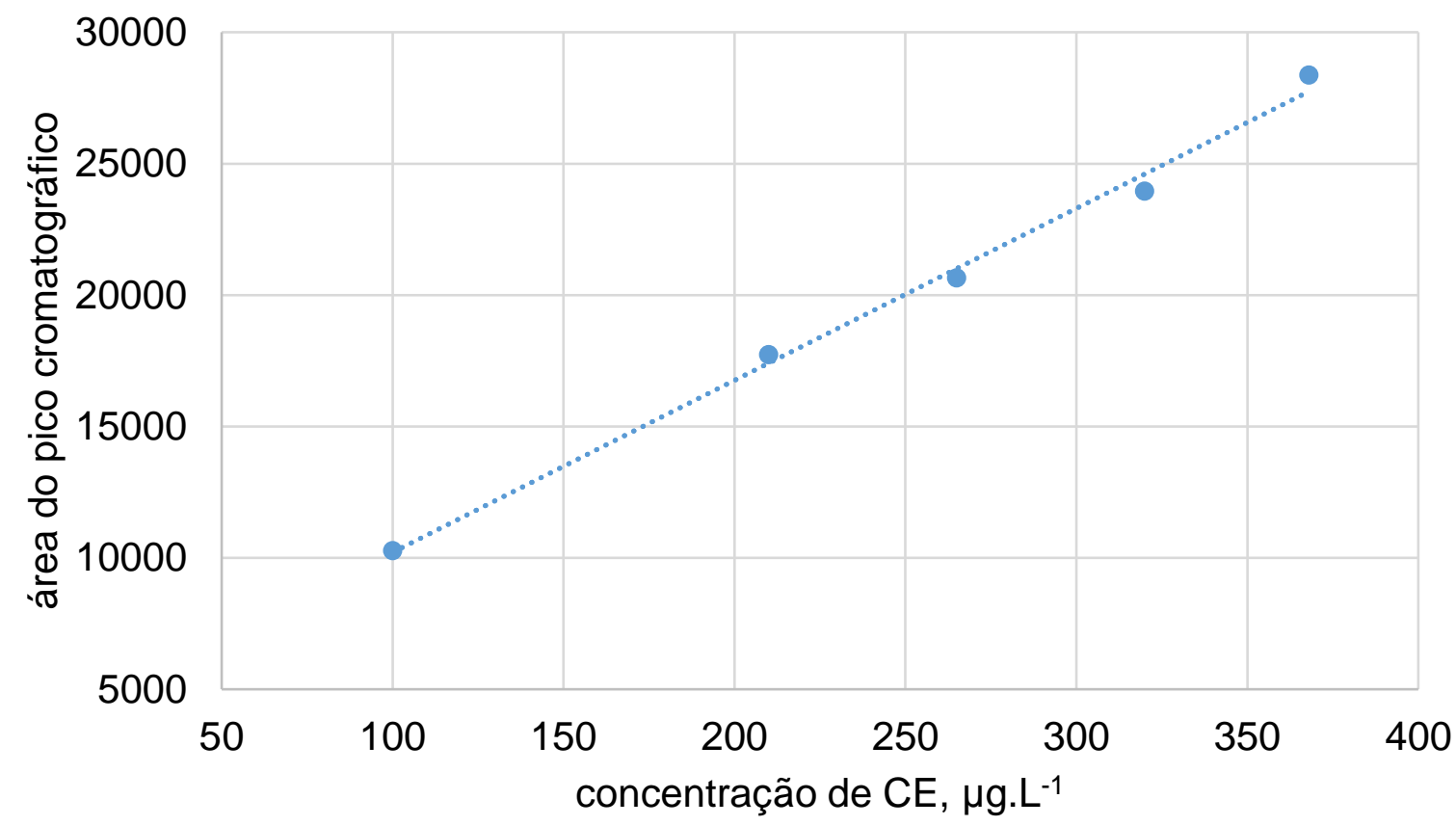

Fonte: autoria própria, gerado por Microsoft Excel $2013 \AA$.

Tabela 10 - Parâmetros de desempenho para a primeira curva de calibração (IQSC/USP).

\begin{tabular}{|c|c|c|c|c|c|}
\hline \multicolumn{6}{|c|}{ Avaliação da Homocedasticidade (Teste de Cochran) } \\
\hline \multirow{2}{*}{\multicolumn{2}{|c|}{\begin{tabular}{|c|} 
Calculado \\
Tabelado
\end{tabular}}} & 0,43 & \multicolumn{3}{|c|}{ Homocedástico } \\
\hline & & \multirow{2}{*}{$\frac{0,54}{\text { Test de Grubbs: }}$} & \multicolumn{3}{|c|}{ (MMQO) $y=65,43 x+3667,68$} \\
\hline \multicolumn{2}{|c|}{$\begin{array}{c}\text { Tabelado } \\
\text { Outlier para resíduos por nível }\end{array}$} & & \multicolumn{2}{|c|}{ Nenhum outiler } & \\
\hline $\begin{array}{c}\text { Parâmetros de } \\
\text { desempenho }\end{array}$ & $\begin{array}{c}\text { Critério de } \\
\text { aceitabiliddade }\end{array}$ & \multicolumn{3}{|c|}{ Valor obtido } & Aprovação \\
\hline LQ & $\begin{array}{c}10 \times \text { desvio } \\
\text { padrão da } \\
\text { amostra branca }\end{array}$ & \multicolumn{3}{|c|}{ valor < que P1 da curva } & Sim \\
\hline Linearidade & $r \geq 0,99$ & \multicolumn{3}{|c|}{0,9972} & Sim \\
\hline \multirow{5}{*}{$\begin{array}{c}\text { Precisão } \\
\text { (repetibilidade) }\end{array}$} & \multirow{5}{*}{$\begin{array}{l}\text { CV } \leq 20 \% \text { em } \\
\text { cada nível }\end{array}$} & 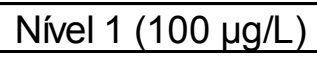 & \multicolumn{2}{|c|}{$11,65 \%$} & Sim \\
\hline & & Nível $2(210 \mu \mathrm{g} / \mathrm{L})$ & \multicolumn{2}{|c|}{$12,54 \%$} & Sim \\
\hline & & Nível $3(265 \mu \mathrm{g} / \mathrm{L})$ & \multicolumn{2}{|c|}{$10,31 \%$} & Sim \\
\hline & & Nível $4(320 \mu \mathrm{g} / \mathrm{L})$ & \multicolumn{2}{|c|}{$6,89 \%$} & Sim \\
\hline & & Nível $5(368 \mu \mathrm{g} / \mathrm{L})$ & \multicolumn{2}{|c|}{$11,33 \%$} & $\operatorname{Sim}$ \\
\hline \multirow{6}{*}{ Exatidão } & \multirow{6}{*}{$\begin{array}{l}\text { CV } \leq 20 \% \text { em } \\
\text { cada nível }\end{array}$} & Nível & Desvio & CV & Aprovação \\
\hline & & $100 \mu \mathrm{g} / \mathrm{L}$ & $\pm 1,86 \%$ & $18,79 \%$ & Sim \\
\hline & & $210 \mu \mathrm{g} / \mathrm{L}$ & $\pm 1,46 \%$ & $16,08 \%$ & Sim \\
\hline & & $265 \mu \mathrm{g} / \mathrm{L}$ & $\pm 2,59 \%$ & $12,71 \%$ & Sim \\
\hline & & $320 \mu \mathrm{g} / \mathrm{L}$ & $\pm 3,49 \%$ & $8,23 \%$ & Sim \\
\hline & & $368 \mu \mathrm{g} / \mathrm{L}$ & $\pm 2,42 \%$ & $13,13 \%$ & Sim \\
\hline
\end{tabular}

Fonte: autoria própria, produzido com o software Conflab Validação®. 
Tabela 11 - Valores experimentais para a segunda curva de calibração (IQSC/USP).

\begin{tabular}{|c|c|c|c|c|c|}
\hline \multirow{2}{*}{$\begin{array}{c}\begin{array}{c}\text { Nível de } \\
\text { concentração } \\
(\mu \mathrm{g} / \mathrm{L})\end{array} \\
100 \\
\end{array}$} & \multicolumn{5}{|c|}{ Sinais das replicatas (área) } \\
\hline & 9554 & 10391 & 9789 & 9839 & 10944 \\
\hline 155 & 12731 & 14602 & 13135 & 10732 & 11312 \\
\hline 210 & 17597 & 20574 & 17171 & 14979 & 14673 \\
\hline 265 & 25255 & 19443 & 18126 & 16979 & 20928 \\
\hline 320 & 23837 & 23629 & 22749 & 24167 & 23521 \\
\hline
\end{tabular}

Fonte: autoria própria.

Figura 29 - Gráfico da linearidade para a segunda curva de calibração (IQSC/USP).

\section{Linearidade}

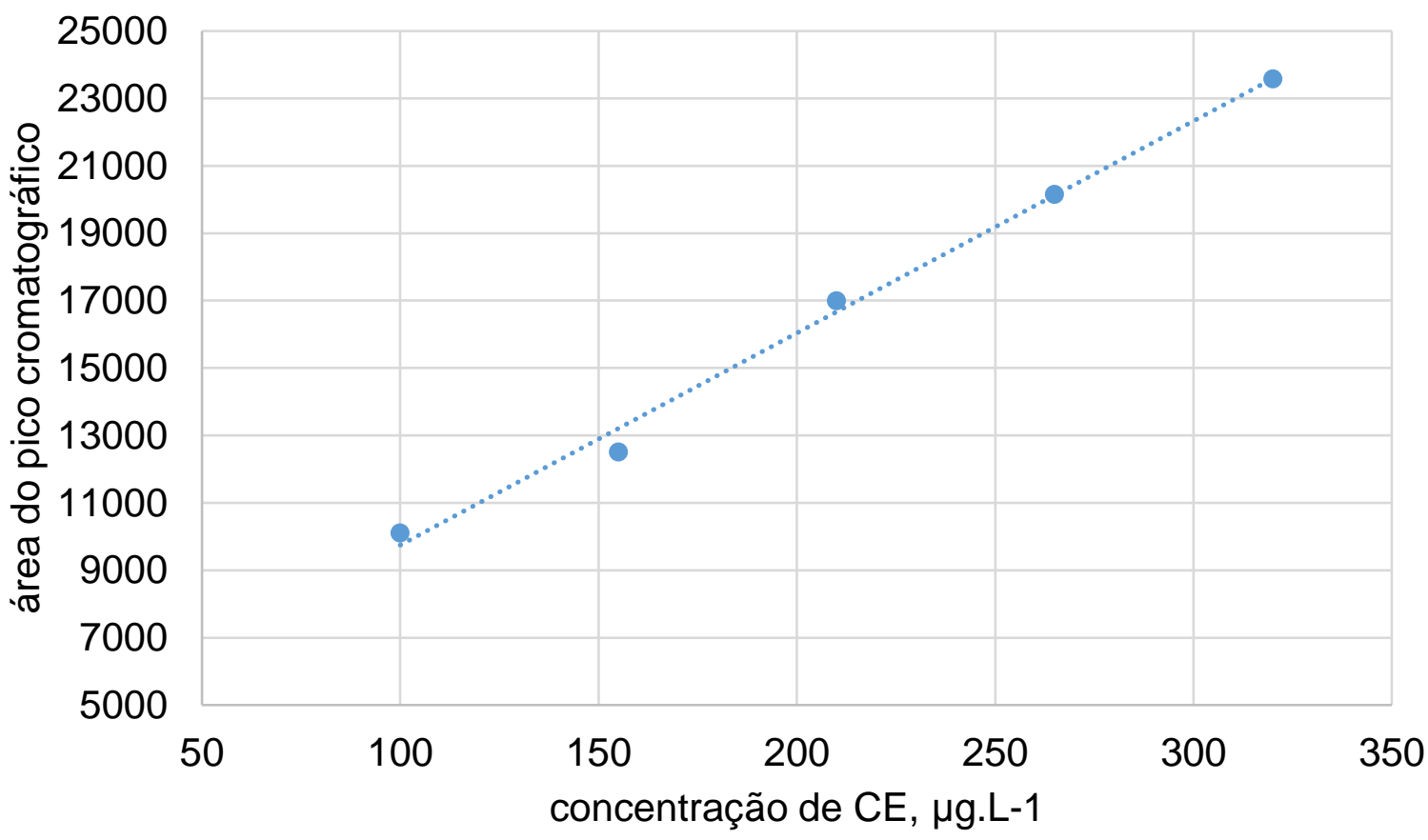

Fonte: autoria própria, gerado por Microsoft Excel 2013®.

Conforme o teste de Cochran (Tabela 12) os valores calculados e tabelados foram muito próximos, mas ainda assim indicaram heterocedasticidade dos resíduos como pode ser observado pela Figura 30. Essa figura, principalmente para os resíduos absolutos, pode ser correlacionada com os conceitos da Figura 7, sobre como 0 aumento da concentração do analito pode também aumentar a dispersão dos dados e o aumento da incerteza dentro da curva de calibração. 
Tabela 12 - Parâmetros de desempenho para a segunda curva de calibração (IQSC/USP).

\begin{tabular}{|c|c|c|c|c|c|}
\hline \multicolumn{6}{|c|}{ Avaliação da Homocedasticidade (Teste de Cochran) } \\
\hline \multirow{2}{*}{\multicolumn{2}{|c|}{$\begin{array}{l}\text { Calculado } \\
\text { Tabelado }\end{array}$}} & 0,55 & \multicolumn{3}{|c|}{ Heterocedástico } \\
\hline & & 0,54 & \multicolumn{3}{|c|}{ (MMQP) $y=61,55 x+3863,96$} \\
\hline \multicolumn{2}{|c|}{ Outlier para resíduos por nível } & Test de Grubbs: & \multicolumn{2}{|c|}{ Nenhum outiler } & \\
\hline $\begin{array}{l}\text { Parâmetros de } \\
\text { desempenho }\end{array}$ & $\begin{array}{c}\text { Critério de } \\
\text { aceitabiliddade }\end{array}$ & \multicolumn{3}{|c|}{ Valor obtido } & Aprovação \\
\hline LQ & $\begin{array}{c}10 \times \text { desvio } \\
\text { padrão da } \\
\text { amostra branca }\end{array}$ & \multicolumn{3}{|c|}{ valor < que P1 da curva } & Sim \\
\hline Linearidade & $r \geq 0,99$ & \multicolumn{3}{|c|}{0,9994} & Sim \\
\hline \multirow{5}{*}{$\begin{array}{c}\text { Precisão } \\
\text { (repetibilidade) }\end{array}$} & \multirow{5}{*}{$\begin{array}{c}\text { CV } \leq 20 \% \text { em } \\
\text { cada nível }\end{array}$} & Nível $1(100 \mu \mathrm{g} / \mathrm{L})$ & \multicolumn{2}{|c|}{$5,55 \%$} & Sim \\
\hline & & Nível $2(155 \mu \mathrm{g} / \mathrm{L})$ & \multicolumn{2}{|c|}{$12,27 \%$} & Sim \\
\hline & & Nível $3(210 \mu \mathrm{g} / \mathrm{L})$ & \multicolumn{2}{|c|}{$14,00 \%$} & Sim \\
\hline & & Nível $4(265 \mu \mathrm{g} / \mathrm{L})$ & \multirow{2}{*}{\multicolumn{2}{|c|}{$\frac{15,95 \%}{2.23 \%}$}} & Sim \\
\hline & & Nível $5(320 \mu \mathrm{g} / \mathrm{L})$ & & & Sim \\
\hline \multirow{6}{*}{ Exatidão } & \multirow{6}{*}{$\begin{array}{c}\mathrm{CV} \leq 20 \% \text { em } \\
\text { cada nível }\end{array}$} & Nível & $\begin{array}{c}\text { Desvio } \\
\text { padrão (s) }\end{array}$ & CV & Aprovação \\
\hline & & $100 \mu \mathrm{g} / \mathrm{L}$ & $\pm 6,87 \%$ & $8,35 \%$ & Sim \\
\hline & & $155 \mu \mathrm{g} / \mathrm{L}$ & $\pm 6,45 \%$ & $16,82 \%$ & Sim \\
\hline & & $210 \mu \mathrm{g} / \mathrm{L}$ & $\pm 3,09 \%$ & $17,48 \%$ & Sim \\
\hline & & $265 \mu \mathrm{g} / \mathrm{L}$ & $\pm 0,57 \%$ & $19,17 \%$ & Sim \\
\hline & & $320 \mu \mathrm{g} / \mathrm{L}$ & $\pm 0,35 \%$ & $2,60 \%$ & Sim \\
\hline
\end{tabular}

Fonte: autoria própria, produzido com o software Conflab Validação®.

Figura 30 - Representação gráfica do comportamento dos resíduos na segunda curva de calibração comprovando a heterocedasticidade (IQSC/USP).

RESIDUOS ABSOLUTOS

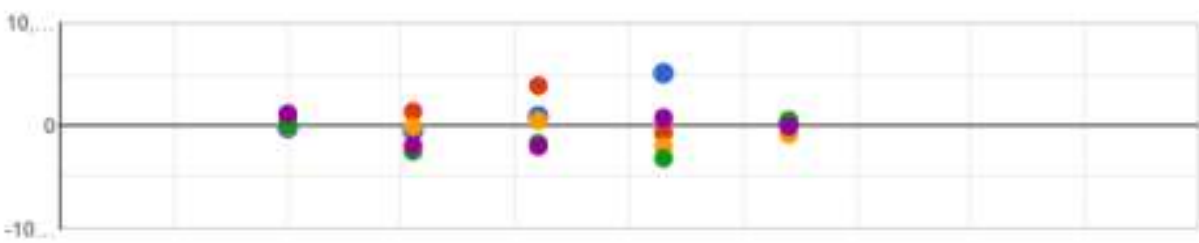

RESIDUOS RELATINOS

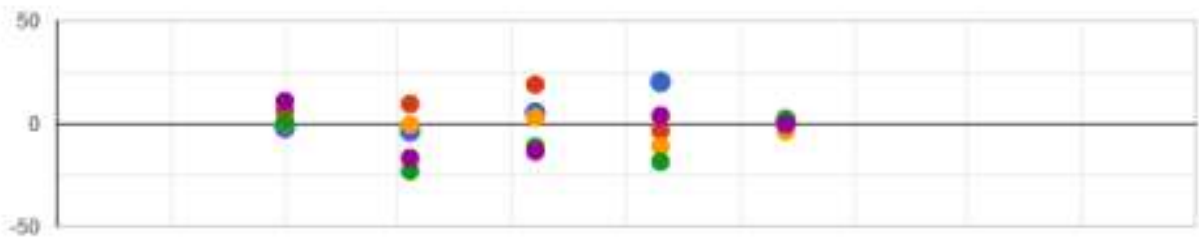

Fonte: autoria própria, produzido com o software Conflab Validação®.

Em caso de heterocedasticidade, as equações para os cálculos ponderados aplicadas pelo software Conflab Validação® são distintas das mencionadas no tópico 2.4.2 e seguem descritas a seguir: 
- Coeficiente angular ponderado, inclinação ponderada $\left(\mathrm{m}_{\mathrm{w}}\right)$

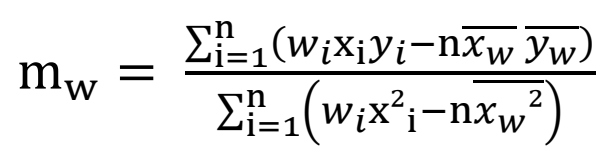

Equação 46

- Coeficiente linear ponderado, intercepto ponderado $\left(b_{w}\right)$

$$
\mathrm{b}_{\mathrm{w}}=\overline{\mathrm{y}_{\mathrm{w}}}-\mathrm{m} \overline{\mathrm{x}_{\mathrm{w}}}
$$

- Coeficiente de correlação da regressão ponderada ( $\left.r_{w}\right)$

$$
r_{w}=\frac{\sum_{i=1}^{n} w_{i} \sum_{i=1}^{n} w_{i} x_{1} y_{i}-\sum_{i=1}^{n} w_{i} x_{i} \sum_{i=1}^{n} w_{i} y_{i}}{\sqrt{\left[\sum_{i=1}^{n} w_{i} \sum_{i=1}^{n} w_{i} x^{2}{ }_{i}-\left(\sum_{i=1}^{n} w_{i} x_{i}\right)^{2}\right]\left[\sum_{i=1}^{n} w_{i} \sum_{i=1}^{n} w_{i} y_{i}^{2}-\left(\sum_{i=1}^{n} w_{i} y_{i}\right)^{2}\right]}}
$$

Equação 48

Sendo que wi são os pesos adotados para o cálculo. Existem algumas formas de calcular esse peso. O caso mais recorrente em química analítica é o que as variâncias são diretamente proporcionais aos valores da variável estudada ( $\mathrm{x}$ ); adotase peso na forma de $1 / x$. Quando há réplicas de ensaios, utiliza-se o inverso do quadrado da variância de cada réplica dos valores experimentais $\left(\mathrm{si}^{2}\right)$ como peso. Portanto, sendo "p" o número de ensaios:

$$
\mathrm{w}_{\mathrm{i}}=\mathrm{p} \frac{1 / \mathrm{s}_{\mathrm{i}}^{2}}{\sum_{\mathrm{i}=1}^{\mathrm{n}} 1 / \mathrm{s}_{\mathrm{i}}^{2}}
$$

Tabela 13 - Precisão intermediária do método validado no IQSC/USP.

\begin{tabular}{|c|c|c|c|}
\hline $\begin{array}{c}\text { Critério de } \\
\text { aceitabilidade }\end{array}$ & Nível & $\begin{array}{c}\text { Valor } \\
\text { obtido }\end{array}$ & Aprovação \\
\hline \multirow{4}{*}{$\begin{array}{c}\text { CV } \leq 20 \% \text { em } \\
\text { cada nível }\end{array}$} & $100 \mu \mathrm{g} / \mathrm{L}$ & $14,27 \%$ & Sim \\
\cline { 2 - 4 } & $155 \mu \mathrm{g} / \mathrm{L}$ & $15,71 \%$ & Sim \\
\cline { 2 - 4 } & $210 \mu \mathrm{g} / \mathrm{L}$ & $16,83 \%$ & Sim \\
\cline { 2 - 4 } & $265 \mu \mathrm{g} / \mathrm{L}$ & $12,67 \%$ & Sim \\
\cline { 2 - 4 } & $320 \mu \mathrm{g} / \mathrm{L}$ & $4,92 \%$ & Sim \\
\cline { 2 - 4 } & $368 \mu \mathrm{g} / \mathrm{L}$ & $18,86 \%$ & Sim \\
\hline
\end{tabular}

Fonte: autoria própria.

O cálculo da incerteza foi realizado considerando os parâmetros da primeira curva (usada para a análise de background da matriz e para o cálculo do valor de fortificação para a produção do lote, vide tópico 5.2.1.). Foram consideradas as incertezas da linearidade e da precisão de repetibilidade no nível $210 \mu \mathrm{g} / \mathrm{L}$, que é o valor alvo do valor de propriedade para o MR a ser produzido. $O$ fator de expansão 
considerado foi o t de Student para 4 graus de liberdade em um nível de $95 \%$ de confiança igual a 2,78 (correspondente às análises em quintuplicatas) conforme orientado pelo Brasil (2015).

Tabela 14 - Incertezas padrão e expandidas do método IQSC/USP.

\begin{tabular}{|c|c|c|}
\hline Fonte & $\begin{array}{l}\text { Incerteza } \\
\text { padrão }\end{array}$ & $\begin{array}{l}\text { Incerteza } \\
\text { padrão } \\
\text { percentual }\end{array}$ \\
\hline Linearidade & $14,48 \mu \mathrm{g} / \mathrm{L}$ & $6,90 \%$ \\
\hline $\begin{array}{c}\text { Precisão } \\
\text { (repetibilidade) }\end{array}$ & $26,33 \mu \mathrm{g} / \mathrm{L}$ & $12,54 \%$ \\
\hline $\begin{array}{c}\text { Incerteza } \\
\text { padrão } \\
\text { percentual em } \\
210 \mu \mathrm{g} / \mathrm{L} \\
\end{array}$ & $\begin{array}{c}\text { Fator de } \\
\text { expansão } \\
\text { normal, } k\end{array}$ & $\begin{array}{c}\text { Incerteza } \\
\text { expandida, U }\end{array}$ \\
\hline $14,31 \%$ & 2 & $28,62 \%$ \\
\hline $\begin{array}{c}\text { Incerteza } \\
\text { padrão } \\
\text { percentual em } \\
210 \mu \mathrm{g} / \mathrm{L}\end{array}$ & $\begin{array}{l}\text { Fator de } \\
\text { expansão } \\
\text { T Student }\end{array}$ & $\begin{array}{c}\text { Incerteza } \\
\text { expandida, U }\end{array}$ \\
\hline $14,31 \%$ & 2,78 & $39,78 \%$ \\
\hline
\end{tabular}

Fonte: autoria própria.

Todas as análises comprovaram que o método foi validado e que é apto para ser utilizado para a caracterização do candidato a MR. 


\subsubsection{Validação do método desenvolvido para o Laboratório Federal de Defesa Agropecuária (LFDA-SP), Seção Laboratorial Avançada de análises físico-químicas de bebidas e vinagres (SLAV/BEB Jundiaí)}

Como anteriormente, para o estudo de precisão intermediária foram realizadas duas curvas de calibração, mas desta vez com analistas diferentes em um intervalo de 29 dias para a realização do estudo da precisão intermediária. A incerteza da linearidade foi calculada para a concentração alvo da legislação para CE $(210 \mu \mathrm{g} / \mathrm{L})$ regulamentada pela Instrução Normativa № 28 de 08 de agosto de 2014 (BRASIL,

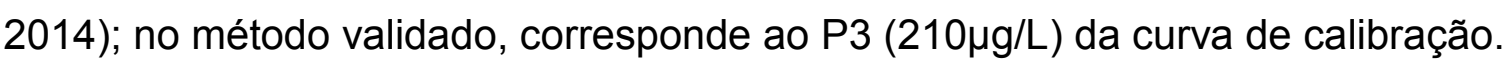

Tabela 15 - Parâmetros de desempenho para a primeira curva de calibração (LFDA-SP)

\begin{tabular}{|c|c|c|c|c|c|}
\hline \multicolumn{6}{|c|}{ Avaliação da Homocedasticidade (Teste de Cochran) } \\
\hline \multicolumn{2}{|c|}{ Calculado } & 0,62 & \multicolumn{3}{|c|}{ Heterocedástico } \\
\hline \multirow{2}{*}{\multicolumn{2}{|c|}{$\begin{array}{c}\text { Tabelado } \\
\text { Outlier para resíduos por nível }\end{array}$}} & 0,60 & \multicolumn{3}{|c|}{ (MMQP) $y=191,19 x+14,54$} \\
\hline & & Test de Grubbs: & \multicolumn{2}{|c|}{ Nenhum outiler } & \\
\hline $\begin{array}{l}\text { Parâmetros de } \\
\text { desempenho }\end{array}$ & $\begin{array}{c}\text { Critério de } \\
\text { aceitabiliddade }\end{array}$ & \multicolumn{3}{|c|}{ Valor obtido } & Aprovação \\
\hline LQ & $\begin{array}{c}10 \times \text { desvio } \\
\text { padrão da } \\
\text { amostra branca }\end{array}$ & \multicolumn{3}{|c|}{$\begin{array}{c}1,609 \mu \mathrm{g} / \mathrm{L} \\
\text { valor }<\text { que P1 da curva }\end{array}$} & Sim \\
\hline Linearidade & $r \geq 0,99$ & \multicolumn{3}{|c|}{0,999} & Sim \\
\hline \multirow{5}{*}{$\begin{array}{c}\text { Precisão } \\
\text { (repetibilidade) } \\
\text { e Linearidade }\end{array}$} & \multirow{5}{*}{$\begin{array}{l}\text { CV } \leq 20 \% \text { em } \\
\text { cada nível }\end{array}$} & Nível $1(100 \mu \mathrm{g} / \mathrm{L})$ & \multicolumn{2}{|c|}{$11,37 \%$} & Sim \\
\hline & & Nível $2(155 \mu \mathrm{g} / \mathrm{L})$ & \multicolumn{2}{|c|}{$14,19 \%$} & Sim \\
\hline & & Nível $3(210 \mu \mathrm{g} / \mathrm{L})$ & \multicolumn{2}{|c|}{$10,01 \%$} & Sim \\
\hline & & Nível $4(320 \mu \mathrm{g} / \mathrm{L})$ & \multirow{2}{*}{\multicolumn{2}{|c|}{$\begin{array}{l}13,70 \% \\
19,12 \%\end{array}$}} & Sim \\
\hline & & Nível $5(368 \mu \mathrm{g} / \mathrm{L})$ & & & Sim \\
\hline \multirow{6}{*}{ Exatidão } & \multirow{6}{*}{$\begin{array}{l}\mathrm{CV} \leq 20 \% \text { em } \\
\text { cada nível }\end{array}$} & Nível & $\begin{array}{c}\text { Desvio } \\
\text { padrão (s) }\end{array}$ & CV & Aprovação \\
\hline & & $100 \mu \mathrm{g} / \mathrm{L}$ & $\pm 1,22 \%$ & $11,36 \%$ & Sim \\
\hline & & $155 \mu \mathrm{g} / \mathrm{L}$ & $\pm 4,23 \%$ & $14,18 \%$ & Sim \\
\hline & & $210 \mu \mathrm{g} / \mathrm{L}$ & $\pm 1,44 \%$ & $10,01 \%$ & Sim \\
\hline & & $320 \mu \mathrm{g} / \mathrm{L}$ & $\pm 0,73 \%$ & $13,69 \%$ & Sim \\
\hline & & $368 \mu \mathrm{g} / \mathrm{L}$ & $\pm 0,51 \%$ & $19,12 \%$ & Sim \\
\hline
\end{tabular}

Fonte: autoria própria, produzido com o software Conflab Validação®. 
Tabela 16 - Parâmetros de desempenho para a segunda curva de calibração (LFDA/SP).

\begin{tabular}{|c|c|c|c|c|c|}
\hline \multicolumn{6}{|c|}{ Avaliação da Homocedasticidade (Teste de Cochran) } \\
\hline \multirow{2}{*}{\multicolumn{2}{|c|}{$\begin{array}{l}\text { Calculado } \\
\text { Tabelado }\end{array}$}} & 0,69 & \multicolumn{3}{|c|}{ Heterocedástico } \\
\hline & & 0,60 & \multicolumn{3}{|c|}{ (MMQO) $y=259,20 x+25427,14$} \\
\hline \multicolumn{2}{|c|}{ Outlier para resíduos por nível } & Test de Grubbs: & Nenhul & utiler & \\
\hline $\begin{array}{l}\text { Parâmetros de } \\
\text { desempenho }\end{array}$ & $\begin{array}{c}\text { Critério de } \\
\text { aceitabiliddade }\end{array}$ & \multicolumn{3}{|c|}{ Valor obtido } & Aprovação \\
\hline LQ & $\begin{array}{c}10 \times \text { desvio } \\
\text { padrão da } \\
\text { amostra branca }\end{array}$ & \multicolumn{3}{|c|}{$\begin{array}{c}102,629 \mu \mathrm{g} / \mathrm{L} \\
\text { valor }<\mathrm{P} 1 \text { da curva }\end{array}$} & Sim \\
\hline Linearidade & $r \geq 0,99$ & \multicolumn{3}{|c|}{0,990} & Sim \\
\hline \multirow{5}{*}{$\begin{array}{c}\text { Precisão } \\
\text { (repetibilidade) e } \\
\text { Linearidade }\end{array}$} & \multirow{5}{*}{$\begin{array}{c}\mathrm{CV} \leq 20 \% \text { em } \\
\text { cada nível }\end{array}$} & Nível $1(155 \mu \mathrm{g} / \mathrm{L})$ & \multirow{2}{*}{\multicolumn{2}{|c|}{ 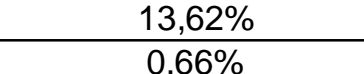 }} & Sim \\
\hline & & Nível $2(210 \mu \mathrm{g} / \mathrm{L})$ & & & Sim \\
\hline & & Nível $3(265 \mu \mathrm{g} / \mathrm{L})$ & \multicolumn{2}{|c|}{$7,67 \%$} & Sim \\
\hline & & Nível $4(320 \mu \mathrm{g} / \mathrm{L})$ & \multicolumn{2}{|c|}{$8,68 \%$} & Sim \\
\hline & & Nível 5 (368 $\mu \mathrm{g} / \mathrm{L})$ & \multicolumn{2}{|c|}{$14,66 \%$} & Sim \\
\hline \multirow{6}{*}{ Exatidão } & \multirow{6}{*}{$\begin{array}{l}\text { CV } \leq 20 \% \text { em } \\
\text { cada nível }\end{array}$} & Nível & $\begin{array}{c}\text { Desvio } \\
\text { padrão (s) }\end{array}$ & cV & Aprovação \\
\hline & & $155 \mu \mathrm{g} / \mathrm{L}$ & $\pm 5,33 \%$ & $5,43 \%$ & Sim \\
\hline & & $210 \mu \mathrm{g} / \mathrm{L}$ & $\pm 4,14 \%$ & $3,62 \%$ & Sim \\
\hline & & $265 \mu \mathrm{g} / \mathrm{L}$ & $\pm 1,02 \%$ & $4,86 \%$ & Sim \\
\hline & & $320 \mu \mathrm{g} / \mathrm{L}$ & $\pm 5,35 \%$ & $6,15 \%$ & Sim \\
\hline & & $368 \mu \mathrm{g} / \mathrm{L}$ & $\pm 1,44 \%$ & $10,81 \%$ & Sim \\
\hline
\end{tabular}

Fonte: autoria própria, produzido com o software Conflab Validação®.

Tabela 17 - Precisão intermediária do método validado no LFDA/SP.

\begin{tabular}{c|c|c|c}
\hline $\begin{array}{c}\text { Critério de } \\
\text { aceitabilidade }\end{array}$ & Nível & $\begin{array}{c}\text { Valor } \\
\text { obtido }\end{array}$ & Aprovação \\
\hline \multirow{4}{*}{$\begin{array}{c}\text { CV } \leq 20 \% \text { em } \\
\text { cada nível }\end{array}$} & $100 \mu \mathrm{g} / \mathrm{L}$ & $15,45 \%$ & Sim \\
\cline { 2 - 4 } & $155 \mu \mathrm{g} / \mathrm{L}$ & $3,75 \%$ & $\mathrm{Sim}$ \\
\cline { 2 - 4 } & $210 \mu \mathrm{g} / \mathrm{L}$ & $6,65 \%$ & $\mathrm{Sim}$ \\
\cline { 2 - 4 } & $265 \mu \mathrm{g} / \mathrm{L}$ & $7,26 \%$ & $\mathrm{Sim}$ \\
\cline { 2 - 4 } & $320 \mu \mathrm{g} / \mathrm{L}$ & $7,03 \%$ & $\mathrm{Sim}$ \\
\cline { 2 - 4 } & $368 \mu \mathrm{g} / \mathrm{L}$ & $11,94 \%$ & $\mathrm{Sim}$ \\
\hline
\end{tabular}

Fonte: autoria própria.

Se o CE estiver abaixo de $210 \mu \mathrm{g} / \mathrm{L}$, independente se é nível traço ou não, a amostra já foi aprovada; caso a amostra esteja com altos teores de CE e seja necessário fazer a quantificação, recomenda-se a diluição da amostra para os limites da curva de calibração e realizar a quantificação por meio dos fatores de diluição.

O cálculo da incerteza do método considerou a incerteza da linearidade e a incerteza da precisão intermediária no nível $210 \mu \mathrm{g} / \mathrm{L}$, que é o valor crítico de aprovação ou reprovação das amostras de fiscalização analisadas pelos LFDAs. Diferentemente da caraterização do candidato a MR, esse método será utilizado na rotina do laboratório federal e é importante considerar a incerteza da precisão 
intermediária. Por isso, a incerteza do método também foi realizada com os valores da precisão da segunda curva, realizada por um funcionário do LFDA/SP. Nesse caso, o coeficiente de expansão utilizado é o $t$ de Student para 9 graus de liberdade com $95 \%$ de confiança no valor de 2,26, correspondente ao desvio de 10 ensaios realizados no estudo de precisão intermediária.

Tabela 18 - Incertezas padrão e expandidas do método LFDA/SP.

\begin{tabular}{|c|c|c|}
\hline Fonte & $\begin{array}{c}\text { Incerteza } \\
\text { padrão }\end{array}$ & $\begin{array}{c}\text { Incerteza } \\
\text { padrão } \\
\text { percentual }\end{array}$ \\
\hline Linearidade & $8,08 \mu \mathrm{g} / \mathrm{L}$ & $3,85 \%$ \\
\hline $\begin{array}{c}\text { Precisão } \\
\text { Intermediária em } \\
210 \mu \mathrm{g} / \mathrm{L}\end{array}$ & $14,15 \mu \mathrm{g} / \mathrm{L}$ & $6,74 \%$ \\
\hline $\begin{array}{c}\text { Incerteza padrão } \\
\text { percentual em } \\
210 \mu \mathrm{g} / \mathrm{L}\end{array}$ & $\begin{array}{c}\text { Fator de } \\
\text { expansão } \\
\text { normal, } k\end{array}$ & $\begin{array}{c}\text { Incerteza } \\
\text { expandida, U }\end{array}$ \\
\hline $7,76 \%$ & 2 & $15,52 \%$ \\
\hline $\begin{array}{c}\text { Incerteza padrão } \\
\text { percentual em } \\
210 \mu \mathrm{g} / \mathrm{L}\end{array}$ & $\begin{array}{l}\text { Fator de } \\
\text { expansão T } \\
\text { Student }\end{array}$ & $\begin{array}{c}\text { Incerteza } \\
\text { expandida, } U\end{array}$ \\
\hline $7,76 \%$ & 2,26 & $17,54 \%$ \\
\hline
\end{tabular}

Fonte: autoria própria.

Nota-se que a incerteza do método IQSC/USP RQALab (39,78\%) é maior que o validado no LFDA/SP-SLAV/BEB Jundiaí (17,54\%). Essa diferença era esperada visto que os cromatógrafo dos laboratórios de pesquisa das universidades não são de uso exclusivo para um único analito e matriz como acontece com parte dos equipamentos dos laboratórios federais, caso da análise de CE pelo LFDA/SP.

Todas as análises comprovaram que o método foi validado e que é apto para ser utilizado na rotina do LFDA/SP-SLAV/BEB Jundiaí. O relatório completo do desenvolvimento do método e da validação do mesmo foi elaborado e enviado para os auditores fiscais responsáveis pela unidade. 


\subsection{PRODUÇÃO DO MATERIAL DE REFERÊNCIA}

\subsubsection{CARACTERIZAÇÃO DO MATERIAL DE REFERÊNCIA (MÉTODO IQSC/USP RQA Lab)}

Por solicitação do LFDA/SP, o material de referência deveria ser produzido na matriz cachaça não adoçada, portanto, já se esperava uma quantidade inicial de $\mathrm{CE}$ na matriz. Isto posto, no mesmo dia que a primeira curva de calibração foi feita, analisou-se em quintuplicata o teor de CE presente na matriz. Os dados da Tabela 19 foram calculados com base nos parâmetros apresentados na Tabela 10.

Tabela 19 - Background do teor de CE na matriz.

\begin{tabular}{c|cccc|c|c|}
\hline Ensaio & $\mathbf{1}$ & $\mathbf{2}$ & $\mathbf{3}$ & $\mathbf{4}$ & $\mathbf{5}$ & Média \\
\hline Área & 5390 & 8705 & 8114 & 6185 & 7390 & 7156,80 \\
\hline \multicolumn{7}{c}{} \\
\hline
\end{tabular}

Fonte: autoria própria.

A amostra cedida pela Companhia Müller de Bebidas, utilizada para a produção do MR apresentou um valor de background de 53,326 $\mu \mathrm{g} / \mathrm{L}$ de CE, ou seja, 156,674 $\mu \mathrm{g}$ abaixo do limite da legislação, sendo necessário fortificar a matriz com CE para obtermos um material com concentração próxima ao limite da legislação. Portanto, $250 \mathrm{~mL}$ da matriz foram fortificados com $39 \mu \mathrm{L}$ da solução estoque na concentração de 1g/L de CE. Essa solução foi produzia no mesmo dia que a segunda curva de calibração do método IQSC/USP RQA Lab e analisada em 7 ensaios. Os dados da Tabela 20 foram calculados com base nos parâmetros apresentados na Tabela 12.

Tabela 20 - Caracterização do valor de propriedade após a fortificação.

\begin{tabular}{|c|c|c|c|c|c|c|c|c|}
\hline Ensaio & $\mathbf{1}$ & $\mathbf{2}$ & $\mathbf{3}$ & $\mathbf{4}$ & $\mathbf{5}$ & $\mathbf{6}$ & $\mathbf{7}$ & \multirow{2}{*}{ Média } \\
\hline Área & 18589 & 18942 & 17097 & 18027 & 18725 & 18507 & 19066 & \\
\hline [CE] $\boldsymbol{\mu g} / \mathbf{L}$ & 239,24 & 244,97 & 215,00 & 230,11 & 241,45 & 237,90 & 246,99 & 236,52 \\
\hline
\end{tabular}

Fonte: autoria própria.

Figura 31 - Fontes de incerteza consideradas na caracterização. 


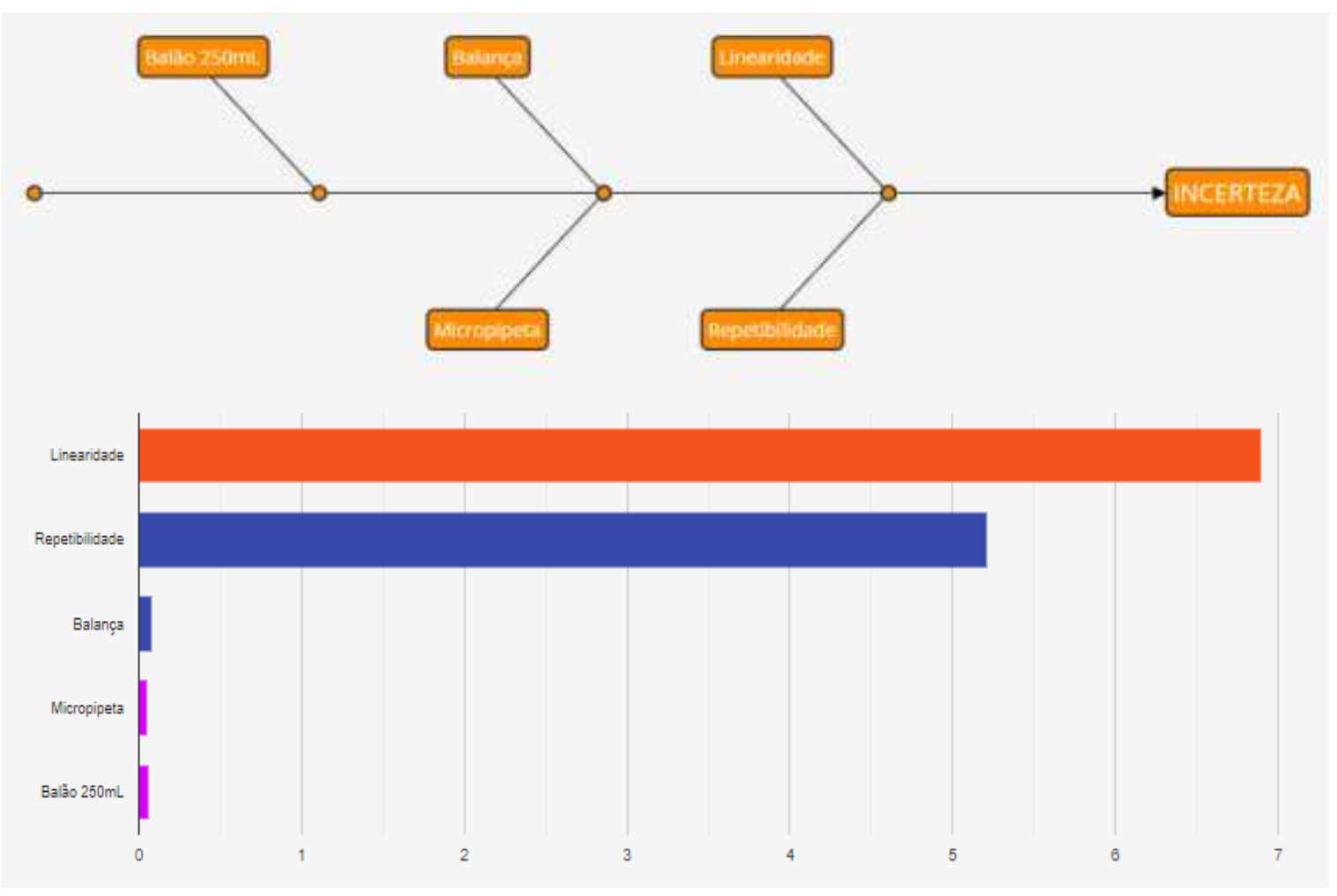

Fonte: autoria própria, produzido com o software Conflab Incertezas ${ }^{\circledR}$.

Conforme os dados da Tabela 20, o valor de propriedade caracterizado para o candidato a MR foi de 236,52 $\mu \mathrm{g} / \mathrm{L}$. Para o cálculo da incerteza da caracterização (Uchar) foram consideradas as seguintes fontes de incerteza: incerteza da linearidade homocedástica da segunda curva de calibração utilizada para a quantificação de CE na matriz fortificada; incerteza da repetibilidade dos 7 ensaios da quantificação; incerteza da balança utilizada para a pesagem do CE para a produção da solução estoque; incerteza da micropipeta utilizada para a fortificação da matriz; incerteza do balão volumétrico utilizado para a produção do lote do candidato a MR.

As contribuições de cada fonte de incerteza podem ser observadas pelo diagrama de Ishikawa e pelo diagrama de Pareto ilustrados na Figura 31. Percebe-se que as fontes que mais contribuem são a da linearidade e da repetibilidade dos resultados. A Tabela 1, apresenta os valores das incertezas padrão obtidas. 
Tabela 21 - Componentes de incerteza da $u_{\text {char }}$ para o valor de $210 \mu \mathrm{g} / \mathrm{L}$.

\begin{tabular}{|c|c|c|}
\hline Componente de incerteza & $\begin{array}{c}\text { Incerteza } \\
\text { padrão }\end{array}$ & $\begin{array}{l}\text { Incerteza } \\
\text { percentual }\end{array}$ \\
\hline Linearidade (Homocedástica) & $14,47 \mu \mathrm{g} / \mathrm{L}$ & $6,89 \%$ \\
\hline Linearidade (Heterocedástica) & $38,68 \mu \mathrm{g} / \mathrm{L}$ & $18,42 \%$ \\
\hline Repetibilidade & $10,95 \mu \mathrm{g} / \mathrm{L}$ & $5,21 \%$ \\
\hline Balança & & $0,08 \%$ \\
\hline Micropipeta & $0,02 \mu \mathrm{L}$ & $0,05 \%$ \\
\hline Balão $250 \mathrm{~mL}$ & $0,15 \mathrm{~L}$ & $0,06 \%$ \\
\hline \multicolumn{3}{|c|}{ Incerteza padrão percentual da caracterização ( $u_{\text {char }}$ ) } \\
\hline & & \\
\hline
\end{tabular}

Fonte: autoria própria, produzido com o software Conflab Incertezas®.

Para o cálculo de Uchar utilizou-se a incerteza padrão da linearidade homocedástica apesar da curva de calibração utilizada na caracterização apresentar heterocedasticidade. Conforme já observado anteriormente na Tabela 12, os valores calculados e críticos para o teste de Cocrhan foram muito próximos entre si e qualquer tipo de erro aleatório na análise, como variação na integração dos picos cromatográficos, poderia alterar o resultado para homocedástico. Visto que para 0 método utilizado na caracterização (IQSC/USP RQA Lab), tanto a primeira curva utilizada para a análise de background quanto a outra produzida meses depois para os estudos de homogeneidade, estabilidade e avaliação das amostras de fiscalização, apresentaram comportamento homocedástico e, portanto, é mais um indício de que é seguro admitir homocedasticidade para o cálculo da incerteza da linearidade nesse caso. O valor da incerteza padrão para a linearidade calculada como heterocedástica foi incluída na Tabela 21 para exemplificar numericamente como que os limites de confiança ilustrados na Figura 7 são amplificados com o tratamento de MMQP.

É importante sempre observar a homocedasticidade das curvas analíticas, principalmente quando cálculos de incerteza estiverem envolvidos para evitar subestimar ou superestimar os limites de confiança do resultado.

\subsection{HOMOGENEIDADE}

Quando o experimento foi realizado, a norma ISO Guia 35:2020 ainda não havia sido atualizada e na versão 2012 não havia uma orientação precisa sobre a quantidade de frascos ideal para o estudo da homogeneidade e, por isso, escolheuse o máximo de 30 frascos que a norma recomendava. Pela atualização de 2020 sabe- 
se que, para lotes de 100 unidades ou menos, 3 unidades ou $10 \%$ da produção do lote (no caso, 10 unidades) já seriam suficientes.

O objetivo foi avaliar a heterogeneidade significativa dos candidatos a MR produzidos. Isso foi realizado por avaliações estatísticas que compara a dispersão dos resultados obtidos entre vários frascos do lote com a precisão de repetibilidade da medição para determinar o desvio padrão entre as unidades (Sbb). Esse desvio padrão é necessário para o cálculo da incerteza associada à heterogeneidade (ubb) do material. Os valores das áreas obtidas com o estudo da homogeneidade em que a ANOVA foi computada são apresentados na Tabela 22. Para a avaliação da homogeneidade, realizou-se ANOVA de fator único (Tabela 23).

É importante informar que para evitar possíveis tendências nas medições provenientes de repetições dos frascos, as quintuplicatas de cada frasco não foram realizadas de forma sequencial, ou seja, todos os frascos eram analisados em unicata e depois reorganizados aleatoriamente para uma nova batelada de análises. Foram realizadas 5 bateladas de análises para obter as 5 replicatas de cada frasco. Esse procedimento evita uma falsa observação de tendências no lote de amostras prejudicando o estudo da homogeneidade entre os frascos. Portanto, os dados da Tabela 22 foram organizados para facilitar a observação e também para o cálculo da ANOVA de fator único.

Os valores de concentração da Tabela 22 foram obtidos a partir das áreas integradas aplicadas na regressão da segunda curva de calibração (Tabela 12), mesma regressão utilizada para a caracterização do material, pois o estudo de homogeneidade foi realizado logo após a determinação do valor de propriedade do

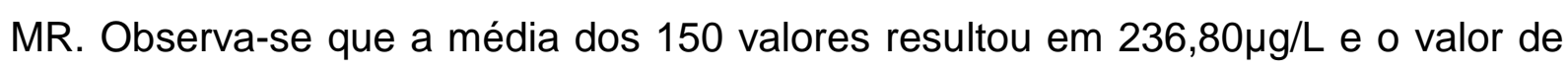
propriedade caracterizado em 7 ensaios para o candidato a MR foi de $236,52 \mu \mathrm{g} / \mathrm{L}$. Portando, para os cálculos de transformação de incerteza padrão da homogeneidade em incerteza percentual da homogeneidade foi utilizado o valor $236,80 \mu \mathrm{g} / \mathrm{L}$. Como as incertezas não podem ser somadas se não estiverem na mesma unidade, essa

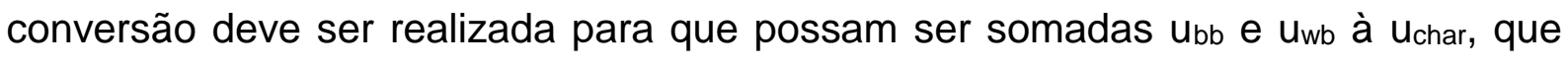
também já está em valores percentuais. 
Tabela 22 - Concentração de CE correspondente aos sinais analíticos de cada área integrada.

\begin{tabular}{|c|c|c|c|c|c|c|}
\hline & Frasco & 1 & 2 & 3 & 4 & 5 \\
\hline 1 & 5 & 216,04 & 319,61 & 221,85 & 186,42 & 243,96 \\
\hline 2 & 7 & 235,83 & 215,86 & 161,51 & 308,47 & 213,50 \\
\hline 3 & 10 & 253,60 & 169,23 & 196,74 & 234,14 & 248,32 \\
\hline 4 & 13 & 208,35 & 207,83 & 199,43 & 268,63 & 250,33 \\
\hline 5 & 17 & 261,58 & 219,55 & 208,45 & 345,05 & 225,70 \\
\hline 6 & 19 & 237,64 & 129,03 & 171,49 & 193,88 & 156,91 \\
\hline 7 & 21 & 209,81 & 171,80 & 311,05 & 193,75 & 216,41 \\
\hline 8 & 25 & 279,56 & 243,54 & 208,99 & 178,26 & 229,03 \\
\hline 9 & 30 & 254,72 & 158,21 & 294,98 & 178,94 & 242,37 \\
\hline 10 & 39 & 183,06 & 300,72 & 191,36 & 222,97 & 314,88 \\
\hline 11 & 41 & 258,75 & 184,61 & 229,34 & 271,37 & 282,83 \\
\hline 12 & 48 & 194,88 & 298,80 & 204,48 & 216,17 & 220,42 \\
\hline 13 & 50 & 186,68 & 215,26 & 226,53 & 174,30 & 285,57 \\
\hline 14 & 51 & 180,89 & 292,92 & 208,82 & 149,55 & 272,62 \\
\hline 15 & 53 & 184,81 & 184,66 & 290,92 & 211,52 & 227,80 \\
\hline 16 & 57 & 325,69 & 262,37 & 303,23 & 285,49 & 212,75 \\
\hline 17 & 59 & 257,84 & 187,10 & 180,63 & 294,33 & 186,74 \\
\hline 18 & 61 & 241,92 & 229,54 & 310,69 & 255,68 & 285,44 \\
\hline 19 & 64 & 237,58 & 255,09 & 265,36 & 207,95 & 255,06 \\
\hline 20 & 69 & 222,68 & 242,28 & 310,87 & 268,50 & 270,80 \\
\hline 21 & 72 & 238,65 & 191,15 & 307,62 & 172,23 & 258,26 \\
\hline 22 & 77 & 291,13 & 197,30 & 169,59 & 281,37 & 149,46 \\
\hline 23 & 80 & 317,53 & 143,01 & 312,69 & 267,07 & 220,03 \\
\hline 24 & 83 & 269,15 & 195,27 & 223,79 & 306,53 & 327,67 \\
\hline 25 & 85 & 308,09 & 218,44 & 285,77 & 188,30 & 286,81 \\
\hline 26 & 90 & 299,37 & 283,66 & 250,07 & 265,88 & 267,08 \\
\hline 27 & 91 & 222,29 & 280,16 & 261,50 & 320,15 & 241,67 \\
\hline 28 & 94 & 272,51 & 318,75 & 215,16 & 286,27 & 236,72 \\
\hline 29 & 98 & 211,10 & 178,38 & 187,13 & 144,06 & 230,98 \\
\hline \multirow[t]{3}{*}{30} & 100 & 262,60 & 142,39 & 257,84 & 203,95 & 249,72 \\
\hline & {$[C E] \mu g / L$} & 244,14 & 221,22 & 238,93 & 236,04 & 243,66 \\
\hline & \multicolumn{3}{|c|}{ [CE] média: } & 236,80 & $\mu g / L$ & \\
\hline
\end{tabular}

Fonte: autoria própria, produzido com o software Microsoft Excel 2013®.

Pela Tabela 22 observa-se que a média dos valores do estudo da homogeneidade reforça que o valor certificado em $236,5 \mu \mathrm{g} / \mathrm{L}$ para o MR está correto. A ISO Guia 80:2014 considera que essa é uma forma eficaz de determinar um indicativo do valor de propriedade do material de referência.

Tabela 23 - ANOVA de fator único do estudo da homogeneidade.

\begin{tabular}{lcrcccc}
\hline Fonte da variação & SQ & gl & MQ & F & valor-P & F crítico \\
\hline Entre grupos & 81554,31 & 29 & 2812,218 & 1,262523 & 0,191708 & 1,562071 \\
Dentro dos grupos & 267294,9 & 120 & 2227,458 & & & \\
Total & 348849,2 & 149 & & & & \\
\hline
\end{tabular}

Fonte: autoria própria, produzido com o software Microsoft Excel $2013 \AA$.

Com os valores da Tabela 23, as incertezas ubb e uwb foram calculadas de acordo com a Equação 4 e com a Equação 5, respectivamente. A homogeneidade dentro das unidades geralmente não é estudada para casos de uso único e não é considerada no cálculo da incerteza da homogeneidade. Entretanto, como o candidato 
a MR está sendo desenvolvido para que cada frasco seja utilizado mais de uma vez, a recomendação da norma é para que o valor da uwb seja considerado no cálculo. A incerteza padrão percentual da homogeneidade (unom) foi calculada de acordo com a Equação 6. Os valores são apresentados na Tabela 24.

A norma ABNT ISO Guia 35:2020 já considera homogeneidade comprovada quando o $\mathrm{F}$ calculado for menor que o valor crítico do $\mathrm{F}$ tabelado. Pela Tabela 23 pode observar que $F_{\text {calculado }}<F_{\text {tabelado, }}$ ou em outros termos, $\frac{F_{\text {calculado }}}{F_{\text {tabelado }}}=0,81<1$. Dessa forma, é verdadeira a hipótese nula $\left(\mathrm{H}_{0}\right)$ de que não há variação estatisticamente significativa entre os valores médios das fontes de variação entre e dentro dos frascos. Portanto, a homogeneidade foi comprovada.

Tabela 24 - Componentes de incerteza da unom.

\begin{tabular}{|c|c|c|c|}
\hline \multicolumn{2}{|c|}{ Componente de incerteza } & $\begin{array}{c}\text { Incerteza } \\
\text { padrão (uq/L) }\end{array}$ & $\begin{array}{l}\text { Incerteza } \\
\text { percentual }\end{array}$ \\
\hline \multirow{2}{*}{$\begin{array}{l}\text { Homogeneidade entre os } \\
\text { frascos }\end{array}$} & $S^{2}{ }_{b b}=u_{b b}^{2}$ & 116,95 & $49,39 \%$ \\
\hline & $s_{b b}=u_{b b}$ & 10,81 & $4,57 \%$ \\
\hline $\begin{array}{l}\text { Homogeneidade dentro dos } \\
\text { frascos }\end{array}$ & $s_{w b}=u_{w b}$ & 47,20 & $19,93 \%$ \\
\hline \multicolumn{4}{|c|}{ Incerteza padrão percentual da homogeneidade $\left(u_{\text {hom }}\right)$} \\
\hline \multicolumn{4}{|c|}{$20,45 \%$} \\
\hline
\end{tabular}

Fonte: autoria própria, produzido com o software Microsoft Excel 2013®.

A homogeneidade foi observada também pela análise do valor-p foi igual a 0,19 que é bem maior que 0,05 ( $p>0,05$, Tabela 23). Isso quer dizer que como para a ANOVA de fator único adotou-se $5 \%$ como valor de rejeição da hipótese nula ( $\mathrm{H}_{0}=$ há homogeneidade no lote), a probabilidade de encontrar um valor analítico tão discrepante entres os frascos que comprove heterogeneidade no lote é menor que 5\% e o os frascos são homogêneos entre si. Fica garantido que o valor de propriedade do material é homogêneo em todos os frascos do lote produzido. 


\subsection{ESTABILIDADE}

Para ambos os estudos de estabilidade, realizados no cromatógrafo do Laboratório de Química Ambiental - IQSC/USP pelo método IQSC/USP RQA Lab anteriormente validado, uma nova curva de calibração foi produzida e os dados da linearidade como equação da reta, coeficientes de correlação e determinação, ANOVA, teste de normalidade por Shapiro-wilk, teste de homocedasticidade por Cochran e teste de outliers por Grubbs gerados pelo software Conflab Validação ${ }^{\circledR}$ podem ser verificados no Apêndice B.

\subsubsection{ESTABILIDADE DO ARMAZENAMENTO}

Adotou-se o método isócrono pois, ao analisar todos os frascos nas mesmas condições de repetibilidade, a precisão das medições é melhor do que no método clássico. Ao excluir pequenas divergências causadas pela precisão intermediária ao adotar o método isócrono, a componente incerteza de estabilidade (ults) agregada ao valor certificado também é menor que a produzida pelo método clássico, o que torna o estudo da estabilidade de longa duração mais apurado.

As fontes de incertezas previstas em um estudo de estabilidade para variações no valor certificado com o passar do tempo incluem: repetibilidade das medições; variabilidade entre as análises do sistema de medição; heterogeneidade entre os frascos do lote.

A Figura 32 é o gráfico obtido para o estudo da estabilidade do armazenamento. O coeficiente angular ( $\beta_{1}$, Equação 8) foi pequeno, menor que 1. É por esse parâmetro que se faz a análise de tendências. Para materiais estáveis, é esperado que esse valor seja baixo, portanto esse já é um indicativo de que o candidato a MR possui estabilidade de longo prazo. 
Figura 32 - Gráfico do estudo de estabilidade do armazenamento.

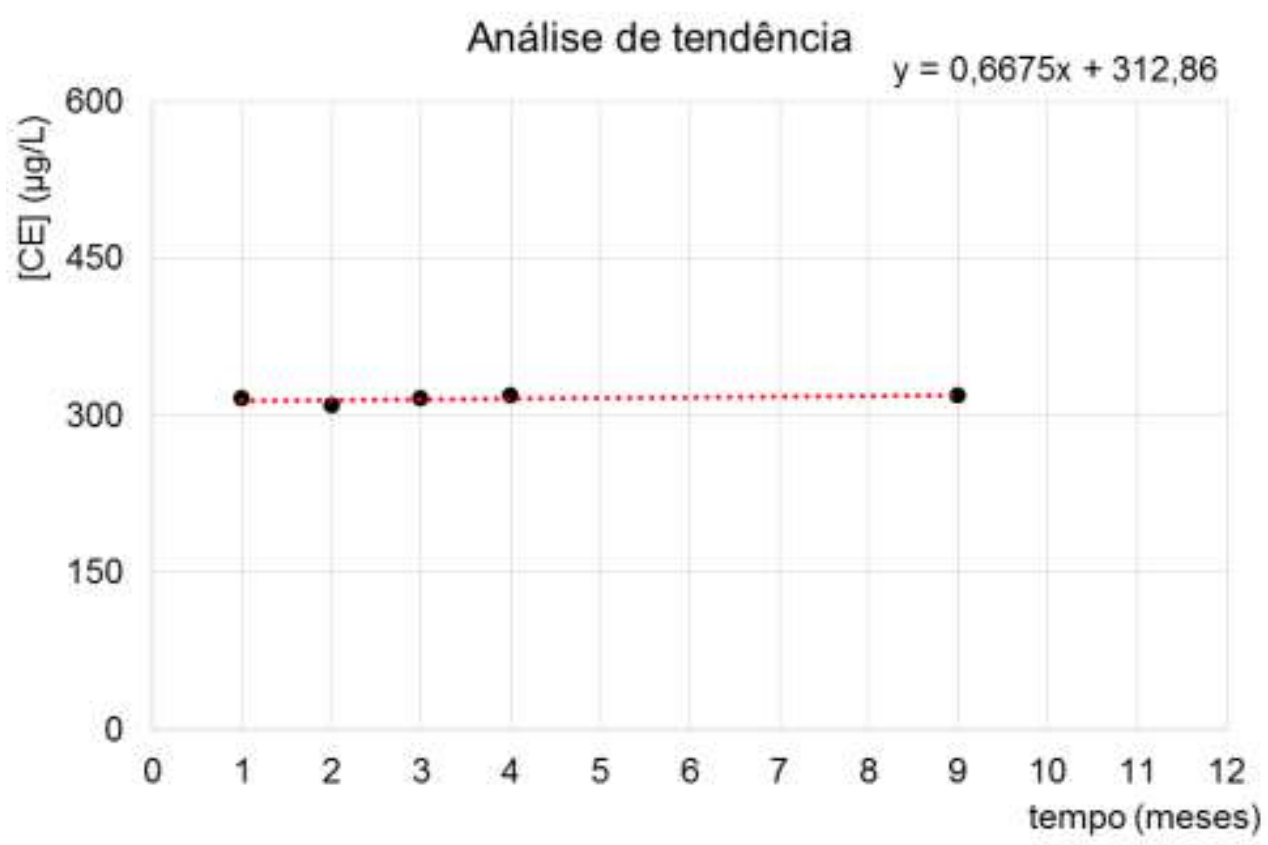

Fonte: autoria própria, produzido com o software Microsoft Excel 2013®.

Legenda: o nono mês corresponde ao mês de análise de todas as amostras do modo isócrono, ou seja, é o tempo zero. Sendo assim, o primeiro mês corresponde às amostras que ficaram 9 meses sob temperatura ambiente.

A confirmação da estabilidade foi realizada por meio do cálculo de $S_{(\beta 1)}$ (Equação 9) que é o desvio padrão do coeficiente angular; ou o desvio padrão da tendência de variação do valor de propriedade do material com o passar do tempo. Esse desvio padrão também pode ser calculado pela Equação 24, pois são equações equivalentes. $O$ valor $S_{(\beta 1)}$ é utilizado para comparar o coeficiente angular $\beta_{1}$ com o valor $t$ de Student para $n-2$ graus de liberdade com $95 \%$ de confiança. Para a confirmação da estabilidade, a relação da Equação 11 deve ser satisfeita. Como esse estudo de estabilidade foi realizado em um período de 9 meses, n-2 é igual a 7. O t de Student a um nível de 95\% de confiança para esse grau de liberdade é 2,364. O valor calculado para $\mathrm{s}(\beta 1)$ foi de $5,05 \mu \mathrm{g} / \mathrm{L}$ e o valor de $\beta_{1}$ foi de $0,6675 \mu \mathrm{g} / \mathrm{L}$, conforme pode ser observado pela equação do gráfico ilustrado pela Figura 32. A condição $|\beta 1|<\mathrm{t}_{0,95} \mathrm{n}-2 \cdot \mathrm{s}_{\beta 1}$ foi confirmada e, portanto, pode-se concluir que o candidato a material de referência é estável e não possui tendências significativas à degradação no período de tempo estudado.

Nesse caso, conforme a norma ABNT ISO Guia 35:2020 informa, com a comprovação experimental da estabilidade do material não há necessidade de calcular a incerteza da instabilidade do armazenamento (Ults) pois o seu valor seria desprezível se comparada a incerteza da caracterização (Uchar) podendo ser omitido 
do cálculo da incerteza do valor certificado. Da mesma forma, a estimativa do tempo de validade do material não é necessária ser realizada uma vez comprovada a estabilidade do armazenamento.

Outro fator importante a se considerar é que esse lote de material de referência foi produzido dentro de um programa de pós-graduação e o valor de propriedade não será monitorado por longos períodos de tempo como normalmente laboratórios especializados nesse tipo de produção faz. Por isso, optou-se por estabelecer um tempo de validade planejado. É de responsabilidade do usuário do MR verificar periodicamente o valor de propriedade.

Analisando a equação da reta da Figura 32 é possível observar que o coeficiente linear é de $312,86 \mu \mathrm{g} / \mathrm{L}$ e que o coeficiente angular é baixo, porém não nulo. Como o valor de propriedade foi certificado em $236,500 \mu \mathrm{g} / \mathrm{L}$ pode aparentar que houve uma formação de CE com o passar do tempo, porém é mais provável que houve uma concentração do carbamato de etila devido a uma possível evaporação da matriz já que os materiais foram armazenados em vials. Um forte indício dessa hipótese é o valor médio dos valores do estudo da homogeneidade em que trinta frascos mantido em $-4^{\circ} \mathrm{C}$ até o dia da análise foram determinados em 236,80 $\mu \mathrm{g} / \mathrm{L}$ (Tabela 22). Outro fator é que o valor $312,86 \mu \mathrm{g} / \mathrm{L}$ está dentro da incerteza estabelecida para o material, conforme será demonstrado posteriormente. Caso estivesse disponível essa possibilidade, percebe-se agora esse problema seria contornado ao produzir o material de referência em ampolas, porém cada unidade perderia a característica do múltiplo uso.

\subsubsection{ESTABILIDADE DO TRANSPORTE}

O objetivo desse teste foi forçar uma possível degradação do material para simular possíveis alterações que poderiam surgir durante o transporte e que não seriam perceptíveis nas condições planejadas para o armazenamento.

As condições planejadas para o estudo de estabilidade de curto prazo devem considerar as condições extremas que o material pode ser submetido durante 0 transporte. No caso deste trabalho, os MR enviados para os laboratórios participantes do ensaio de proficiência não ficariam mais do que 60hs em transporte. Assim sendo, o estudo foi conduzido condicionando 2 frascos em estufa termostatizada a $40^{\circ} \mathrm{C}$ por 72hs. Por meio de ANOVA, os valores dos sinais analíticos das triplicatas desses dois frascos foram comparados com os valores das triplicatas dos dois frascos recém 
tirados do congelador para o estudo da estabilidade de longo prazo no tempo zero (mês outubro). Obteve-se a Tabela 25.

Tabela 25 - ANOVA de fator único para o estudo da estabilidade de transporte.

\begin{tabular}{|c|c|c|c|c|c|c|}
\hline Fonte da variação & $\mathbf{S Q}$ & gl & MQ & $\mathbf{F}$ & valor-P & F crítico \\
\hline Entre grupos & 8280,3 & 3 & 2760,083333 & 1,3425 & 0,3274 & 4,0662 \\
\hline Dentro dos grupos & 16448 & 8 & 2056 & & & \\
\hline Total & 24728 & 11 & & & & \\
\hline
\end{tabular}

Fonte: autoria própria, produzido com o software Microsoft Excel 2013®.

Tanto pelo teste $\mathrm{F}$ quanto pelo valor-p ficou comprovado que não há diferença entre os frascos que foram submetidos às $72 \mathrm{hs}$ a $40^{\circ} \mathrm{C}$ e os que foram analisados recém tirados do condicionamento de $-4^{\circ} \mathrm{C}$. Com a comprovação de ausência de variâncias significativas pela ANOVA, adicionalmente calculou-se também um teste $t$ para variâncias equivalentes, apresentado como Tabela 26.

Tabela 26 - Teste-t de duas variáveis com variâncias equivalentes para os valores de área de pico cromatográfico do estudo de estabilidade de transporte.

\begin{tabular}{|c|c|c|}
\hline & $\begin{array}{c}\text { Amostras de controle } \\
\left(-4^{\circ} \mathrm{C}\right)\end{array}$ & $\begin{array}{c}\text { Amostras estressadas } \\
\left(40^{\circ} \mathrm{C} / 72 \mathrm{hs}\right)\end{array}$ \\
\hline Média & 1635,1667 & 1650,3333 \\
\hline Variância & 1663,7667 & 3143,8667 \\
\hline $\begin{array}{c}t \text { calculado } \\
t \text { crítico bicaudal }\end{array}$ & \multicolumn{2}{|c|}{$\begin{array}{l}0,5358 \\
2,2281\end{array}$} \\
\hline
\end{tabular}

Fonte: autoria própria, produzido com o software Microsoft Excel 2013®.

Enquanto a ANOVA verifica se há diferenças estatisticamente significativas na dispersão dos dados das replicatas dentro e entre grupos, o teste t de Student compara os valores das médias dos grupos e verifica se há concordância entre os valores. No caso aplicado, a condição a ser analisada é se as médias dos sinais analíticos das amostras de controle e estressadas são diferentes entre si (hipótese alternativa), por isso utilizou-se a análise bicaudal. Como a hipótese nula é sempre adotada como igualdade entre os valores analisados e somente é rejeitada caso o valor do parâmetro calculado seja maior que o valor crítico tabelado, pelos dados da Tabela 26, é observado que não houve variação significativa na concentração de CE durante o estudo de estabilidade de transporte.

A título de esclarecimento, caso o objetivo da análise fosse verificar uma diferença entre as amostras de controle e estressadas esperando-se uma tendência entre os valores (segunda hipótese alternativa), por exemplo "amostras estressadas 
apresentam menor valor na concentração do analito pois é esperada uma degradação", a análise deve ser realizada na abordagem unicaudal.

A estabilidade do material para as condições de transporte foi comprovada por teste F, valor-p e teste t de Student.

\subsection{ESTIMATIVA DA INCERTEZA DO MATERIAL DE REFERÊNCIA}

A busca por otimizar o processo de medição é para que o valor medido seja sempre o mais próximo possível do valor real. Entretanto, o resultado de medição será a estimativa do valor verdadeiro e o valor real será sempre desconhecido. É essa estimativa que possui uma incerteza associada ao valor. Tanto o valor verdadeiro quanto o erro (aleatório ou sistemático) são conceitos abstratos, mas são úteis pois a estimativa "valor medido \pm incerteza" pode ser determinada por meio da análise do mensurando e das considerações das principais fontes de incertezas.

Em uma análise com replicatas, é muito provável que os valores medidos serão diferentes entre si e que a média dos valores também não correspondem ao valor real do mensurando; são as fontes de incerteza que causam isso. Na prática, existem inúmeras fontes de incerteza influenciando o resultado de medição, chegando a ser considerada uma quantidade próxima do infinito, tanto que se utiliza a distribuição normal (Gaussiana) como base de cálculo dos desvios padrão, incertezas padrão, incerteza expandida e fator de cobertura. Todavia, é sabido que as fontes de incerteza possuem diferentes graus de contribuição e é comum considerar apenas as mais influentes para os cálculos da incerteza combinada. Pela Figura 33 isso fica bem claro.

A incerteza padrão combinada percentual da caracterização (Uchar) apresentou contribuição majoritária da incerteza proveniente da linearidade. Revendo os parâmetros de desempenho da curva de calibração que imputou essas incertezas (Tabela 12), observa-se que essa curva foi construída por MMQP porque apresentou heterocedasticidade. $\mathrm{O}$ teste de Cochran entre o valor calculado e o tabelado foram muito próximos $(0,55$ e 0,54 , respetivamente). É possível que alguma fonte de variação relativa à repetibilidade, proveniente do amostrador automático ou do fluxo de gás no injetor ou coluna, possa ter causado a variação na dispersão dos resíduos já que a primeira curva se mostrou homocedástica com bastante diferença entre os valores calculados e tabelados (0,43 e 0,54, respetivamente). Como já justificado anteriormente, a componente de incerteza padrão percentual da linearidade para essa curva foi calculada com base na regressão ordinária para a concentração $210 \mu \mathrm{g} / \mathrm{L}$ e, 
conforme ilustrado na Figura 33, a incerteza padrão da linearidade com tratamento ponderado $(18,42 \%)$ é muito superior à incerteza para a mesma curva de calibração quando calculada com tratamento ordinário (6,89\%).

Analisando a Figura 7, é compreensível esse aumento nos limites de confiança do valor central, pois a curva do método validado foi pensada para que o valor crítico da legislação ficasse centralizado para ter as menores incertezas sobre o valor em caso homocedástico. Em contrapartida, a variação dos limites de confiança entre os tratamentos MMQO e MMQP também é mais acentuada nessa região da curva.

Ainda em relação à uchar, percebe-se que as maiores fontes de incertezas em métodos cromatográficos se encontram no método da análise, relativo às variações instrumentais e que as etapas de preparo das soluções e pesagem dos padrões pouco influenciam no valor final da incerteza combinada.

A Figura 33 ainda demonstra que a unom apresentou grande contribuição da incerteza da homogeneidade dentro dos frascos ( $u_{w b}=19,43 \%$ ) em relação à incerteza padrão da homogeneidade entre os frascos ( $u_{b b}=4,57 \%$ ). O valor de $u_{w b}$ pode ser desconsiderado do cálculo da unom nos casos em que o material é de uso único, entretanto esse não é o caso do material desenvolvido. Adicionalmente, pela ISO Guia 35:2020 é previsto também que existe alto risco de heterogeneidade dentro do frasco quando o tamanho da alíquota for substancialmente menor do que o tamanho da amostra, como no caso do MR desenvolvido; cada análise do método utiliza $2 \mu \mathrm{L}$ do vial com $2 \mathrm{~mL}$ de material, já era esperada uma uwb considerável para o cálculo da Unom. Esse tipo de problema é tão comum que o próprio Inmetro recomenda no certificado do MRC de CE em solução hidroalcoólica que comercializa, disponível como Anexo $A$, que a alíquota mínima para a garantia de uma amostragem homogênea é de $1,5 \mathrm{~g}$ dos $6 \mathrm{~mL}$ totais de material envasado (INMETRO, 2019). Essa é uma incerteza proveniente da característica do modo de uso do material, mas não implica que a homogeneidade entre os frascos está prejudicada, assim como apenas provar homogeneidade entre os frascos não implica que as amostragens dentro do frasco serão homogêneas.

Por fim, a incerteza padrão percentual $\left(U_{M R C}=22,20 \%\right)$ foi calculada conforme a Equação 17: desconsiderando a incerteza padrão percentual relacionada à instabilidade de armazenamento do material ( $\mathrm{ults}_{\mathrm{ts}}$ ) e considerando a incerteza padrão percentual relacionada à heterogeneidade dentro dos frascos ( $\left.u_{w b}\right)$. A incerteza 
expandida foi calculada conforme a Equação 18 com fator de expansão k=2 e UMRC foi igual a $44,40 \%$.

Pela Figura 33 ainda é possível observar o impacto que o tratamento da regressão ponderada devido à heterocedasticidade incorpora ao valor de uMRc. Considerando a incerteza da linearidade heterocedástica, a UMRC do material produzido aumentaria de $22,20 \%$ para $28,01 \%$, somente por questão de tratamento estatístico dos dados. Caso fosse possível eliminar a heterogeneidade dentro dos frascos, a uMRC passaria de $22,20 \%$ para $9,77 \%$ e a UMRC cairia de $44,40 \%$ para $19,54 \%$.

Figura 33 - Gráfico comparativo das contribuições das incertezas padrão percentuais e combinadas de cada fonte de incerteza considerada.

\section{Fontes de incertezas e suas contribuições}

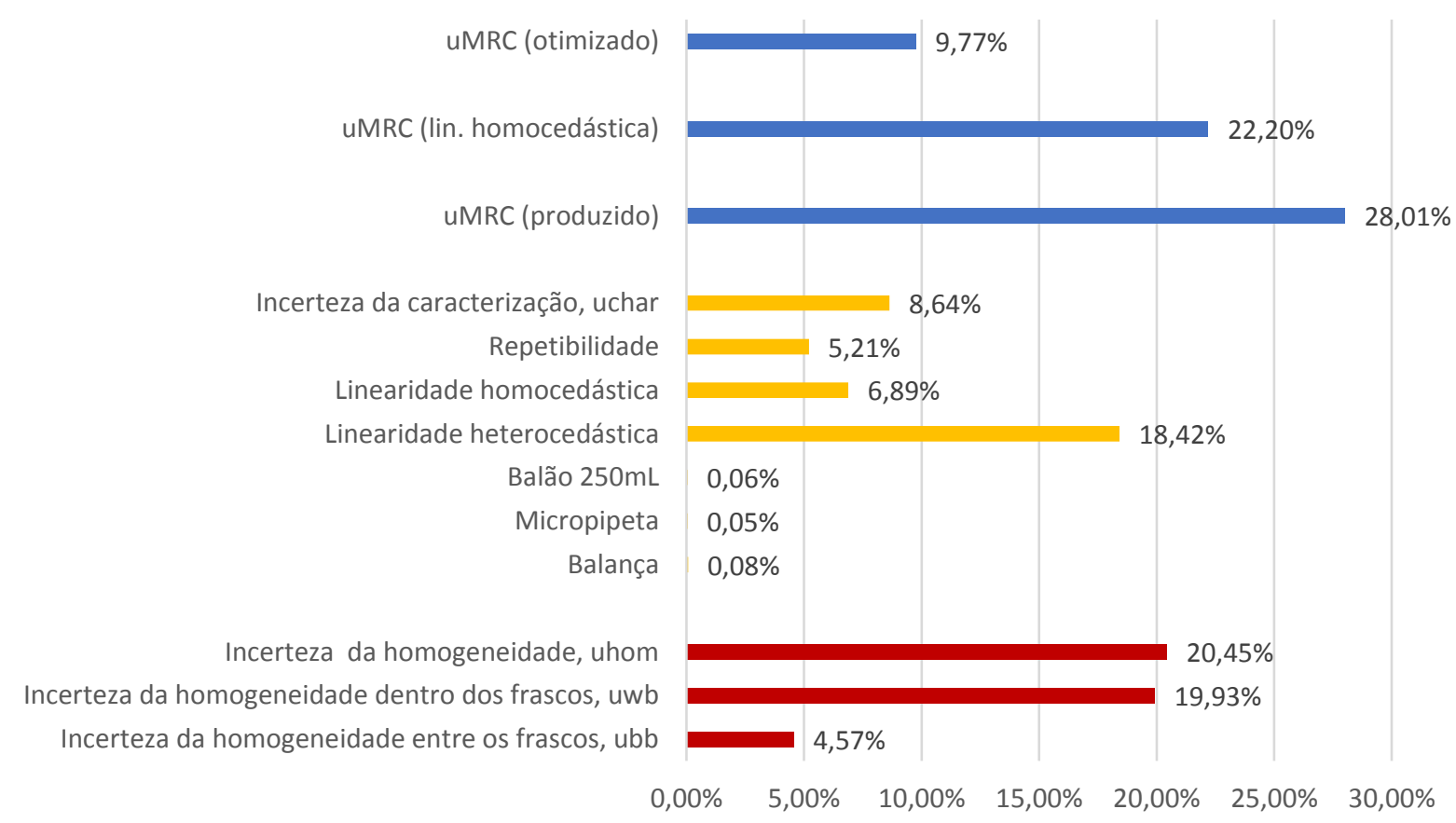

Fonte: autoria própria, produzido com os softwares Conflab Incerteza $\AA^{\circledR}$ e Microsoft Excel $2013 \AA$.

Aqui vale a discussão de que a incerteza expandida $(U)$ difere do erro e nem pode ser considerada como uma estimativa do erro pelo fato de que ela não possui um sinal e não indica possíveis erros sistemáticos existentes (ver Figura 9, Figura 10 e Figura 11). Deve ser considerada como estimativa de qual é a maior diferença absoluta possível entre o valor medido e o valor real, logo, é esperado que o valor do erro seja menor que a incerteza da medição.

Outro ponto a se observar, é que as incertezas padrão combinadas tendem a se assemelhar em magnitude com a incerteza padrão mais influente. Isso se deve ao 
fato de que a somatória das incertezas padrão é do tipo soma quadrática (Equação 6 e Equação 17): os menores valores são suprimidos pelos maiores valores.

Essas análises mostram que, tão importante quanto a aquisição dos dados é a consideração dos tratamentos estatísticos corretos, muitas vezes negligenciados pelos pesquisadores como apontado por Baker (2016).

\subsection{CERTIFICAÇÃO DO MATERIAL DE REFERÊNCIA}

O material apresentou estabilidade de transporte e estabilidade de armazenamento além de homogeneidade entre os frascos. Com isso, é garantido que nenhum laboratório participante do ensaio de proficiência foi prejudicado por variação no valor de propriedade. A incerteza uwb relativa à heterogeneidade dentro dos frascos foi adicionada ao valor UMRC já que não foi realizado um estudo de quantidade mínima de amostragem para garantir a homogeneidade dentro dos frascos. Portanto, o valor certificado foi de $(236,500 \pm 105,006) \mu \mathrm{g} / \mathrm{L}$ ( $\mathrm{k}=2$, normal).

A título de comparação, o Fapas é um grande provedor de ensaios de proficiência na área de alimentos e água, mundialmente reconhecido e referência nessa prestação de serviço. Além de promover EP, também produz e comercializa materiais de referência. No Anexo B está disponível uma ficha de dados de um material de referência para uma série de congêneres orgânicos em uísque. É possível observar que as faixas das incertezas expandidas desse material variam de 13,03\% até $42,08 \%$ do valor de propriedade do material, conforme a Tabela 27.

Tabela 27 - Valores de referência para incertezas expandidas de congêneres orgânicos em uísque material de referência produzido pelo FAPAS.

\begin{tabular}{ccccc}
\hline Analito & $\begin{array}{c}\text { Valor } \\
\text { certificado }\end{array}$ & Faixa & Unidade & $\mathbf{U}$ \\
\hline Acetaldeído & 3,85 & $\pm 1,62$ & $\begin{array}{c}\mathrm{g} / 100 \mathrm{~mL} \text { de } \\
\text { álcool anidro }\end{array}$ & $42,08 \%$ \\
\hline Acetato de etila & 13,61 & $\pm 2,08$ & $\begin{array}{c}\mathrm{g} / 100 \mathrm{~mL} \text { de } \\
\text { álcool anidro }\end{array}$ & $15,28 \%$ \\
\hline Metanol & 4,66 & $\pm 0,84$ & $\begin{array}{c}\mathrm{g} / 100 \mathrm{~mL} \text { de } \\
\text { álcool anidro }\end{array}$ & $18,02 \%$ \\
\hline Propanol & 32,17 & $\pm 4,32$ & $\begin{array}{c}\mathrm{g} / 100 \mathrm{~mL} \text { de } \\
\text { álcool anidro }\end{array}$ & $13,43 \%$ \\
\hline 2-metilpropan-1-ol & 15,22 & $\pm 2,28$ & $\begin{array}{c}\mathrm{g} / 100 \mathrm{~mL} \text { de } \\
\text { álcool anidro }\end{array}$ & $14,98 \%$ \\
\hline 2-metilbutan1-ol + & 39,13 & $\pm 5,10$ & $\begin{array}{c}\mathrm{g} / 100 \mathrm{~mL} \text { de } \\
\text { álcool anidro }\end{array}$ & $13,03 \%$ \\
\hline 3-metilbutan-1-ol & & & & \\
\hline
\end{tabular}

Fonte: adaptado de Anexo B. 
Com base nos dados obtidos do Anexo B, observa-se que o material se aproxima dos valores de incerteza expandida produzidos pelo Fapas. Isto posto, atende a finalidade de seu uso no LFDA/SP-SLAB/BEB Jundiaí. Além do laboratório agora possuir um método validado para análise de CE, o MR produzido está na faixa de concentração crítica da legislação e foi eliminado o efeito matriz entre o MRC de CE em solução hidroalcoólica do Inmetro e as amostras de fiscalização. O material de referência desenvolvido pode ser utilizado para verificar o $t_{r}$ dos fragmentos $\mathrm{m} / \mathrm{z} 44$, 62 e 72 para a identificação do CE nas amostras do programa de fiscalização do Ministério. O certificado está apresentado no Apêndice C.

\subsection{ENSAIO DE PROFICIÊNCIA}

Participaram quatro laboratórios acreditados, dois do estado de SP e dois do estado de MG. Esse ensaio de proficiência precisou adotar um tratamento estatístico próprio para EP devido a presença de poucos participantes.

Para ensaios entre 20 e 30 laboratórios, ou mais, é muito comum utilizar o escore z como parâmetro de desempenho. Entretanto, para EPs com menos de 20 participantes a estatística robusta do Algoritmo A para o cálculo das médias e desvios padrão robustos é comprometida e o escore z não pode ser calculado com base no valor do desvio padrão dos participantes (ISO, 2015).

A norma ISO 13528:2015, para orientação do tratamento estatístico de EP, fornece a alternativa de se utilizar o modelo de Horwitz adaptado por Thompson para o cálculo do desvio padrão com base na concentração do valor designado. Dessa forma, o cálculo do escore z se torna independente do desvio padrão dos valores entres os participantes e se relaciona apenas com o item do ensaio. Todos os laboratórios serão comparados pelo seu desempenho na análise do valor designado do item de ensaio, independente de um número mínimo de participantes.

Entretanto, é necessário lembrar que o modelo matemático de Horwitz para o cálculo do desvio padrão de métodos analíticos é um modelo empírico. Isso quer dizer que foi construído sob uma série de experimentos, realizados ainda na década de 80 . Em 40 anos a análise instrumental evoluiu muito. É incomparável o poder analítico que temos disponível atualmente em relação à quando o modelo de Horwitz foi desenvolvido. Por isso, para o desenvolvimento deste trabalho, ficou resolvido acautelar-se sobre o uso exclusivo de um parâmetro de desempenho dependente do 
modelo de Horwitz. É possível que este modelo matemático já esteja subestimando valores.

Outros parâmetros de desempenho podem ser utilizados e são dependentes das incertezas dos laboratórios participantes e da incerteza do valor designado do item do ensaio (BELLI et al., 2007; ABNT, 2011; ISO, 2015). Calculados conforme Equação 34, Equação 35, Equação 36 e Equação 37, são apresentados os resultados na Tabela 28.

Tabela 28 - Parâmetros de desempenho dos laboratórios participantes do ensaio de proficiência.

\begin{tabular}{|c|c|c|c|c|c|c|c|c|}
\hline \multicolumn{9}{|c|}{ Valores calculados com base na incerteza informada pelos participantes } \\
\hline & & QAe097p & & QAe901p & & QAe843p & & $2 A e 965 p$ \\
\hline $\begin{array}{c}\mathbf{x}(\mu \mathrm{g} / \mathrm{L}) \\
\mathbf{U}(\text { participante })\end{array}$ & $\begin{array}{l}304,00 \\
6,91 \%\end{array}$ & Desempenho & $\begin{array}{l}247,00 \\
10,53 \%\end{array}$ & Desempenho & $\begin{array}{l}247,91 \\
4,53 \%\end{array}$ & Desempenho & $\begin{array}{l}257,00 \\
7,39 \%\end{array}$ & Desempenho \\
\hline z ( $\sigma$ Horwitz) & 1,44 & satisfatório & 0,22 & satisfatório & 0,24 & satisfatório & 0,44 & satisfatório \\
\hline $\mathrm{D} \%$ & $28,54 \%$ & & $4,44 \%$ & & $4,82 \%$ & & $8,67 \%$ & \\
\hline Escore zeta (ろ) & 3,00 & alerta & 0,46 & satisfatório & 0,51 & satisfatório & 0,91 & satisfatório \\
\hline$E_{n}$ & 1,50 & insatisfatório & 0,23 & satisfatório & 0,26 & satisfatório & 0,46 & satisfatório \\
\hline
\end{tabular}

\begin{tabular}{|c|c|c|c|c|c|c|c|c|}
\hline \multicolumn{9}{|c|}{ Valores calculados com base na incerteza calculada pela linearidade (Conflab) } \\
\hline & & QAe097p & & QAe901p & & QAe843p & & QAe965p \\
\hline $\begin{array}{c}x(\mu g / L) \\
U(\text { Conflab) }\end{array}$ & $\begin{array}{l}304,00 \\
7,70 \%\end{array}$ & Desempenho & $\begin{array}{r}247,00 \\
1,33 \%\end{array}$ & Desempenho & $\begin{array}{r}247,91 \\
0,69 \%\end{array}$ & Desempenho & $\begin{array}{l}257,00 \\
10,02 \%\end{array}$ & Desempenho \\
\hline z ( $\sigma$ Horwitz) & 1,44 & satisfatório & 0,22 & satisfatório & 0,24 & satisfatório & 0,44 & satisfatório \\
\hline D\% & $28,54 \%$ & 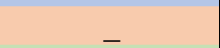 & $4,44 \%$ & & $4,82 \%$ & & $8,67 \%$ & \\
\hline 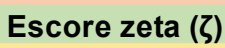 & 3,00 & alerta & 0,47 & satisfatório & 0,51 & satisfatório & 0,90 & satisfatório \\
\hline$E_{n}$ & 1,50 & insatisfatório & 0,24 & satisfatório & 0,26 & satisfatório & 0,45 & satisfatório \\
\hline
\end{tabular}

Fonte: autoria própria, produzido com os softwares Conflab Incerteza $\AA$ e Microsoft Excel $2013 \AA$.

Os laboratórios enviaram os valores das curvas de calibração e também os valores das incertezas de seus métodos. Com os dados das curvas, pelos softwares

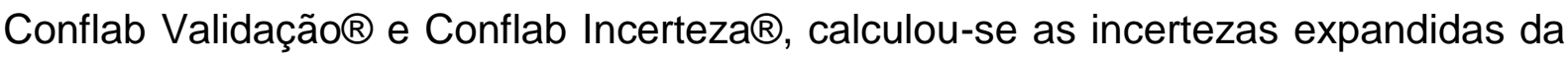
linearidade das curvas. Calculou-se o desempenho dos laboratórios tanto pelas incertezas enviadas quanto pelas incertezas da linearidade calculadas pelo provedor; como já estudado anteriormente, para a quantificação de uma amostra, a incerteza da linearidade é a componente mais influente na magnitude da incerteza expandida.

O parâmetro $\mathrm{D} \%$ representa a diferença percentual do valor do quantificado pelo participante do valor designado pelo provedor. Observa-se pela Tabela 28 que o escore z com desvio padrão de Horwitz aprovou todos os laboratórios enquanto pelos parâmetros dependentes das incertezas a aprovação foi mais criteriosa deixando o participante RQAe097p com desempenho questionável, em alerta para a necessidade de possível tomada de ação. Com isso, explora-se a ideia de que para ensaios de proficiência com poucos participantes o ideal é utilizar parâmetros de desempenho 
dependentes das incertezas, sem correr o risco de subestimar aprovações com base em um modelo matemático antigo.

Outro ponto a se considerar é que o provedor dos EP que faça uso de parâmetros de desempenho dependentes de incertezas também forneça o serviço de calcular as incertezas dos laboratórios. Isso pode evitar que o participante superestime esse valor e consiga uma aprovação questionável.

Cada vez mais tendemos para produtos mais diversificados e com nichos mais específicos. É uma tendência que ensaios de proficiências de poucos participantes sejam mais requisitados e é uma necessidade estar preparado para essa demanda de forma adequada. Rudaz e Feinberg (2018) discutem sobre a possibilidade de que as incertezas possam vir a ser parâmetros globais e únicos para a avaliação sobre a adequação dos resultados, métodos e decisões sobre as finalidades a que se aplicam.

A equação utilizada pelo software para a determinação da incerteza da regressão ordinária, regulamentada por meio da Guia CG4 (EURACHEM, 2012), segue descrita pela Equação 50:

$$
\frac{\mathrm{s}}{\mathrm{b}_{1}}=\sqrt{\left(\frac{1}{\mathrm{p}}+\frac{1}{\mathrm{n}}+\frac{\left(\mathrm{C}_{0}-\overline{\mathrm{C}}\right)^{2}}{\mathrm{~S}_{\mathrm{xx}}}\right)}
$$

Onde $\mathrm{p}$ : número de pontos totais calibrados; $\mathrm{n}$ : número de replicatas na amostra. Analisando esta equação percebe-se que quanto maiores os valões de $\mathrm{p} e$ de $n$, menor será a incerteza. Por isso foi solicitado para que os laboratórios realizassem as análises em até 7 níveis em quintuplicatas (Apêndice A). Quanto menor a incerteza, maior o preciosismo do resultado analítico. Novamente, reitera-se a ideia de que os valores das incertezas podem ser adotados como "padrão ouro" no momento de diferenciar os serviços prestados pelos laboratórios.

\subsection{DIAGNÓSTICO DE TEOR DE CE EM CACHAÇA NACIONAIS - AMOSTRAS DE FISCALIZAÇÃO}

Essa avaliação foi realizada logo após os estudos de estabilidade e utilizou a mesma curva de calibração que apresentou homocedasticidade, coeficiente de correlação $r=0,9973$ e coeficiente de determinação $r^{2}=0,9946$. A análise completa da 
linearidade dessa curva realizada pelo Conflab Validação® pode ser verificada no Apêndice B.

Para o estudo, foram analisadas 18 amostras em triplicata no método IQSC/USP validado com $39,78 \%$ de incerteza expandida. Os resultados são apresentados na Tabela 29.

Tabela 29 - Concentrações de CE encontradas em amostras de cachaça não adoçada o programa de fiscalização do MAPA.

\begin{tabular}{ccccc}
\hline Estado & Amostra & \multicolumn{3}{c}{ CE $(\boldsymbol{\mu g} / \mathbf{L})$} \\
\hline CE & CE20-A & 202,00 & \pm & 80,36 \\
CE & CE20-B & 209,74 & \pm & 83,43 \\
MA & MA19 & - & - & - \\
MG & MG20-A & - & - & - \\
MG & MG20-B & - & - & - \\
MG & MG20-C & - & - & $-\overline{5}, 29$ \\
MG & MG20-D & 314,95 & \pm & - \\
PR & PR19 & - & - & - \\
RS & RS19-A & - & - & - \\
RS & RS19-B & - & - & - \\
RS & RS19-C & - & - & - \\
SC & SC19-A & 146,72 & \pm & 58,36 \\
SC & SC19-B & - & - & - \\
SP & SP17-A & - & - & - \\
SP & SP17-B & - & - & - \\
SP & SP18-A & - & - & - \\
SP & SP18-B & - & - & - \\
SP & SP18-C & 342,10 & \pm & 136,09 \\
\hline
\end{tabular}

Fonte: autoria própria. Legenda: valores em azul estão dentro dos limites críticos da legislação de $210 \mu \mathrm{g} / \mathrm{L}$; valores não indicados são de amostras reprovadas com concentração muito superior ao último

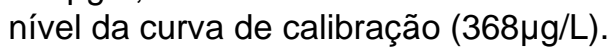

Vale ressaltar aqui que o método IQSC/USP RQA Lab apresentou uma incerteza superior ao calculado para o método validado para o laboratório federal (39,78\% e 17,54\%, respectivamente) por motivos já discutidos no tópico 5.2.1. Nesse contexto, espera-se que mais amostras de fiscalização sejam reprovadas pelo LFDA/SP que possui uma instrumentação específica para esses ensaios e, consequentemente, menor incerteza no método de análise.

\section{CONCLUSÕES}

Em parceria com o Ministério da Agricultura, Pecuária e Abastecimento (MAPA), dentro do Laboratório Federal de Defesa Agropecuária na unidade avançada 
de Jundiaí (LFDA/SP-SLAV/BEB) foi desenvolvido e validado um método cromatográfico para análise de carbamato de etila em bebidas destiladas, por isso, no momento é o único laboratório federal apto a realizar esse controle.

Também por solicitação do MAPA, foi produzido um lote de material de referência de carbamato de etila em matriz de cachaça não adoçada para esse laboratório utilizar como controle de qualidade nas análises de rotina. O material apresentou homogeneidade e estabilidade com valor certificado em (236,500 \pm 105,006) $\mu \mathrm{g} / \mathrm{L}(\mathrm{k}=2$, normal).

Realizou-se um ensaio de proficiência com laboratórios da Rede Brasileira de Laboratórios de Ensaio (RBLE) do Inmetro para análise de CE em cachaça não adoçada. Com esse estudo, foi verificada a importância que as estimativas das incertezas assumem em ensaios de proficiência de poucos participantes e que, para além disso, podem assumir maior relevância como parâmetro de desempenho dos laboratórios; como alguns autores já sugeriram, que talvez venham a se tornar um parâmetro global de avaliação.

Aplicando todo o trabalho de produção do material de referência, desenvolvimento e validação do método para análise de cachaça não adoçada, foram analisadas amostras do programa de fiscalização do MAPA cedidas pelo LFDA/SP. Esse estudo revelou que muitas cachaças ainda estão sendo comercializadas com altos teores de CE. É necessário que os produtores mantenham maior controle do teor desse composto nas suas produções, visto que o país é um grande produtor e exportador desse produto e que o CE é um congênere orgânico tóxico, potencialmente carcinogênico.

Com este trabalho foi possível fornecer ferramentas para um correto monitoramento do CE em cachaça, uma vez que em parceria com o LFDA/SP foi possível validar um método para as análises de rotina, além de produzir um material para que possa ser utilizado no controle de qualidade intralaboratorial destas análises. O EP demonstrou que, apesar de poucos participantes, estes tiveram em sua maioria resultados adequados. No entanto, apesar dos laboratórios analisarem corretamente, o diagnóstico quanto à presença de $\mathrm{CE}$ em cachaça reforçou a importância deste monitoramento uma vez que um número expressivo, e preocupante, de resultados reprovados foram encontrados. Estes resultados reforçaram que as ferramentas desenvolvidas neste mestrado serão extremamente úteis e aplicadas neste monitoramento. 


\section{REFERÊNCIAS}

ALVES, N. P.; DE MORAES, D. N. Metrologia química e a utilização de materiais de referência em medições químicas. São José dos Campos: QUIIMLAB Universidade do Vale do Paraíba, 2003. 19 p.

ANALITICAWEB. Colunas capilares para GC. Colunas capilares - OV. São Paulo, 2020. Disponível em: https://www.analiticaweb.com.br/p.php?Bid=p3d24b0dc8aa68. Acesso em: 15 out. 2020.

ARESTA, M.; BOSCOLO, M.; FRANCO, D. W. Copper(II) catalysis in cyanide conversion into ethyl carbamate in spirits and relevant reactions. Journal of Agricultural and Food Chemistry, Washington, v. 49, n. 6, p. 2819-2824, 2001.

ASSOCIAÇÃO BRASILEIRA DE NORMAS TÉCNICAS. ABNT ISO Guia 30:2016: materiais de referência - termos e definições selecionados. Rio de Janeiro: ABNT, 2016. 9 p.

ASSOCIAÇÃO BRASILEIRA DE NORMAS TÉCNICAS. ABNT ISO Guia 35:2020: materiais de referência: guia para caracterização e avaliação de homogeneidade e estabilidade. Rio de Janeiro: ABNT, 2020. 118 p.

ASSOCIAÇÃO BRASILEIRA DE NORMAS TÉCNICAS. ABNT NBR ISO/IEC 17025:2017: requisitos gerais para a competência de laboratórios de ensaio e calibração. Rio de Janeiro: ABNT, 2017. 32 p.

ASSOCIAÇÃO BRASILEIRA DE NORMAS TÉCNICAS. ABNT NBR ISO/IEC 17043:2011: avaliação de conformidade: requisitos gerais para ensaios de proficiência. Rio de Janeiro: ABNT, 2011. 46 p.

ATKINS, P.; JONES, L. Princípios de química. Tradução de Ricardo Bicca de Alencastro. 5 ed. Porto Alegre: Bookman, 2012. 1026 p.

BAKER, M. Is there a reproducibility crisis? Nature, London, v. 533, p. 452-454, 2016.

BARCELOS, L. V. F.; CARDOSO, M. G.; VILELA, F. J.; DOS ANJOS, J. P. Teores de carbamato de etila e outros componentes secundários em diferentes cachaças produzidas em três regiões do estado de Minas Gerais: Zona da Mata, Sul de Minas e Vale do Jequitinhonha. Química Nova, São Paulo, v. 30, n. 4, p. 1009-1011, 2007.

BELLI, M.; ELLISON, S. L. R.; FAJGELI, A.; KUSELMAN, I.; SANSONE, U.; WEGSCHEIDER, W. Implementation of proficiency testing schemes for a limites number of paticipants. Accreditation and Quality Assurance, Heidelberg, v. 12, p. 391-398, 2007. DOI: 10.1007/s00769-006-0247-0

BRASIL. Ministério da Agricultura, Pecuária e Abastecimento. Instrução normativa no 13 de 29 de junho de 2005. Regulamento Técnico para Fixação dos Padrões de Identidade e Qualidade para Aguardente de Cana e para Cachaça. Diário Oficial da União (DOU), Brasília, 30 de junho de 2005, Seção 1, p. 4. Disponível em: https://pesquisa.in.gov.br/imprensa/jsp/visualiza/index.jsp?data=30/06/2005\&jornal=1 \&pagina=4\&totalArquivos=256. Acesso em: 10 set. 2019. 
BRASIL. Ministério da Agricultura, Pecuária e Abastecimento. Instrução normativa no 01 de 16 de janeiro de 2007. Critérios para Credenciamento, Reconhecimento, Extensão de Escopo e Monitoramento de Laboratórios no Ministério da Agricultura, Pecuária e Abastecimento (MAPA). Diário Oficial da União (DOU), Brasília, 17 de janeiro de 2007, Seção 1, p. 1 - 3. Disponível em: https://pesquisa.in.gov.br/imprensa/jsp/visualiza/index.jsp?jornal=1 \&pagina=1\&data= 17/01/2007\&totalArquivos=80. Acesso em: 10 set. 2019.

BRASIL. Ministério da Agricultura, Pecuária e Abastecimento. Instrução normativa n 57 de 11 de dezembro de 2013. Diário Oficial da União (DOU), Brasília, 12 de dezembro de 2013, Seção 1, p. 5 - 9. Disponível em:

https://pesquisa.in.gov.br/imprensa/jsp/visualiza/index.jsp?data=12/12/2013\&jornal=1 \&pagina=5\&totalArquivos=184. Acesso em: 12 set. 2019.

BRASIL. Ministério da Agricultura, Pecuária e Abastecimento. Instrução normativa n 28 de 8 de agosto de 2014. Diário Oficial da União (DOU), Brasília, 11 de agosto de 2014, Seção 1, p. 7. Disponível em:

https://pesquisa.in.gov.br/imprensa/jsp/visualiza/index.jsp?data=11/08/2014\&jornal=1 \&pagina=7\&totalArquivos=100. Acesso em: 13 set. 2019.

BRASIL. Ministério da Agricultura, Pecuária e Abastecimento. Manual de garantia da qualidade analítica: áreas de identidade e qualidade de alimentos e de insumos. Brasília: Ministério da Agricultura, Pecuária e Abastecimento, 2015. 51 p.

BRASIL. Ministério da Indústria, Comércio Exterior e Serviços. COMEX STAT: Exportação e importação geral. Brasília: Ministério da Indústria, Comércio Exterior e Serviços, 2019a. Disponível em: http://comexstat.mdic.gov.br/pt/geral/2820. Acesso em: 27 mar. 2020.

BRASIL. Ministério da Indústria, Comércio Exterior e Serviços. COMEX STAT: Exportação e importação geral. Brasília: Ministério da Indústria, Comércio Exterior e Serviços, 2019b. Disponível em: http://comexstat.mdic.gov.br/pt/geral/2821. Acesso em: 27 mar. 2020.

BRASIL. Ministério da Indústria, Comércio Exterior e Serviços. Portaria № 2, de 4 de janeiro de 2017. Regimento Interno do Instituto Nacional de Metrologia, Qualidade e Tecnologia - INMETRO. Diário Oficial da União (DOU). Brasília, 05 de janeiro de 2017, Seção 1, p. 42. Disponível em:

https://pesquisa.in.gov.br/imprensa/jsp/visualiza/index.jsp?data=05/01/2017\&jornal=1 \&pagina=42\&totalArquivos=64. Acesso em: 17 out. 2019.

BUREAU INTERNATIONAL DES POIDS ET MESURES. Joint Committee for Guides in Metrology. Evaluation of measurement data: guide to the expression of uncertainty in measurement (GUM). Sévres: BIPM, 2008. 126 p.

BUREAU INTERNATIONAL DES POIDS ET MESURES. International metrology in the field of chemistry and biology. Sévres: BIPM, [20--]. Disponível em: https://www.bipm.org/metrology/chemistry-biology/. Acesso em: 15 out. 2019.

CANTANHEDE, L.B.; DE LIMA, J. B.; LOPES, G. S.; FARIAS, R. F.; BEZERRA, C. W. B. Uso de sílica e sílica-titânica organofuncionalizadas para a remoção de $\mathrm{Cu}(\mathrm{II})$ em aguardentes. Ciência e Tecnologia de Alimentos, Campinas, v. 25, n. 3, p. 500-505, 2005. 
CARUSO, M. S. F.; NAGATO, L. A. F.; ALABURDA, J. Benzo(A)pireno, carbamato de etila e metanol em cachaças. Química Nova, São Paulo, v. 33, n.9, p. 19731976, 2010.

CIOLA, R. Fundamentos da cromatografia a gás. São Paulo: Editora Edgard Blücher Ltda, 1985. 266 p.

CLEGG, B. S.; FRANK, R. Detection and quantitation of trace levels of ethyl carbamate in alcoholic beverages by selected ion monitoring. Journal of Agricultural and Food Chemistry, Washington, v. 36, p. 502-505, 1988.

CONFLAB. Incerteza: software para cálculos de incerteza. Versão 1.0.0.0. [S. I.]: QualiLab, 2018. Disponível em: https://www.conflab.com.br/home. Acesso em: 15 set. 2019.

CONFLAB. Validação: software para validação de métodos. Versão 1.0.0.0 . [S. I.]: QualiLab, 2018. Disponível em: https://www.conflab.com.br/home. Acesso em: 15 set. 2019.

CORDEIRO, P. J. M. Práticas de cromatografia a gás. São Paulo: Scortecci, 2011. $99 \mathrm{p}$.

DA ROCHA, G. M. Metrologia científica e industrial: ciência e tecnologia apoiando a inovação e competitividade da indústria. Revista Analytica, São Paulo, n. 85, p. 3236, 2016.

DE ANDRADE-SOBRINHO, L. G.; BOSCOLO, M.; LIMA-NETO, B. S.; FRANCO, D. W. Carbamato de etila em bebidas alcoólicas (cachaça, tiquira, uísque e grapa). Química Nova, São Paulo, v. 25, n. 6B, p. 1074-1077, 2002.

DE ANDRADE-SOBRINHO, L. G.; CAPPELINI, L. T. D.; DA SILVA, A. A.; GALINARO, C. A.; BUCHVISER, S. F.; CARDOSO, D. R.; FRANCO, D. W. Teores de carbamato de etila em aguardentes de cana e mandioca - parte II. Química Nova, São Paulo, v. 32, n. 1, p. 116-119, 2009.

DE LA CRUZ, M. H. C.; RODRIGUES, J. M.; COUTO, P. R. G.; DA CUNHA, V. S. Estimativa da incerteza de medição em análise cromatográfica: abordagem sobre a quantificação de carbamato de etila em cachaça. Química Nova, São Paulo, v. 33, n. 7, p. 1578-1584, 2010.

DE OLIVEIRA FILHO, J. H.; BORTOLETTO, A. M.; ALCARDE, A. R. Qualidade póscolheita de colmos de cana armazenados e seus reflexos na produção de cachaça. Brazilian Journal of Food Technology, Campinas, v. 19, e2015069, 2016. DOI: 10.1590/1981-6723.6915

DOS ANJOS, J. P.; CARDOSO, M. G.; SACZK, A. A.; ZACARONI, L. M.; SANTIAGO, W. D.; DÓREA, H. S.; MACHADO, A. M. de R. Identificação do carbamato de etila durante o armazenamento da cachaça em tonel de carvalho (Quercus sp) e recipiente de vidro. Química Nova, São Paulo, v. 34, n. 5, p. 874878, 2011. 
EMPRESA BRASLEIRA DE PESQUISA AGROPECUÁRIA. Agência Embrapa de Informação Tecnológica. Árvore do conhecimento. Cana-de-açúcar. Cachaça. Brasília, 2008. Disponível em: https://www.agencia.cnptia.embrapa.br/gestor/canade-acucar/arvore/CONT000fiog 1ob502wyiv80z4s473agi63ul.html\#. Acesso em: 19 out. 2020.

EURACHEM. CITAC Guide CG 4: quantifying uncertainty in analytical measurement. 3. ed. [S. I.], 2012. 133 p.

EUROPEAN PT INFORMATION SYSTEM (EPTIS). [S. I.], 2020. Disponível em: https://eptis.org/about.htm. Acesso em: 20 mai. 2020.

GALINARO, C. A.; FRANCO, D.W. Formação de carbamato de etila em aguardentes recém-destiladas - proposta para seu controle. Química Nova, São Paulo, v. 34, n. 6, p. 996-1000, 2011.

HARRIS, D. C. Análise química quantitativa. 8. ed. Rio de Janeiro: LTC, 2012. 900 p.

INSTITUTO DE PESOS E MEDIDAS DO ESTADO DE SÃO PAULO. Bureau internacional de pesos e medidas - BIPM. São Paulo: IPEM, 2013. Disponível em: http://www.ipem.sp.gov.br/index.php?option=com_content\&view=article\&id=1197\%3 Abureau-inernacional-de-pesos-e-medidas-bipm\&catid=67\&ltemid=260. Acesso em: 13 out. 2019.

INSTITUTO NACIONAL DE METROLOGIA, NORMALIZAÇÃO E QUALIDADE INDUSTRIAL. Metrologia científica: a metrologia química no Inmetro. Brasília: INMETRO, 2018a. Disponível em

http://www.inmetro.gov.br/metcientifica/metquimica.asp. Acesso em: 20 set. 2019.

INSTITUTO NACIONAL DE METROLOGIA, NORMALIZAÇÃO E QUALIDADE INDUSTRIAL. Metrologia científica: estrutura hierárquica de rastreabilidade. Brasília: INMETRO, 2018b. Disponível em http://www.inmetro.gov.br/metcientifica/estrutura.asp. Acesso em: 20 set. 2019.

INSTITUTO NACIONAL DE METROLOGIA, NORMALIZAÇÃO E QUALIDADE INDUSTRIAL. Vocabulário internacional de metrologia: conceitos fundamentais e gerais e termos associados (VIM). Edição luso-brasileira. Duque de Caxias: INMETRO, 2012. 94 p.

INSTITUTO NACIONAL DE METROLOGIA, NORMALIZAÇÃO E QUALIDADE INDUSTRIAL (INMETRO). Orientação sobre a validação de métodos analíticos DOQ-CGCRE-008. Coordenação Geral de Acreditação: revisão 05. Brasília: INMETRO, 2016. $31 \mathrm{p}$.

INSTITUTO NACIONAL DE METROLOGIA, NORMALIZAÇÃO E QUALIDADE INDUSTRIAL. Metrologia científica: descrição de MRC. Brasília: INMETRO, 2019. Disponível em http://www.inmetro.gov.br/metcientifica/mrc-descricao/mrc-8507.asp. Acesso em: 10 dez. 2019.

INTERNATIONAL ORGANIZATION FOR STANDARDIZATION. ISO 13528:2015. statistical methods for use in proficiency testing by interlaboratory comparison. Geneva: ISO, 2015. 90 p. 
INTERNATIONAL ORGANIZATION FOR STANDARDIZATION. ISO Guide 24:1978: guidelines for the acceptance of testing and inspection agencies by certification bodies. Geneva: ISO, 1978. Disponível em: https://www.iso.org/standard/19733.html. Acesso em: 20 mai. 2020.

INTERNATIONAL ORGANIZATION FOR STANDARDIZATION. ISO Guide 25:1990. general requirements for the competence of calibration and testing laboratories Geneva: ISO, 1990. 6 p. Disponível em: https://www.iso.org/standard/19734.html. Acesso em: 20 mai. 2020

INTERNATIONAL ORGANIZATION FOR STANDARDIZATION. ISO Guide 38:1983. Geneva: ISO, 1983. Disponível em: https://www.iso.org/standard/19744.html. Acesso em: 20 mai. 2020

INTERNATIONAL ORGANIZATION FOR STANDARDIZATION. ISO Guide 45:1985. Geneva: ISO, 1985. Disponível em: https://www.iso.org/standard/19751.html. Acesso em: 20 mai. 2020

INTERNATIONAL ORGANIZATION FOR STANDARDIZATION. ISO Guide 49:1986. Geneva: ISO, 1986. Disponível em: https://www.iso.org/standard/19755.html. Acesso em: 20 mai. 2020

INTERNATIONAL ORGANIZATION FOR STANDARDIZATION. ISO Guide 58:1993. Calibration and testing laboratory accreditation systems - General requirements for operation and recognition. Geneva: ISO, 1993. 6 p. Disponível em: https://www.iso.org/standard/21678.html. Acesso em: 20 mai. 2020

INTERNATIONAL ORGANIZATION FOR STANDARDIZATION. ISO Guide 80:2014(E). Guidance for the in-house preparation of quality control materials (QCMs). Geneva: ISO, 2014. 50 p. Acesso em: 23 mai. 2021.

INTERNATIONAL ORGANIZATION FOR STANDARDIZATION. ISO/IEC 17025:1999. General requirements for the competence of testing and calibration laboratories. Geneva: ISO, 1999. 26 p. Disponível em: https://www.iso.org/standard/30239.html. Acesso em: 20 mai. 2020

INTERNATIONAL ORGANIZATION FOR STANDARDIZATION. ISO/IEC 17025:2017. General requirements for the competence of testing and calibration laboratories. Geneva: ISO, 2017. 30 p.

KARASEK, F. W.; CLEMENT, R. E. Basic gas chromatography - mass spectrometry: principles and techniques. New York: Elsevier, 1988. 201 p.

LACHENMEIER, D. W.; LIMA, M. C. P.; NÓBREGA, I. C. C.; PEREIRA, J. A. P.; KERR-CORREAA, F.; KANTERES, F.; REHM, J. Cancer risk assessment of ethyl carbamate in alcoholic beverages from Brazil with special considerations ti the spirits cachaça and tiquira. BMC Cancer, London, v. 10, p. 1-15, 2010. DOI: 10.1186/1471-2407-10-266

LANÇAS, F. M. Cromatografia em fase gasosa. São Carlos: Acta, 1993. 254 p. 
LELIS, V. G.; CHAVES, J. B. P.; DUTRA, M. B. de L.; REIS, R. S.; LESSA, J. B. Ocorrência de carbamato de etila em cachaças de alambique e em aguardentes industriais. Revista Ceres, Viçosa, v. 61, n. 4, p. 467-474, 2014.

LINSINGER, T. P. J.; PAUWELS, J.; LAMBERTY, A.; SCHIMMEL, H. G.; VAN DER VEEN, A. M. H.; SIEKMANN, L. Estimating the uncertinty of stability for matrix CRMs. Frenesius Journal Analytical Chemistry, Berlin, v. 370, p. 183-188, 2001.

McNAIR, H. M.; MILLER, J. M. Basic gas chromatografy. New York: John Wiley \& Sons, 1998. $200 \mathrm{p}$.

MENDITTO, A., PATRIARCA, M., MAGNUSSON, B. Understanding the meaning of accuracy, trueness and precision. Accreditation and Quality Assurance, Heidelberg, v. 12, n. 1, p. 45-47, 2007. DOI: 10.1007/s00769-006-0191-z

MILLER, J. N.; MILLER, J. C. Statistics and chemometric for analytical chemistry. 6. ed. London: Pearson Education Limited, 2010. 278 p.

NATIONAL INSTITUTE OF STANDARDS AND TECHNOLOGY. About NIST. Gaithersburg, 2017. Disponível em: https://www.nist.gov/about-nist. Acesso em: 20 out. 2019.

OLIVARES, I. R. B. Gestão de qualidade em laboratórios. 4. ed. Campinas: Editora Átomo, 2019. 176 p.

OLIVARES, I. R. B.; LOPES, F. A. Essential steps to providing reliable results using the analytical quality assuarance cycle. Trends in Analytical Chemistry, Amsterdam, v. 35, p. 109-121, 2012. DOI: 10.1016/j.trac.2012.01.004

OLIVARES, I. R. B.; SOUZA, G. B.; NOGUEIRA, A.R.A.; TOLEDO, G.T.K.; MARCKI, D. C. Trends in development of certified reference materials for chemical analysis: focus on food, water, soil and sediment matrices. Trends in Analytical Chemistry, Amsterdam, v. 100, p. 53-64, 2018. DOI: 10.1016/j.trac.2017.12.013

RUDAZ, S.; FEINBERG, M. From method validation to result assessment: estabilished facts and pending questions. Trends in Analytical Chemistry, Amsterdam, v. 105, p. 68-74, 2018. DOI: 10.1016/j.trac.2018.04.013

SCOTT, R. P. W. Introduction to analytical gas chromatography. New York: Marcel Dekker, 1998. 397 p. (Chromatographic science series, v. 76).

SKOOG, D. A.; HOLLER, F. J.; NIEMAN, T. A. Princípios de análise instrumental. Tradução de Ignez Caracelli, Celso Isolani, Regina Helena de Almeida Santos, Regina Helena Porto Francisco. 5. ed. Porto Alegre: Bookman, 2002. 836 p.

SKOOG, D.; WEST, D.; HOLLER, J.; CROUCH, S. Fundamentos de química analítica. São Paulo: Thompson Learning, 2006. 1067 p.

SORATO, A. N; VARVAKIS, G; HORII, J. A certificação agregando valor à cachaça do Brasil. Ciência e Tecnologia de Alimentos, Campinas, v. 27, n. 4, p. 681-687, 2007.

TAYLOR, J. K. Handbook for SRM users. Gaithersburg: National Bureau of Standars, $1985.98 \mathrm{p}$. 
THE NOBEL PRIZE. The Nobel Prize in Chemistry 1952. Stockholm, 2019. Disponível em: https://www.nobelprize.org/prizes/chemistry/1952/summary/. Acesso em: 12 dez. 2019.

THE OBSERVATORY OF ECONOMIC COMPLEXITY. Brazil. [S. I.]: OEC, [20--]. Disponível em: https://oec.world/pt/profile/country/bra/\#Exporta\%C3\%A7\%C3\%A3o. Acesso em: 17 out. 2019.

VENTURINI FILHO, W. G. Bebidas alcoólicas: ciência e tecnologia. 2 ed. São Paulo: Blucher, 2016. v. 1, p. 307-358.

VISENTAINER, J. V. Aspectos analíticos da resposta do detector de ionização em chama para ésteres de ácidos graxos em biodiesel e alimentos. Química Nova, São Paulo, v. 35, n. 2, p. 274-279, 2012.

WORLD HEALTH ORGANIZATION. International Agency for Research on Cancer. Alcohol consumption and ethyl carbamate. Lyon, 2010. 1028 p. (Monographs on the evaluation of carcinogenic risks to humans, v. 96).

ZACARONI, L. M.; CARDOSO, M. G.; SACZK, A. A.; SANTIAGO, W. D.; DOS ANJOS, J. P. Caracterização e quantificação de contaminantes em aguardentes de cana. Química Nova, São Paulo, v. 34, n. 2, p. 320-324, 2011. 


\section{APÊNDICE A}

\section{R०A Research in Quality Assurance for Laboratories}

\section{FORMULÁRIO DO ENSAIO DE PROFICIÊNCIA}

Congêneres orgânicos em bebidas destiladas e retificadas

Material de Referência C02_20 - Congêneres orgânicos em cachaça não adoçada Analito: carbamato de etila

\section{IDENTIFICAÇÃO DO PARTICIPANTE}

Razão social:

Loradouro:

Contatos:

Responsável técnico:

e-mail:

\section{DESCRIÇÃO DO MÉTODO}

Equipamentos e Insumos

Condiçőes cromatográficas

Preparo de amostra por padrão interno (pi)

Padrăo(s) interno(s) utilizado(s):

Concentração(s) do(s) padrăo(s) interno(s):

Preenchimento necessário apenas caso o laboratório adotou um ou mais padrões internos para as quantificações. 


\section{APRESENTAÇÃO DOS RESULTADOS}

\section{Respostas cromatográficas para a curva analítica}

O participante deve preencher a quantidade de níveis que normalmente utiliza em suas análises de rotina não sendo obrigatório a realização dos 7 pontos analíticos, mas todas as análises devem ser realizadas em 5 ensaios (quintuplicata).

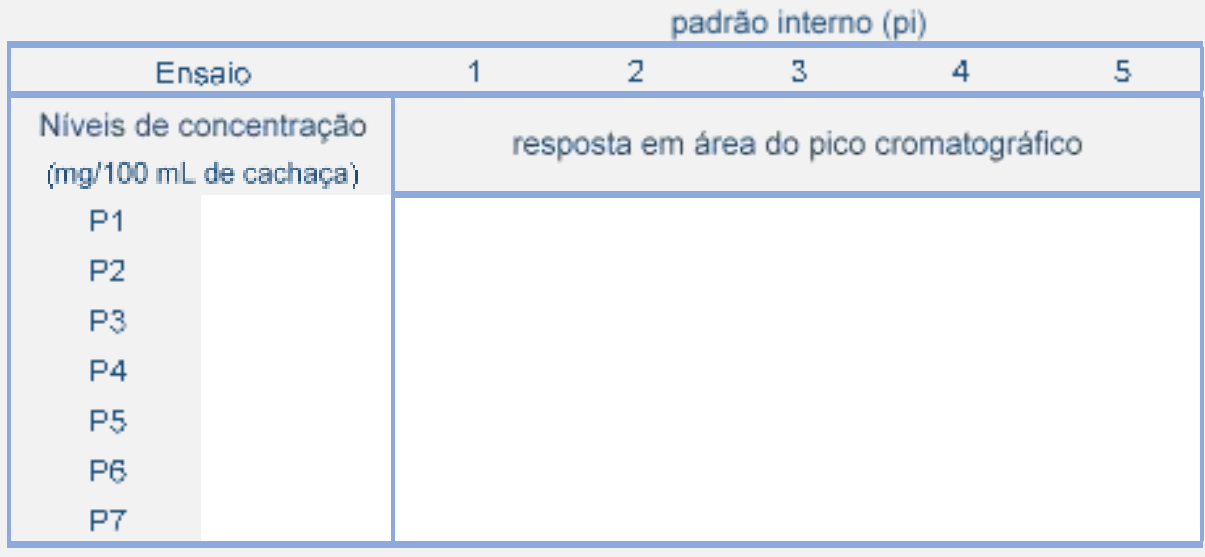

Carbamato de Etila

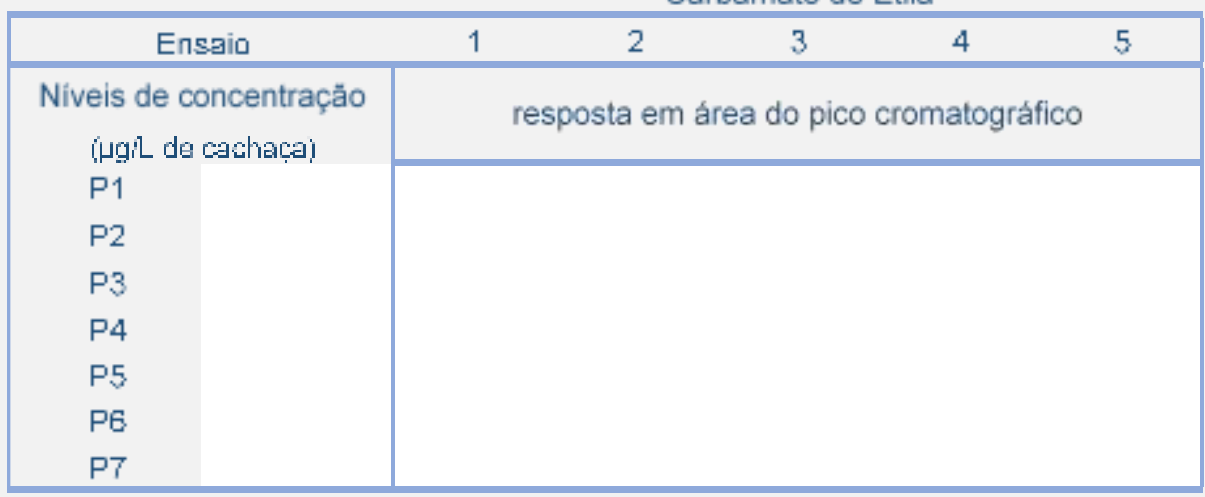

Respostas cromatográficas para o MRC C02_20

Carbamato de Etila

\begin{tabular}{|c|ccccc|}
\hline \multirow{2}{*}{ Ensaios } & \multicolumn{5}{|c|}{ resposta em área do pico cromatográfico } \\
& 1 & 2 & 3 & 4 & 5 \\
\hline sinal & & & & & \\
\hline
\end{tabular}


Concentração de carbamato de etila no MRC C02_20

Carbamato de etila

$\pm$

ug/L de cachaça

Fator de expansåo utilizado:

Caso o laboratório envie o valor da incerteza expandida, o cálculo do desempenho do participante será realizado tanto por índice $Z$ quanto pelo índice zeta e EZ Score, senão a avaliação do desempenho será feita apenas pelo cálculo do índice Z. Para isso, solicitamos o certificado de calibração da seringa de injeçāo e sua tolerância para adicionarmos ao cálculo da incerteza. 


\section{APÊNDICE B}

Relatório do Conflab Validação $\circledast$ para a linearidade da curva analítica gerada para os estudos de estabilidade e para a avaliação das amostras de fiscalização do MAPA.

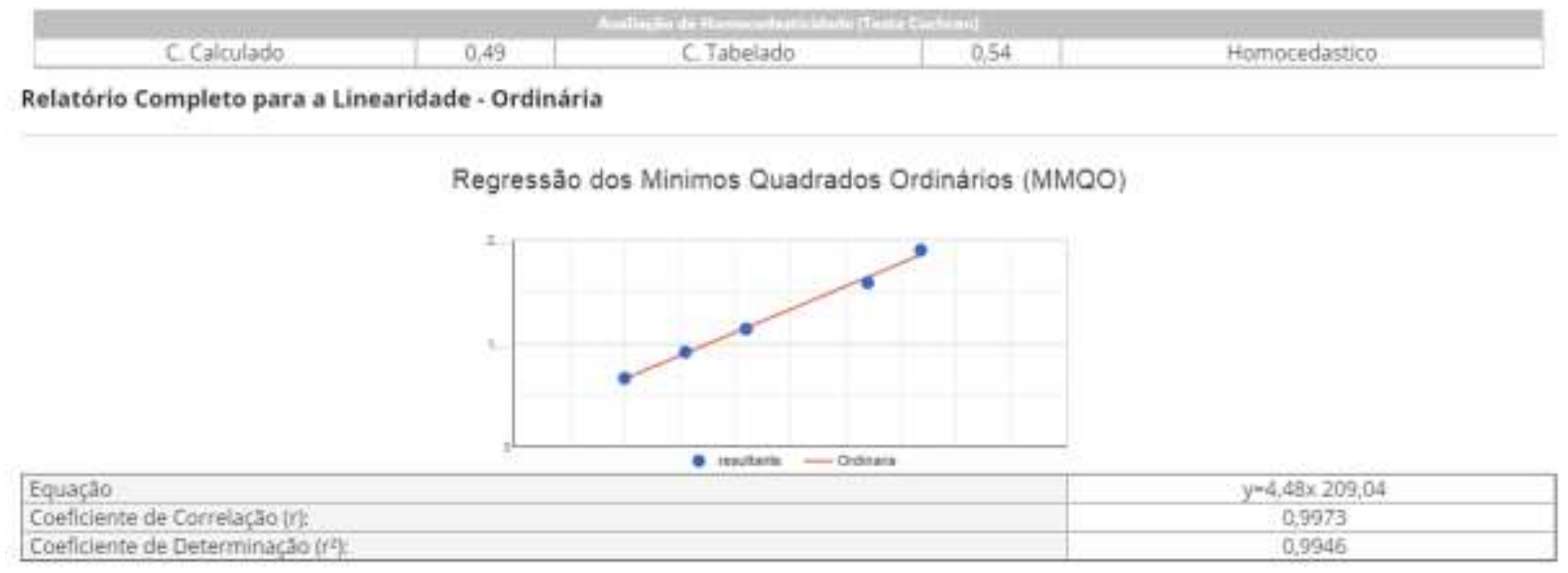

\begin{tabular}{|c|c|c|c|c|}
\hline & & 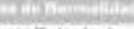 & 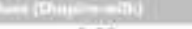 & \\
\hline \multicolumn{5}{|c|}{ 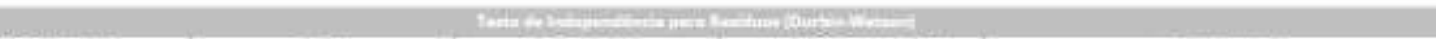 } \\
\hline D Calculado & 2,54 & D Tabeludo & $d_{i}: 1.35 \quad d_{0}: 1.49$ & inçonclusivo \\
\hline \multicolumn{5}{|c|}{ Tomingie } \\
\hline F Calculado & 549,76 & F Tabelado & 17.44 & Y efetivamente varia em funças de $\mathrm{X}$. \\
\hline \multicolumn{5}{|c|}{ 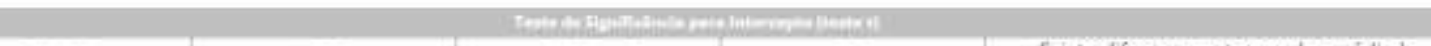 } \\
\hline
\end{tabular}

Residuos

\begin{tabular}{|c|c|c|c|c|c|}
\hline \multirow{2}{*}{\multicolumn{2}{|c|}{$\begin{array}{l}\text { Apresentar residuos } \\
\text { Teste de outliers utilizando }\end{array}$}} & \multirow{2}{*}{\multicolumn{2}{|c|}{$\begin{array}{l}\text { OAbsolutos } \\
\text { OTeste de Grubbs (total) }\end{array}$}} & \multirow{2}{*}{\multicolumn{2}{|c|}{$\begin{array}{l}\text { Oreiativos } \\
\text { OTeste de Grubbs por nivel }\end{array}$}} \\
\hline & & & & & \\
\hline Conc. $(\mathrm{G} / \mathrm{s} / \mathrm{M})$ & Replicata 1 & Replicate 2 & Replicata 3 & Aeplicata 4 & Replicata! \\
\hline 100 & 87,412 & $-96,588$ & 18,412 & $-96,588$ & 116,412 \\
\hline 155 & 136,263 & 53,263 & 37,263 & $-32,737$ & $-130,737$ \\
\hline 210 & $-35,886$ & $-12,886$ & -152.886 & -159886 & 30,114 \\
\hline 320 & $.197,184$ & $\$ 3,816$ & 0,184 & $.107,184$ & 23,184 \\
\hline 368 & 9,995 & 15,995 & 158,995 & 64,005 & 115,995 \\
\hline
\end{tabular}

Gráficos de Residuos

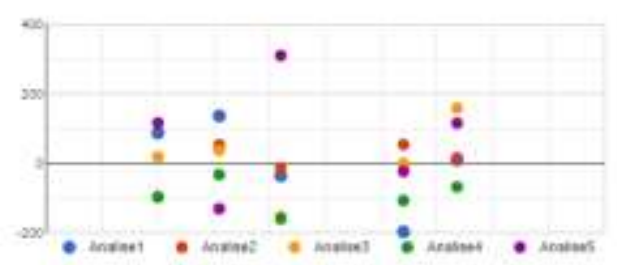

Desvio:

\begin{tabular}{|c|c|c|c|c|c|c|}
\hline \multirow{2}{*}{ Cone (ㅂgg/) } & \multicolumn{5}{|c|}{ Desvio (\%) } & \multirow{2}{*}{ Coeficiente de Variaçlo (E) } \\
\hline & Aeplicata 1 & Replicata 2 & Replicato 3 & Moplicata 4 & Replicata 5 : & \\
\hline 100 & 19.531 & 21,582 & 4,114 & 21.582 & 26011 & 15,10 \\
\hline 155 & 19.643 & 7,678 & 5.372 & 4719 & 18.847 & 10,95 \\
\hline 210 & 3.818 & 1.371 & 16.267 & 17,012 & 32996 & 16.78 \\
\hline 320 & 13,768 & 3,758 & 0,013 & 7.484 & 1,619 & 6.21 \\
\hline 368 & 0.607 & 0,971 & 9.654 & 4.129 & 7,043 & 4.76 \\
\hline
\end{tabular}


Regressão dos Minimos Quadrados Ponderada (MMOP)

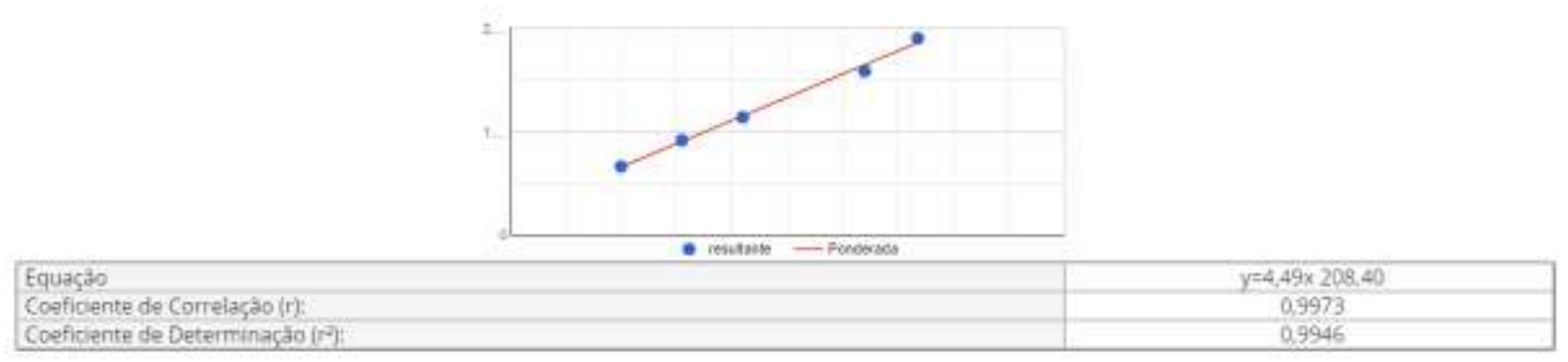

\begin{tabular}{|c|c|c|c|c|}
\hline \multicolumn{5}{|c|}{ 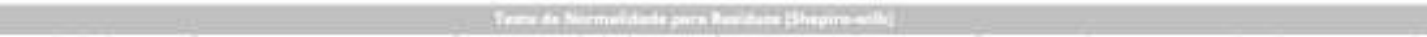 } \\
\hline W Calculado & 0,97 & WTabeiado & 0,92 & Os residuos possuem distribulę̧ăo normal. \\
\hline \multicolumn{5}{|c|}{ 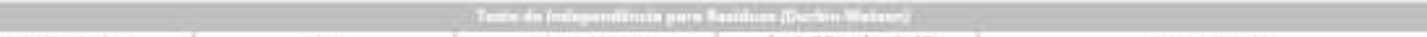 } \\
\hline \multicolumn{5}{|c|}{ 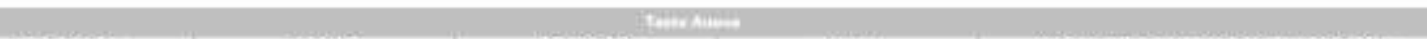 } \\
\hline FCalkulado & 556.86 & FTabelado & 17.44 & Y efetivamente varia emi funçào de $X$. \\
\hline \multicolumn{5}{|c|}{ 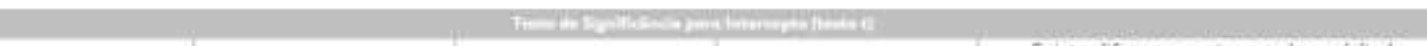 } \\
\hline tCalculado) & 4.48 & tTabelado) & 2,78 & $\begin{array}{c}\text { Existe diferença entre o valor médio b } \\
\text { experimental e o valor } 0 \text {. }\end{array}$ \\
\hline
\end{tabular}

Residuos

\begin{tabular}{|c|c|c|c|c|c|}
\hline \multirow{2}{*}{\multicolumn{2}{|c|}{$\begin{array}{l}\text { Apresentar residuos } \\
\text { Teste de outliers utilizando }\end{array}$}} & \multirow{2}{*}{\multicolumn{2}{|c|}{$\begin{array}{l}\text { OAbsolutos } \\
\text { OTeste de Grubbs (total) }\end{array}$}} & \multirow{2}{*}{\multicolumn{2}{|c|}{$\begin{array}{l}\text { ORelativos } \\
\text { Oteste de Grubbs por nivel }\end{array}$}} \\
\hline & & & & & \\
\hline Conci(ugl) & Replicata 1 & Replicata 2 & Replicase 3 & Replicata 4 & Replicata 5 \\
\hline 155 & 134,239 & 51,239 & 35,239 & $-34,761$ & -132761 \\
\hline 210 & $-38,856$ & $.15,656$ & $-155,856$ & +162856 & 307,144 \\
\hline 320 & $-202,046$ & 48,954 & $-5,046$ & $-112,046$ & $-28,046$ \\
\hline
\end{tabular}

Graficos de Residuos

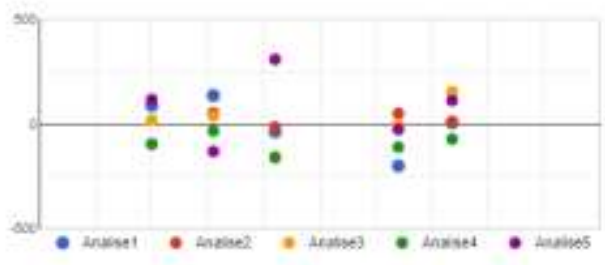

Desvio:

\begin{tabular}{|c|c|c|c|c|c|c|}
\hline \multirow{2}{*}{ Conc. (ug/L) } & \multicolumn{5}{|c|}{ Deswio (4) } & \multirow{2}{*}{ Copficinnte de Variario ( $\%$ ) } \\
\hline & Replicata 1 & Replicata 2 & Replicata 3 & Replicata 4 & Replicata 5 & \\
\hline 100 & 19,217 & 21,739 & 3,858 & 21,739 & 25,672 & 15,10 \\
\hline 155 & 19,277 & 7,358 & 5,060 & 4,992 & 19,065 & 10,95 \\
\hline 210 & 4,118 & 1,681 & 16,520 & 17,262 & 32.555 & 16,78 \\
\hline 320 & 14,054 & 3.405 & 0,351 & 7,794 & 1.951 & 6.21 \\
\hline 368 & 0,261 & 0,623 & 9.273 & 4.457 & 6.672 & 4.76 \\
\hline
\end{tabular}




\section{APÊNDICE C \\ Certificado de Material de Referência}

Identificação do item

MR: Carbamato de etila em cachaça não adoçada

Código do lote: MR C02_20

Data de emissão: 20/12/2020

Descrição e preparação do $M R$

Este MR é uma solução de carbamato de etila em cachaça não adoçada envasado em frasco âmbar contendo $2 \mathrm{~mL}$ de solução.

Metodologia analítica

Foi realizado o estudo de estabilidade de armazenamento pelo método isócrono por um período de 9 meses sob condições de temperatura ambiente. O estudo de estabilidade de transporte foi realizado sob condicionamento a $40^{\circ} \mathrm{C}$ por $72 \mathrm{hs}$. Ambos os estudos foram realizados com 2 pontos no tempo. A homogeneidade entre os frascos também foi verificada. Todos os estudos e a caracterização foram realizados sob as condições cromatográficas do método validado nas condições: cromatógrafo a gás Shimadzu, modelo GC-2010 PLUS em coluna DB-WAX $(60 \mathrm{~m} \times 0,25 \mathrm{~mm} \times 0,25 \mu \mathrm{m})$ acoplado a um espectrômetro de massas quadrupolo. Injetor: temperatura: $250^{\circ} \mathrm{C}$; modo de injeção: splitless; tempo de amostragem: $1 \mathrm{~min}$; volume de injeção: $2 \mu \mathrm{L}$; fluxo de gás $(\mathrm{He})$ na coluna: $1 \mathrm{~mL} / \mathrm{min}$; modo: velocidade linear. Programação da temperatura do forno: $90^{\circ} \mathrm{C}$ estável por $2 \mathrm{~min}$, de $90^{\circ} \mathrm{C}$ a $200^{\circ} \mathrm{C} \mathrm{com}$ incremento de $10^{\circ} \mathrm{C} / \mathrm{min}$, estável por $2 \mathrm{~min}$; tempo total da corrida de $15 \mathrm{~min}$. Detector de massas: temperatura da interface: $230^{\circ} \mathrm{C}$; fonte de íons: $250^{\circ} \mathrm{C}$; sistema de ionização: impacto de elétrons a 70 eV; corte de solvente para ligar o detector: 9 min; modo de aquisição: SIM; íons monitorados: 44, 62 e 74; event time: 0,30s.

Recomendação de uso e armazenamento

Este material deve ser mantido em temperatura $-4^{\circ} \mathrm{C}$ ou inferior e protegido de incidência de luz.

Destinado para análises de determinação de carbamato de etila em cachaça não adoçada e para o desenvolvimento, validação e controle de qualidade de métodos analíticos em matrizes alcoólicas similares à cachaça não adoçada. 
Após a sua abertura este material deve ser manuseado rapidamente. É tóxico, potencialmente carcinogênico. Deve-se evitar inalação ou contato com a pele. É recomendado o uso de EPIs como luvas, jaleco e óculos ao manuseá-lo.

Foi realizado o estudo de homogeneidade dentro do frasco, mas não foi realizado estudo de amostragem mínima para garantir a homogeneidade dentro do frasco. A incerteza associada ao estudo foi adicionada ao valor da incerteza expandida.

A integridade do material é garantida até o seu primeiro uso. 0 certificado perde a validade caso o material seja danificado, contaminado ou alterado.

Valor certificado

O valor certificado apresenta a faixa de confiança para qual as maiores fontes de incertezas conhecidas foram estudadas e consideradas.

O valor certificado com a sua incerteza expandida para um nível de confiança de $95 \%$ e fator de cobertura $\mathrm{k}=2$ está descrito na Tabela 1 :

Tabela 1 - Valor certificado de carbamato de etila em $\mu \mathrm{g} / \mathrm{L}$ (ppb) em cachaça não adoçada.

\begin{tabular}{ccc}
\hline Contaminante & Valor $(\mu \mathrm{g} / \mathrm{L})$ & $\mathrm{U}^{*}(\mu \mathrm{g} / \mathrm{L})$ \\
\hline Carbamato de etila & 236,500 & 105,006
\end{tabular}

* A incerteza expandida foi calculada pela combinação das contribuições das incertezas da caracterização e da homogeneidade conforme ISO Guia 35:2020: linearidade, repetibilidade, vidrarias, balança analítica, micropipetas, homogeneidade entre os frascos e homogeneidade dentro dos frascos.

Prazo de validade

Este material se mostrou estável por tempo indeterminado, desde que armazenado conforme as recomendações deste certificado. Entretanto, como não será mantido um estudo de monitoramento desse lote ao longo do tempo, não será possível comunicar ao usuário caso alguma alteração no valor certificado aconteça. Desta forma, após a data 20/12/2021 este certificado perde a garantia.

Referências

ASSOCIAÇÃO BRASILEIRA DE NORMAS TÉCNICAS (ABNT). ABNT ISO Guia 35:2020: Materiais de referência - Guia para caracterização e avaliação de homogeneidade e estabilidade, Rio de Janeiro, 2020. 118 p. 


\section{ANEXO A}

\section{Certificado de Material de Referência}

DIMCI 1299/2014f

Vimeru de Certificade

\section{Identificaçalo do iltem}

MRC: Carbamato de etila em soluçìo hidroaloo6tica (equivalente à cachaça)

Dnidade produtora: Divisăo de Motrologia Qulmica e Térnica (Dimup)

Numeracão de lote: MRC 8507,0001

Código de servipa: 8507
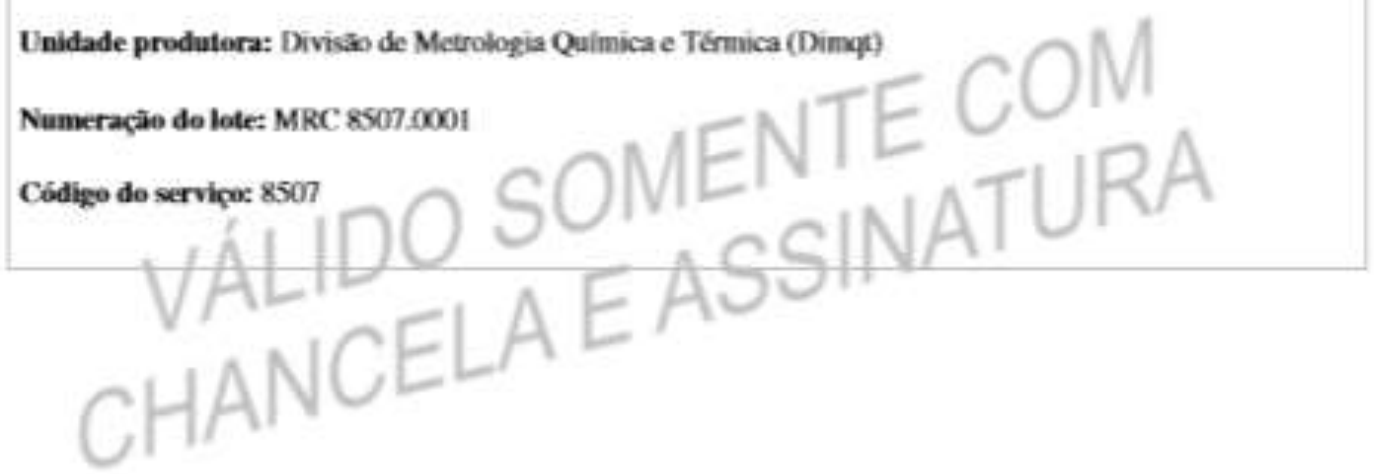

$17 / 12 / 2019$

Data de enibsase

Bruno Carius Garrido

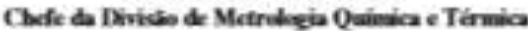

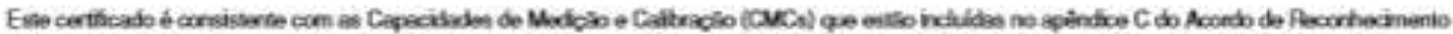

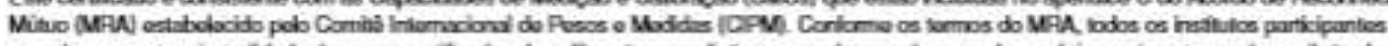

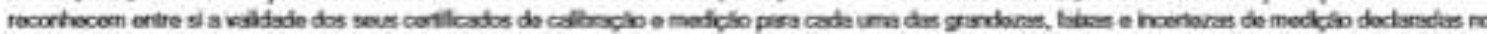
Aplndioe C (paes muicres dotathes we hilipilimum bipm orgl)

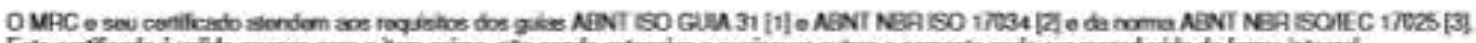

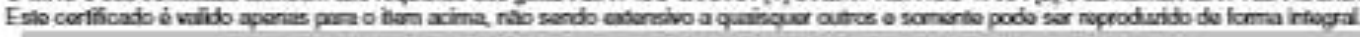

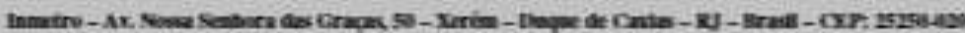

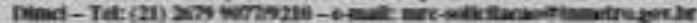




\section{Certificado de Material de Referência}

DIMCI 1299/2014f

Nínere de Certificado

\section{Descriçào e preparaçào do MRC}

Este Material de Refertacia Certificado (MRC) consiste de una soluço de cartamato de etila em solucho hidroalcostica a $36 \%$ (m/m), equivalente a $43 \%(\mathrm{v} / \mathrm{v})$, preparada através do métiodo gravimétrico. O MRC foi envasado em frasco amubar de vidro borossilicato contendo $6 \mathrm{ml}$. de soluçäo.

\section{Metodologia analifica}

Os estudos de homogeneidade, estabilidade e caracterimaclo foram realirados pela tiknica de cromatografia gasosa com espectrometria de massas de dilvipido isotópica (CG-EMDD). Condipies cronatograficas: Coluna

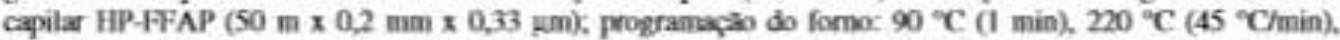
permaneceado nesta lemperatura por 4 minutos, lemperatura do injetor $240{ }^{\circ} \mathrm{C}$, modo de injecalo em split (racalo 1:10), fluxo do gás de arraste hétio $1 \mathrm{ml} / \mathrm{min}$; volume de injeça 1 lpI. Condiptes do espectrónetro de massas. lonizacäo por elétrons a $70 \mathrm{eV}$; modo de aquisiçio so monitoramento de ion seleciopado (SIM); temperatura da fonte de fons, linha de transferência e interface de $230^{\circ} \mathrm{C}, 230^{\circ} \mathrm{Ce} 150^{\circ} \mathrm{C}$, respectivaniente.

\section{Rastreabilidade metrológica}

O valor certificado para o carhanato de etsla poosui rastreahinidade melrológica por meio do aso de gravimetria $e$

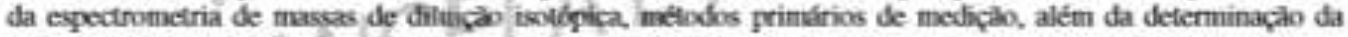
purera do cartamato de ctila utilizado para o preparo das soluçies de calibraçio.

\section{Uso pretendido}

Este MRC tem sua utilimaclo destinada a ensaios para a determinacto de cartamato de etila em cachaç e para o desenvolvimento, validaciào e controle de qualidade de nétodos analitices para a determinacióo deste analito em amostras de cachaca e hebidas com toor alcoxilico similar. A commtatividade nào foi avaliada.

\section{Instruçèes para uso}

Este MRC deve ser manipulado o mais rápiobo possivel após abertura do frasoo, Material tóxico.

A fim de garantir a tomada de uma amostra bonsoginea, a quantidade minima a ser utilizada é $1,5 \mathrm{~g}$

\section{Transporte e armazenagea}

Este MRC deve ser armanenado em local protegido contra a incidtacia de luz e em temperatura de $(4 \pm 2)^{\circ} \mathrm{C}$.

Todas as informaçes referentes as transponte e seguranca estäo contidas na FSPQ (Ficha de lnformaça de Segurança de Produtos Quimicos), fisponiveis no enderop̧o eletrinico (wwwinmetro gov.hr). 


\section{Certificado de Material de Referência}

DIMCI 1299/2014f

Nímere de Certificade

\section{Valor certificado}

0 valor certificado 6 o que apresenta a mais clevada confiança na sta exatidiso e para o qual todas as fontes de erro conhecidas ou potenciais foram pesquisadas e considerades.

$O$ valor certificado deste MRC com saa incertera expandicla $(U)$ para um nivel de confianca de aproximsadamente $95 \%$ e fatior de ahrangëncia $k=2$ [4] estäo dexcrilos nas Tabelas 1 e 2 ;

Tabelal: Valor certificado de carbamato de elila em ne/g de soltaço hidrualcóolica

\begin{tabular}{ccc}
\hline Contaminande & $\begin{array}{l}\text { Volor } \\
(\mathrm{ne} / \mathrm{g})\end{array}$ & $\begin{array}{c}U \\
(\mathrm{se} / \mathrm{g})\end{array}$ \\
\hline Cartamato de ctila & 149,2 & 5.7
\end{tabular}

Tahela 2: Valor certificado de cartaruato de etila cor nighul, de soluçäo hidroalooslica.

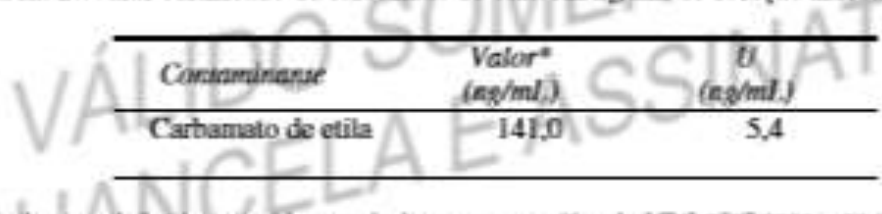

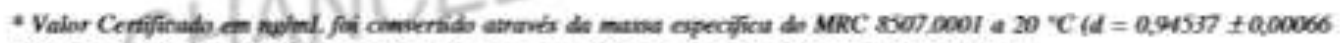

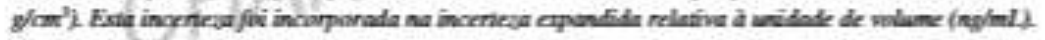

A incortera expandida foi calculada pela combinaplo das contribuip̧es das incerteras de estabilidade de longa $\mathrm{c}$ curta duraçio, da caracterizaço e da homopeneidade do lote, conforne o ISO GUM [4] e ARNT ISO Guia 35 [5]. O grau de bomogeneidade deste MRC foi deterninedo e a incertera inenente à heterogeneidade da amostra estí incluida na incentera expandida do MRC [S].

As medipies analiticas foram realirades por R. R. R. Almeida, I. M. Monkeiro e M. P. Vicentim. A avaliagào dos resultados foi realizada por E. C. P. Rego.

\section{Prazo de validade}

O MRC 8507.0001 é valido ato 31 de dezenabro de 2021.

Este MRC deve ser manuseado e armanenado de acondo com as instrucjes contidss neste certificado.

O certificado nào terá valor caso o MRC seja danificado, contamintado ou alterndo.

O inmeiro garanle a integridade deste MRC até o seu primeiro uso.

O Inmetro mantem um programa de monitoramento de todos os MRC Quakquer alteracko no vabor certificado observada durante o monitorannento será imediatamente conanicada ao usukfio. 
148

Certificado de Material de Referência

DIMCI 1299/2014f

Observaçōes

Este certificado cancela e substitui o certificado DIMCI 1299/2014 e enitido em 01/10/2019.

Rejerências

[1] ARNT ISO GUIA 31-2017, Maleriais de referíncia - Conteído de ocrtificados, rótulos e documentaçìn associada.

[2] ABNT NBR ISO 17034:2017, Requisitos gerais para a competlncia de produlores de material de referlncia. [3] ABNT NBR ISO/EC 17025:2017, Requisitos gerais para compeléncia de laboratórios de ensabo e calihracho.

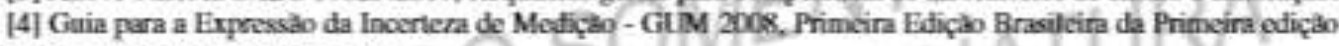
do Bli'M de 2008 , Inmetro, 2012

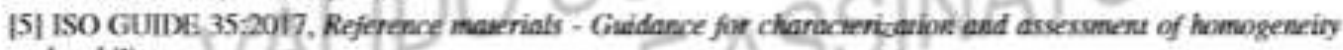
and suability.

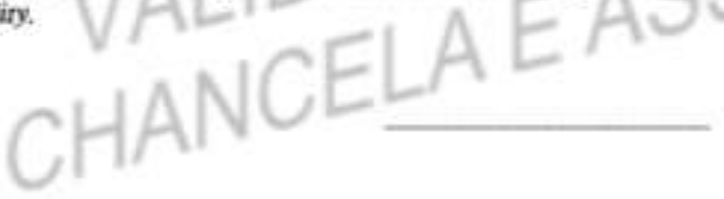

Trie vo 
ANEXO B

\section{f a pas?}

The Food and Environment Research Agency
Sand Hutton, York, YO411LZ
el: +44 (0)1904462100 Fax +44(0)1904 500440
testmaterials@fapas.com www.fapas.com

\begin{tabular}{|l|r|}
\hline FAPAS QC MATERIAL DATA SHEET & T1368QC \\
\hline Matrix & Whisky \\
\hline Weight / Volume of Contents & $200 \mathrm{mI}$ \\
\hline
\end{tabular}

\begin{tabular}{|c|c|c|c|c|}
\hline Analyte & $\begin{array}{c}\text { Assigned } \\
\text { Value, } \\
\mathrm{X}_{\mathrm{a}}\end{array}$ & $\begin{array}{l}\text { Range for } \\
\qquad|z| \leq 2\end{array}$ & Units & $\begin{array}{c}\text { No. of data } \\
\text { points } \\
\text { producing } \mathrm{X}_{\mathrm{a}}\end{array}$ \\
\hline Alcoholic Strength (real) & 39.81 & $\begin{array}{l}39.49- \\
40.14\end{array}$ & $\%$ volume & 19 \\
\hline Alcoholic Strength (apparent) & 39.78 & $\begin{array}{l}39.46- \\
40.10 \\
\end{array}$ & $\%$ volume & 21 \\
\hline Ethanal (acetaldehyde) & 3.85 & $2.23-5.46$ & $\begin{array}{c}g / 100 \mathrm{~L} \text { of } \\
\text { absolute alcohol }\end{array}$ & 33 \\
\hline Ethyl Acetate & 13.61 & $\begin{array}{l}11.53- \\
15.69\end{array}$ & $\begin{array}{c}g / 100 \mathrm{~L} \text { of } \\
\text { absolute alcohol }\end{array}$ & 38 \\
\hline Methanol & 4.66 & $3.82-5.50$ & $\begin{array}{l}g / 100 \mathrm{~L} \text { of } \\
\text { absolute alcohol }\end{array}$ & 40 \\
\hline Propan-1-ol & 32.17 & $\begin{array}{l}27.85- \\
36.49\end{array}$ & $\begin{array}{c}g / 100 \mathrm{~L} \text { of } \\
\text { absolute alcohol }\end{array}$ & 37 \\
\hline 2-Methylpropan-1-ol & 15.22 & $\begin{array}{l}12.94- \\
17.51\end{array}$ & $\begin{array}{c}g / 100 \mathrm{~L} \text { of } \\
\text { absolute alcohol }\end{array}$ & 37 \\
\hline $\begin{array}{l}\text { 2-Methylbutan-1-ol + } \\
\text { 3-Methylbutan-1-ol (sum) }\end{array}$ & 39.13 & $\begin{array}{l}34.03- \\
44.23\end{array}$ & $\begin{array}{c}\text { g/100L of } \\
\text { absolute alcohol }\end{array}$ & 36 \\
\hline
\end{tabular}

\begin{tabular}{|l|}
\hline This data sheet is applicable until \\
\hline Recommended Storage on receipt \\
\hline Notes \\
\hline - Mix the QC material thoroughly before taking a representative analytical sample \\
- The assigned value has been derived from the consensus of laboratories taking part in \\
proficiency test, using a variety of methods. This is not a certified reference value. \\
- The Range for $|z| \leq 2$ is the concentration range within the limits of \pm 2 z-scores. The \\
assigned value and its range have been established from the proficiency test data and \\
are suitable for use by laboratories as a fit-for-purpose quality control measure. \\
- Stability of the QC material has been established as sufficient for the scope of the \\
proficiency test from previous experience, expert advice and published literature. \\
FAPAS advises that the QC material is analysed within the recommended date. \\
FAPAS QC materials are intended to be used as single-analysis samples. \\
- Full details on the proficiency test procedure used to characterise this QC material are \\
available in the Protocol, Part 1 - Common Principles, freely available to download \\
from the FAPAS website. \\
- Alcoholic strength (apparent) is calculated directly from the density measurement. It \\
does not utilise a distillation step, nor correct for total solids by using pycnometry and \\
applying an obscuration factor. Results obtained by GC are not valid for this analyte. \\
Alcoholic strength (real) should account for total solids content, for example by using a
\end{tabular}

distillation step, using GC or using pycnometry and applying obscuration factor. 